\title{
Impact Tensile Testing of Stainless Steels at Various Temperatures
}

D. K. Morton

R. K. Blandford

March 2008

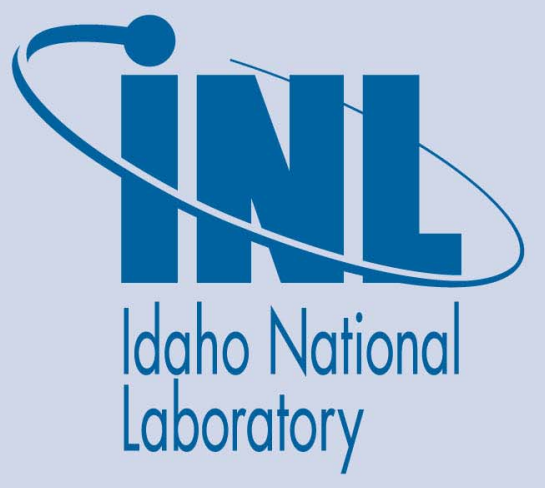

The INL is a U.S. Department of Energy National Laboratory operated by Battelle Energy Alliance 


\title{
Impact Tensile Testing of Stainless Steels at Various Temperatures
}

\author{
D. K. Morton \\ R. K. Blandford \\ March 2008 \\ Idaho National Laboratory \\ Idaho Falls, Idaho 83415 \\ Prepared for the \\ U.S. Department of Energy \\ Assistant Secretary for Environmental Management \\ Under DOE Idaho Operations Office \\ Contract DE-AC07-05ID14517
}


NATIONAL SPENT NUCLEAR FUEL PROGRAM ENGINEERING DESIGN FILE

EDF-NSNF- 082

Revision 0

Page 1 of 3

Title: IMPACT TENSILE TESTING OF STAINLESS STEELS AT VARIOUS TEMPERATURES

1. Activity Title: Transportation and Packaging - Canister Basket

2. WBS No. C.B.30.03.02.02.C2

\begin{tabular}{|r|l|l|l|}
\hline 3. Approval & \multicolumn{1}{|c|}{ Typed Name } & Signature & Date \\
\hline Preparer & D. K. Morton & & \\
\hline Preparer & R. K. Blandford & & \\
\hline Reviewer & S. D. Snow & & \\
\hline PSO QE & N. S. MacKay & & \\
\hline
\end{tabular}

\begin{tabular}{l|ll} 
4. Distribution: & Project File NSNFP File Log No.: 4724.11
\end{tabular}

(Name and Mail Stop) $\quad$ B. W. Carlsen, MS 3710; N. S. MacKay, MS 3710; R. K. Blandford, MS 3760;

D. K. Morton (10 copies), MS 3760; S.D. Snow, MS 3760 
NATIONAL SPENT NUCLEAR FUEL PROGRAM ENGINEERING DESIGN FILE

EDF-NSNF- 082

Revision 0

Page 2 of 3

Title: IMPACT TENSILE TESTING OF STAINLESS STEELS AT VARIOUS TEMPERATURES

5. Purpose: Stainless steels are used for the construction of numerous spent nuclear fuel or radioactive material containers that may be subjected to high strains and moderate strain rates during accidental drop events. Mechanical characteristics of these base materials and their welds under dynamic loads in the strain rate range of concern (1 to 300 per second) are not well documented. However, research is being performed at the Idaho National Laboratory to quantify these characteristics.

The work presented herein discusses tensile impact testing of dual-marked 304/304L and $316 / 316 \mathrm{~L}$ stainless steel material specimens. Both base material and welded material specimens were tested at $-20^{\circ} \mathrm{F}$, room temperature, $300^{\circ} \mathrm{F}$, and $600^{\circ} \mathrm{F}$ conditions. Utilizing a drop weight impact test machine and 1/4-inch and 1/2-inch thick dog bone-shaped test specimens, a strain rate range of approximately 4 to 40 per second (depending on initial temperature conditions) was achieved. Factors were determined (see table below for typical values) that reflect the amount of increased strain energy the material can absorb due to strain rate effects. Using the factors, elevated true stress-strain curves for these materials at various strain rates and temperatures were generated.

\begin{tabular}{|c|c|c|c|c|}
\hline $\begin{array}{c}\text { Strain } \\
\text { rate } \\
\text { (per sec.) }\end{array}$ & $\begin{array}{c}\mathbf{- 2 0} \\
{ }^{\mathbf{O}} \mathbf{F}\end{array}$ & $\begin{array}{c}\text { Room } \\
\text { Temperature }\end{array}$ & $\begin{array}{c}\mathbf{3 0 0} \\
{ }^{\mathbf{0}} \mathbf{F}\end{array}$ & $\begin{array}{c}\mathbf{6 0 0} \\
{ }^{\mathbf{0}} \mathbf{F}\end{array}$ \\
\hline 5 & 1.333 & 1.235 & 1.166 & 1.043 \\
\hline 10 & 1.361 & 1.278 & 1.210 & 1.094 \\
\hline 22 & 1.428 & 1.381 & 1.316 & 1.217 \\
\hline 25 & 1.445 & 1.407 & 1.342 & 1.247 \\
\hline \multicolumn{5}{|c|}{316 L Stainless Steel } \\
\hline 5 & 1.275 & 1.265 & 1.162 & 1.040 \\
\hline 10 & 1.296 & 1.281 & 1.187 & 1.070 \\
\hline 22 & 1.346 & 1.321 & 1.247 & 1.140 \\
\hline 25 & 1.359 & 1.331 & 1.262 & 1.158 \\
\hline \multicolumn{5}{|c|}{}
\end{tabular}

By incorporating the strain rate elevated true stress-strain material curves into an inelastic finite element computer program as the defined material input, significant improvement in the accuracy of the computer analyses was attained. However, additional impact testing is necessary to achieve higher strain rates (up to 300 per second) before complete definition of strain rate effects can be made for accidental drop events and other similar energy-limited impulsive loads.

This research approach, using impact testing and a total energy analysis methodology to quantify strain rate effects, can be applied to many other materials used in government and industry.

The current, principal NSNFP procedures applied to this activity include the following:

- NSNFP Procedure 6.01, Review and Approval of NSNFP Internal Documents

- NSNFP Procedure 6.03, Managing Document Control and Distribution

- NSNFP Procedure 3.04, Engineering Documentation. 
NATIONAL SPENT NUCLEAR FUEL PROGRAM ENGINEERING DESIGN FILE

EDF-NSNF- 082

Revision 0

Page 3 of 3

Title: IMPACT TENSILE TESTING OF STAINLESS STEELS AT VARIOUS TEMPERATURES

\begin{tabular}{|c|l|c|c||}
\hline Total Attachments: & Attachment Nos.: & No. of pages in each: & Total Pages: \\
& Cover sheets, pgs i-x & 10 & \\
& Report, pgs 1-118 & 118 & 157 \\
& Appendix A, pgs A1-A6 & 6 & \\
& Appendix B, pgs B1-B2 & 2 & \\
& Appendix C, pgs C1-C3 & 3 & \\
& Appendix D, pgs D1-D4 & 6 & 6 \\
& Appendix E, pgs E1-E2 & 6 & \\
& Appendix F, pgs F1-F6 & & \\
& Appendix G, pgs G1-G6 & & \\
& & & \\
\hline
\end{tabular}




\section{IMPACT TENSILE TESTING OF STAINLESS STEELS AT VARIOUS TEMPERATURES}

WBS Number C.B.30.03.02.02.C2

March 2008

Authors:

D. K. Morton and R. K. Blandford

Prepared for the

U. S. Department of Energy

Assistant Secretary of Environmental Management

Under DOE Idaho Operations Office

Contract DE-AC07-05ID14517 
This document was developed and is controlled in accordance with NSNFP procedures. Unless noted otherwise, information must be evaluated for adequacy relative to its specific use if relied on to support design or decisions important to safety or waste isolation. 


\section{CONTENTS}

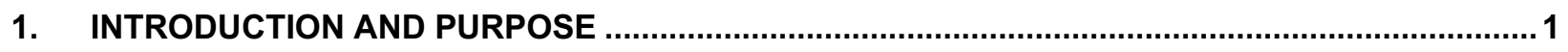

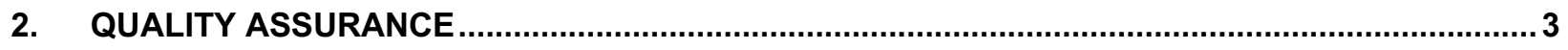

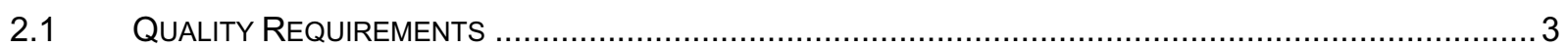

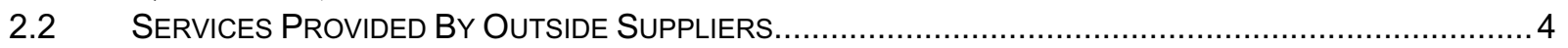

2.2.1 Welding and Weld Examination Services for Welded Plates............................................ 4

2.2.2 Calibration Services ............................................................................................ 5

2.2.3 Computer Support Services for Validated Software ......................................................... 5

2.2.4 Confirmatory Dimensional Measuring Services ............................................................ 5

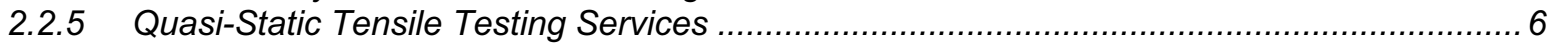

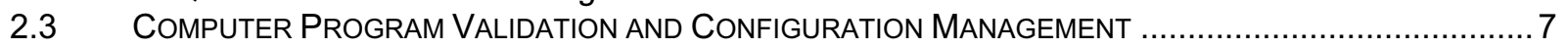

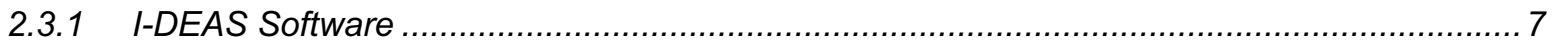

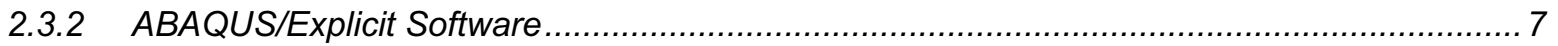

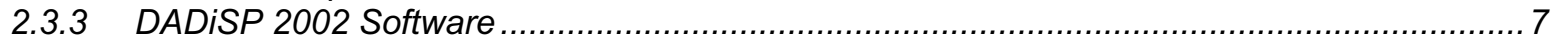

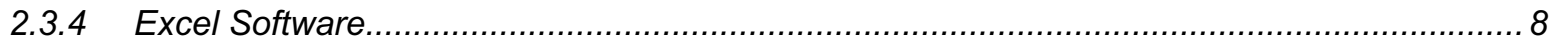

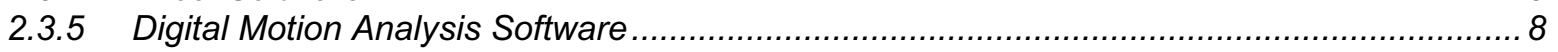

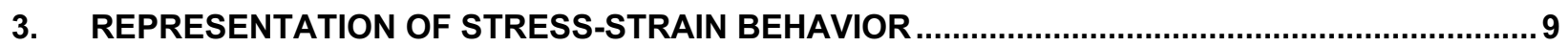

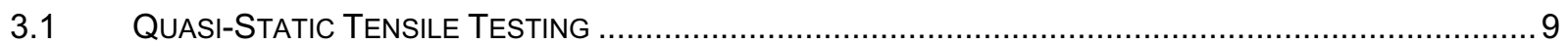

3.2 TYPICAL VARIATIONS IN MATERIAL PROPERTIES ............................................................ 11

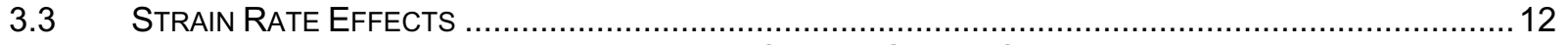

3.4 RECOGNITION OF ENERGy DENSITY IN TRUe StRESS-STRAIN CURVES ................................... 12

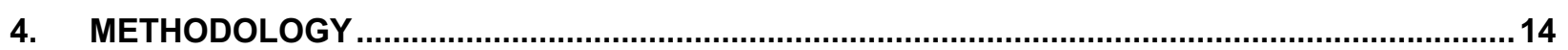

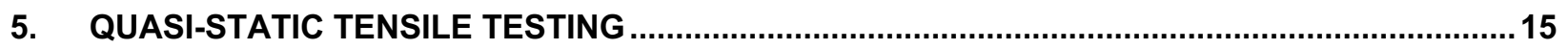

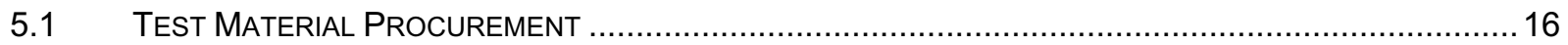

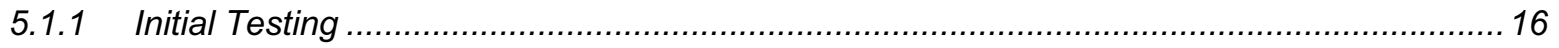

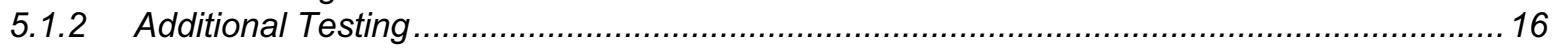

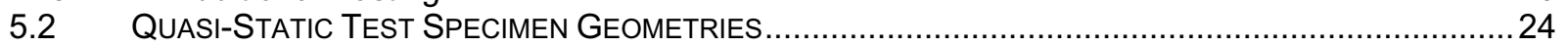

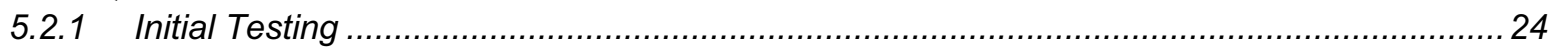

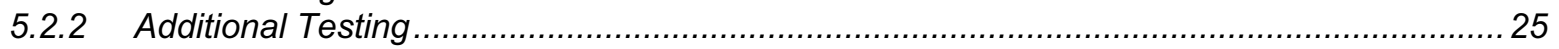

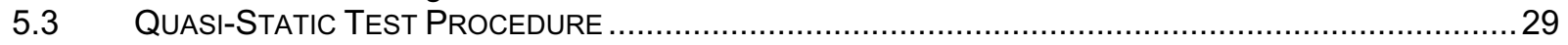

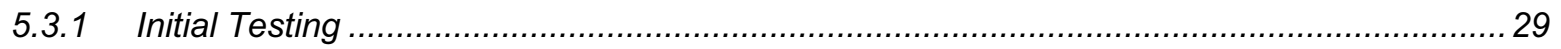

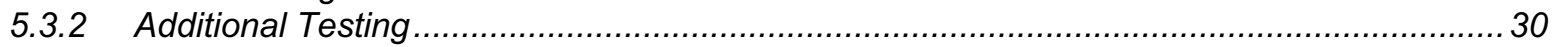

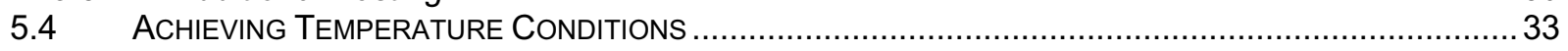

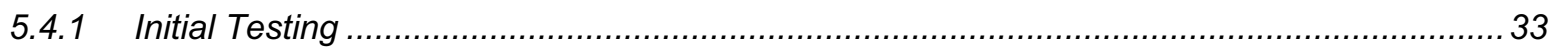

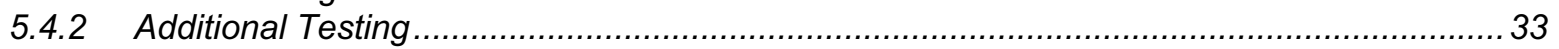

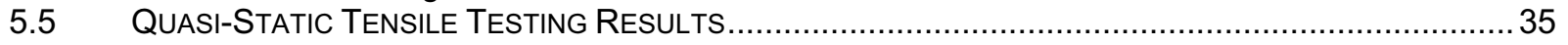

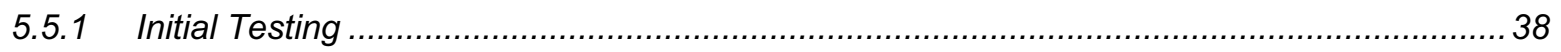

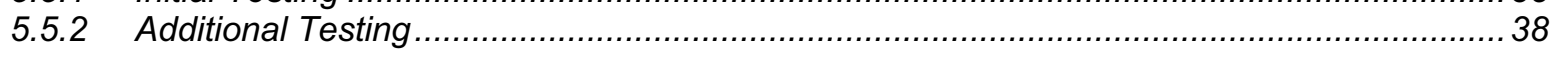

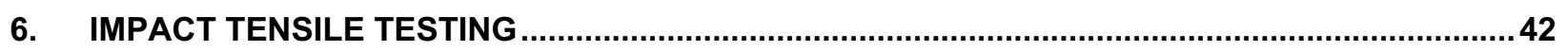

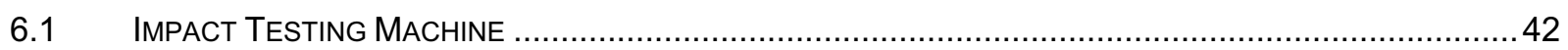

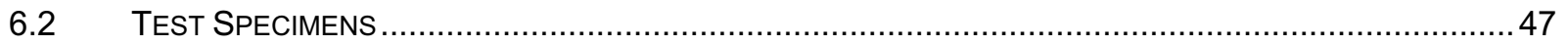

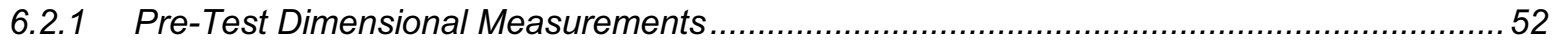

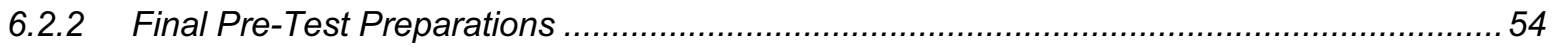

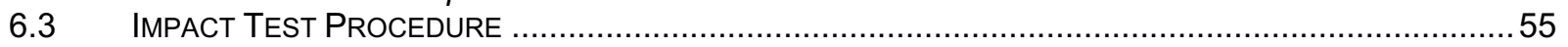

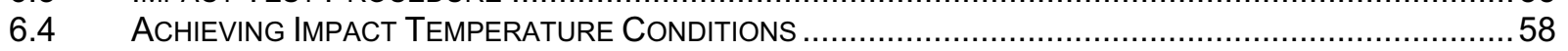

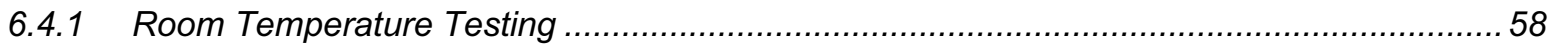

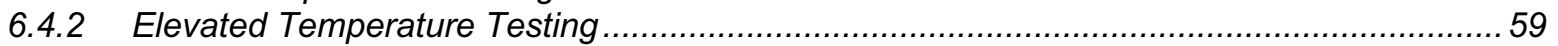

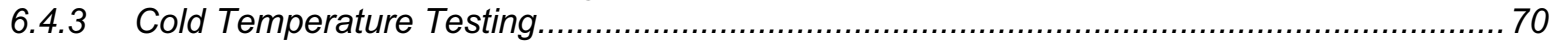

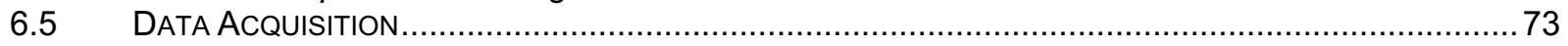



6.5.1 High-Speed Digital Camera.

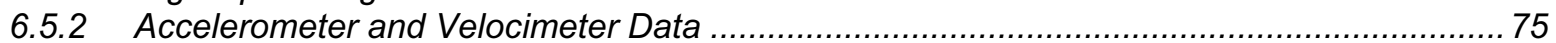

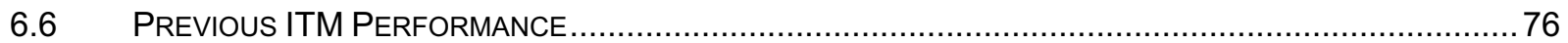

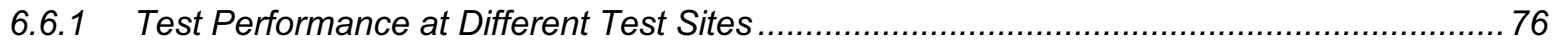
6.6.2 Longitudinal Versus Transverse Specimen Orientation ............................................... 77

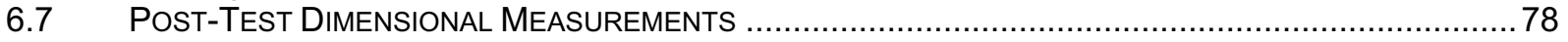

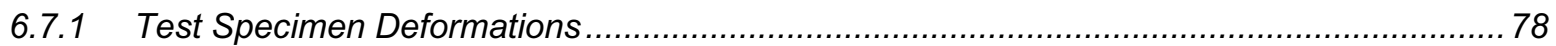

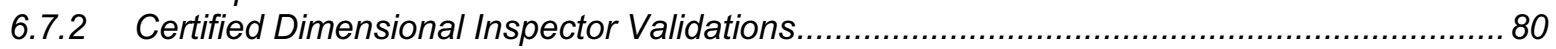

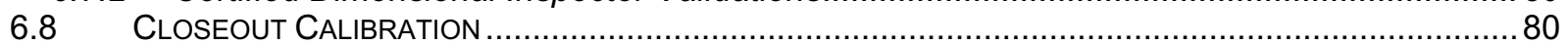

7. TEST RESULTS: DEVELOPMENT OF FACTORS AND STRAIN RATE ELEVATED TRUE

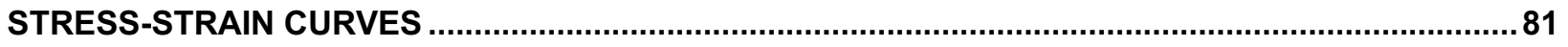

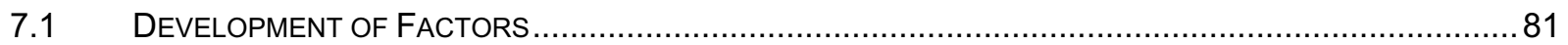

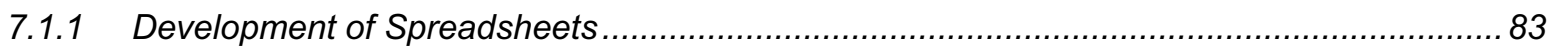

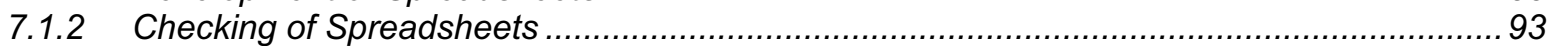

7.2 StRAin RATE EleVATED TRUE STRESS-StRaIn CURVES.................................................. 95

8. USING RESULTS: ABAQUS/EXPLICIT ANALYSES USING STRAIN RATE ELEVATED TRUE

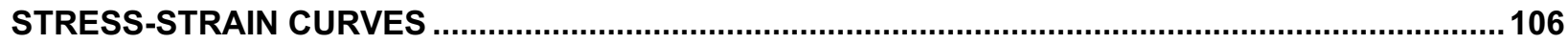

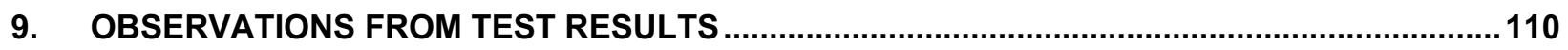

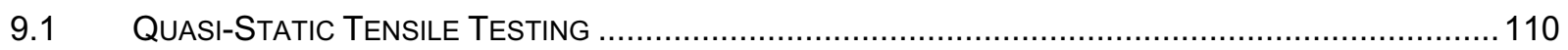

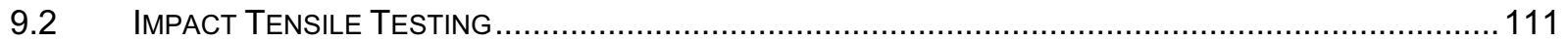

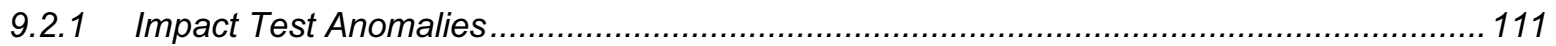

9.2.2 Base Versus Welded Material Responses............................................................. 111

9.3 Factors and StRain Rate EleVATEd TRUe StRESS-Strain CURVES INSIGHTS ......................114

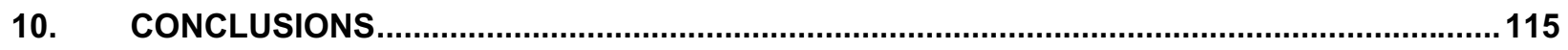

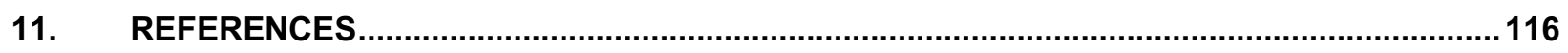

\section{APPENDICES}

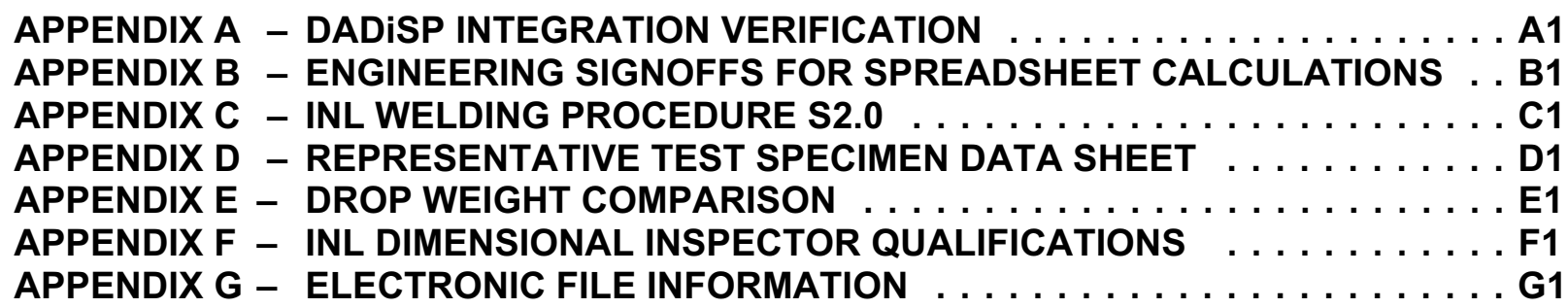




\section{ACKNOWLEDGMENT}

The authors would like to acknowledge the help, technical expertise, perseverance, and wisdom that Tom E. Rahl (NSNFP test team member and recently retired from the Idaho National Laboratory) provided to this material impact testing effort as well as the friendship shared with the authors. 
Author: D. K. Morton and R. K. Blandford

Date: March 2008

Reviewed By: S. D. Snow

EDF-NSNF-082 Page vi of $\mathrm{x}$ 


\section{ABSTRACT}

Stainless steels are used for the construction of numerous spent nuclear fuel or radioactive material containers that may be subjected to high strains and moderate strain rates during accidental drop events. Mechanical characteristics of these base materials and their welds under dynamic loads in the strain rate range of concern ( 1 to 300 per second) are not well documented. However, research is being performed at the Idaho National Laboratory to quantify these characteristics.

The work presented herein discusses tensile impact testing of dual-marked 304/304L and 316/316L stainless steel material specimens. Both base material and welded material specimens were tested at $-20{ }^{\circ} \mathrm{F}$, room temperature, $300{ }^{\circ} \mathrm{F}$, and $600{ }^{\circ} \mathrm{F}$ conditions. Utilizing a drop weight impact test machine and 1/4-inch and 1/2-inch thick dog bone-shaped test specimens, a strain rate range of approximately 4 to 40 per second (depending on initial temperature conditions) was achieved. Factors were determined (see table below for typical values) that reflect the amount of increased strain energy the material can absorb due to strain rate effects. Using the factors, elevated true stress-strain curves for these materials at various strain rates and temperatures were generated.

\begin{tabular}{|c|c|c|c|c|}
\hline $\begin{array}{c}\text { Strain } \\
\text { rate } \\
\text { (per sec.) }\end{array}$ & $\begin{array}{c}\mathbf{- 2 0} \\
{ }^{\circ} \mathbf{F}\end{array}$ & $\begin{array}{c}\text { Room } \\
\text { Temperature }\end{array}$ & $\begin{array}{c}\mathbf{3 0 0} \\
{ }^{\mathbf{0}} \mathbf{F}\end{array}$ & $\begin{array}{c}\mathbf{6 0 0} \\
{ }^{\mathbf{0}} \mathbf{F}\end{array}$ \\
\hline 5 & 1.333 & 1.235 & 1.166 & 1.043 \\
\hline 10 & 1.361 & 1.278 & 1.210 & 1.094 \\
\hline 22 & 1.428 & 1.381 & 1.316 & 1.217 \\
\hline 25 & 1.445 & 1.407 & 1.342 & 1.247 \\
\hline \multicolumn{5}{|c|}{316 L Stainless Steel } \\
\hline 5 & 1.275 & 1.265 & 1.162 & 1.040 \\
\hline 10 & 1.296 & 1.281 & 1.187 & 1.070 \\
\hline 22 & 1.346 & 1.321 & 1.247 & 1.140 \\
\hline 25 & 1.359 & 1.331 & 1.262 & 1.158 \\
\hline
\end{tabular}

By incorporating the strain rate elevated true stress-strain material curves into an inelastic finite element computer program as the defined material input, significant improvement in the accuracy of the computer analyses was attained. However, additional impact testing is necessary to achieve higher strain rates (up to 300 per second) before complete definition of strain rate effects can be made for accidental drop events and other similar energy-limited impulsive loads.

This research approach, using impact testing and a total energy analysis methodology to quantify strain rate effects, can be applied to many other materials used in government and industry. 
Author: D. K. Morton and R. K. Blandford

Date: March 2008

Reviewed By: S. D. Snow 


\section{ACRONYMS}

ASME

ASTM

B\&PV

CFA

CITRC

CMTR

DOE

FY

GV

HRAP

INL

IRC

ITM

LOP

LVDT

NVLAP

NSNFP

OAS

OCRWM

QA

SNF

UTS
American Society of Mechanical Engineers

American Society for Testing and Materials

Boiler and Pressure Vessel

Central Facilities Area (at INL)

Critical Infrastructure Test Range Complex (at INL)

certified material test report

U.S. Department of Energy

fiscal year

gauge volume

hot rolled, annealed, and pickled

Idaho National Laboratory

INL Research Center

Impact Testing Machine

lack of penetration (pertinent to weld examination)

linear variable displacement transducer

National Voluntary Laboratory Accreditation Program

National Spent Nuclear Fuel Program

overall average strain

Office of Civilian Radioactive Waste Management (DOE-RW)

quality assurance

spent nuclear fuel

ultimate tensile strength 
Author: D. K. Morton and R. K. Blandford

Date: March 2008

Reviewed By: S. D. Snow 


\section{IMPACT TENSILE TESTING OF STAINLESS STEELS AT VARIOUS TEMPERATURES}

\section{INTRODUCTION AND PURPOSE}

Most structural design acceptance criteria are stress-based. These stress-based criteria are prudent for normal operating conditions where static loading due to pressure, weight, and thermal loads dominate. Years of experience have repeatedly demonstrated that these criteria (e.g., ASME B31.1 Power Piping Code) have achieved successful designs. However, other component designs become excessively conservative when satisfying these stress-based design criteria for the high stresses typically resulting from low probability, off-normal dynamic events, such as an accidental drop. This conservatism frequently manifests itself as thicker material in an inefficient design. The downside of this inefficiency is that it can significantly elevate life cycle costs and potentially degrade structural performance over the design life of the component.

By extending the knowledge of material responses beyond the typical 'quasi-static' uniaxial tensile test behavior, the accuracy of stresses/strains predicted by finite element method (FEM) inelastic analysis computer codes for low probability (but design governing) dynamic events, such as accidental drops, can be improved. Accurate knowledge of the actual responses of components or structures to dynamic loads means improved designs, safer designs, more costeffective designs, and better overall engineered solutions to the many national infrastructure problems at hand. Examples of dynamic loads include, but are not limited to, radioactive material container drop events, vehicle crashes, vehicle crashes into highway safety barriers or security barriers, and more. These dynamic loads typically yield strain rate responses that are greater than 0.01 per second but less than 300 per second. These moderate strain rates are higher than quasi-static tensile testing rates yet less than strain rates associated with ballistics.

In the past, full-scale component testing was the norm in evaluating the structural integrity of vehicle designs during crashes or the structural integrity and containment capabilities of spent nuclear fuel containers during accidental drop events. Methods for performing nonlinear inelastic analyses were either lacking or very approximate at best. Currently, with improved computational capabilities and software, the trend is to use nonlinear analytical methods, with limited or no actual testing, once the acceptability of the analysis methodology has been established. Improved software and analysis methodologies for performing inelastic, large deformation analyses are now common and offer numerous advantages relative to full-scale component testing, including relatively low cost analytical simulations, ease of evaluating material and design options, elimination of costs associated with actual fabrication, testing, and post-test disposal, etc. In order to rely only on an analytical approach, accurate results from methodologies and software must be demonstrated which in turn mandate a precise definition of inelastic, dynamic material properties (e.g. true stress-strain curves reflecting strain rate effects). Other variables such as temperature, welded material properties, aged material properties, and project specific conditions (if appropriate) must also be considered. 
True stress-strain curves at elevated strain rates (in the range of 1 to 300 per second) are not readily available. Additionally, most published material data do not consider variables such as: full uniform strain range; varying strain rates; temperature; specific material composition and specification; welded material properties; or aged material properties (if appropriate), especially in combinations.

Most metals tend to get stronger as the rate of straining increases. Taking advantage of this phenomenon is desirable when designing for low probability dynamic events. The American Society of Mechanical Engineers (ASME) Boiler and Pressure Vessel (B\&PV) Code, Section III, Division 1, Appendix F (Reference 1) contains rules for performing inelastic (large deformation) analyses. Paragraph F-1322.3(c) permits the adjustment of the stress-strain curve to include strain rate effects resulting from dynamic behavior (e.g., during drop events). However, these code rules also mandate the justification of that adjusted stress-strain curve. Therefore, it is imperative to perform material impact testing in order to provide the necessary justification for using these strain rate elevated true stress-strain curves for inelastic analyses that invoke this Code. The phrase "strain rate elevated" refers to the fact that the strain rate effects on a stressstrain curve reflecting dynamic loading raises the curve upward (higher strength) when compared to a stress-strain curve reflecting quasi-static conditions.

The development of beyond-yield-strength true stress-strain curves of commonly used construction materials, addressing both strain rate and temperature effects is necessary to achieve accurate analytical results. In order to begin to consider these variables, the Department of Energy's (DOE) National Spent Nuclear Fuel Program (NSNFP), working with the Office of Civilian Radioactive Waste Management (OCRWM), and the Idaho National Laboratory (INL), has supported an initial effort into the study of strain rate phenomena. This first phase of material impact testing considered 304/304L and 316/316L dual-stamped stainless steel (hereafter referred to as $304 \mathrm{~L}$ and $316 \mathrm{~L}$, respectively). Both base and welded materials at $-20{ }^{\circ} \mathrm{F}$, room, $300{ }^{\circ} \mathrm{F}$, and $600{ }^{\circ} \mathrm{F}$ temperatures were tested at strain rates between 4 and 40 per second. The strain rates achieved during impact testing were dependent on the temperature of the material as well as the amount of energy imparted to the material. This report addresses the first phase of completed testing. Higher strain rates of interest (40 to 300 per second or more) at the same temperature conditions, using test specimens from the same material heats and welds must be investigated in the future in order to span the entire range of strain rates of interest.

The objective of this research effort was to improve understanding of the strain rate phenomenon by experimentally studying the mechanical properties of candidate materials subjected to impact loading. The purpose of this task was to determine strain rate effects for 304L and 316L stainless steel material under dynamic, impact loading at various cold and hot temperatures. The goal is to ultimately develop true stress-strain curves reflecting various strain rates and temperatures for many materials and provide justification of each strain rate elevated true stress-strain curve. The test data developed can be used to establish an analysis methodology that can then be applied in analytical simulations to more accurately predict the deformation and resulting material straining in the components being evaluated that are subject to dynamic, impulsive loads. The long-term goal is to develop sufficient data to provide clear and distinct guidance regarding impact analysis methodologies and how engineering personnel can perform these analyses and obtain viable results without needing to perform confirmatory testing. This work can also help establish strain-based acceptance criteria for these events. 


\section{QUALITY ASSURANCE}

This document was developed and is controlled in accordance with NSNFP procedures. Unless noted otherwise, information must be evaluated for adequacy relative to its specific use if relied on to support design or decisions important to safety or waste isolation.

The NSNFP procedures applied to this activity implement DOE/RW-0333P, Quality Assurance Requirements and Description (Reference 2), and are a part of the NSNFP QA Program (Reference 3). The NSNFP QA Program has been assessed and accepted by representatives of the Office of Quality Assurance within the Office of Civilian Radioactive Waste Management for work scope of the NSNFP.

The current, principal NSNFP procedures applied to this activity include the following:

- NSNFP 6.01, Review and Approval of NSNFP Internal Documents (Reference 4),

- NSNFP 6.03, Managing Document Control and Distribution (Reference 5),

- NSNFP 3.04, Engineering Documentation (Reference 6).

\subsection{Quality Requirements}

The material testing effort described in this report was required to satisfy the NSNFP Quality Assurance Program. This required the generation of a test plan, establishment of agreements for quality-affecting activities that the NSNFP could not perform, initiation of laboratory (or scientific) notebook usage during the research effort, and documentation of the material testing effort with a final report.

As identified in NSNFP Procedure 11.01 (Reference 7), a test plan prescribes the requirements, controls, and documentation necessary for testing conducted within the NSNFP. The test plan is to provide background information and objectives, identify test requirements, describe the test methodology, specify the test equipment, software, and procured services, state the applicable acceptance criteria, describe the test procedure, and identify the information necessary for the test documentation. If any quality-affecting services need to be procured, NSNFP Procedure 4.02 (Reference 8) describes the process for acquiring government sector services for the NSNFP, including generating a NSNFP Task Management Agreement document. A Task Management Agreement is written to clarify the NSNFP needs, identify any technical requirements, specify deliverables, and discuss other issues required of the provider of the outside services. The providers sign the Task Management Agreement, clearly indicating their awareness of what is required of them.

Regarding the documentation of technical information during actual impact testing, NSNFP Procedure 3.04 identifies the requirements for creating and using a laboratory notebook. Pertinent impact test data were recorded in the laboratory notebook. Additional test data (such as quasi-static tensile test results or voluminous deformation history data) were generated during the research effort but were placed into separate binders (referenced in the laboratory notebook) and are considered part of the laboratory notebook documentation. During periods of test activity, the laboratory notebook was reviewed at approximately monthly intervals by a 
cognizant person (other than the individual filling in the notebook). This laboratory notebook was submitted to the NSNFP to be retained as a quality assurance (QA) record.

The personnel performing the material impact research had ten years or more of engineering experience in structural evaluations and were trained per NSNFP Procedure 2.04 (Reference 9). Software used to perform finite element analysis comparisons to test specimen result met NSNFP 19.01 (Reference 10). Software used to evaluate test data (by performing simple mathematical functions such as adding, multiplying, or integration similar to those capabilities on a handheld calculator) were confirmed with sample problem checks or reviewed like an engineering calculation and reported on in the final documentation (this report). This final test report followed the requirements of NSNFP Procedure 6.01.

Although INL's Consumer Grade - Quality Level 4 process (currently referred to as Commercial Grade - Quality Level 3) was used to procure test specimen materials, ASME Section III approved materials with certified material test reports (CMTRs) were purchased. For confirmation, material samples were tensile tested to verify the CMTR data and to establish the material quasi-static stress-strain curves used by this strain rate research effort.

\subsection{Services Provided By Outside Suppliers}

Certain services not addressed by the NSNFP QA Program needed to be provided by outside suppliers in order for this investigation to proceed. As such, five different activities (addressed in the following subsections) were considered to be quality-affecting. These activities included: (1) welding and weld examination services for the welded plates; (2) calibrating the measuring devices used to determine pre-impact test specimen measurements and post-impact deformations; (3) providing properly controlled hardware and software to perform computer evaluations to predict resulting test specimen deformations; (4) performing confirmatory dimensional measurements of test specimen gages and post-impact test specimens; and (5) determining quasi-static tensile material property (stress-strain) data. These qualityaffecting activities were supplied by the INL as detailed in two NSNFP Task Management Agreement documents, DOE/SNF/TMA-009, Revision 1 (Reference 11) for welding and weld examination services and DOE/SNF/TMA-013, Revision 1 (Reference 12) for the remaining four services. Test Plan DOE/SNF/PP-039, Revision 8 (Reference 13) also discussed these qualityaffecting activities.

\subsubsection{Welding and Weld Examination Services for Welded Plates}

Welding and weld examination services were quality-affecting activities that could not be performed by the NSNFP. Therefore, these activities were performed by a qualified supplier, the INL. This service is discussed in Section 2.3.3 of the Task Management Agreement DOE/SNF/TMA-009. The INL prepared the welded plates (from which test specimens were cut) for dynamic testing in support of Test Plan DOE/SNF/PP-039. The welded plates incorporated the weld joint design anticipated for the Standardized DOE Spent Nuclear Fuel Canisters. Full volumetric radiographic examinations were performed on the completed welds to verify the integrity of the welds prior to dynamic load testing. Examination reports, weld wire material certifications, and the INL Laboratory Notebooks (Reference 14) were submitted to the NSNFP. 


\subsubsection{Calibration Services}

The NSNFP required the services of the INL to initiate or maintain calibration and the associated documentation for specific NSNFP-identified measuring devices, including but not limited to: micrometers, calipers, load cells, accelerometers, etc. Calibration was performed in accordance with INL procedures. The Test Plan (DOE/SNF/PP-039) specified the projectdefined minimum accuracy required for particular NSNFP measuring devices.

The basis for acceptance of calibration services included the calibration labels applied directly to each measuring device (or provided to the NSNFP test personnel for those items where affixing a label was not viable) and the applicable calibration sheet(s). These calibration sheets were made available to the NSNFP test personnel as each measuring device completed calibration prior to use. The INL maintains qualification records for all personnel providing calibration services. The NSNFP test personnel retained applicable calibration sheets for NSNFP record keeping.

\subsubsection{Computer Support Services for Validated Software}

The NSNFP required computer hardware/software services of the INL to provide a computing environment for running the ABAQUS/Explicit software. The ABAQUS/Explicit software was already installed on the identified compute server 'Aurora'. In order to provide adequate documentation in compliance with NSNFP procedures (NSNFP 19.01), the NSNFP performed its own installation test and validation of ABAQUS/Explicit on the hardware and operating system software configuration identified. Any subsequent changes made by the INL that altered the hardware configuration, the operating system software configuration, or the ABAQUS/Explicit software (e.g., adding software updates) would likely nullify the NSNFP software validation. Therefore, the NSNFP requested that the INL maintain a hardware configuration, an operating system configuration, and an ABAQUS/Explicit software configuration (i.e., specific version of the software) for a reasonably long period of time (ideally one year or more). The NSNFP required early notification of any software or hardware configuration changes or scheduled or unexpected maintenance needs that the INL performed so that the impact of any such changes could be evaluated. ABAQUS/Explicit was revalidated prior to continued use after any such configuration changes.

Because the NSNFP performed its own validation and verification of software (e.g., ABAQUS/Explicit) per NSNFP 19.01, compliance with INL procedures associated with software verification and validation were not required. No additional technical requirements beyond those specified by INL procedures, applicable to computer systems operated by the INL are required by the NSNFP.

\subsubsection{Confirmatory Dimensional Measuring Services}

The NSNFP required the services of the INL to implement the INL Quality Assurance Program requirements for Quality Engineering and Inspection activities. Those activities included dimensional measurements on NSNFP-provided test components or impact test specimens. The Test Plan DOE/SNF/PP-039 provided details and requirements with respect to dimensional measurements to be performed by INL Quality Assurance personnel. Sketches, drawings, data sheets, or specifications were provided by the NSNFP to supplement the Test Plan. Measuring devices used were calibrated by the INL Standards and Calibration Laboratory. 
Measurement documentation was provided to the NSNFP test personnel at the completion of the measurement efforts.

The correct dimensional measurement of the test specimens before and after impact testing was significant to the success of this investigation. NSNFP test personnel measured the test specimens before and after impact testing. Pre-test measurements included the use of go/no go gages. Plexiglas templates, referred to as go/no go gages, were developed so that quick, accurate checks of the overall test specimen geometry could be made. These go/no go gages were measured by a qualified INL dimensional inspector and accepted for use by the NSNFP test personnel based on those INL measurements. Pre- and post-test measurements of test specimens were performed by NSNFP test personnel using calibrated calipers. However, to demonstrate the validity of these measurements, post-test measurements of identified impact test specimens were also taken by a qualified INL dimensional inspector.

\subsubsection{Quasi-Static Tensile Testing Services}

The NSNFP required the services of the INL to perform material quasi-static tensile testing at varying temperatures in the range of $-20{ }^{\circ} \mathrm{F}$ to $600{ }^{\circ} \mathrm{F}$. The goal was to obtain sufficient data to adequately plot the quasi-static true stress-strain curve up to test specimen failure. Test Plan DOE/SNF/PP-039 provided details and requirements with respect to this material tensile testing effort. Basic testing requirements were to follow ASTM Standard A 370 (Reference 15), excluding any identified reporting requirements. Sketches, drawings, data sheets, or test requirements were provided by the NSNFP to supplement the Test Plan as appropriate. The tensile test device and any other associated instrumentation providing pertinent data were calibrated by the INL Standards and Calibration Laboratory. NSNFP test personnel or other personnel supporting the NSNFP witnessed the material tensile testing process.

For material initially procured to investigate room temperature strain rate effects in 2004, the quasi-static tensile testing was performed by the Materials Testing Laboratory located at the central facilities of the INL (at CFA-602). The NSNFP Program Applicability Evaluation PAE010 (Reference 16) provided details of how this INL National Voluntary Laboratory Accreditation Program (NVLAP) qualified supplier would perform this service.

The quasi-static material tensile testing performed in 2006 and 2007 for material procured to investigate strain rate effects at varying temperatures was performed at a laboratory located at the INL Research Center (IRC). This service is discussed in Task Management Agreement DOE/SNF/TMA-013. Since the cognizant laboratory personnel at IRC did not have NVLAP accreditation, personnel associated with the Materials Testing Laboratory provided oversight to assure compliance with ASTM A370 requirements. Material data obtained [continuous force-strain (or displacement) data through test specimen failure] was provided to the NSNFP at the completion of the tensile tests. The equipment used for this quasi-static tensile testing was calibrated through the INL Standards and Calibration Laboratory and documented in the INL Laboratory Notebook LAB-771 (Reference 17) submitted to the NSNFP for record retention. 


\subsection{Computer Program Validation and Configuration Management}

Several activities used in this task to evaluate and operate on test data incorporated computer programs including I-DEAS (Reference 18), ABAQUS/Explicit, Version 6.6-3 (Reference 19), DADiSP 2002 (Reference 20), a collection of EXCEL spreadsheets referred to herein as NSNF/MED/017, Revision 1 (Reference 21), and digital motion analysis software used in conjunction with the high-speed digital camera.

\subsubsection{I-DEAS Software}

The I-DEAS Master Series solid modeling computer program was used to create the finite element models of the physical impact tests. A solid model was created first, and then used to generate the finite element model. The following is a summary of the configuration management for I-DEAS. I-DEAS was not used for the calculations - only for modeling purposes. Model verification was performed using ABAQUS/Explicit, Version 6.6-3.

Program Used: I-DEAS 10 NX Series

Computer Used: Dell Precision 450, U.S. Govt. ID 374043

\subsubsection{ABAQUS/Explicit Software}

The computer program ABAQUS/Explicit, a linear and nonlinear finite element analysis software package that is widely used in many industries, was employed to calculate the response of the test specimen model to the impact test events. The ABAQUS/Explicit analytical results were compared to the measured experimental data. Version 6.6-3 was the NSNFP validated version (Reference 22). The following is a summary of the configuration management and validation performed for ABAQUS/Explicit.

Program Used: ABAQUS/Explicit Version: 6.6-3

Computer Used: SGI Model: Altix 4700 (Aurora)

Verification Manual/Test Problem Manual/ Example Manual:

ABAQUS Example Problems Manual, Version 6.6, ABAQUS, Inc.,

Providence, Rhode Island, 2006. (Reference 23)

NSNFP Validation:

Software Report For ABAQUS/Explicit Version 6.6-3, DOE/SNF/REP-107,

Rev. 0, November 2006. (Reference 22)

\subsubsection{DADiSP 2002 Software}

DADiSP 2002 (hereafter referred to as DADiSP) is a technical data analysis and display program that was used to reduce, manipulate, operate on, and plot test data using mathematical functions in a spreadsheet type environment. Therefore, a complete verification and validation 
effort was not deemed necessary. However, insight into the validity of DADiSP results was important. Hence, an effort to verify the specific functions used in DADiSP for this report was completed. Verification of the DADiSP integration functions used in this task is contained in Appendix A.

Program Used: DADiSP 2002

Computer Used: Dell M50 Portable Workstation, U.S. Govt. ID 371849

Dell Precision 470 Workstation, U.S. Govt. ID 384252

\subsubsection{Excel Software}

The collection of Excel spreadsheets used to gather test data, generate stress-strain curves, and calculate the strain rate factors have been processed per the requirements of NSNFP Procedure 19.01. Rather than a verification/validation effort as was done for ABAQUS/Explicit, these spreadsheets were checked just as an engineering hand calculation would be checked. Appendix B identifies the author that generated each spreadsheet and the reviewer of each spreadsheet (including the reviewer's signature).

Software Used: Excel 2003

NSNFP Assigned Identifier: NSNF/MED/017, Revision 1

Computer Used: Dell M50 Portable Workstation, U.S. Govt. ID 371849

Dell Precision 470 Workstation, U.S. Govt. ID 384252

\subsubsection{Digital Motion Analysis Software}

The recording of high-speed digital camera image data and motion analyses were performed with software that was provided with the high-speed digital camera. Only the highspeed digital camera's frame rates could be calibrated (for accurate timing). Since the image data is dependent on each unique camera view, it was not possible to validate the camera software ahead of time. However, the camera digital image was scaled prior to motion analysis to the specimen's measured gauge length between marked points on the test specimen. Additionally, for accuracy checking purposes and following the motion analysis, the final camera determined strain value was compared to the final strain value determined from test specimen measurements made with a calibrated caliper. See Section 6.5.1 for additional details.

Software Used: Photron Motion Tools, Version 1.2.0

Photron Fastcam Viewer, Version 2.4.3.8

Computer Used: Dell M60 Portable Workstation, U.S. Govt. ID 376246

Dell Precision 470 Workstation, U.S. Govt. ID 384252 


\section{REPRESENTATION OF STRESS-STRAIN BEHAVIOR}

In a one-dimensional quasi-static tensile test, a uniform slender test specimen is stretched (ends displaced at a constant rate) along its long central axis. Such testing follows the requirements of ASTM A 370. The results are plotted as a force versus displacement curve, which is a representation of the performance of the test specimen material. From this forcedisplacement curve, engineering stress-strain and true stress-strain curves can be produced using classical engineering relationships.

The term quasi-static is sometimes applied to this 'static' test since a significant length of time and slow strain rate $\left(10^{-5}\right.$ to $10^{-2}$ per second) are involved in performing the uniaxial tensile test. Strain rate behavior is defined as the difference in strength of a stress-strain curve produced under dynamic loading conditions compared to its quasi-static curve.

\subsection{Quasi-Static Tensile Testing}

Stress-strain curves are usually presented as:

- 'Engineering' stress-strain curves, in which the original specimen cross-sectional area is used to determine stress and the change in length divided by the original length determines strain,

- 'True' stress-strain curves, where the instantaneous cross-sectional area of the specimen is used to determine the stress and the strain.

To document a quasi-static tensile test, an engineering stress-strain curve is developed from the load-displacement measurements made during the test on the test specimen (Figure 1, typical for ductile material). The engineering stress, S, plotted on this curve is the average longitudinal stress in the tensile specimen obtained by dividing the load, $\mathrm{P}$, by the original specimen area, $A_{0}$. The engineering strain, e, plotted on the curve is the average linear strain obtained by dividing the change in gauge length, $\Delta \mathrm{L}$, of the specimen by the original length, $\mathrm{L}_{\mathrm{o}}$.

$$
\begin{aligned}
& \mathrm{S}=\mathrm{P} / \mathrm{A}_{\mathrm{o}} \\
& \mathrm{e}=\Delta \mathrm{L} / \mathrm{L}_{\mathrm{o}}
\end{aligned}
$$

The elastic limit, shown as point B in Figure 1, is the greatest stress the material can withstand without measurable permanent strain remaining after complete release of load. The yield strength, shown as point YS in Figure 1, is the stress required to produce a small, specified amount of inelastic deformation. The usual definition of this property is the offset yield strength determined by the stress corresponding to the intersection of the linear elastic segment of the stress-strain curve offset by a specified strain of $0.2 \%(\mathrm{e}=0.002)$. The tensile strength, or ultimate strength, $\mathrm{S}_{\mathrm{u}}$, is the corresponding stress where the maximum load that the material can withstand occurs. This also corresponds to the point where the specimen becomes unstable (onset of necking) and necks down during the remaining course of the tensile test. Necking is the point of rapid, localized reduction of cross-sectional area of a specimen under tensile loading. It is disregarded in calculating engineering stress but is taken into account in determining true stress. Complete fracture (failure point) of the specimen follows necking. 


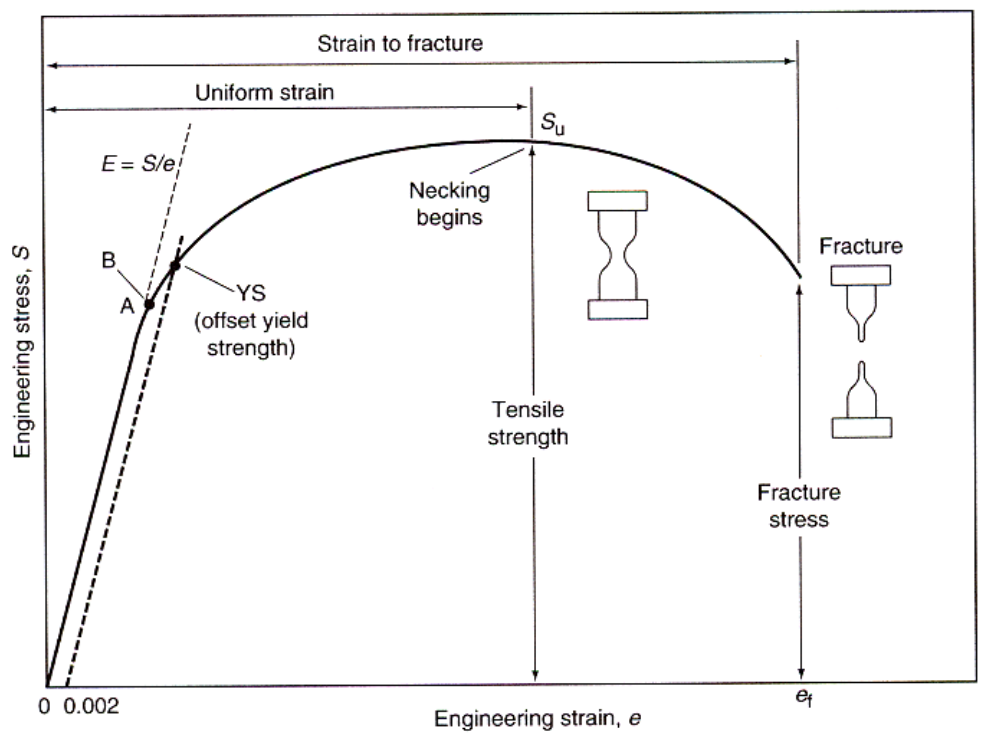

Figure 1. Typical engineering tensile stress-strain curve [from the Atlas of Stress-Strain Curves (Reference 24)].

The engineering stress-strain curve does not give the most accurate indication of the deformation characteristics of a material because it is based on the original specimen dimensions that actually change continuously during the test. Also, at the point of ultimate load, necking begins and the cross-sectional area of the specimen decreases rapidly and the load required to continue deformation lessens, as implied in Figure 1. The average stress based on the original area likewise decreases, and produces the downturn in the engineering stress-strain curve beyond the point of maximum load. In reality, the material continues to strain harden to fracture, so that the stress required to produce further deformation should also increase. If the true stress, based on the actual cross-sectional area of the specimen is used, the stress-strain curve increases continuously to fracture. If the strain measurement is also based on instantaneous measurement, the curve obtained is the true stress-strain curve as illustrated in Figure 2. The true stress-strain curve is also known as the flow curve, because it represents the basic plastic-flow characteristics of the material. The true stress is often referred to as the flow stress. stress by:

Up to the point of necking, the true stress, $\sigma_{\mathrm{t}}$, may be expressed in terms of engineering

$$
\sigma_{\mathrm{t}}=\mathrm{S}(\mathrm{e}+1)
$$

Up to the onset of necking, the true strain, $\varepsilon_{t}$, may be determined from the engineering strain, by:

$$
\varepsilon_{\mathrm{t}}=\ln (\mathrm{e}+1) \text {, where } \ln \text { is the natural } \log \text {. }
$$




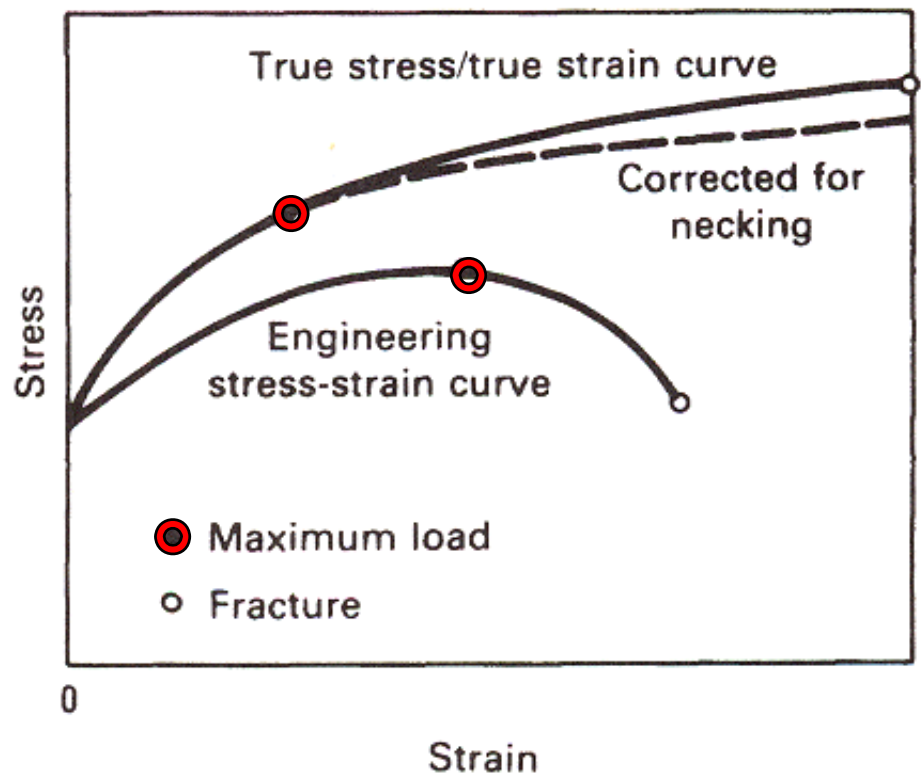

Figure 2. Comparison of engineering and true stress-strain curves [from the Atlas of StressStrain Curves].

Beyond the point of maximum load (necking), the true strain is based on the actual current area, $\mathrm{A}$, and is expressed:

$$
\varepsilon_{\mathrm{t}}=\ln \left(\mathrm{A}_{\mathrm{o}} / \mathrm{A}\right)
$$

and the true stress is based on the load and actual current area:

$$
\sigma_{\mathrm{t}}=\mathrm{P} / \mathrm{A}
$$

At the point of fracture, the true strain $\left(\varepsilon_{t}\right)$ and true stress $\left(\sigma_{t}\right)$ are thus expressed:

$$
\varepsilon_{\mathrm{t}}=\ln \left(\mathrm{A}_{\mathrm{o}} / \mathrm{A}_{\mathrm{f}}\right) \quad \text { and } \quad \sigma_{\mathrm{t}}=\mathrm{P}_{\mathrm{f}} / \mathrm{A}_{\mathrm{f}}
$$

where $\mathrm{A}_{\mathrm{f}}$ is the area at fracture and $\mathrm{P}_{\mathrm{f}}$ is the load at fracture.

The true stress-strain curve beyond the onset of necking (the maximum load or uniform strain limit) is further complicated by the development of radial and hoop stresses in the necking region. The average axial or nominal stress given by $\sigma_{\mathrm{t}}=\mathrm{P} / \mathrm{A}$ is not the true equivalent uniaxial stress because the hoop and radial stresses are not zero. Beyond necking, the nominal stress is often corrected to get the true equivalent uniaxial stress using a Bridgman Correction factor (Reference 25), which is dependent upon specimen geometry (corrected shape in Figure 2).

\subsection{Typical Variations In Material Properties}

Reference 26 provides indications (also listed in Table 1 of this report) of the variation in material property data typically achieved in standard engineering tests [i.e., results of identical tests performed on identical specimens fabricated from one specific heat ${ }^{1}$ and material

\footnotetext{
${ }^{1}$ Heat $-\mathrm{A}$ unique identifying number assigned to the product of one furnace melt.
} 
specification (plate, bar, etc.)]. These typical coefficients of variation basically indicate that even quasi-static tensile testing, which is considered more controllable than dynamic material impact testing, still has a considerable variation in the test data results. Variation is also expected from the dynamic impact tests. However, if dynamic material impact testing can be limited to this same level of variation or less (as evidenced by the accuracy of the analysis comparisons), the impact test results should be considered just as valid and useable as other standard material property test results.

Table 1. Typical Coefficients of Variation.

\begin{tabular}{|l|c|}
\hline \multicolumn{1}{|c|}{ Variable } & Typical Variance (\%) \\
\hline Yield strength of metals & 7 \\
\hline Ultimate strength of metals & 5 \\
\hline Modulus of elasticity of metals & 5 \\
\hline Fracture toughness of metals & 15 \\
\hline Tensile strength of welds & 10 \\
\hline
\end{tabular}

\subsection{Strain Rate Effects}

Strain rate is simply the time rate of straining. Average strain rates for most quasi-static tensile tests range between $10^{-2}$ and $10^{-5}$ per second. Greater strain rates $\left(10^{-1}\right.$ to $10^{2}$ per second and higher) are considered dynamic tests. The literature generally indicates that steels experience an elevation or increase in strength relative to the quasi-static stress level as the strain rate increases; however, the amount of increase is not well defined for many materials and strain rates. The effects of strain rate are generally expressed as an increase in strength relative to the quasi-static stress-strain curve. This report focuses on determining and justifying true stressstrain curves that reflect strain rates ranging from 4 to 40 per second (nominally) for both 304L and $316 \mathrm{~L}$ base and welded material at varying temperatures.

\subsection{Recognition of Energy Density in True Stress-Strain Curves}

It is recognized that the "area under the [engineering] stress-strain curve represents energy absorption per unit volume ... of material" (Reference 27). When looking at the associated true stress-strain curve, the significant area under the curve beyond the uniform strain limit might be interpreted as implying that a substantial amount of energy absorption capacity is available. However, this 'area' is actually strain energy density (e.g., in.-lb./in. ${ }^{3}$ ) and the energy absorption capacity is a function of the volume of material straining. Figure 3 shows an engineering stress-strain curve, the corresponding true stress-strain curve, and the uniform strain limit for a representative stainless steel at room temperature. Figure 4 illustrates the volume of stainless steel material being strained during a typical tensile test with respect to the uniform strain limit. Up to the uniform strain limit, the full volume of material in the test specimen gauge (or reduced area) length is being uniformly strained. Past the uniform strain limit, the material starts to neck, involving only a local and greatly reduced amount of material volume contained within the necking region. In fact, the volume of material involved is constantly decreasing as the strain increases. Figure 4 illustrates that the area under the true stress-strain curve beyond the uniform strain limit cannot be used to determine energy absorption capacity without knowing just how much material volume is being locally strained. Viewing the true stress-strain curve from this 'energy density' perspective is necessary in understanding that there really is only a 
limited amount of energy absorption capacity remaining in the material strained beyond the uniform strain limit. The constantly reducing volume of involved material is also the reason why it is difficult to quantify strain rate effects beyond the uniform strain limit. Since this report is attempting to generate data to support engineering design efforts, limiting the test strains to below the uniform strain limit (the onset of necking) is reasonable.

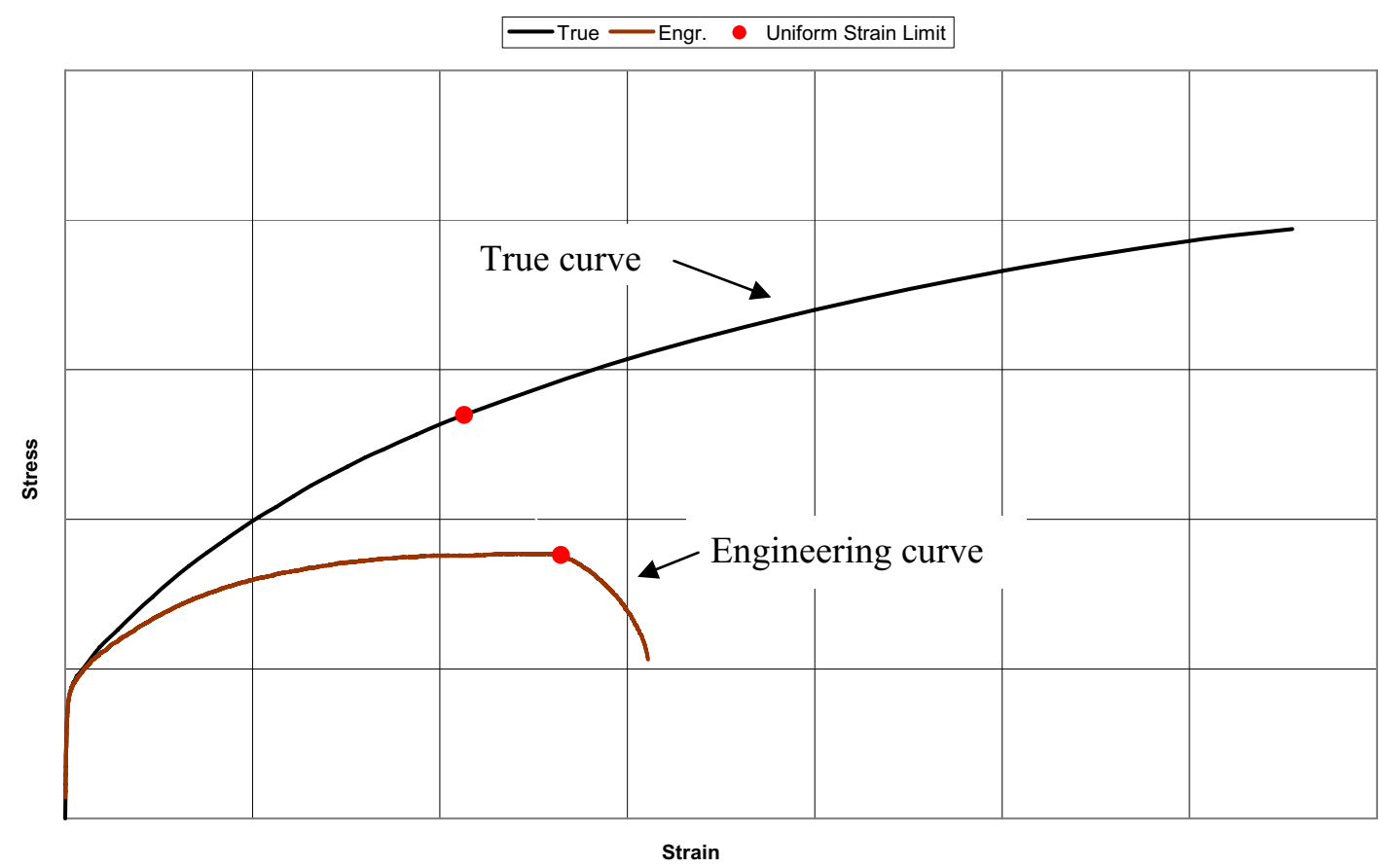

Figure 3. Representative engineering and true stress-strain curves.

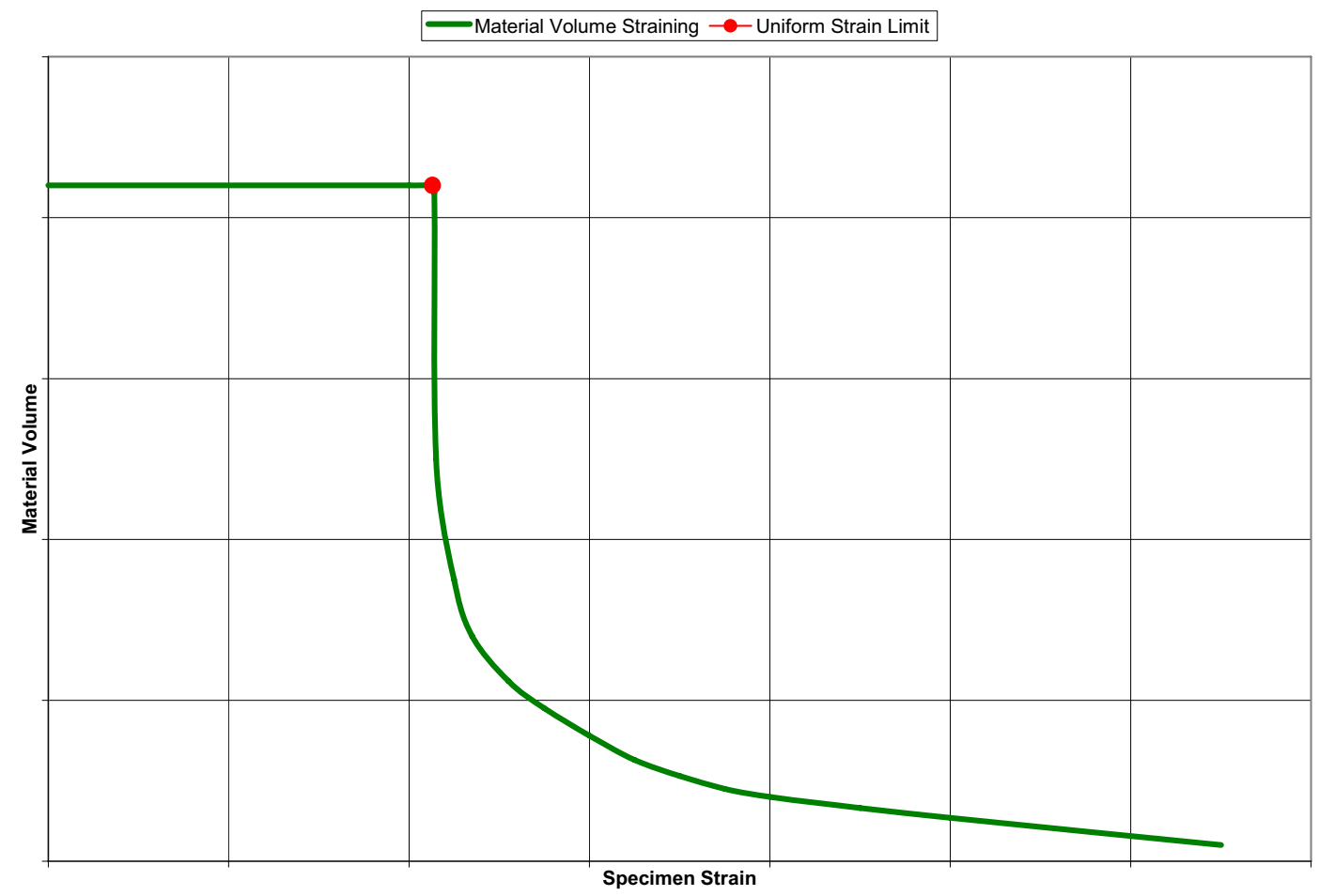

Figure 4. Representation of material volume involved in straining during tensile testing. 


\section{METHODOLOGY}

In order to generate a true stress-strain curve at a specified strain rate, classical engineering mechanics (incorporating conservation of energy and momentum methods) are used. A drop weight device is employed to perform dynamic impact testing at increased strain rates. The energy transferred to the test specimen and causing the tensile deformation is determined assuming an inelastic collision of the drop weight and the test specimen holder. Some kinetic energy is lost during the inelastic impact. This loss is accounted for by applying the reduced velocity predicted by conservation of momentum theory to the combined mass of the drop weight and impact driver when determining the total energy imparted to the test specimen. Energy losses due to other causes are considered negligible.

A 'total impact energy method' was developed using the concept that the area under a true stress-strain curve (up to the uniform strain limit - the strain at the onset of necking) is equivalent to the amount of energy (strain energy) that the test specimen gauge length volume of material can absorb up to a specific strain level achieved in the material. The total impact energy method develops a strain rate elevated true stress-strain curve by multiplying each stress point (beyond yield) on the quasi-static curve by a constant (referred to as the 'factor'). This factor is the ratio of the impact energy (as described above) absorbed by the test specimen's gauge length volume (e.g., in.-lb./in. ${ }^{3}$ ) divided by the area under the quasi-static true stress-strain curve up to the true strain achieved in the impact test specimen. Elevated true stress-strain curves (reflecting strain rate effects) produced using this methodology are considered valid up to the uniform strain limit of the material. Future testing and analysis efforts may better define the curve between the uniform strain limit and failure.

Incorporating the total impact energy method described above, the strain rate elevated true stress-strain curve development effort used a multi-step process summarized as follows:

1. Perform Quasi-Static Tensile Testing - Section 5: Obtain the quasi-static true stressstrain curve(s) of the material(s) under consideration. This is the basis for characterizing the strain rate effects.

2. Perform Impact Tensile Testing - Section 6: Determine the response of test specimens subjected to impact tensile testing. This effort provides the test specimen strain, at a specific rate, when subjected to an impact from a known weight dropped from a known height, in a known test apparatus.

3. Quantify Strain Rate Effects - Section 7: Calculate the factors, establish a reasonable curve fit, and then generate the associated strain rate elevated true stressstrain curves. This effort invokes the methodology briefly described above. Once the factor (for a specific strain rate at a specific temperature) is calculated, the quasi-static curve is used to generate the elevated true stress-strain curve.

4. Perform Analyses for Data Validation - Section 8: Using the strain rate elevated true stress-strain curves as input, perform FEM inelastic analyses of the impact tensile tests to determine the validity of the test data. This effort uses the strain rate data generated to determine its computational effectiveness.

The following sections address each of the above four steps in greater detail. 


\section{QUASI-STATIC TENSILE TESTING}

Strain rate effects are best characterized by comparison to quasi-static tensile test results, expressed as true stress-strain curves. Although 304L and 316L stainless steel materials have been studied for many years and by numerous investigators (e.g., References 28-31), relatively little recent, representative data reflecting current commercial supplier practices and dualstamping is readily available to practitioners. Even less data expressed as true stress-strain relationships out to failure can be found in the literature. Accurate quasi-static stress-strain data were needed for each unique material heat at each temperature to be investigated. To support this moderate strain rate research, considerable quasi-static tensile testing was required. This testing has resulted in a significant amount of basic material data recorded as engineering stressstrain curves and their converted true stress-strain relationships. The results of this quasi-static testing effort, besides establishing an initial basis for the strain rate research, has the added benefit of contributing to the existing data pool for these materials and make the data more readily available to other researchers, engineers, and interested parties. Typical stress-strain values are often of interest for failure analyses and integrity evaluations associated with low probability, extreme loading conditions. Reference 32 provides additional information on this quasi-static testing effort, including resulting material yield strength, ultimate strength, ultimate strain, fracture strength, fracture strain and reduction in area values.

The quasi-static tensile testing discussed herein was conducted in accordance with ASTM procedure A 370 on $304 \mathrm{~L}$ and 316L stainless steel plate materials at temperatures ranging from $-20{ }^{\circ} \mathrm{F}$ to $600{ }^{\circ} \mathrm{F}$. Two plate thicknesses, ten different material heats, and both base and welded material were investigated. NSNFP test personnel were present at all quasi-static tensile testing efforts even though INL personnel were performing the actual testing. This provided important background knowledge and confirmed that the testing performed was appropriate.

Efforts to conduct strain rate research began in 2004 and tensile material properties were required of the materials being investigated. Since the initial effort was to consider room temperatures only, quasi-static tensile testing of 304L and 316L specimens was performed by the Materials Testing Laboratory located at the central facilities of the INL (at CFA-602). This laboratory had National Voluntary Laboratory Accreditation Program (NVLAP) credentials. Because this report incorporates some of the impact testing performed in the initial effort, this report will describe the various aspects addressed in the quasi-static tensile testing for that material. This quasi-static tensile testing effort will be referred to as 'Initial Testing'.

After the initial phase of impact testing, funding was provided to impact test base and welded materials at varying temperatures. Because this called for many impact tests and different test specimen geometries, additional plate material was procured and more quasi-static tensile testing was required. This set of quasi-static tensile testing was performed at the INL Research Center (IRC), located in Idaho Falls, because of the need for testing at varying temperatures. Material tensile testing was performed at $-20{ }^{\circ} \mathrm{F}$, room, $300{ }^{\circ} \mathrm{F}$, and $600{ }^{\circ} \mathrm{F}$ temperatures for both base and welded materials. Because the cognizant laboratory personnel at the IRC did not have NVLAP accreditation, personnel having NVLAP accreditation from the Materials Testing Laboratory provided oversight to assure compliance with ASTM A 370 requirements. This quasi-static tensile testing effort will be referred to as 'Additional Testing'. 


\subsection{Test Material Procurement}

INL's Consumer Grade - Quality Level 4 process was used to procure test specimen materials. However, the materials were always stamped as ASME SA-240 (Reference 33) plate and the associated certified material test reports (CMTRs) were obtained. The alloys were procured from various manufacturers as 4 -foot by 10 -foot plates. The as-received plate material was hot rolled, annealed, and pickled (HRAP finish). For procurement confirmation purposes, the quasi-static tensile testing results were used to verify the CMTR data as well as determine the necessary stress-strain relationships.

\subsubsection{Initial Testing}

The initial material impact testing effort procured two $1 / 2$-inch thick plates, one 304L and one $316 \mathrm{~L}$ in FY04. The 304L plate had a heat number of $10 \mathrm{~W} 8$ and the $316 \mathrm{~L}$ plate had a heat number of 09T9. This material yielded pertinent impact test data that has been incorporated into this report.

\subsubsection{Additional Testing}

The additional material testing effort started in FY05 with the procurement of four plates of stainless steel material. In order to achieve strain rates below 16 per second, two 1/4-inch thick plates were procured. The $1 / 4$-inch thick $304 \mathrm{~L}$ plate had a heat number of 485896 and the $316 \mathrm{~L}$ plate had a heat number of $48 \mathrm{R} 8$. In order to achieve strain rates above 16 per second, two $1 / 2-$ inch thick plates were procured. The $1 / 2$-inch thick $304 \mathrm{~L}$ plate had a heat number of $54 \mathrm{M} 7$ and the $316 \mathrm{~L}$ plate had a heat number of 230468 . These plates were designated to be used for both base and welded material impact testing. Having base and welded material test specimens from the same material heat would allow for more direct comparison of strain rate responses.

This material was to be handled by many individuals and different organizations while being machined, welded, examined, etc. In order to maintain proper traceability throughout this entire strain rate research effort, it was recognized that each plate material needed to be color coded upon receipt. Both the $1 / 4$-inch and the $1 / 2$-inch $304 \mathrm{~L}$ plate material were painted bright yellow while the $1 / 4$-inch and $1 / 2$-inch $316 \mathrm{~L}$ plate material were painted a light blue.

Differentiation between the $1 / 4$ - and $1 / 2$-inch thick plates was easy so the same color was used for both thicknesses. Figure 5 shows a freshly painted $1 / 2$-inch thick 304L plate and Figure 6 shows a freshly painted $1 / 2$-inch thick $316 \mathrm{~L}$ plate.

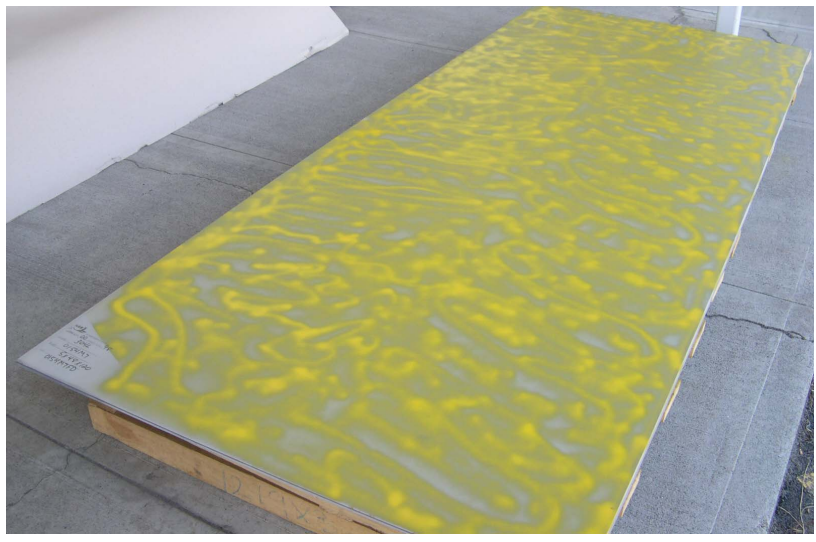

Figure 5. Painted $1 / 2$-inch thick 304L plate. 


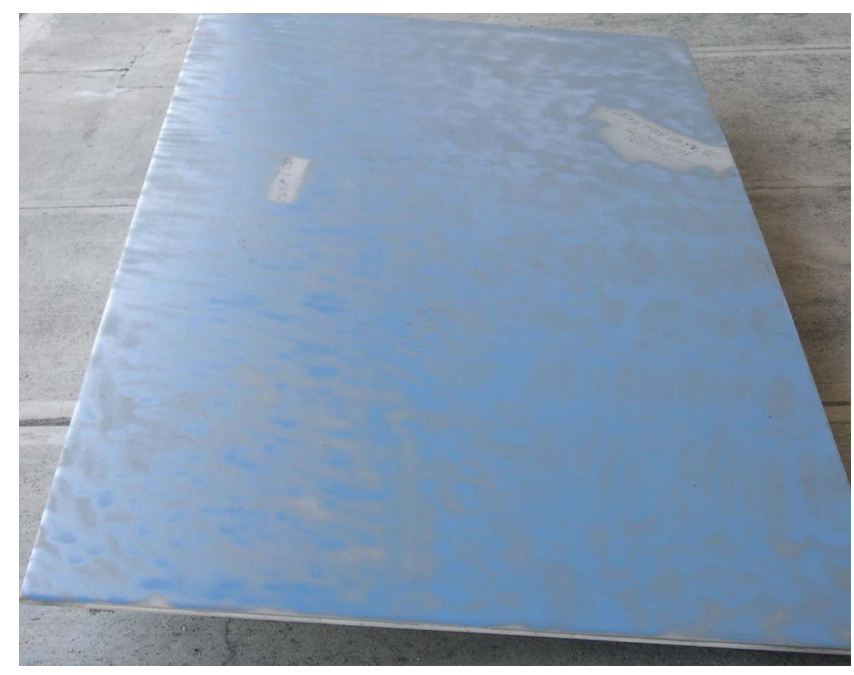

Figure 6. Painted 1/2-inch thick 316L plate.

From the perspective of this research effort, the welding of the 'bright yellow and light blue' plates described above and the associated weld examination process also had to be procured. As previously described in Section 2.2.1, the INL provided these welding and weld examination services. The first step was to cut the $4 \times 10$-foot plate into a number of smaller plates that could be more easily handled during and after welding. Water jet cutting was used to accomplish this. Figure 7 pictures the 304L plate cut into 5-1/2-inch wide by 26 -inch long (in the direction the plate was rolled at the mill) pieces. After weld preparations (Figure 8) were machined (Figure 9), plate pairs were welded together using a gas tungsten arc welding process (Figure 10) identified as Weld Procedure S2.0 (see Appendix C) from the INL Welding Manual (Reference 34). Unique plate numbers were written (in the format of WXX with a permanent marker) on the upper right hand corner of each welded plate to maintain traceability. For example, as seen in Figure 10, plate W16 was being welded (even though weld machine obscures the 'W'). Weld wire ER308L was used for the 304L plate material and weld wire ER316L was used for the 316L plate material. As can be seen in Figure 10, a copper backing bar was used as well as a small run out tab at both ends (to get, as much as possible, a full plate length weld up to the plate edges). After completing the weld on the top side (painted side) with two weld passes, the reverse side of the weld was 'back gouged' (at an INL machine shop) to prepare that side for welding. Small imperfections at the surface where the copper backing bar was stationed needed to be removed with a small groove. The final single weld pass was made down that groove, completing the welded plate. Figure 11 shows a close-up view of the final weld appearance. The plate welds (also identified with the same unique plate number) were then radiographed and evaluated per INL procedure TPR 4970, Appendix C (Reference 35) to determine their acceptability. TPR 4970, Appendix C invokes ASME B\&PV Code, Section III, Class 1 weld radiographic acceptance criteria. Figure 12 shows how the plates were marked for identification and weld examination. The radiograph film length was six inches. Measuring from the top (with the plate number in the upper right hand corner), the plate was marked to identify distances of 4 thru 10 inches and 16 thru 22 inches. These two 6-inch intervals captured the weld length that would become the gauge length for the welded impact test specimens. If additional weld material needed to be used for quasi-static tensile testing, additional radiography was performed on those additional weld lengths. At the completion of the INL effort, all welds passed the examination criteria, as evidenced by Reference 14. 


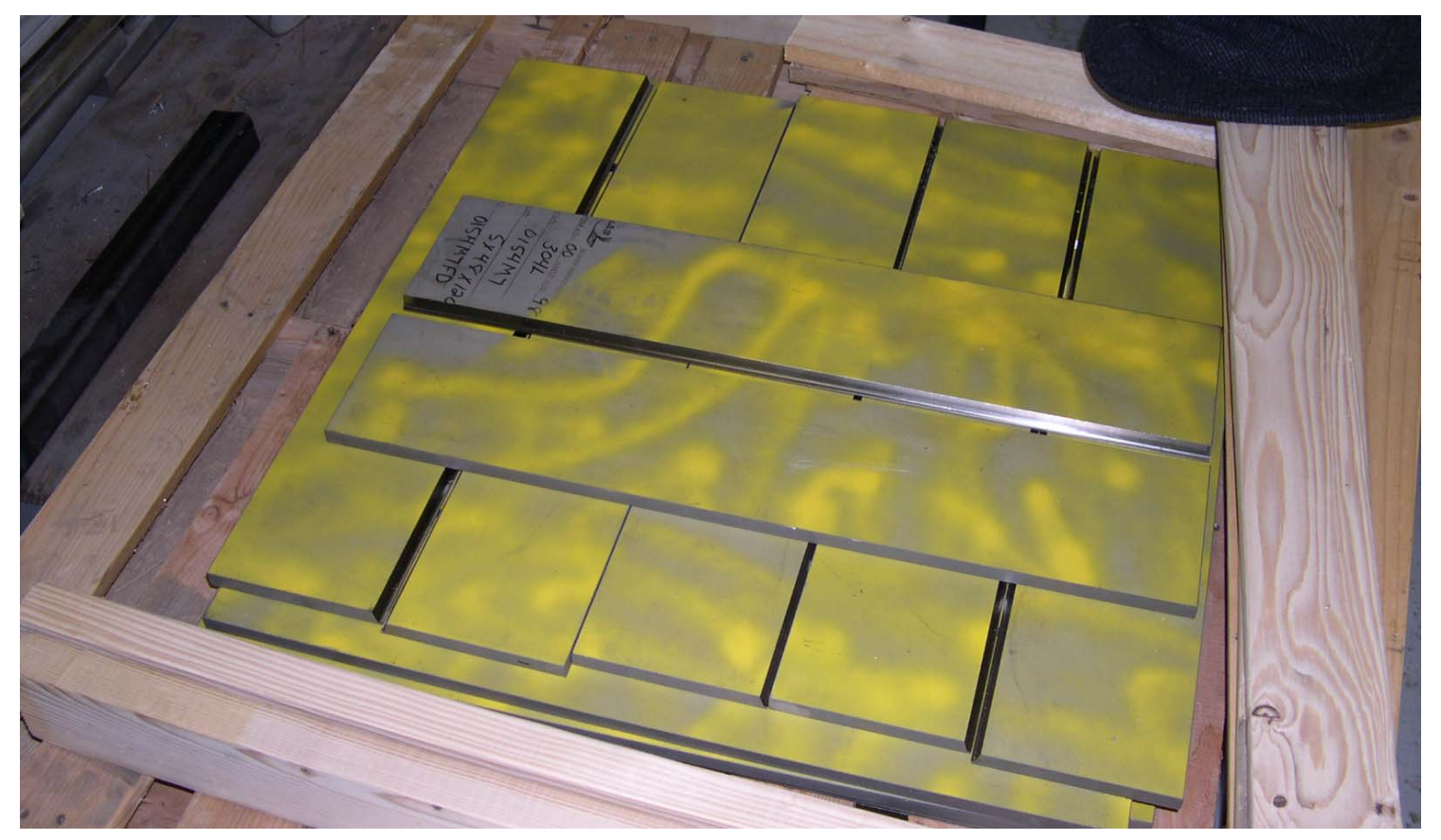

Figure 7. 304L plates cut and weld prepared.

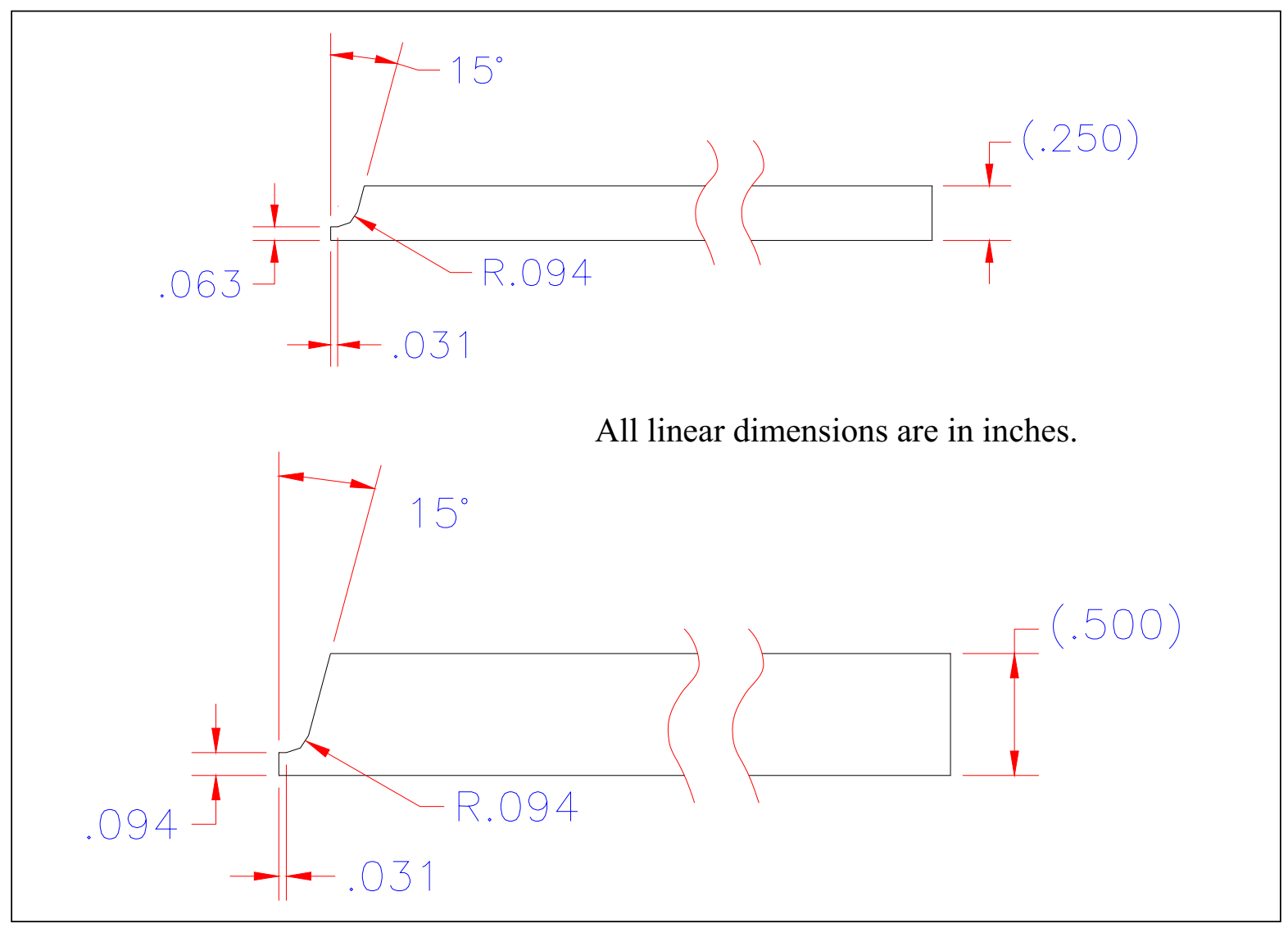

Figure 8. Example weld preparation profiles used on $1 / 4$-inch and $1 / 2$-inch thick plate material. 


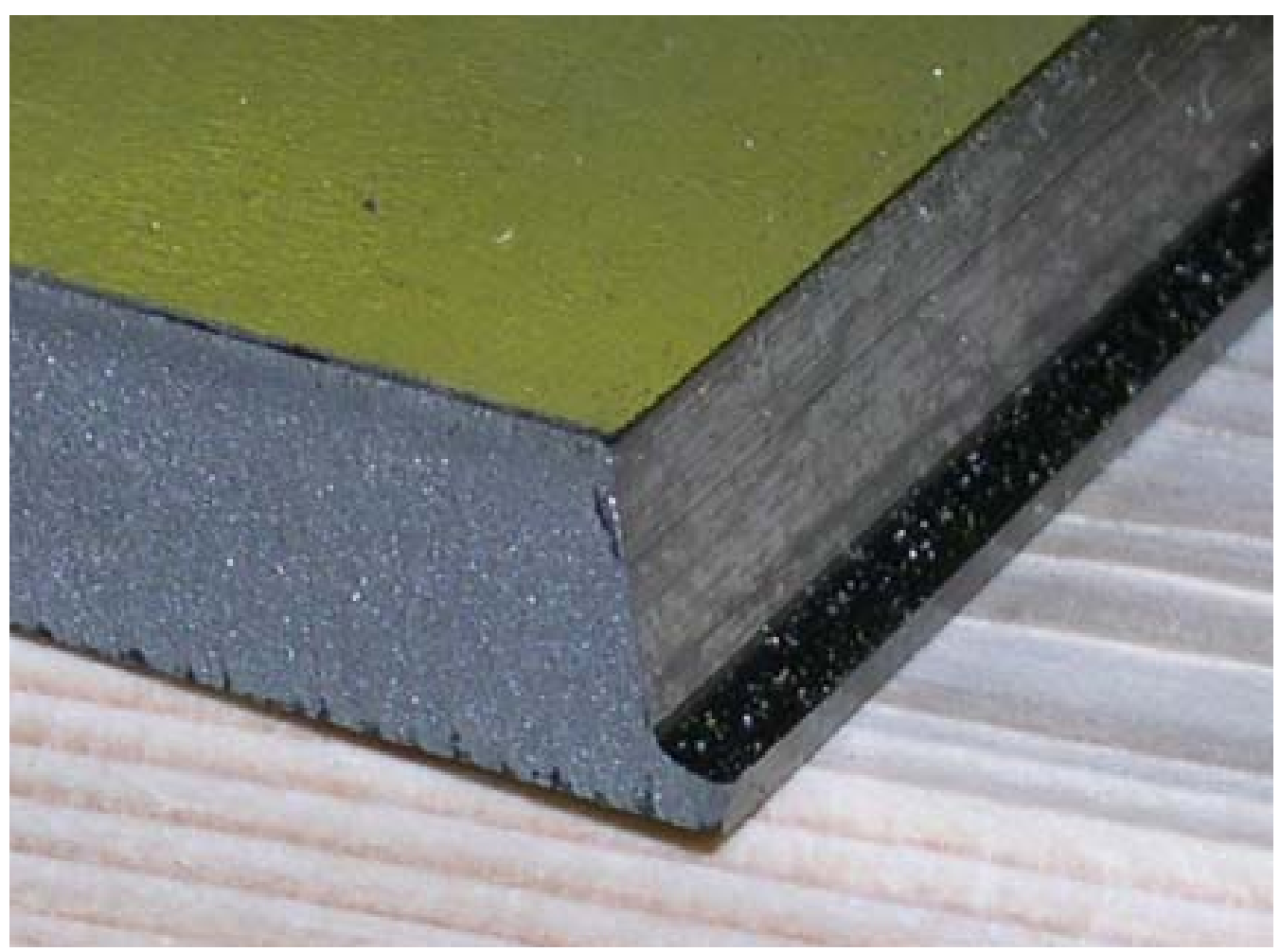

Figure 9. Close-up of machined weld preparation on $1 / 2$-inch thick plate.

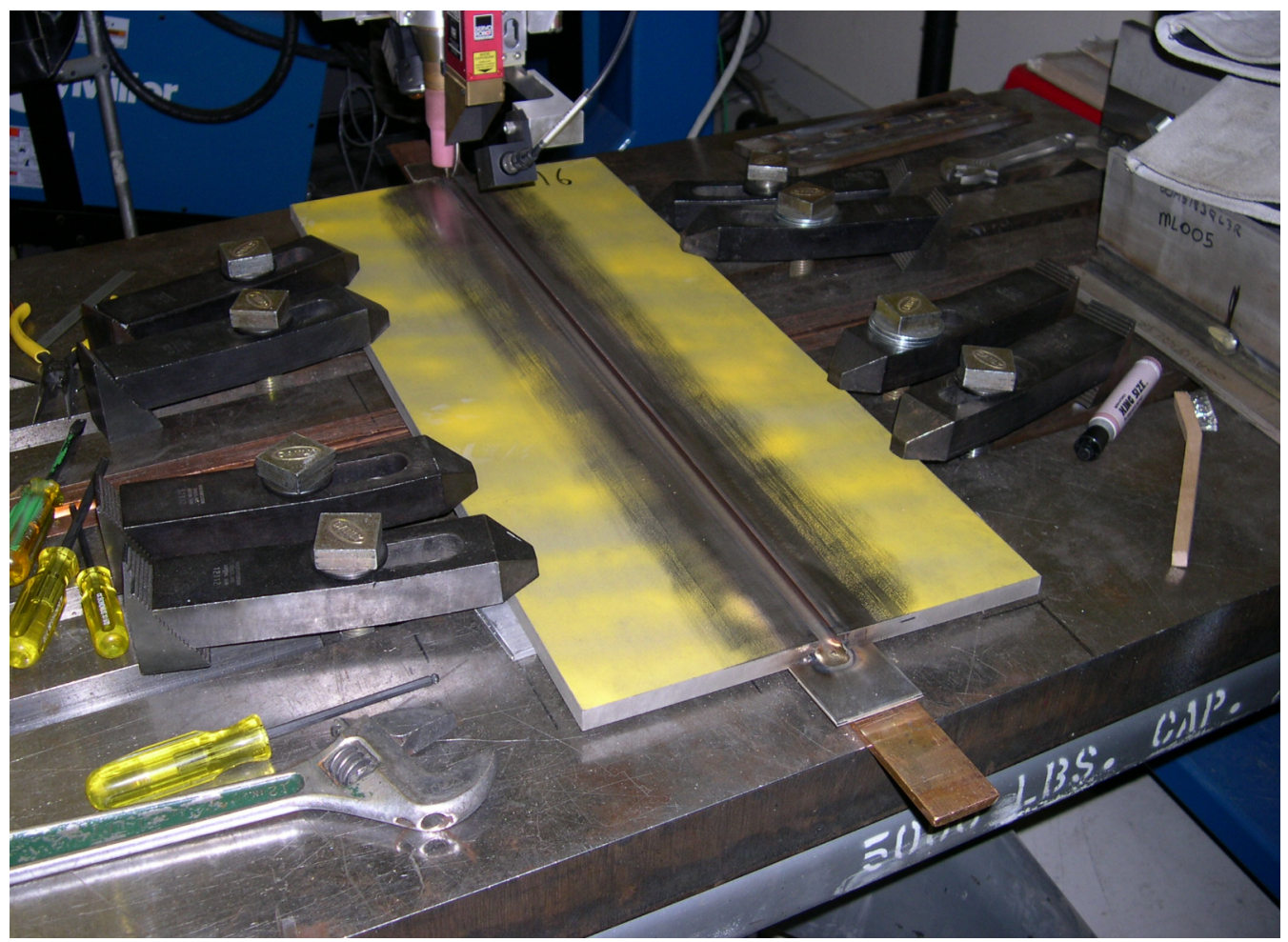

Figure 10. 304L plates being welded. 


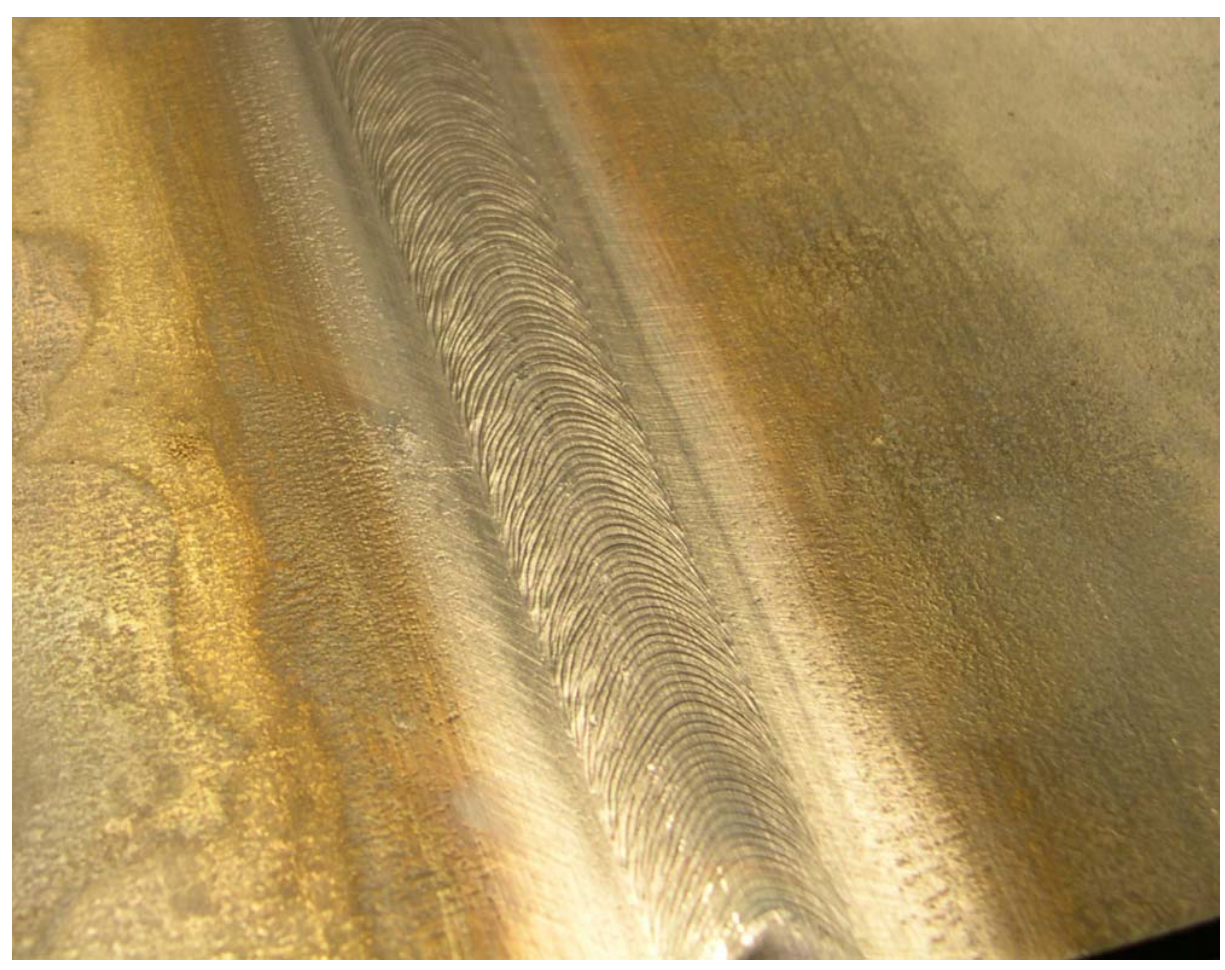

Figure 11. Close-up of final weld appearance on the welded plates.

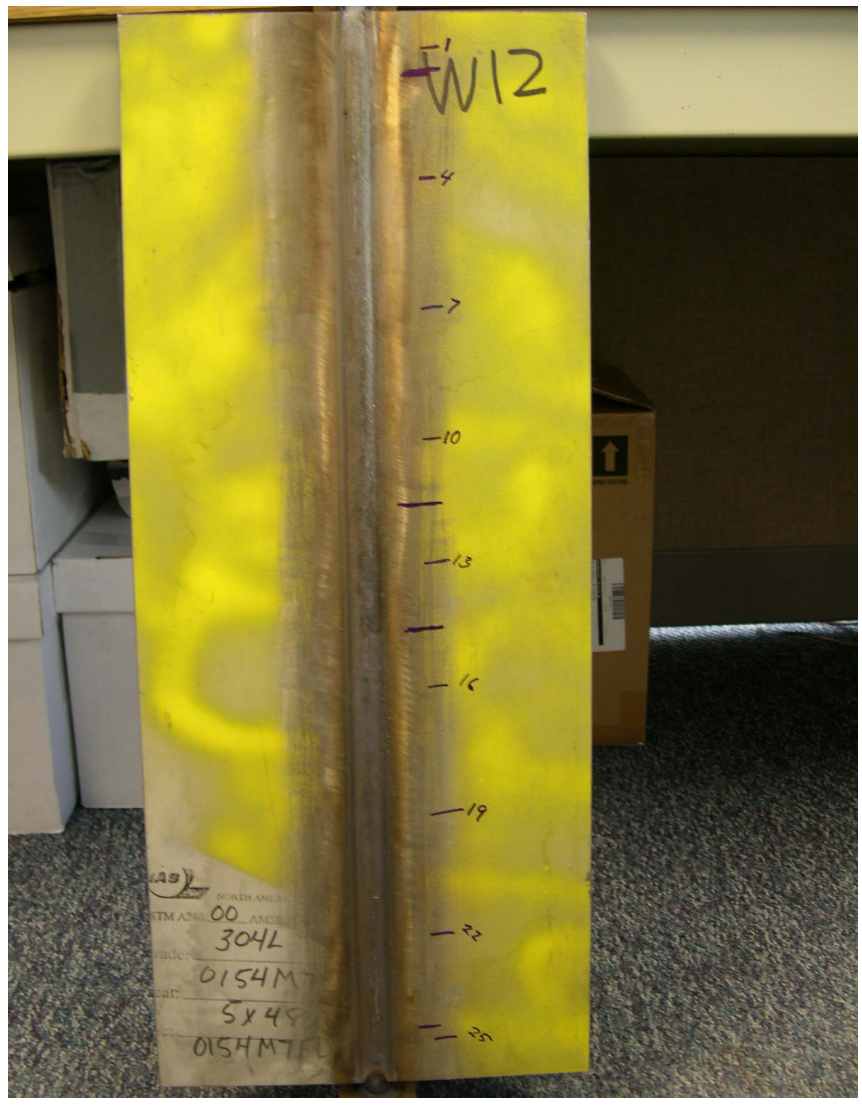

Figure 12. Markings showing where radiographs were taken on the welded plate. 
During the plate welding effort, NSNFP test personnel maintained two lists that noted the material and thickness of each marked plate, the plate's facility location (for tracking fabrication progress on top side welding, back gouging, reverse side welding, repairs, weld examination, etc.), and if the welded plate was used for quasi-static tensile test specimens, impact test specimens, or placed in storage for future use. Tables 2 and 3 show these 'final status' lists for the $304 \mathrm{~L}$ and the $316 \mathrm{~L}$ welded plates respectively. Obviously, during the fabrication and weld examination efforts, these tables were 'living documents', constantly being revised and updated but capturing plate specific details related to the welding and weld examination process. For example, a plate number in the format of WXX indicated that the plate was welded and passed the weld examination process on the first attempt. A plate number in the format of WXX R1 indicated that the welding was completed but did not pass the radiography examination on the first attempt and the weld needed to be repaired. After the weld repair effort was completed, the plate passed the weld examination effort. A plate number in the format of WXX-2 indicates that the initial weld did not pass the weld examination or the wrong weld wire was used and the entire weld needed to be removed and the process started over. In those cases, the welded plate was cut apart and the central portion of the plate (approximately a 1 to 1-1/4-inch wide strip including the weld) was removed. The long edges (that were the outside edges of the previous welded plate) were then weld prepped (using the same geometry as before) and the plates were then welded together again. As the final step, these plates and new welds were radiographed again for final examination. Tables 2 and 3 also indicate that certain 1/4-inch welded plates had an initial indication of a 'lack of penetration' (LOP). However, this finding was questioned by the INL weld engineer and upon reading further radiography efforts and evaluating cut, etched, and polished test coupons (from plate W57), these LOP indications were finally accepted.

The INL submitted their documentation (Reference 14) generated during this welding and weld examination process to the NSNFP. Included in that documentation were the laboratory notebooks, identification of weld process parameters, weld examination results, and the associated radiographs. Notes were made by INL personnel that additional radiography was performed but the reason was unknown. Actually, the additional radiographs were performed at the request of NSNFP test personnel to examine portions of welds that were to be used for quasistatic tensile testing. This data package is in the NSNFP document control center and can be reviewed for more detailed information. Note that the real purpose behind the weld documentation was to establish that the welds being tested (for either quasi-static tensile testing or impact tensile testing) were representative and acceptable with no significant flaws that could adversely affect either test results. Hence, welds meeting the radiographic requirements were mandated. Actual canister closure welds would only be welded from one side but the reverse side or back pass performed for this research effort was necessary to provide sufficient welded material for material testing purposes.

Since the welding of the above plates took a substantial amount of time, more plate material was procured in FY06. This plate material would permit an earlier onset of impact testing with new test specimen geometries. In addition, this material would yield a good estimate of the required amount of drop weight and drop height necessary to achieve the desired strain rates for the limited number of welded plate test specimens. Two $1 / 4$-inch thick plates were procured (the $304 \mathrm{~L}$ plate had a heat number of $64 \mathrm{~A} 1$ and the $316 \mathrm{~L}$ plate had a heat number of $76 \mathrm{H} 3$ ) and two $1 / 2$-inch thick plates were procured (the $304 \mathrm{~L}$ plate had a heat number of $72 \mathrm{~K} 9$ and the $316 \mathrm{~L}$ plate had a heat number of $67 \mathrm{~K} 0$ ). These plates were initially referred to as our 
'auxiliary' plate material but the test data from these plates were later deemed just as significant as any other. It also permitted the incorporation of more material heats into the resulting data collection.

Table 2. 304L welded plate material history.

\begin{tabular}{|c|c|c|c|c|}
\hline $\begin{array}{c}\text { Plate } \\
\text { Identifier }\end{array}$ & $\begin{array}{l}\text { Thickness } \\
\text { (in.) }\end{array}$ & $\begin{array}{l}\text { Current } \\
\text { Location }\end{array}$ & Status & $\begin{array}{c}\text { Designated } \\
\text { Use }\end{array}$ \\
\hline W1-2 & $1 / 2$ & 613 & Cut/Reweld/B-done/1W-done/TS & D-4-4/TS \\
\hline W2-2 & $1 / 2$ & 613 & Cut/Reweld/Storage & \\
\hline W3 & $1 / 2$ & 613 & Storage & \\
\hline W4 R1 & $1 / 2$ & 613 & Weld Repair/Storage & \\
\hline W5 & $1 / 2$ & 613 & B-done/TS & D-4-4/TS \\
\hline W6 & $1 / 2$ & 613 & B-done/W-done & D-4-4 \\
\hline W7 & $1 / 2$ & 613 & B-done/W-done & D-4-4 \\
\hline W8 & $1 / 2$ & 613 & B-done/W-done & D-4-4 \\
\hline W9 & $1 / 2$ & 613 & B-done/W-done & D-4-4 \\
\hline W10 & $1 / 2$ & 613 & B-done/TS & D-4-4/TS \\
\hline W11 R1 & $1 / 2$ & 613 & Weld Repair/Storage & \\
\hline W12 & $1 / 2$ & 613 & Storage & \\
\hline W13 & $1 / 2$ & 613 & Storage & \\
\hline W14 R1 & $1 / 2$ & 613 & Weld Repair/Storage & \\
\hline W15 R1 & $1 / 2$ & 613 & Weld Repair/Storage & \\
\hline W16 & $1 / 2$ & 613 & Storage & \\
\hline W49 & $1 / 4$ & 613 & Storage & \\
\hline W50* & $1 / 4$ & 613 & B-done/TS & $\mathrm{D}-2-2 / \mathrm{TS}$ \\
\hline W51 & $1 / 4$ & 613 & Storage & \\
\hline W52* & $1 / 4$ & 613 & Storage & \\
\hline W53 & $1 / 4$ & 613 & Storage & \\
\hline W54 & $1 / 4$ & 613 & B-done/W-done & $\mathrm{D}-2-2$ \\
\hline W55* & $1 / 4$ & 613 & Only weld specimens cut out & $\mathrm{D}-2-2$ \\
\hline W56* & $1 / 4$ & 613 & B-done/W-done & $\mathrm{D}-2-2$ \\
\hline W57* & $1 / 4$ & 613 & Partial cut/B-done/1W-done/TS & $* \mathrm{~S} * / \mathrm{TS} / \mathrm{D}-2-2$ \\
\hline W58 & $1 / 4$ & 613 & Only weld specimens cut out & D-2-2 \\
\hline W59* & $1 / 4$ & 613 & B-done/W-done & $\mathrm{D}-2-2$ \\
\hline W60-2 & $1 / 4$ & 613 & Cut/Reweld/Storage & \\
\hline W61 & $1 / 4$ & 613 & Storage & \\
\hline W62 & $1 / 4$ & 613 & Storage & \\
\hline W63 & $1 / 4$ & 613 & B-done/W-done & D-2-2 \\
\hline W64* & $1 / 4$ & 613 & Storage & \\
\hline \multicolumn{5}{|c|}{$\begin{array}{ll}\text { Notes: } & \text { B - Base material } \mathrm{W}-\text { Weld material } \mathrm{TS}-\text { Quasi-static tensile test specimen } \\
& \mathrm{D}-2-2 \text { and } \mathrm{D}-4-4 \text { are impact test specimen geometry designations } \\
& * \text { - Initial lack of penetration }(\mathrm{LOP}) \text { indication later acceptable } \\
& * \mathrm{~S} * \text { - Special Top Welded D-2-2 cut out with initial lack of penetration (LOP) for test/examination of } \\
& \text { circular coupons }\end{array}$} \\
\hline
\end{tabular}


Table 3. 316L welded plate material history.

\begin{tabular}{|c|c|c|c|c|}
\hline $\begin{array}{c}\text { Plate } \\
\text { Identifier }\end{array}$ & $\begin{array}{l}\text { Thickness } \\
\text { (in.) }\end{array}$ & $\begin{array}{c}\text { Current } \\
\text { Location }\end{array}$ & Status & $\begin{array}{c}\text { Designated } \\
\text { Use }\end{array}$ \\
\hline W17 & $1 / 2$ & 613 & B-done/TS & D-4-4/TS \\
\hline W18 & $1 / 2$ & 613 & B-done/W-done & D-4-4 \\
\hline W19 & $1 / 2$ & 613 & B-done/W-done & D-4-4 \\
\hline W20 & $1 / 2$ & 613 & B-done/W-done & D-4-4 \\
\hline W21 & $1 / 2$ & 613 & B-done/W-done & D-4-4 \\
\hline W22 & $1 / 2$ & 613 & Storage & \\
\hline W23 & $1 / 2$ & 613 & B-done/W-done/TS & D-4-4/TS \\
\hline W24 & $1 / 2$ & 613 & Storage & \\
\hline W25 & $1 / 2$ & 613 & Storage & \\
\hline W26 & $1 / 2$ & 613 & Storage & \\
\hline W27 & $1 / 2$ & 613 & Storage & \\
\hline W28 & $1 / 2$ & 613 & B-done/1W-done/TS & D-4-4/TS \\
\hline W29 & $1 / 2$ & 613 & Storage & \\
\hline W30 & $1 / 2$ & 613 & Storage & \\
\hline W31 & $1 / 2$ & 613 & Storage & \\
\hline W32 R1 & $1 / 2$ & 613 & Weld Repair/Storage & \\
\hline W33 & $1 / 4$ & 613 & Storage & \\
\hline W34* & $1 / 4$ & 613 & B-done/W-done & $\mathrm{D}-2-2$ \\
\hline W35 R1 & $1 / 4$ & 613 & Weld Repair/Storage & \\
\hline W36* & $1 / 4$ & 613 & B-done/W-done & D-2-2 \\
\hline W37-2 & $1 / 4$ & 613 & Cut/Reweld/Storage & \\
\hline W38* & $1 / 4$ & 613 & Storage & \\
\hline W39* & $1 / 4$ & 613 & Only weld specimens cut out & D-2-2 \\
\hline W40* & $1 / 4$ & 613 & Storage/TS & D-2-2/TS \\
\hline W41* & $1 / 4$ & 613 & Only weld specimens cut out & $\mathrm{D}-2-2$ \\
\hline W42* & $1 / 4$ & 613 & Storage & \\
\hline W43-2 & $1 / 4$ & 613 & Cut/Reweld/Storage & \\
\hline W44* & $1 / 4$ & 613 & B-done/W-done & $\mathrm{D}-2-2$ \\
\hline $\mathrm{W} 45^{*}$ & $1 / 4$ & 613 & B-done/W-done & $\mathrm{D}-2-2$ \\
\hline W46 & $1 / 4$ & 613 & Storage & \\
\hline W47 & $1 / 4$ & 613 & Storage & \\
\hline W48* & $1 / 4$ & 613 & B-done/1W-done/TS & $\mathrm{D}-2-2 / \mathrm{TS}$ \\
\hline \multicolumn{5}{|c|}{$\begin{array}{l}\text { Notes: } \mathrm{B}-\text { Base material } \mathrm{W}-\text { Weld material } \mathrm{TS}-\text { Quasi-static tensile test specimen } \\
\text { D-2-2 and D-4-4 are impact test specimen geometry designations } \\
\text { * - Initial lack of penetration (LOP) indication later acceptable }\end{array}$} \\
\hline
\end{tabular}




\subsection{Quasi-Static Test Specimen Geometries}

The quasi-static tensile test specimens, satisfying the geometry recommendations of ASTM A 370, were either rectangular or round in cross section, depending on the test machine used to perform the tensile testing.

\subsubsection{Initial Testing}

The test specimen geometry used in the initial phase of quasi-static tensile testing was the 'Sheet-Type Subsized Specimen' identified in ASTM A 370. Figure 13 illustrates the rectangular cross section test specimen geometry used. Smaller pieces of material from the full $304 \mathrm{~L}$ and $316 \mathrm{~L}$ plates were cut out and marked (using a permanent marker) indicating the material type, heat number, and the longitudinal (parallel to) or transverse (perpendicular to) orientation with respect to the mill rolling direction of the plate. These smaller pieces were provided to the INL's machine shop to fabricate the test specimens. Only one smaller piece at a time was provided to the machine shop in order to assure proper distinction between $304 \mathrm{~L}$ and 316L material and the proper plate orientation (longitudinal or transverse). Only after each batch of test specimens were received back from the machine shop would another plate be provided for more test specimen fabrication efforts. These specimens, marked with an alphanumeric identifier, material type, heat number, and orientation (transverse or blank indicating longitudinal), did not receive any heat treatments following this machining.

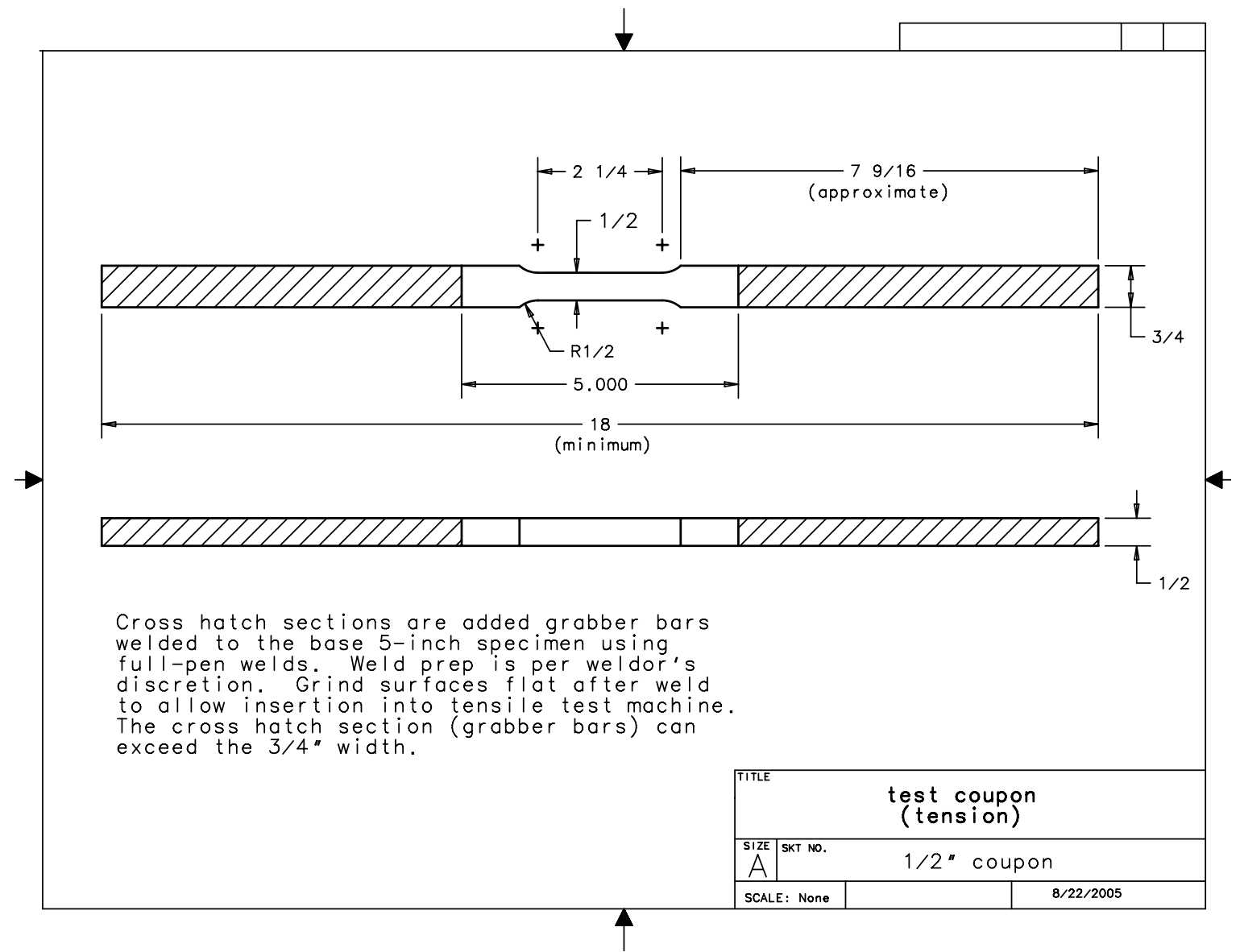

Figure 13. Sheet-type subsized specimen geometry used for initial quasi-static testing. 


\subsubsection{Additional Testing}

A slightly different approach from that described for the initial testing was taken to fabricate quasi-static tensile test specimens for the additional testing, including the use of round test specimens. However, only longitudinal oriented (parallel with the plate rolling direction) test specimens were fabricated from these plates. The 'auxiliary' base material blanks were water jet cut from the large $4 \times 10$-foot plates (see the smaller rectangular cutouts in Figures 14 and 15). Color coding occurred as these water jet cut blanks were removed from these plates. Figures 14 and 15 show the color coding used for both thicknesses of the 304L material (orange) and the $316 \mathrm{~L}$ material (purple), respectively. The color coding was used for material traceability.

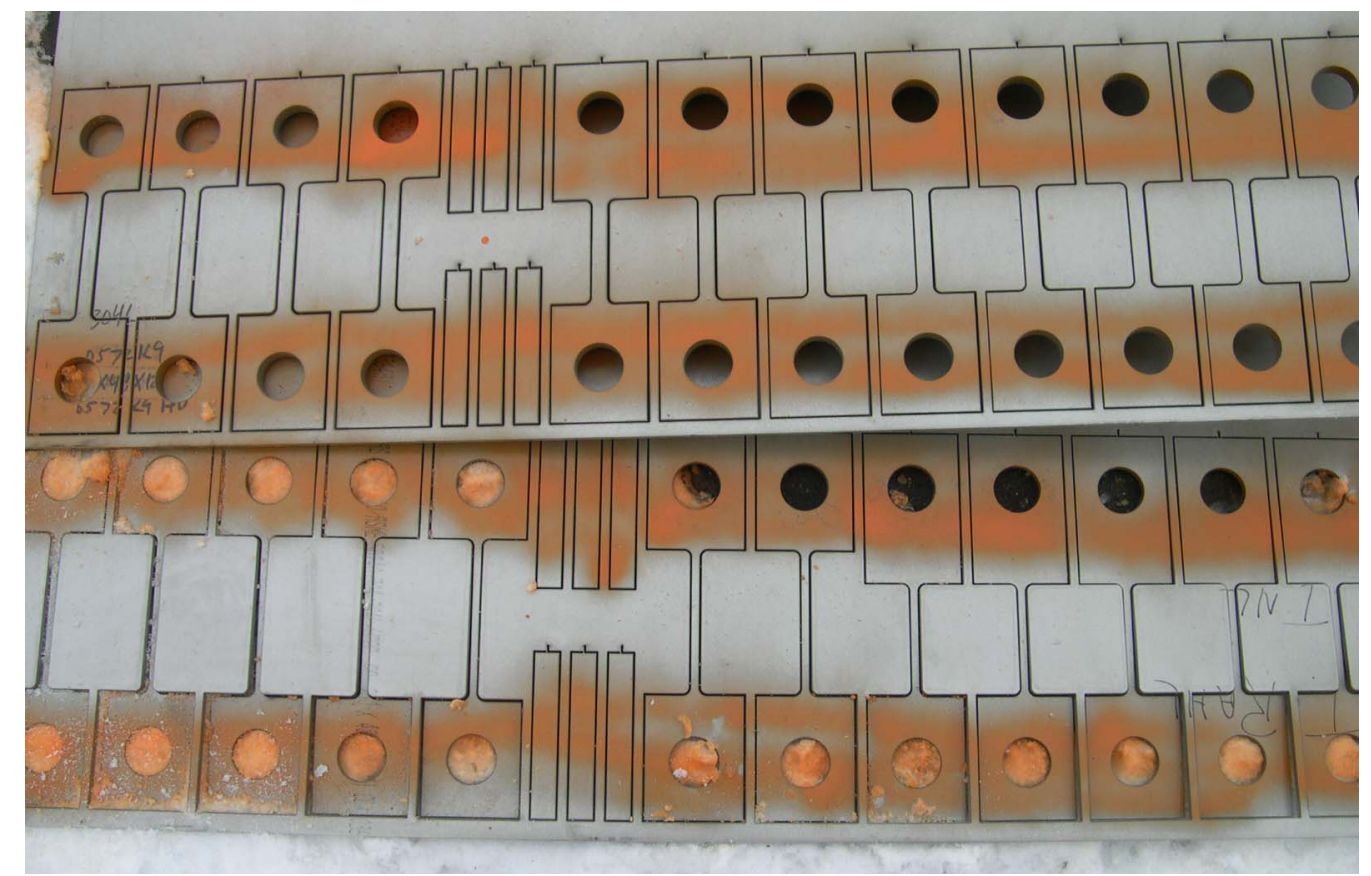

Figure 14. Auxiliary 304L plate with orange paint coding.

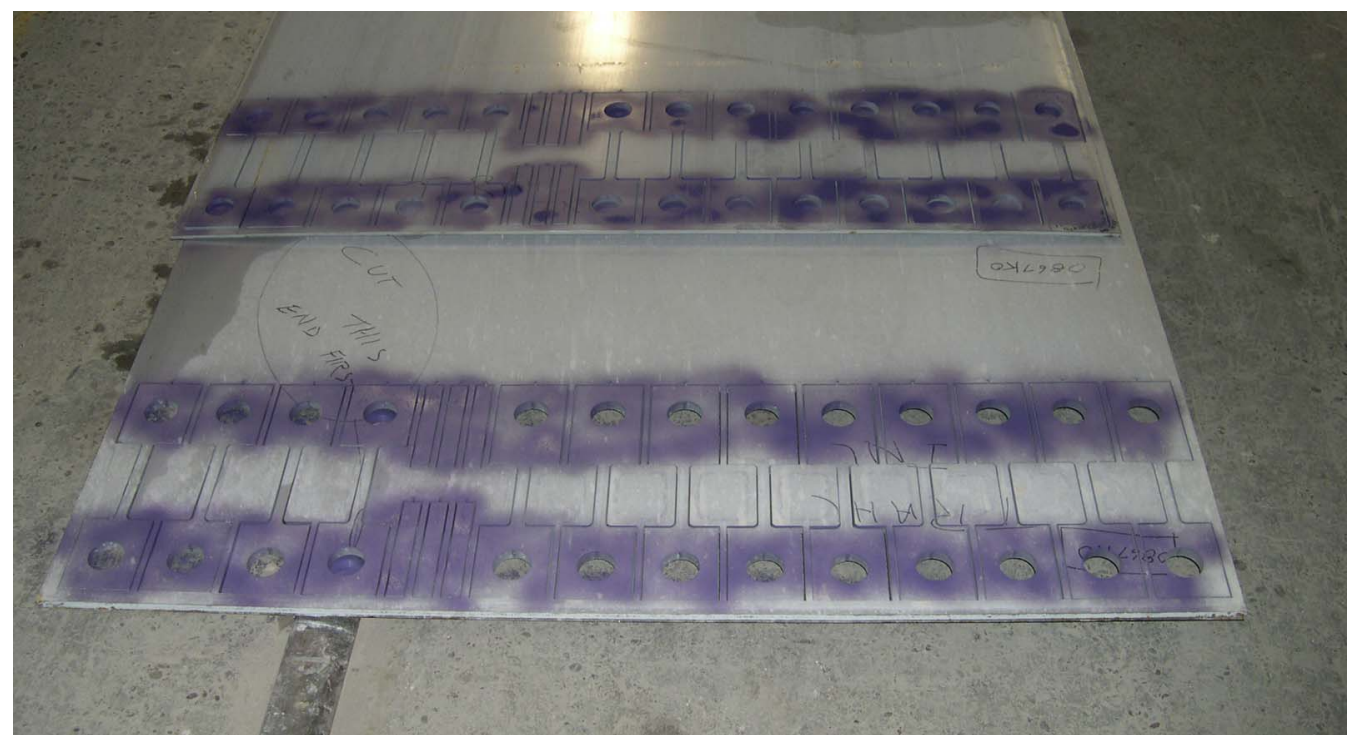

Figure 15. Auxiliary $316 \mathrm{~L}$ plate with purple paint coding. 
The base material blanks from the welded plates material (heat numbers 485896, 48R8, 54M7, and 230468) described in the previous section were cut from the remaining 'drop' material produced when cutting the 5-1/2-inch by 26 -inch long plates from the 4 by 10 -foot plates. These smaller drop plate pieces were marked to establish the longitudinal direction (parallel with the plate's rolling direction) and the material type and heat number. These smaller pieces of drop material from the 304L and 316L plates were then provided to the INL's machine shop to fabricate the test specimens. Only one smaller plate at a time was provided to the machine shop in order to assure proper distinction between 304L and 316L material. Only after each batch of test specimens were received back from the machine shop would another plate be provided for more fabrication efforts.

The welded material blanks were cut from the welded plates. Figures 16 and 17 below show examples of welded material blanks water jet cut from the welded plates. As was done for the base material, the welded blanks (identified by color and thickness) were controlled by NSNFP test personnel so as to maintain full traceability between 304L and 316L welded material during test specimen fabrication.

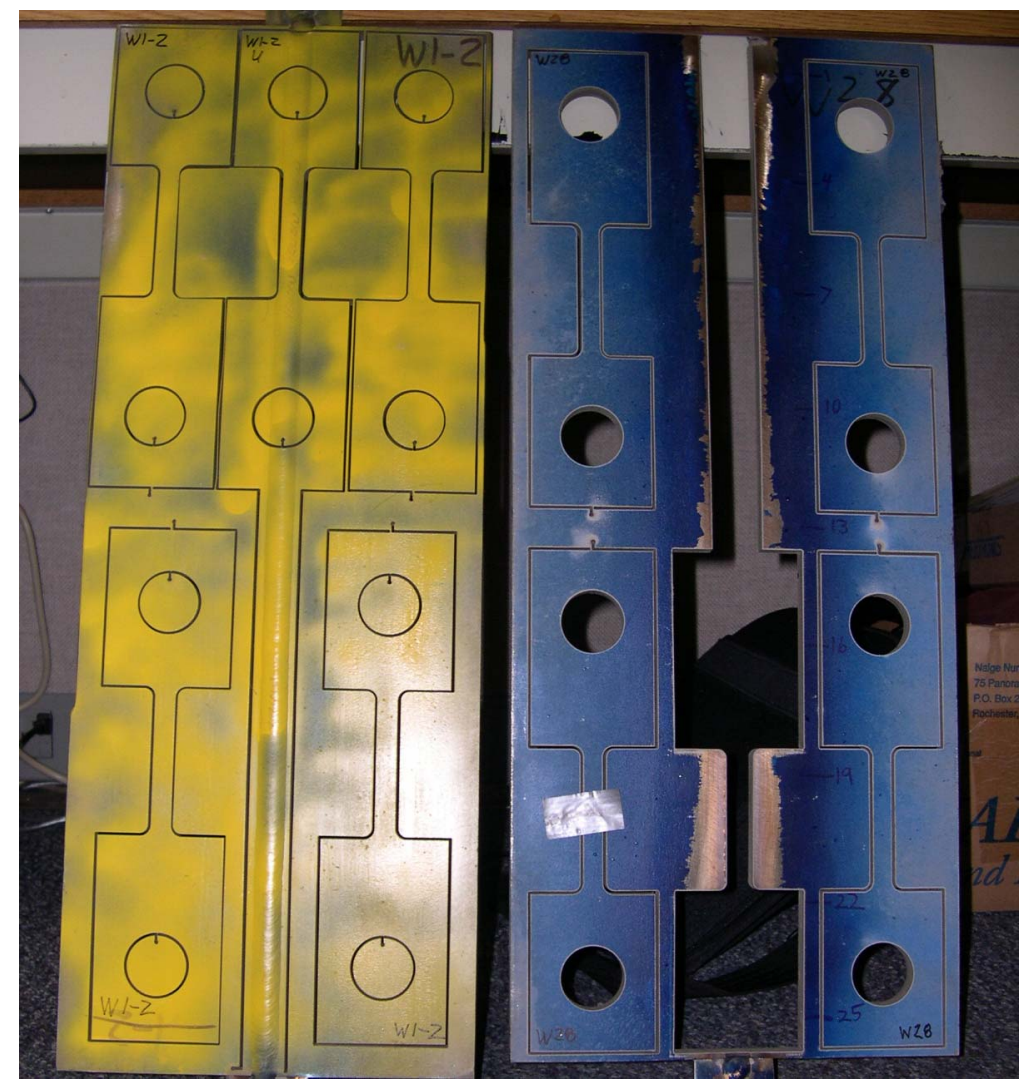

Figure 16. Both 304L and 316L 1/2-inch thick welded plates showing welded material blanks (attached to impact test specimens, which were later removed). 


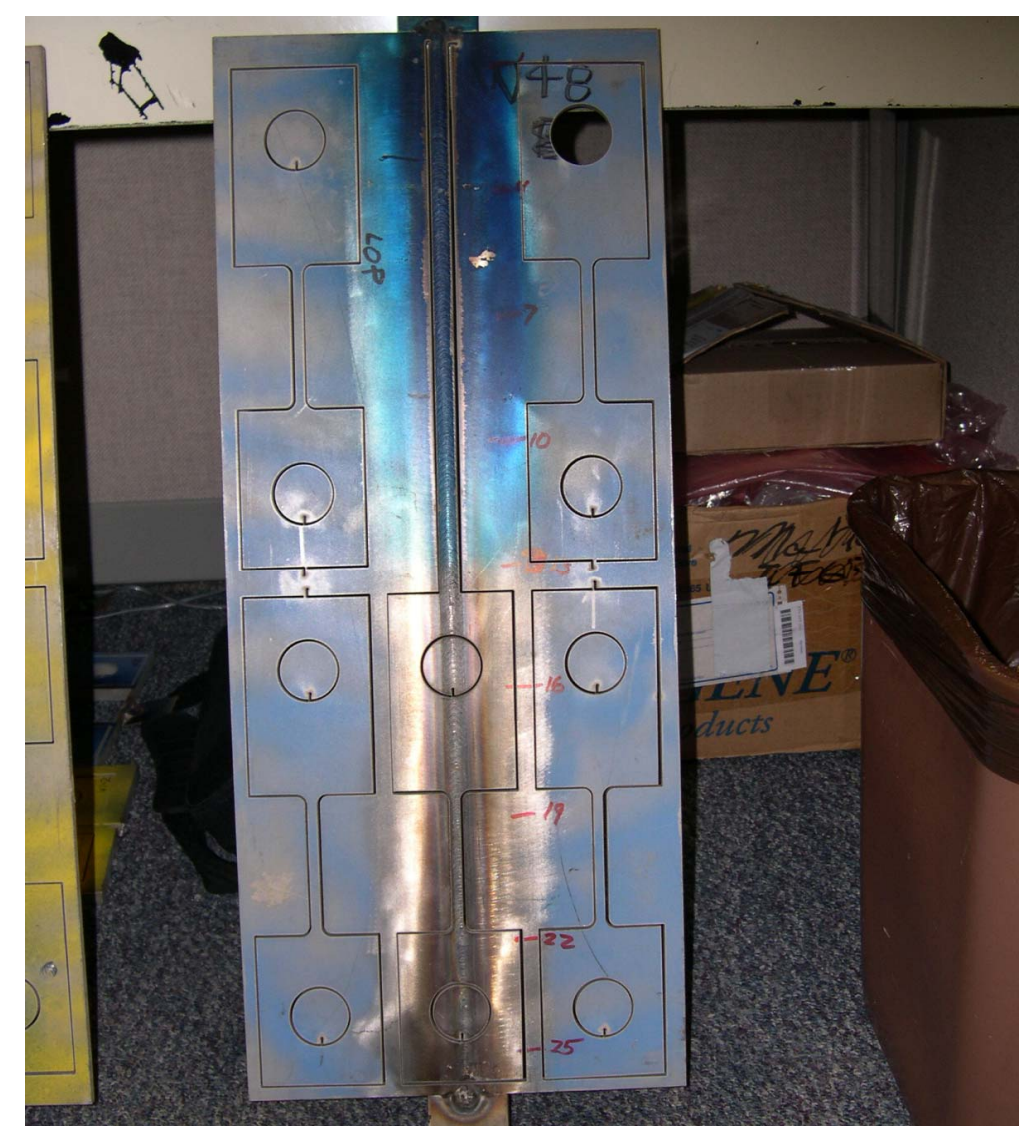

Figure 17. 316L 1/4-inch thick plate showing welded material blank cut from the plate (also attached to impact test specimen, which was later removed).

With the base and welded material blanks or smaller drop plate pieces (obtained as described above), it was now possible to fabricate the test specimens. The test specimen geometry depended upon the plate thickness. The $1 / 2$-inch thick plate blanks were machined into round, small-sized 0.350 inch diameter test specimens as shown in Figure 18. Specimen blanks from the $1 / 4$-inch thick plates were machined into round, small-sized 0.160 -inch diameter specimens as shown in Figure 19. The test specimens were marked (with a unique numerical identifier) to indicate material type, heat number, and whether the test specimen was either base or welded material. The ends of the specimens outside of the gauge length were threaded to match the holders on the tensile test machine. Test specimens were not heat treated following machining. 


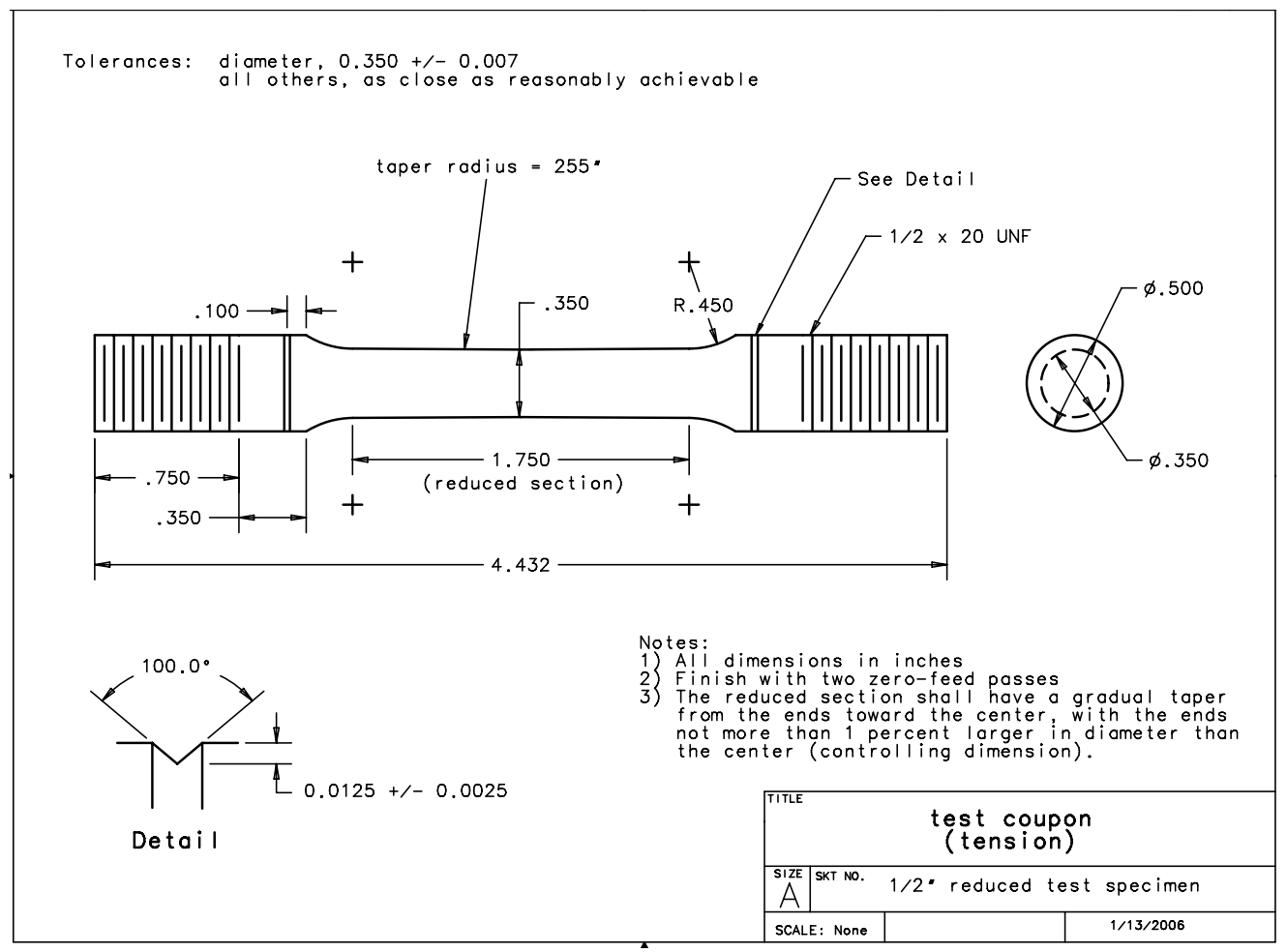

Figure 18. Round, small-size 0.350-inch diameter quasi-static tensile test specimen used for additional testing of $1 / 2$-inch thick plate.

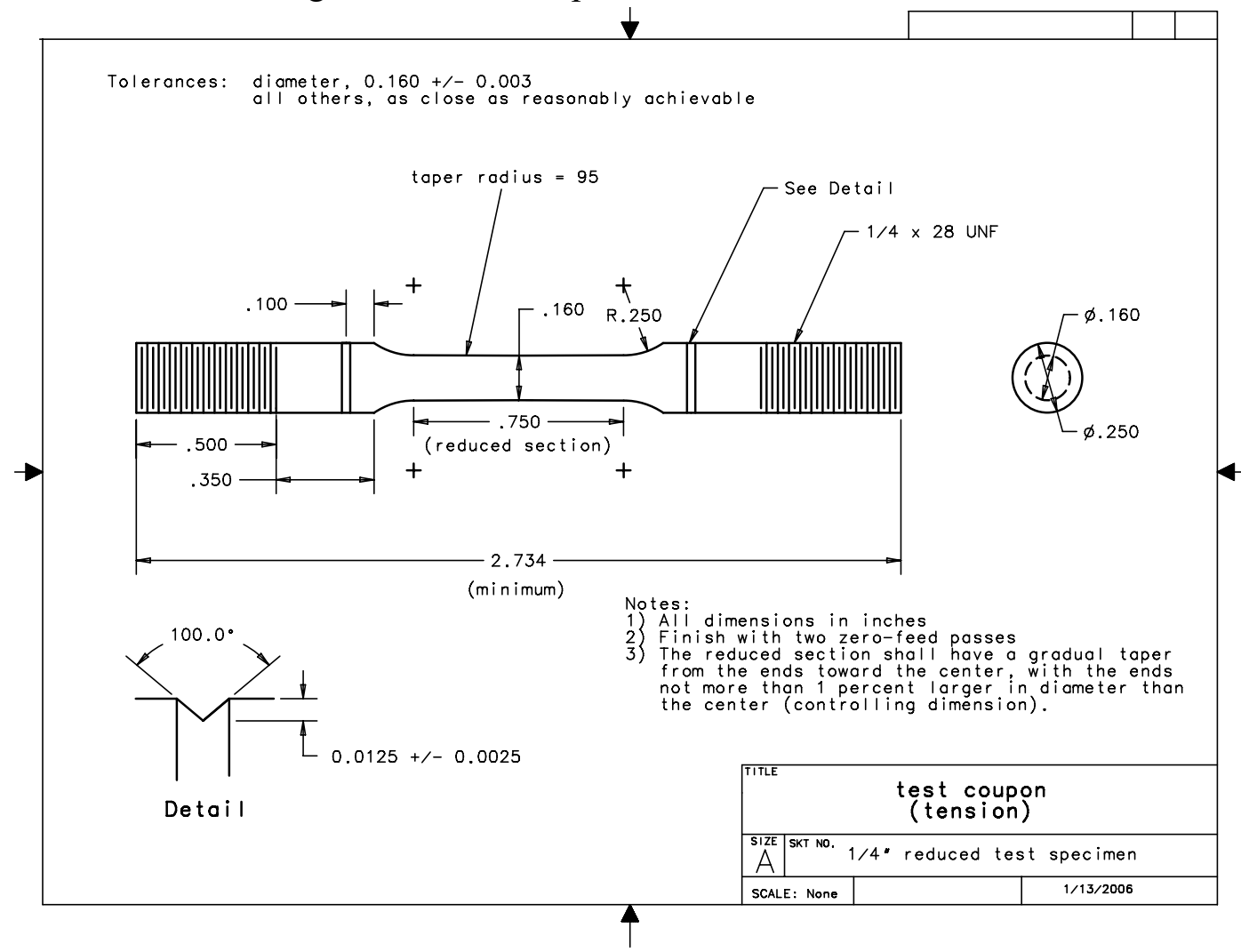

Figure 19. Round, small-sized 0.160-inch diameter quasi-static tensile test specimen used for additional testing of $1 / 4$-inch thick plate. 


\subsection{Quasi-Static Test Procedure}

The quasi-static tensile testing procedures followed the requirements of ASTM A 370 except for the stated reporting requirements. A total of three tensile tests for each material heat (and each orientation if applicable) at each temperature under consideration, for base and welded material as applicable, were performed. The quasi-static tensile testing was performed by INL personnel with NSNFP test personnel in attendance to assure acceptable data was obtained.

\subsubsection{Initial Testing}

Quasi-static tensile tests were performed at the Materials Testing Laboratory on February 19 and June 3, 2004. Mr. H. C. Bean, laboratory manager, conducted the tests using the TiniusOlsen tensile test machine (see Figure 20). Test specimen dimensions were measured by the INL laboratory manager prior to tensile testing. NSNFP test personnel also recorded continuous force-displacement data for the entire duration of each test (load initiation through specimen failure). Both longitudinal and transverse oriented test specimens were tensile tested. The flat ends of the test specimens were inserted into plate grippers as seen in Figure 21. The strain rate achieved during the quasi-static tensile testing was approximately $10^{-3}$ to $10^{-4}$ per second.

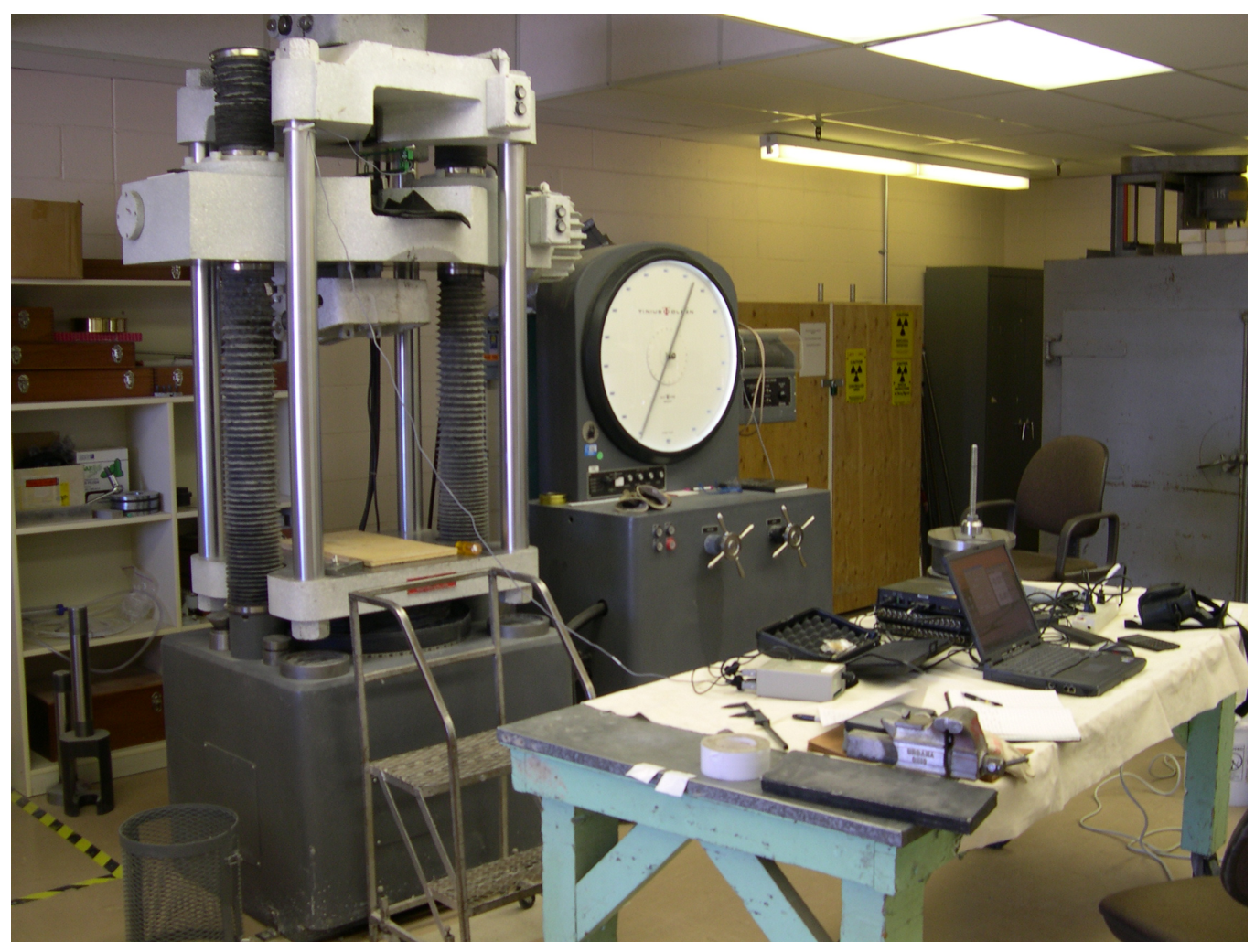

Figure 20. Tinius-Olsen tensile test machine at the Materials Testing Laboratory. 


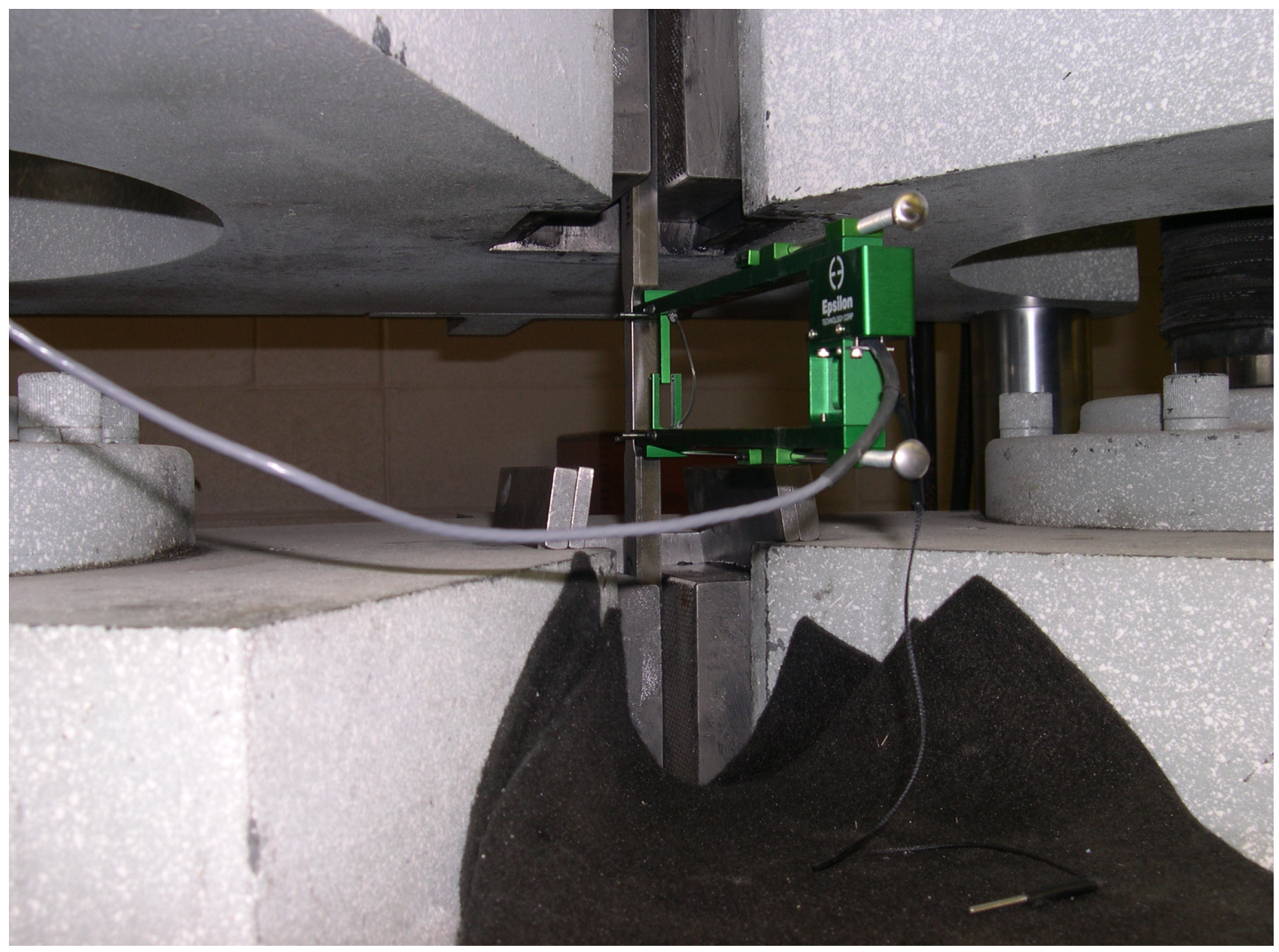

Figure 21. Close-up of inserted test specimen with extensometer attached.

\subsubsection{Additional Testing}

Conventional quasi-static tensile tests were performed at $-20{ }^{\circ} \mathrm{F}$, room temperature, $300{ }^{\circ} \mathrm{F}$, and $600^{\circ} \mathrm{F}$ using an Instron Model 4505 universal testing machine with a maximum capacity of 22,000 pounds. Prior to tensile testing, each specimen was dimensionally checked. Those measurements were used in the determination of the test specimen's cross sectional area or were within acceptable tolerances to use the nominal cross sectional area. These round specimens were gripped in threaded connectors, aligned using pins and clevises, and loaded by a crosshead displacement that produced strain rates of approximately $10^{-3}$ to $10^{-4}$ per second. Force-displacement output was continuously recorded to specimen failure. LabVIEW 7.0 (Reference 36) software was used to record and display the specimen temperature, forcedisplacement and engineering stress-strain data, and write the data to an Excel file for evaluation.

The $-20^{\circ} \mathrm{F}$ temperature testing was achieved using an insulated 'coldbox' surrounding the test specimen and extensometer. Liquid nitrogen was fed into the coldbox to achieve the desired initial temperature conditions of $-20^{\circ} \mathrm{F}$ and to maintain those conditions throughout the tensile test. Figure 22 shows this test setup, including the three thermocouples attached to the test specimen.

For the room temperature tests, displacements were measured over the specimen gauge length using an extensometer. Figure 23 shows a room temperature tensile test setup with the extensometer in place. The room temperature within the laboratory was considered acceptable for temperature conditions. 


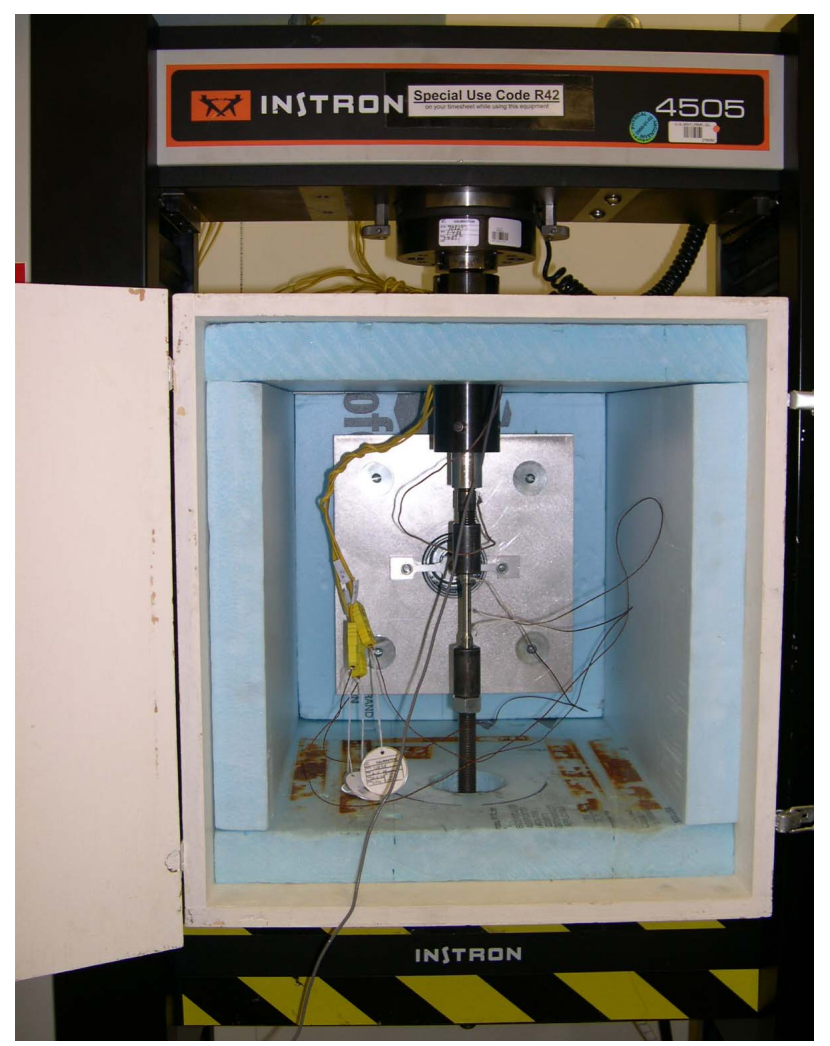

Figure 22. Cold $\left(-20^{\circ} \mathrm{F}\right)$ temperature tensile testing setup.

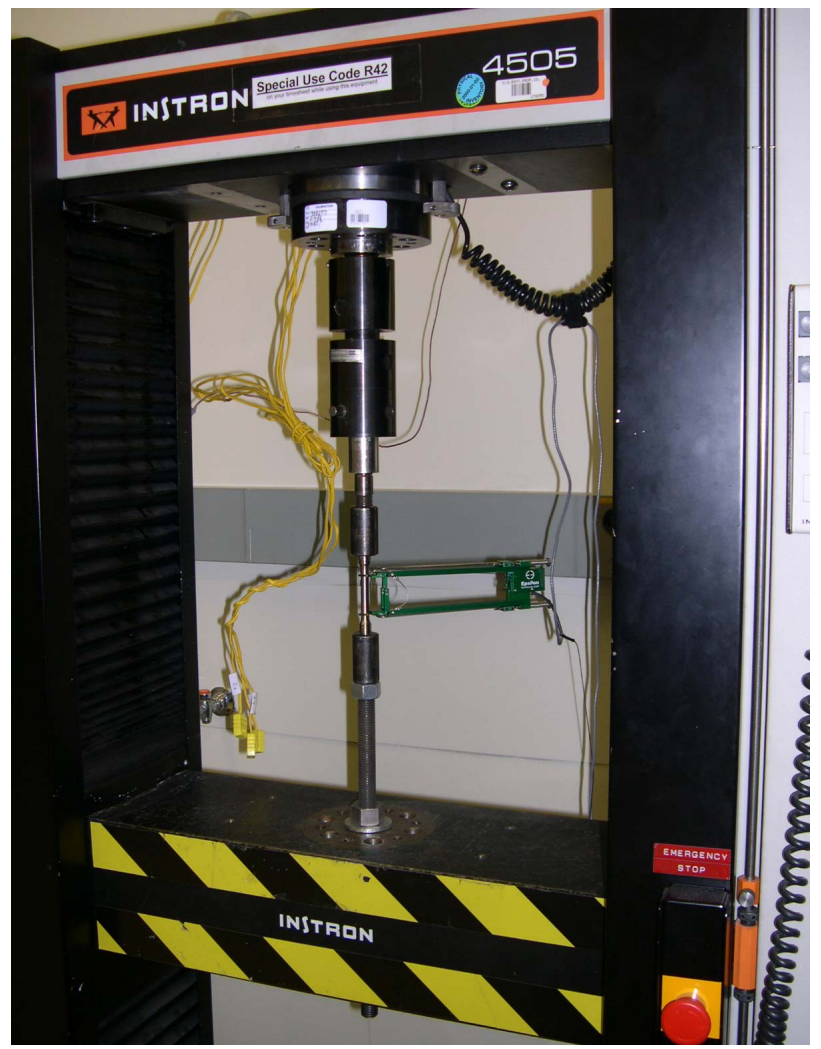

Figure 23. Room temperature tensile testing setup at IRC. 
For the $300{ }^{\circ} \mathrm{F}$ and $600{ }^{\circ} \mathrm{F}$ tests, an electric furnace enclosure was used. Because the extensometer was not compatible with the temperatures inside the furnace enclosure, two coupled, vertical rods, one on each side of the test specimen and attached to the upper specimen holder, transferred the deformation in the gauge length to an extensometer and linear variable displacement transducer (LVDT) located outside of the furnace. The elevated temperature tensile test setup is shown in Figure 24 with the furnace open to show the specimen with transfer rods, extensometer, and LVDT. Figure 25 shows an alternate furnace setup that was also used.

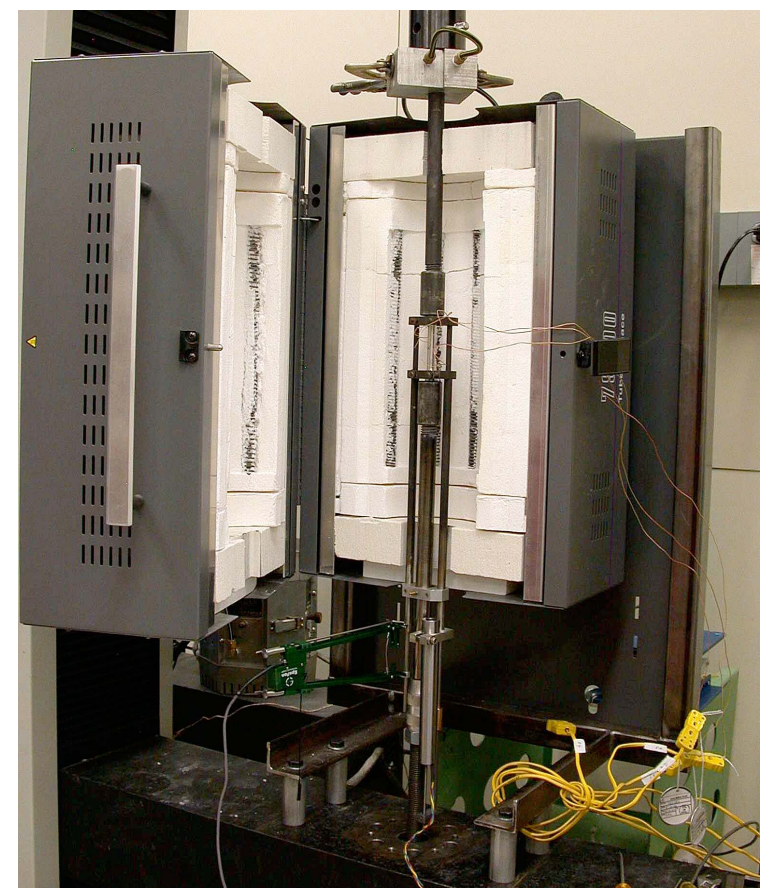

Figure 24. Elevated temperature tensile testing setup with furnace door open.

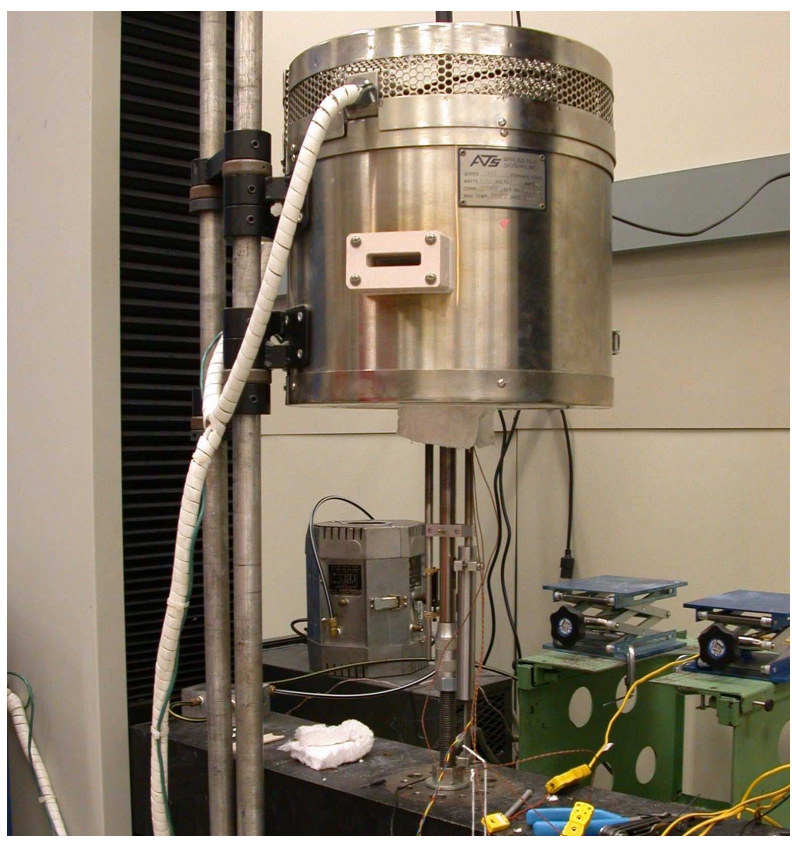

Figure 25. Alternate furnace setup used with door closed. 


\subsection{Achieving Temperature Conditions}

Due to the importance of achieving the proper temperatures for the quasi-static tensile testing performed, this section provides more details of how and what temperatures conditions were achieved during the quasi-static tensile testing.

\subsubsection{Initial Testing}

The quasi-static tensile testing at the Materials Testing Laboratory was performed in a typical office/laboratory conditioned environment at ambient room conditions, meaning that the temperature was in the $65^{\circ} \mathrm{F}$ to $75^{\circ} \mathrm{F}$ range per the laboratory manager, Mr. H. C. Bean. This falls within a very close $71{ }^{\circ} \mathrm{F} \pm 6{ }^{\circ} \mathrm{F}$ temperature range. Hence, these test specimen temperatures were acceptable.

\subsubsection{Additional Testing}

For the room temperature tests, test specimen temperatures were not directly measured for every test. Recorded data for three different days from the INL Lab Notebook LAB-771 (that documented the quasi-static tensile testing at the IRC) indicates the room temperature ranged from 72 to $74{ }^{\circ} \mathrm{F}$ on those days. The engineer in charge of the tensile testing (Mr. R. Lloyd) indicated that the anticipated worst temperature range in the IRC labs would be $68^{\circ} \mathrm{F}$ to $77^{\circ} \mathrm{F}$, also within a very close $71{ }^{\circ} \mathrm{F} \pm 6{ }^{\circ} \mathrm{F}$ temperature range. These room temperature conditions were acceptable.

Test specimen temperatures other than room conditions (while in a furnace or cold box) were monitored throughout each tensile test cycle using temperature data from three thermocouples attached (thin wire spot-welded) to each test specimen. Figure 26 shows three thermocouples attached at the top, middle, and bottom locations of the gauge length of a typical round test specimen machined from $1 / 2$-inch thick plate.

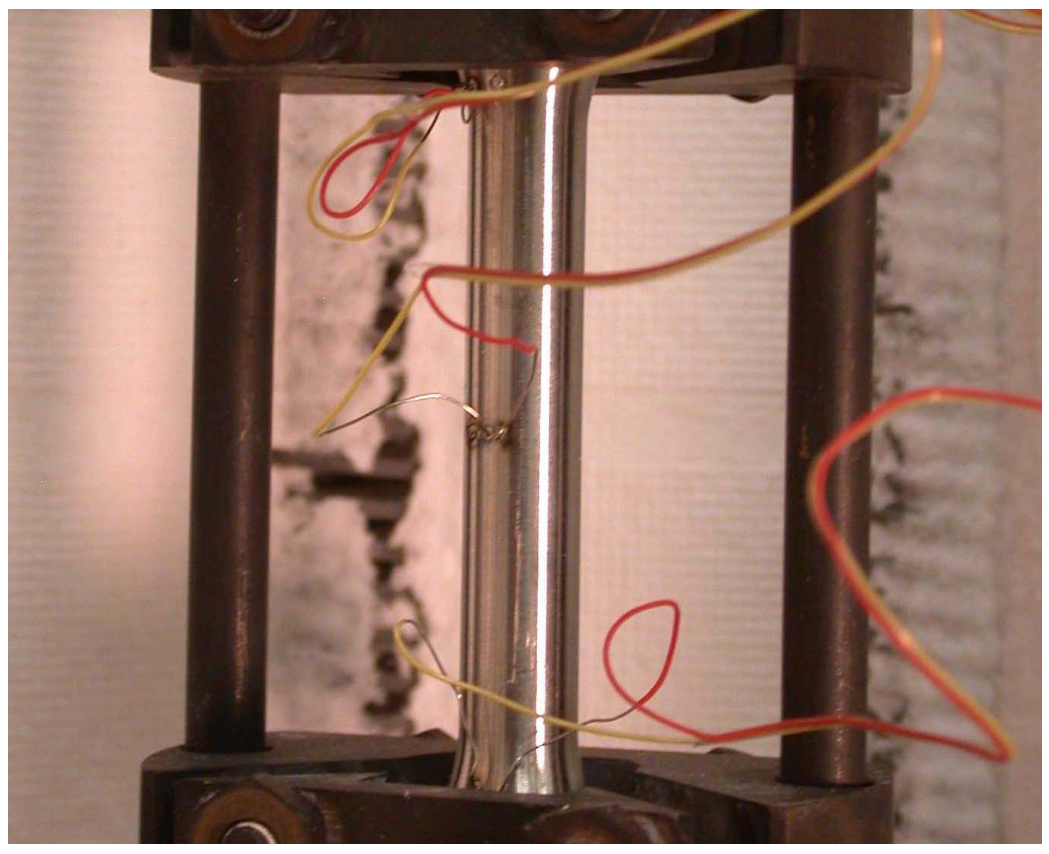

Figure 26. Thermocouples attached to a quasi-static tensile test specimen. 
Prior to beginning the quasi-static tensile test, the test specimens were allowed to uniformly 'soak' to the designated test temperature. Because of the small size of the test specimens, automated methods of preheating, pre-cooling and holding the specimens at appropriate conditions during the quasi-static tensile test were not employed. The three temperatures from the test specimen were monitored by the laboratory technician and furnace or cold box temperatures were manually adjusted as necessary so that variations in test specimen temperatures were minimized as much as possible.

The temperature data for the three thermocouples were recorded. These three temperatures were averaged and then the maximum and the minimum average temperatures achieved during the quasi-static tensile testing (from test start to test specimen fracture) were established. These data are included in files 1A and 1B on the Report CD-R (Reference 37) included with this report. Laboratory Notebook NSNF/SN/04.01 (hereafter referred to as NSNFP Lab Notebook) Binder Volume 6 (Reference 38) contains a summary of these maximum and minimum average temperatures for the quasi-static tensile tests that were actually used as a basis for establishing the true stress-strain properties for that specific material and temperature conditions. Table 4 summarizes the test specimen temperature ranges measured during the 2006 and 2007 quasi-static tensile testing of 304L and 316L stainless steels performed by the INL for the NSNFP.

Table 4. Worst case average temperature ranges achieved during quasi-static tensile testing.

\begin{tabular}{|c|c|}
\hline $\begin{array}{c}\text { Desired Test } \\
\text { Temperature }\end{array}$ & $\begin{array}{c}\text { Worst Case Average Temperature } \\
\text { Range Achieved }\end{array}$ \\
\hline$-20^{\circ} \mathrm{F}$ & $+14 /-5^{\circ} \mathrm{F}$ \\
\hline $300^{\circ} \mathrm{F}$ & $+13 /-8^{\circ} \mathrm{F}$ \\
\hline $600^{\circ} \mathrm{F}$ & $+18 /-19^{\circ} \mathrm{F}$ \\
\hline
\end{tabular}

Table 4 temperature ranges are the worst-case ranges for all basis testing completed. Most of the tests had temperatures much closer to the desired test temperature. However, even these worst-case temperature ranges are considered acceptable. The data on the Report CD-R contains the maximum and minimum average temperatures for the entire test interval, including the onset of necking through final rupture. However, the material impact testing effort only used data up to the onset of necking. Therefore, the temperature ranges listed above in Table 4 reflect the averaged maximum and minimum temperature ranges achieved up to the onset of necking.

The upper worst-case temperature range result for the $-20{ }^{\circ} \mathrm{F}$ testing $\left(+14{ }^{\circ} \mathrm{F}\right)$ appears somewhat high until it is recognized that the test specimens actually get hotter during tensile testing near the middle location due to the material straining. This fact is clearly illustrated by the plot of measured test specimen temperatures for Test \#141, a 316L material test (see Figure 27). Even though the environment was kept close to $-20{ }^{\circ} \mathrm{F}$ (as evidenced by the top and bottom temperatures), the middle temperature rose much higher (due to material straining), significantly affecting the average temperature results. However, this is the physical phenomenon that occurs during actual drop events. The important fact is that the starting (soaked) temperature and the sustained environment (represented by the larger end portions of the test specimen) adequately 
reflect the $-20^{\circ} \mathrm{F}$ conditions. Heat generation also occurs in the higher temperature tensile tests but the temperature values are more removed from zero, making the effects less noticeable.

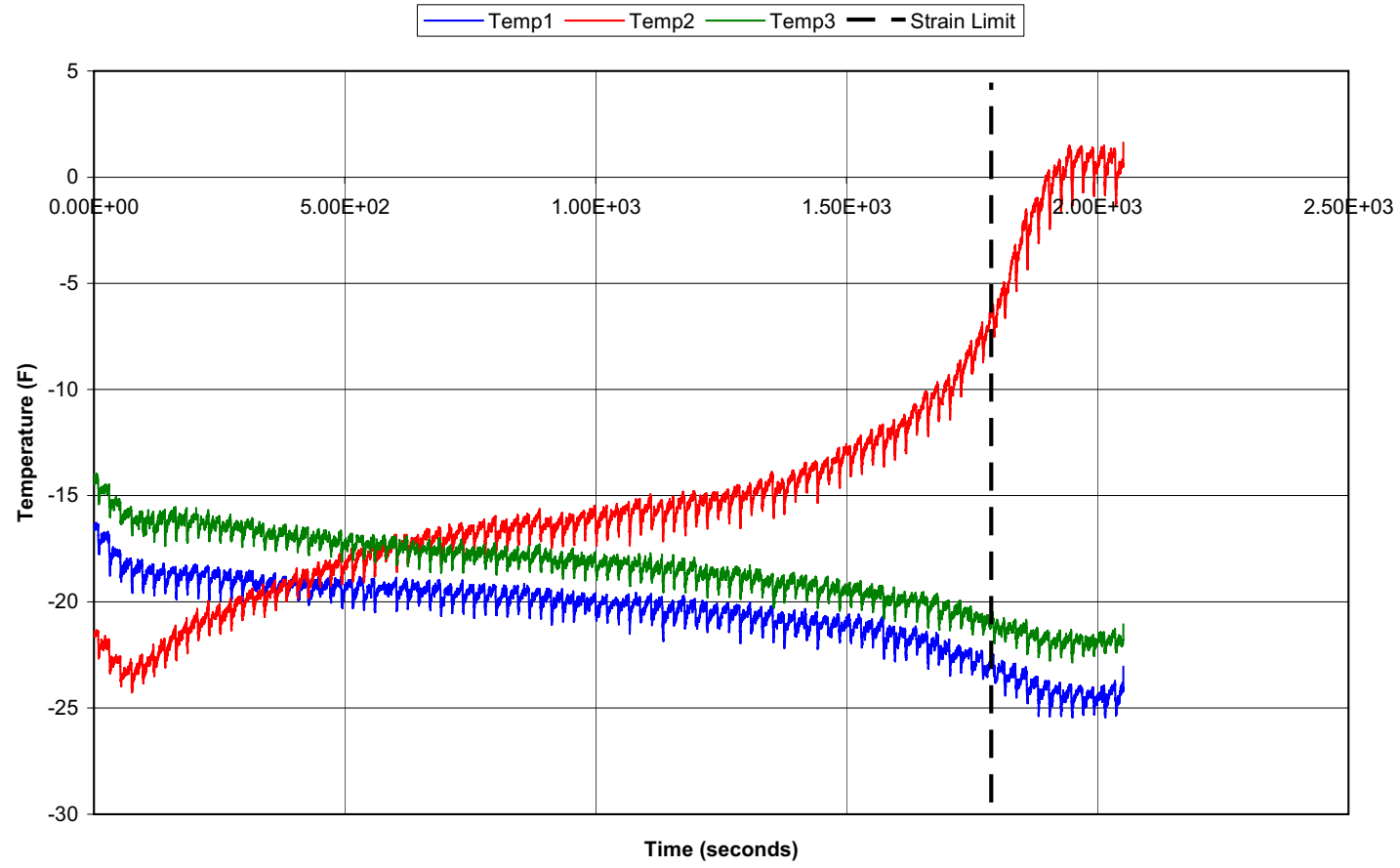

Figure 27. Data from three thermocouples showing how middle temperature rises due to straining during $-20{ }^{\circ} \mathrm{F}$ tensile test.

\subsection{Quasi-Static Tensile Testing Results}

A significant number of quasi-static tensile tests (over 160) were performed in order to support the material impact testing effort discussed herein. As previously mentioned, three tensile tests for each material heat (and each plate orientation if applicable) at each temperature under consideration for both base and welded material were performed. One test was chosen from each set of three tests that best represented typical results. Because the number of tests for a particular set of conditions was limited to three, statistical methods were not employed to establish an average or mean result. All three tests were plotted as engineering stress-strain curves and the most representative specimen result was chosen for the applicable set of conditions.

Tables 5 and 6 list the specific quasi-static tensile test specimen identifier (of the three tests performed) chosen to represent that specific material condition. These tables (with background colors matching the material color coding) include both 'initial' and 'additional' testing. Tables 5 and 6 address only the longitudinally oriented test specimen results. In the tables, 'NA' indicates that quasi-static testing was not performed for those specific conditions. As earlier discussed, transverse oriented test specimens (perpendicular to the plate's rolling direction) were also quasi-static tensile tested at the INL Materials Testing Laboratory under room temperature conditions. These transverse test results were performed to help assess any potential response variation in test specimens reflecting varying orientation with respect to the direction that the plate material was rolled at the mill. Section 6.6.2 contains specific 
information regarding the comparison of results between longitudinal and transverse oriented quasi-static and impact tensile tests.

Table 5. Identification of 304L tensile tests establishing basis true stress-strain curves.

\begin{tabular}{|c|c|c|c|c|c|}
\hline Material & Thickness & Heat & Type & Temp. (F) & Specimen Used \\
\hline \multirow{43}{*}{ 304L } & \multirow{26}{*}{$\begin{array}{c}\text { 1/2-inch } \\
\text { Thick }\end{array}$} & \multirow{8}{*}{ 10W8 } & \multirow{4}{*}{ Base } & -20 & NA \\
\hline & & & & Room & MT03 \\
\hline & & & & 300 & NA \\
\hline & & & & 600 & NA \\
\hline & & & \multirow{4}{*}{ Weld } & -20 & NA \\
\hline & & & & Room & NA \\
\hline & & & & 300 & NA \\
\hline & & & & 600 & NA \\
\hline & & \multirow{10}{*}{ 54M7 } & \multirow{5}{*}{ Base } & & \\
\hline & & & & -20 & 156 \\
\hline & & & & Room & 153 \\
\hline & & & & 300 & 146 \\
\hline & & & & 600 & 151 \\
\hline & & & & & \\
\hline & & & \multirow{4}{*}{ Weld } & -20 & $183 \mathrm{~W}$ \\
\hline & & & & Room & $177 \mathrm{~W}$ \\
\hline & & & & 300 & $171 \mathrm{~W}$ \\
\hline & & & & 600 & $179 \mathrm{~W}$ \\
\hline & & \multirow{8}{*}{$72 K 9$} & \multirow{4}{*}{ Base } & & \\
\hline & & & & $\frac{-20}{\text { Room }}$ & $\begin{array}{l}106 \\
113\end{array}$ \\
\hline & & & & 300 & 109 \\
\hline & & & & 600 & 111 \\
\hline & & & \multirow{4}{*}{ Weld } & -20 & NA \\
\hline & & & & Room & NA \\
\hline & & & & 300 & NA \\
\hline & & & & 600 & NA \\
\hline & \multirow{17}{*}{$\begin{array}{c}\text { 1/4-inch } \\
\text { Thick }\end{array}$} & \multirow{8}{*}{ 64A1 } & \multirow{4}{*}{ Base } & -20 & 13 \\
\hline & & & & Room & 2 \\
\hline & & & & 300 & 5 \\
\hline & & & & 600 & 8 \\
\hline & & & \multirow{4}{*}{ Weld } & -20 & NA \\
\hline & & & & Room & NA \\
\hline & & & & 300 & NA \\
\hline & & & & 600 & NA \\
\hline & & & \multirow{5}{*}{ Base } & & \\
\hline & & \multirow{8}{*}{485896} & & -20 & 55 \\
\hline & & & & Room & 47 \\
\hline & & & & 300 & 50 \\
\hline & & & & 600 & 53 \\
\hline & & & \multirow{4}{*}{ Weld } & -20 & $81 \mathrm{~W}$ \\
\hline & & & & Room & $73 \mathrm{~W}$ \\
\hline & & & & 300 & $74 \mathrm{~W}$ \\
\hline & & & & 600 & $77 \mathrm{~W}$ \\
\hline
\end{tabular}


Table 6. . Identification of 316L tensile tests establishing basis true stress-strain curves.

\begin{tabular}{|c|c|c|c|c|c|}
\hline Material & Thickness & Heat & Type & Temp. (F) & Specimen Used \\
\hline \multirow{43}{*}{$316 \mathrm{~L}$} & \multirow{26}{*}{$\begin{array}{c}\text { 1/2-inch } \\
\text { Thick }\end{array}$} & \multirow{8}{*}{ 09T9 } & \multirow{4}{*}{ Base } & -20 & NA \\
\hline & & & & Room & MT12 \\
\hline & & & & 300 & NA \\
\hline & & & & 600 & NA \\
\hline & & & \multirow{4}{*}{ Weld } & -20 & NA \\
\hline & & & & Room & NA \\
\hline & & & & 300 & NA \\
\hline & & & & 600 & NA \\
\hline & & \multirow{10}{*}{$67 \mathrm{KO}$} & & & \\
\hline & & & \multirow{4}{*}{ Base } & -20 & 125 \\
\hline & & & & Room & 128 \\
\hline & & & & 300 & 120 \\
\hline & & & & 600 & 123 \\
\hline & & & \multirow{5}{*}{ Weld } & & \\
\hline & & & & -20 & NA \\
\hline & & & & Room & NA \\
\hline & & & & 300 & NA \\
\hline & & & & 600 & NA \\
\hline & & \multirow{8}{*}{230468} & \multirow{4}{*}{ Base } & 20 & 141 \\
\hline & & & & Room & $\begin{array}{l}141 \\
138\end{array}$ \\
\hline & & & & 300 & 131 \\
\hline & & & & 600 & 135 \\
\hline & & & \multirow{4}{*}{ Weld } & -20 & $181 \mathrm{~W}$ \\
\hline & & & & Room & $167 \mathrm{~W}$ \\
\hline & & & & 300 & $161 \mathrm{~W}$ \\
\hline & & & & 600 & $164 \mathrm{~W}$ \\
\hline & \multirow{17}{*}{$\begin{array}{c}\text { 1/4-inch } \\
\text { Thick }\end{array}$} & \multirow{9}{*}{$48 \mathrm{R} 8$} & \multirow{4}{*}{ Base } & -20 & 42 \\
\hline & & & & Room & 33 \\
\hline & & & & 300 & 35 \\
\hline & & & & 600 & 37 \\
\hline & & & \multirow{4}{*}{ Weld } & -20 & $84 \mathrm{~W}$ \\
\hline & & & & Room & $63 \mathrm{~W}$ \\
\hline & & & & 300 & $66 \mathrm{~W}$ \\
\hline & & & & 600 & $68 \mathrm{~W}$ \\
\hline & & & & & \\
\hline & & \multirow{8}{*}{$76 \mathrm{H3}$} & \multirow{4}{*}{ Base } & -20 & 26 \\
\hline & & & & Room & 17 \\
\hline & & & & 300 & 19 \\
\hline & & & & 600 & 22 \\
\hline & & & \multirow{4}{*}{ Weld } & -20 & NA \\
\hline & & & & Room & NA \\
\hline & & & & 300 & NA \\
\hline & & & & 600 & NA \\
\hline
\end{tabular}


The quasi-static tensile tests were performed through the entire material response range, out to failure. However, because the impact testing only needed to use data out to the uniform strain limit (the strain at the onset of necking), no Bridgman correction was applied to this data.

\subsubsection{Initial Testing}

Quasi-static tensile tests were performed on 304L and 316L plate material at the INL Materials Testing Laboratory following the tension test guidelines of ASTM A 370. Three test specimens were tested for each material and MT03 was chosen as typical for the 304L material and MT12 was chosen as typical of the 316L material. The quasi-static engineering and true stress-strain curves developed from these tests are contained on the Report CD-R, files $1 \mathrm{~A}$ and $1 \mathrm{~B}$.

\subsubsection{Additional Testing}

Quasi-static tensile tests were performed on 304L and 316L plate material at the INL Research Center following the tension test guidelines of ASTM A 370. Three test specimens were tested for each material and Table 5 shows the tests chosen as typical for the 304L material and Table 6 shows the tests chosen as typical of the 316L material. The quasi-static engineering and true stress-strain curves developed from these tests are contained on the Report CD-R, files $1 \mathrm{~A}$ and $1 \mathrm{~B}$ (data is too voluminous for incorporation into the pages of this report).

For a typical test sequence, specimens were tensile tested to failure with the specimen beginning to 'neck' after achieving the maximum engineering strength followed shortly by fracture of the specimen. As the neck progressed to failure, non-uniform geometry altered the uniaxial stress state to a complex stress state involving shear components as well as normal stresses. Specimens typically failed in a combination of shear and tensile 'cup and cone' geometry characteristic of ductile materials and is illustrated in Figure 28. The tensile testing of welded material test specimens was performed identical to the base material tests. However, the welded material specimens looked unique when compared to the base material specimens shown in Figure 28. Figure 29 shows a close-up picture of a welded material test specimen where the surface roughness (known as the 'orange peel' effect due to the straining of the irregular grain structure resulting from the welding) can be seen.

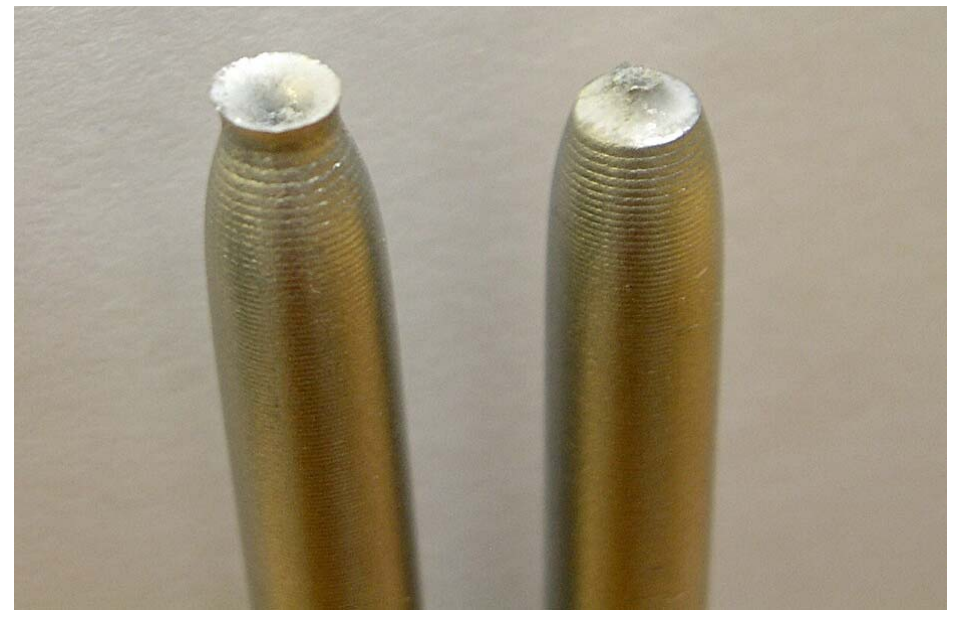

Figure 28. 'Cup and cone' type failure at fracture point. 


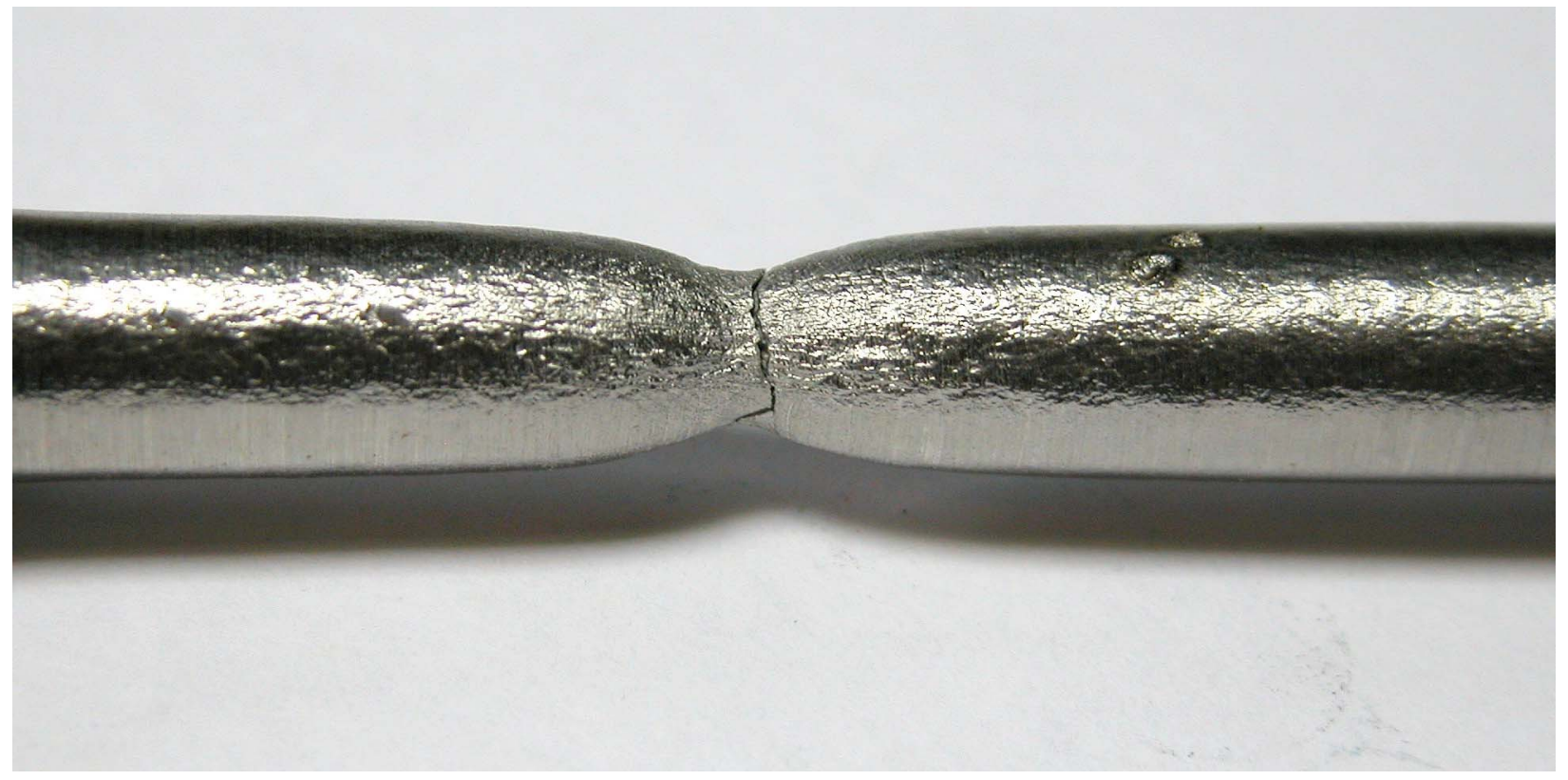

Figure 29. Welded quasi-static tensile test specimen showing 'orange peel' effect.

In order to substantiate the quasi-static stress-strain curves determined herein, an attempt was made to locate similar data published in the literature. A limited amount of comparative data was found for 304 stainless steel and is illustrated in Figure 30 as true stress-strain terminated at or near the uniform stress limit. Figure 30 shows a combination of data from two sources (identified in the legend and most likely from different material heats) taken from Reference 24 at the temperatures indicated. Figure 31 shows the true quasi-static stress-strain curves derived herein from a single material heat (54M7) for the four temperature conditions considered in this investigation. These results are typical and representative of the quasi-static tensile test finding for the $304 \mathrm{~L}$ plate material. The Figure 31 curves have been terminated at their uniform strain limits.

By comparing Figures 30 and 31, one can see great similarities, even though different material heats are involved. Stress and strain magnitudes are comparable as are the data trends. The true stress-strain curves lower with increasing temperature in both figures. The uniform strain limit reduces with increasing temperatures above room temperature (the $600^{\circ} \mathrm{F}$ curve from the published data is from a different source than the other three curves so a definitive conclusion cannot be made there but this conclusion is true for the $300^{\circ} \mathrm{F}$ data). The shape of the 304 and $304 \mathrm{~L}$ true stress-strain curves at cold temperatures take on a unique shape. (For the most part, this phenomenon was not observed in the $316 \mathrm{~L}$ material tested although a small, but noticeable hump was noted for one $316 \mathrm{~L}$ base material specimen tested at $-20^{\circ} \mathrm{F}$.) Therefore, the quasistatic true stress-strain curves obtained herein are indeed acceptable and representative. The testing methodology used herein was appropriate.

Finally, establishing the uniform strain limits (in terms of true strain) was important in order to establish the acceptable limits for the impact testing. Based on the quasi-static testing performed, Table 7 indicates the uniform strain limits established for both the base and welded materials at the temperatures considered. Background colors match the color coding used for each material. 


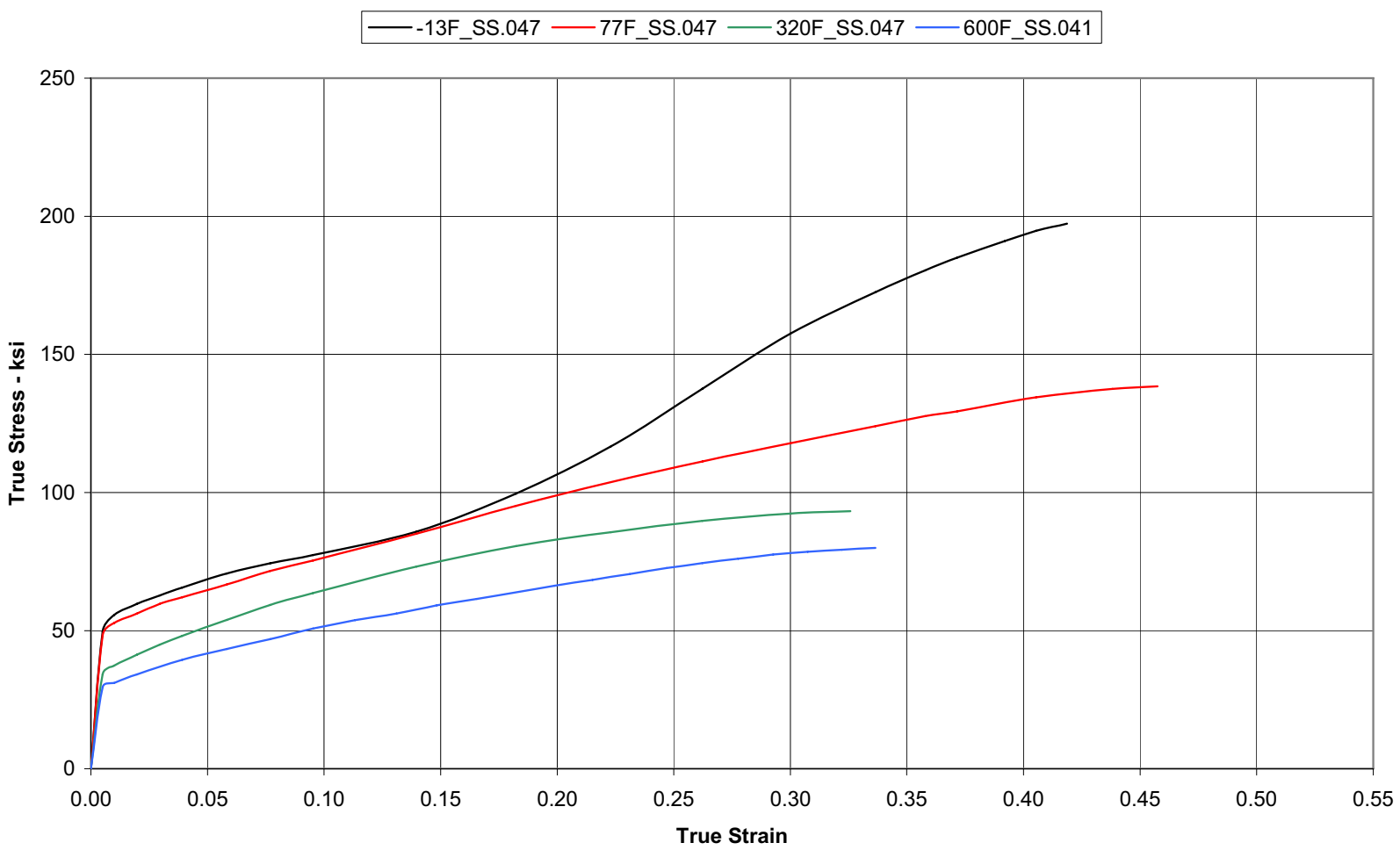

Figure 30. Stress-strain curves from published 304 data in Atlas of Stress-Strain Curves.

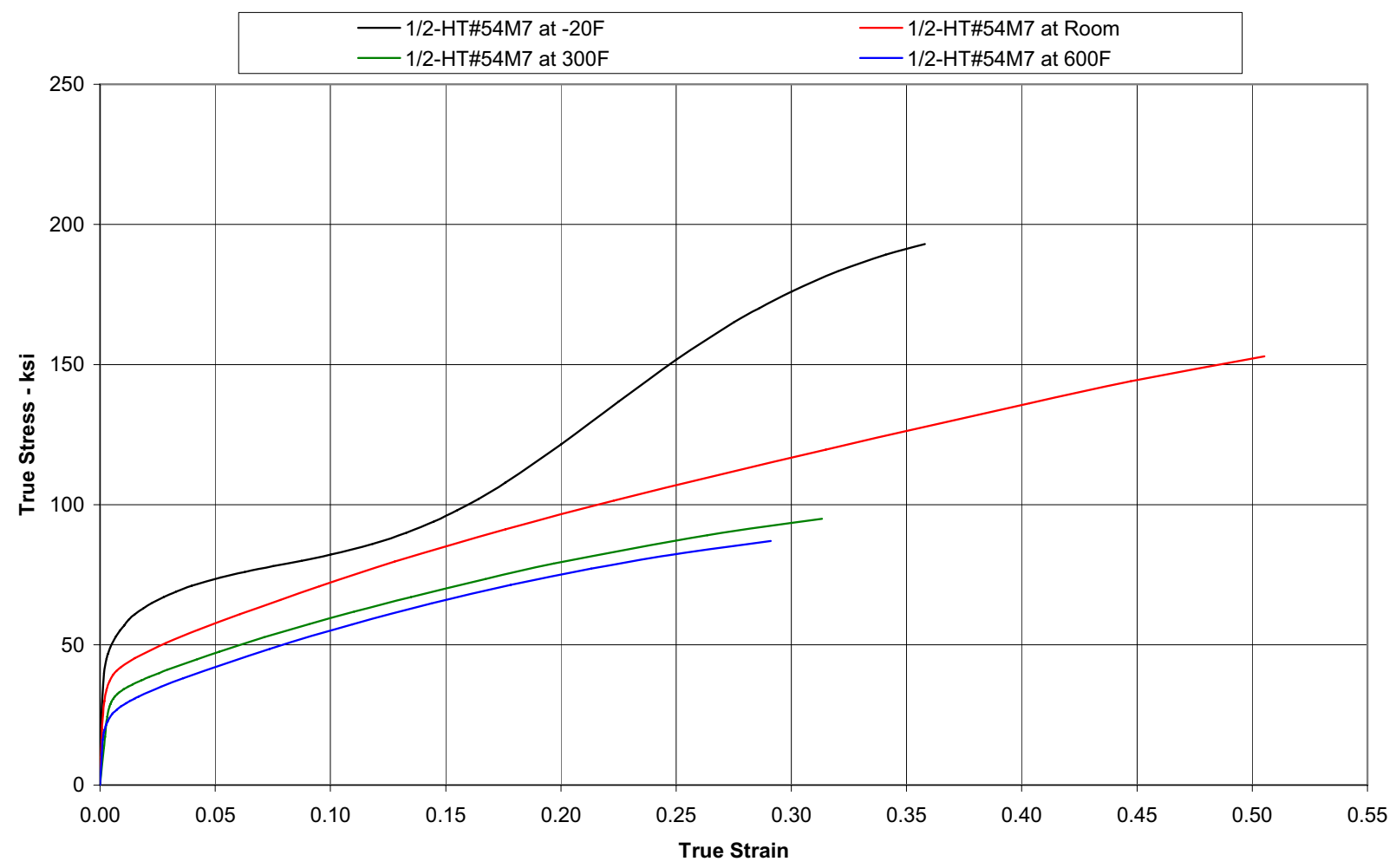

Figure 31. 304L stress-strain curves determined from INL testing discussed herein. 
Table 7. Uniform strain limits established for base and welded materials.

\begin{tabular}{|c|c|c|c|c|c|}
\hline \multirow{2}{*}{$\begin{array}{c}\text { Thickness } \\
\text { (inches) }\end{array}$} & \multirow{2}{*}{ Material } & \multirow{2}{*}{ Heat \# } & \multirow{2}{*}{$\begin{array}{c}\text { Temp. } \\
\left({ }^{0} \mathbf{F}\right)\end{array}$} & \multicolumn{2}{|c|}{ Uniform Strain Limit } \\
\hline & & & & Base & Weld \\
\hline \multirow{16}{*}{$1 / 4$} & \multirow{8}{*}{ 304L } & \multirow{4}{*}{485896} & -20 & 0.38 & 0.47 \\
\hline & & & 70 & 0.46 & 0.39 \\
\hline & & & 300 & 0.30 & 0.21 \\
\hline & & & 600 & 0.25 & 0.23 \\
\hline & & \multirow{4}{*}{$64 \mathrm{~A} 1$} & -20 & 0.44 & - \\
\hline & & & 70 & 0.52 & - \\
\hline & & & 300 & 0.31 & - \\
\hline & & & 600 & 0.29 & - \\
\hline & \multirow{8}{*}{$316 \mathrm{~L}$} & \multirow{4}{*}{$48 R 8$} & -20 & 0.51 & 0.42 \\
\hline & & & 70 & 0.46 & 0.40 \\
\hline & & & 300 & 0.28 & 0.25 \\
\hline & & & 600 & 0.27 & 0.24 \\
\hline & & \multirow{4}{*}{$76 \mathrm{H3}$} & -20 & 0.52 & - \\
\hline & & & 70 & 0.48 & - \\
\hline & & & 300 & 0.31 & - \\
\hline & & & 600 & 0.28 & - \\
\hline \multirow{18}{*}{$1 / 2$} & \multirow{9}{*}{ 304L } & \multirow{4}{*}{$54 \mathrm{M} 7$} & -20 & 0.36 & 0.38 \\
\hline & & & 70 & 0.48 & 0.37 \\
\hline & & & 300 & 0.32 & 0.21 \\
\hline & & & 600 & 0.29 & 0.20 \\
\hline & & \multirow{4}{*}{$72 K 9$} & -20 & 0.36 & - \\
\hline & & & 70 & 0.50 & - \\
\hline & & & 300 & 0.31 & - \\
\hline & & & 600 & 0.28 & - \\
\hline & & $10 \mathrm{~W} 8$ & 70 & 0.42 & - \\
\hline & \multirow{9}{*}{$316 \mathrm{~L}$} & \multirow{4}{*}{230468} & -20 & 0.40 & 0.37 \\
\hline & & & 70 & 0.46 & 0.35 \\
\hline & & & 300 & 0.30 & 0.25 \\
\hline & & & 600 & 0.28 & 0.20 \\
\hline & & \multirow{4}{*}{$67 \mathrm{Ko}$} & -20 & 0.43 & - \\
\hline & & & 70 & 0.41 & - \\
\hline & & & 300 & 0.27 & - \\
\hline & & & 600 & 0.25 & - \\
\hline & & 09T9 & 70 & 0.40 & - \\
\hline
\end{tabular}




\section{IMPACT TENSILE TESTING}

The data needed to justify the definition of appropriate material responses considering strain rate effects was obtained using an impact test device. This impact test device (identified as the Impact Testing Machine or ITM) is a drop weight tower that drops a large weight from an identified height onto a test fixture that holds the material test specimens. By using a combination of different weights, different drop heights, and different specimen sizes, varying strain levels and strain rates can be achieved in the test specimens.

\subsection{Impact Testing Machine}

The goal behind the design of the ITM was to create a test device that could be used to investigate strain rate responses of multiple materials (including steels, plastics, etc.) as well as structural impact responses of actual components (e.g., impact limiter material or concrete specimens) small enough to fit within the ITM. Hydraulic-based systems could evaluate constant strain rate effects (with certain limits on strain rates and test specimen sizes) but the representation of an actual drop event or vehicle crash would not be present. Rather than pursuing a costly hydraulic-based test apparatus design with a smaller test specimen capacity, the ITM could test larger-sized material specimens and accurately reflect true impact loads (energylimited events) with dropped weights nearing 1600 pounds (or more if needed). From the instant of impact during a drop event or crash, energy dissipation occurs. This is a response that is important to reflect during these material impact tests so that proper insights into analysis methodologies can be obtained.

During FY03, the ITM (see Figure 32) was taken from the conceptual design stage to an assembled test apparatus. The basic concept behind the ITM design is that of a falling weight (from heights up to 13 feet) impacting a test specimen resulting in permanent deformation. The falling weight is controlled within a vertical tower, while the loading on the test specimen is controlled by way of a specimen holder or test fixture. The ITM consists of a drop tower (including base plate, structural tube framing and vertically slotted pipe with an attached hoist), a drop weight (sometimes referred to as a 'pig') which was fabricated from 14-inch diameter bar stock, a drop hook (electronic quick release mechanism), and the test fixture. The drop weight (pig) is designed so that cylindrical disks of pre-determined weight can be added to vary the total magnitude of the dropped weight. The ITM is approximately 23 feet tall.

Major components of the tower, the drop weights, and the test specimen fixtures (that hold the test specimens) were fabricated. Figure 33 shows these components, ready for assembly. Figure 34 illustrates the three specimen fixtures or holders (for shear, bending, and tension loading investigations) that were also fabricated. The bending fixture has had limited test use (not discussed herein) and the shear specimen fixture has not yet seen service.

The major components of the drop tower were then assembled. A four-sided enclosure was also fabricated with the goal to confine potential fragments and reduce noise concerns for the NSNFP test personnel. The assembled ITM (see Figure 35) was then located at the INL's Reactor Test Complex, in the Materials Test Reactor building. Later on, the ITM was moved to another location at the INL. See Section 6.6.1 for additional information. 


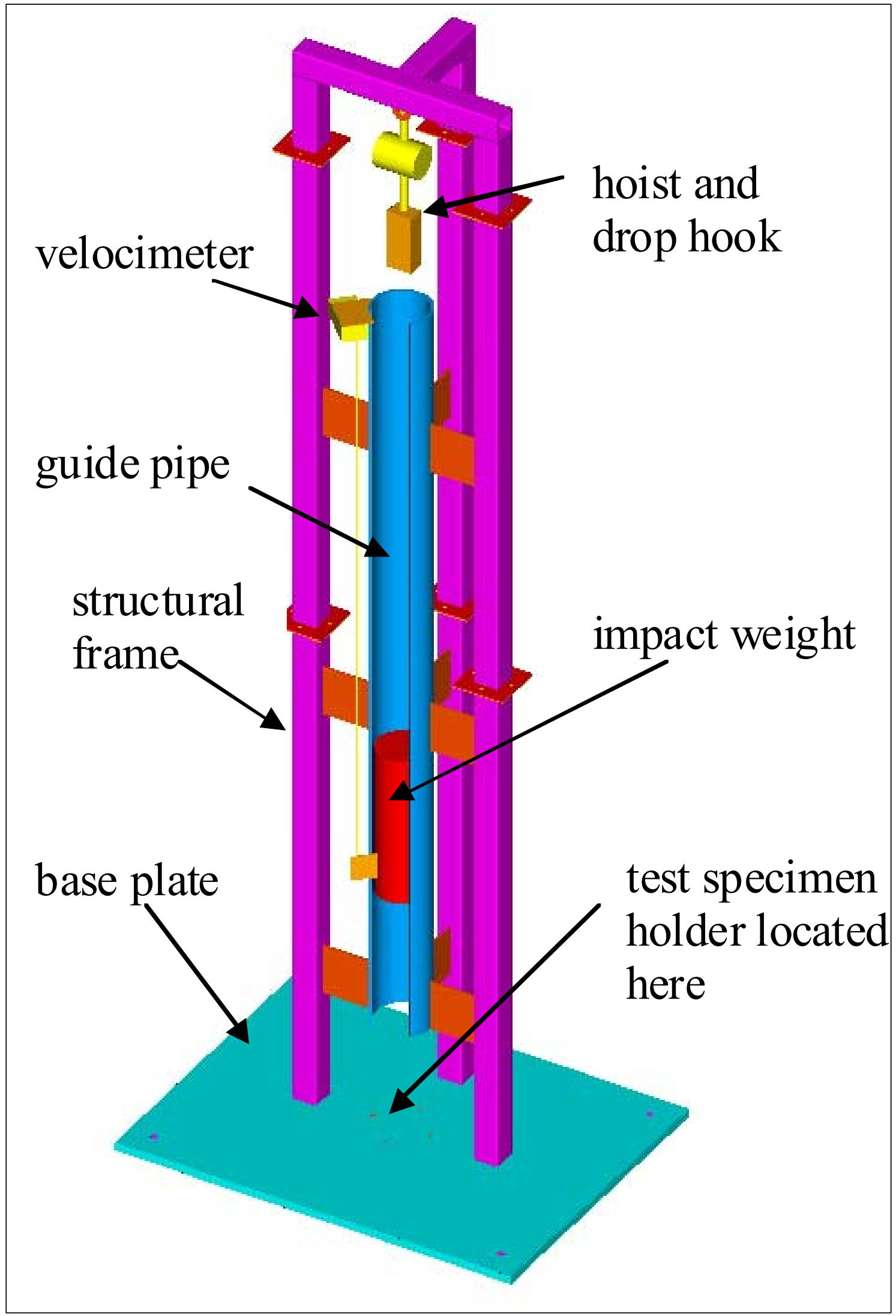

Figure 32. Conceptual design of Impact Testing Machine (ITM). 

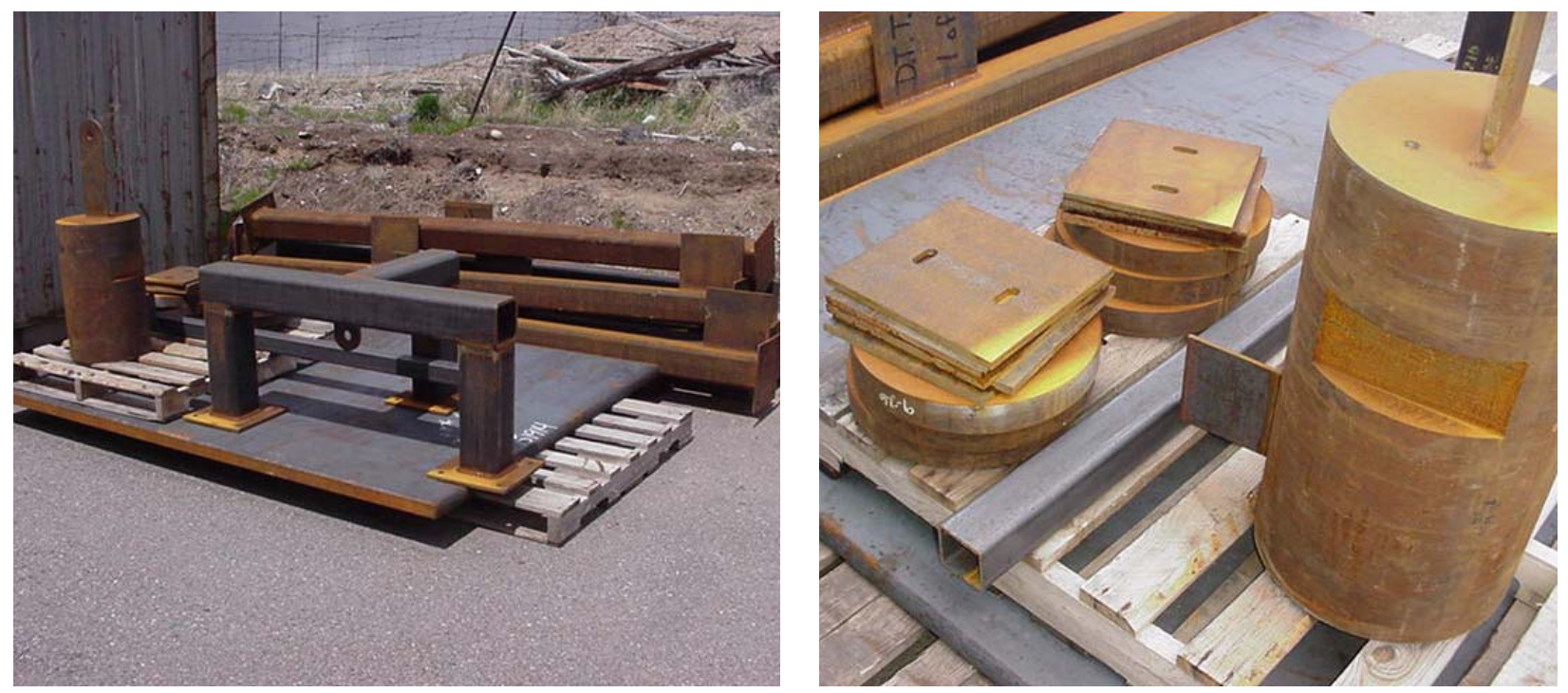

Figure 33. ITM fabricated components ready for assembly.

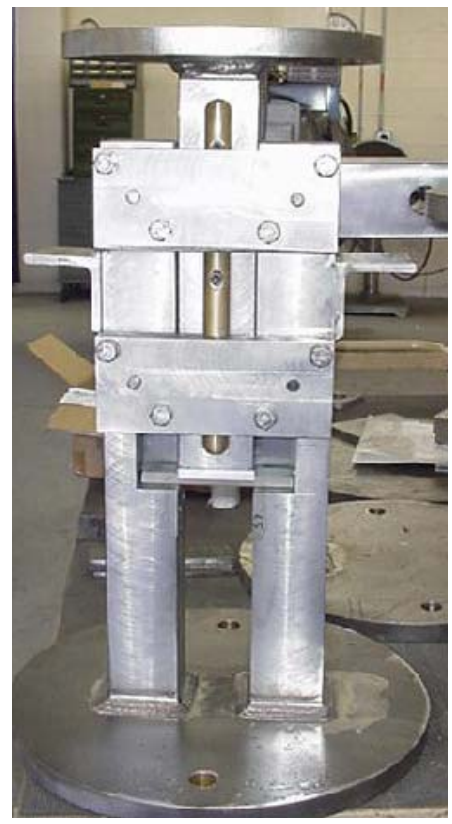

Shear specimen fixture

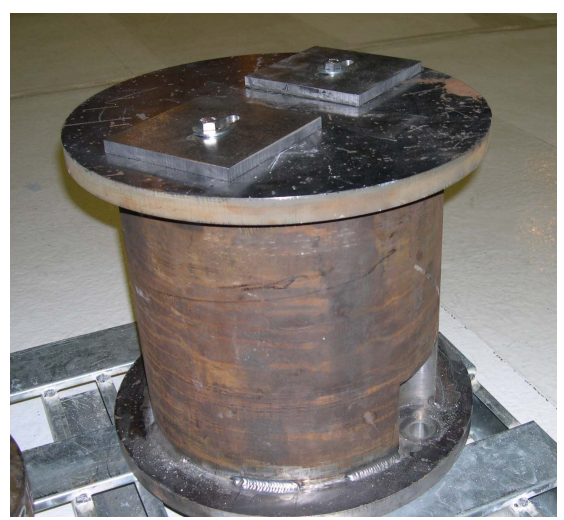

Bending specimen fixture

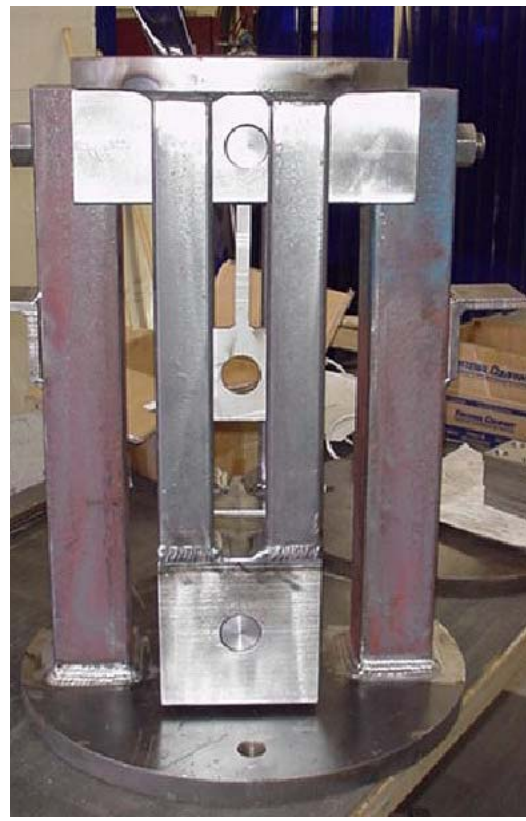

Tension specimen fixture

Figure 34. Three existing ITM test specimen fixtures. 


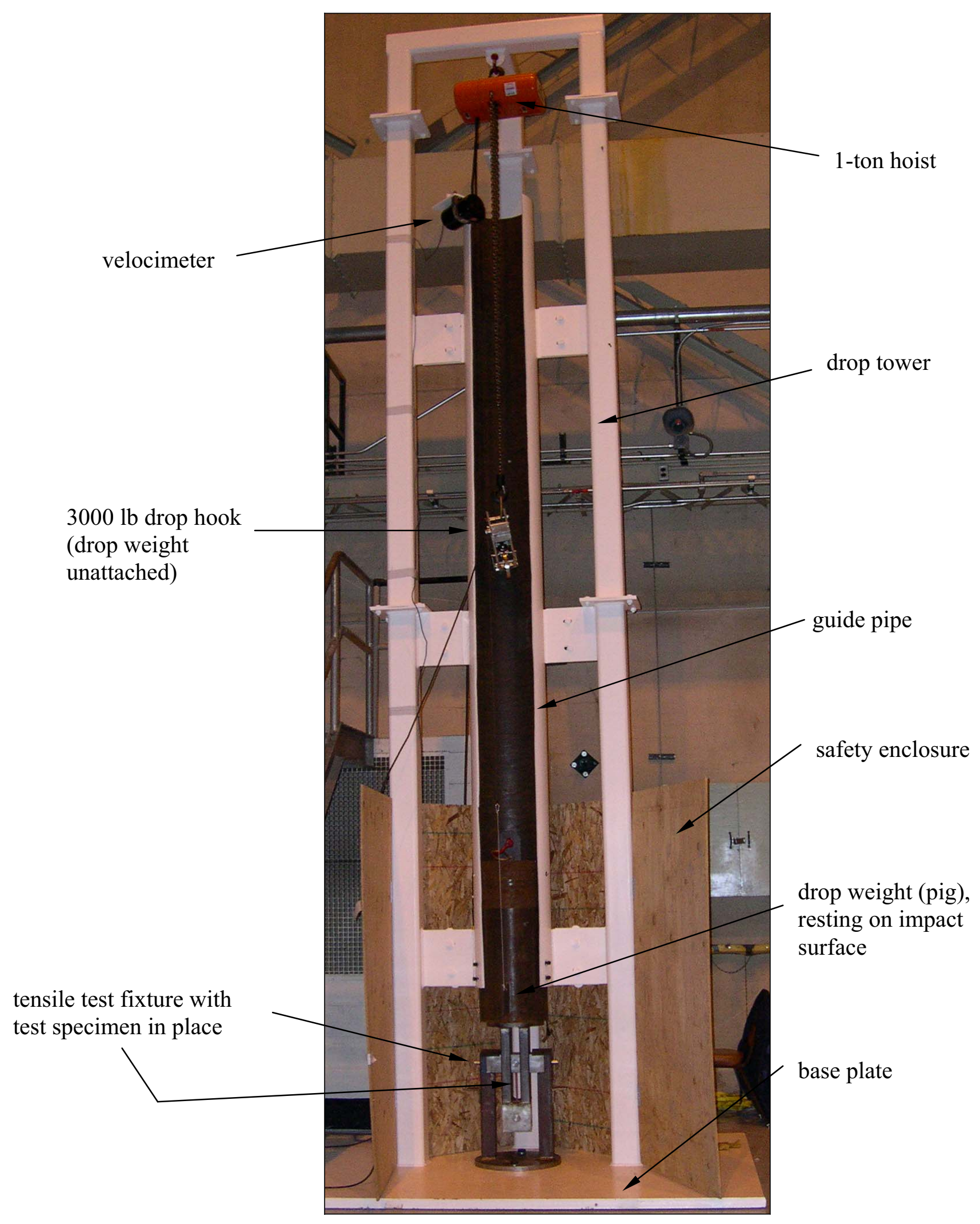

Figure 35. Installed Impact Testing Machine at the Material Test Reactor building. 
Drop weight impact test machines are typically used for compression testing. To carry out a tensile test under moderate strain rates, the ITM incorporated a special tensile holding fixture. The tensile test fixture (previously pictured in Figure 34) is illustrated in Figure 36 with specific components identified. The tensile test specimen fixture consists of a support stand and an impact driver. The support stand is made up of a bottom plate that bolts to the ITM base plate, two vertical legs, and an upper cross-member. The impact driver consists of a top (impact surface) plate, four vertical legs, and a lower cross-member. All structural members of the impact driver and support stand were fabricated from solid bar and plate carbon steel. The impact driver is connected to the support stand through the pinned ends of the dog bone-shaped tensile test specimen. During a test, the dropped weight impacts the impact driver on the tensile test fixture that is centered under the slotted guide pipe. The dropped weight contacts the impact driver, transferring its kinetic energy to the test specimen by way of the lower cross-member. The impact force is applied to the lower end of the tensile test specimen and is reacted through the upper end of the specimen into the upper cross-member of the fixture support stand. The pinned ends on the test specimen provide for pure tension loading of the specimen. [Note that in October-November 2005, the lower cross-member's top surface was notched (approximately 1-1/4-inch wide and 1-1/2-inch deep, both front and back) so that the bottom punch marks on the original test specimens could be visually seen.]

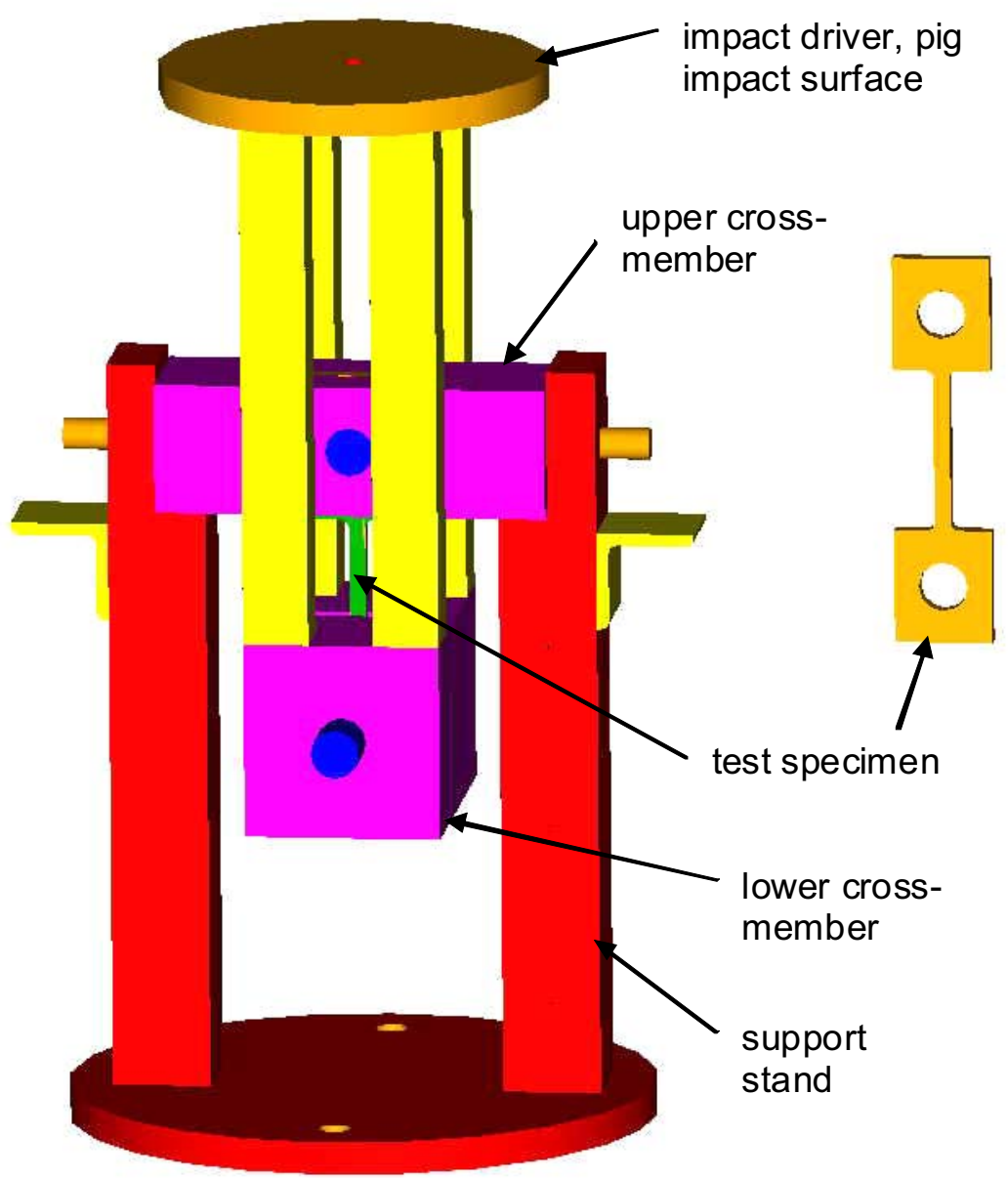

Figure 36. ITM tensile test specimen fixture. 


\subsection{Test Specimens}

The initial phase of material impact testing performed in FY04 and continuing into FY05 was performed at room temperature conditions and used a dog bone-shaped test specimen as identified in Figure 37 (geometry 'A'). Note that the test length includes the gauge length (uniform cross section along entire length) as well as both end transitions. All test specimens were water jet cut from their respective plates (see Section 5.1.1). Color coding, applied when multiple test specimens were cut from the entire plate at one time, was used to differentiate not only 304L or 316L material but was also used to differentiate longitudinal versus transverse oriented test specimens. Figure 38 illustrates the 304L plate already water jet cut and painted. Red indicated longitudinal test specimens, yellow indicated transverse test specimens, and green indicated shear blank specimens (for future use). Figure 39 illustrates the 316L plate already water jet cut and painted. Black indicated longitudinal test specimens, white indicated transverse test specimens, and brown indicated shear blank specimens for future use.

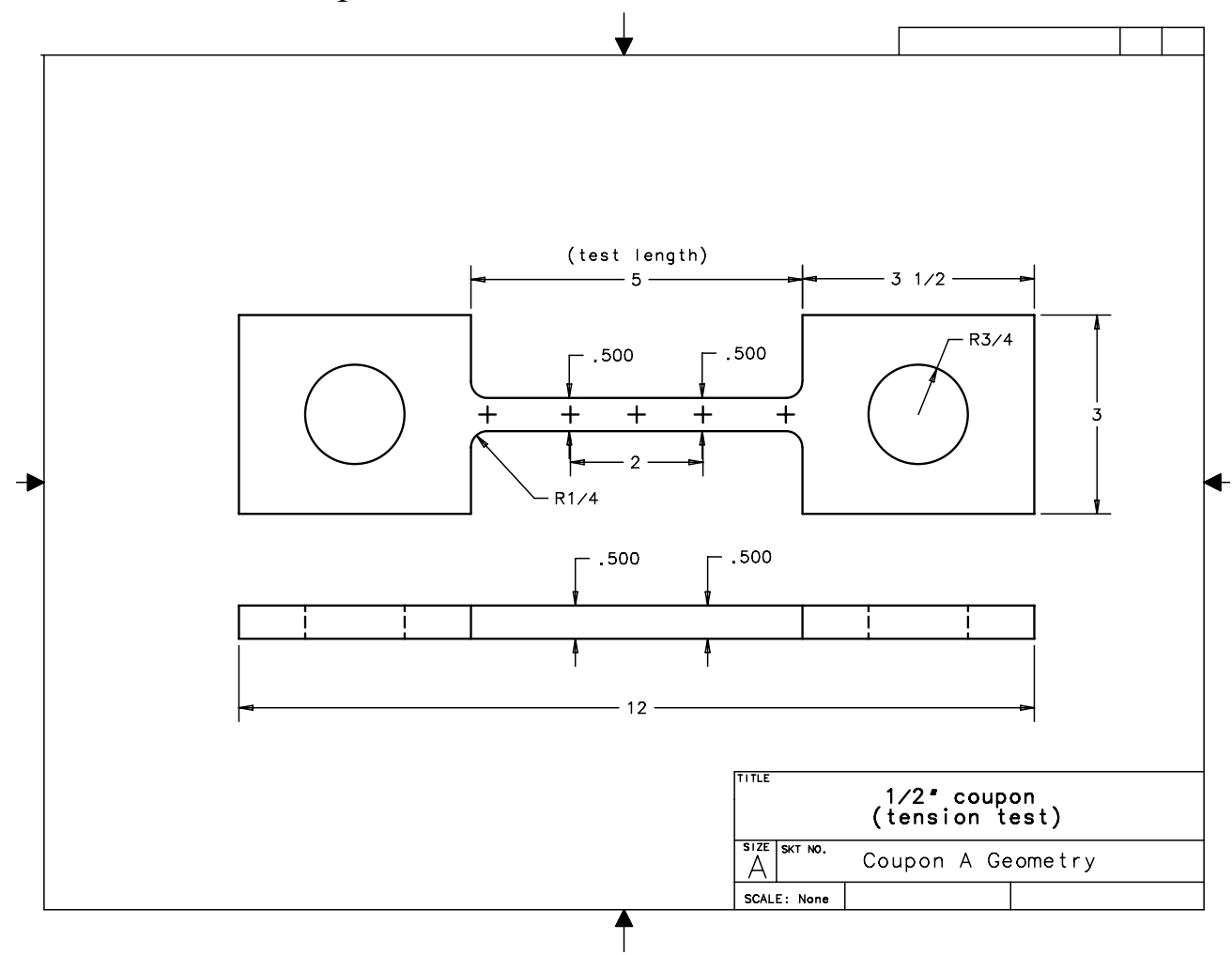

Figure 37. Tensile test specimen 'A' for initial material impact testing.

This initial testing allowed the NSNFP test personnel to gain valuable insights regarding the response of this test specimen geometry. Basically, this geometry worked well with strain rates in the 25 per second range but attempts to get strain rates of 10 per second produced low strains that were difficult to measure. Continuing material impact testing performed in FY05 permitted the testing and evaluation of many geometries. The results indicated that the test specimens needed to be long enough to avoid substantial end-effect complications yet be short enough to achieve the highest strain rates possible. Strains also needed to be large enough to be measurable by a highspeed digital camera. Low strains (near the yield strength) were difficult to measure (pixel limitations of the camera) and they did not clearly define a reasonable amount of area beneath the stress-strain curve (energy absorbed by the material). Larger strains were easier to measure and produced reasonable amounts of area beneath the stress-strain curve. 


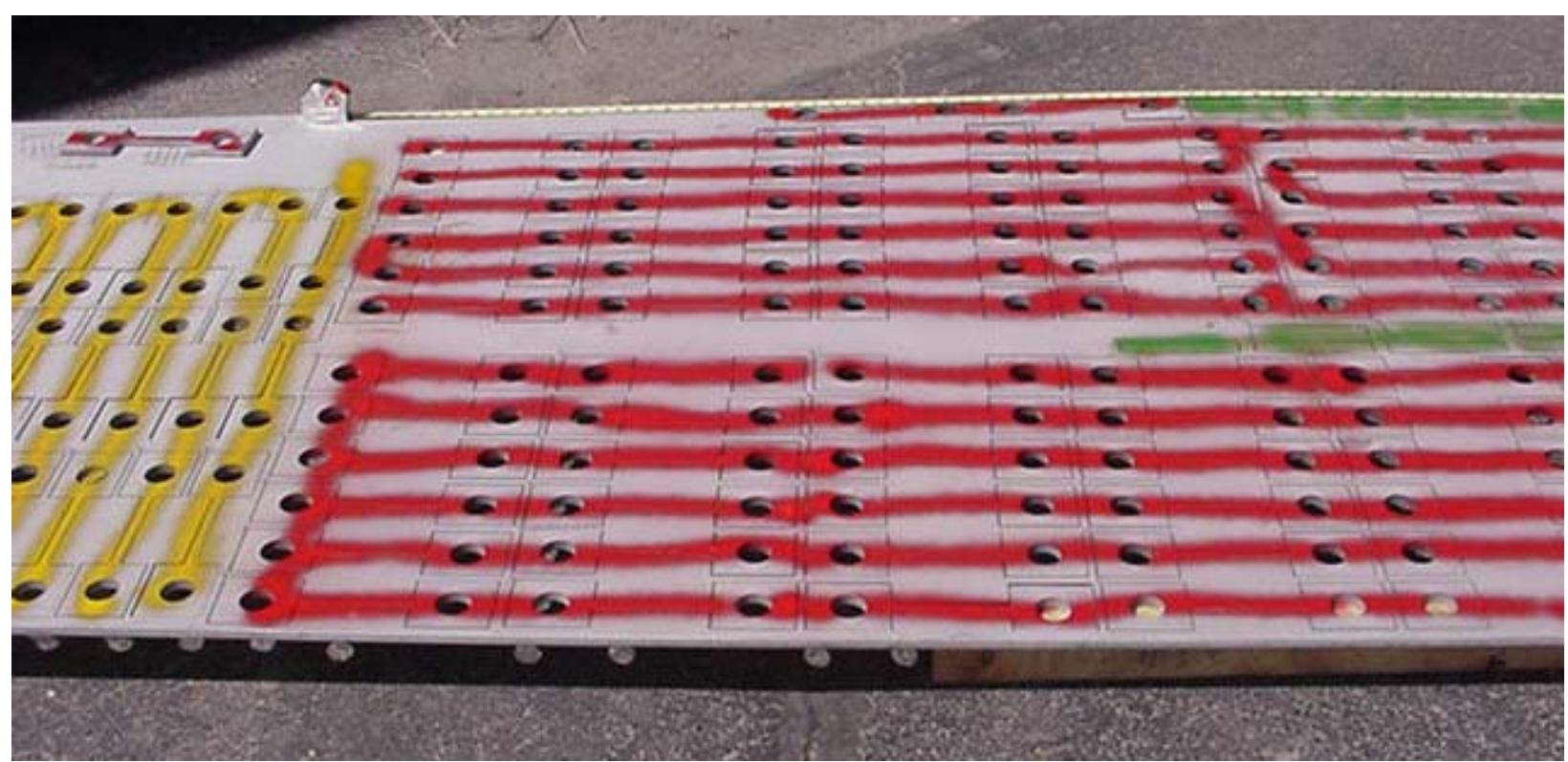

Figure 38. Initial 304L plate water jet cut and test specimens painted.

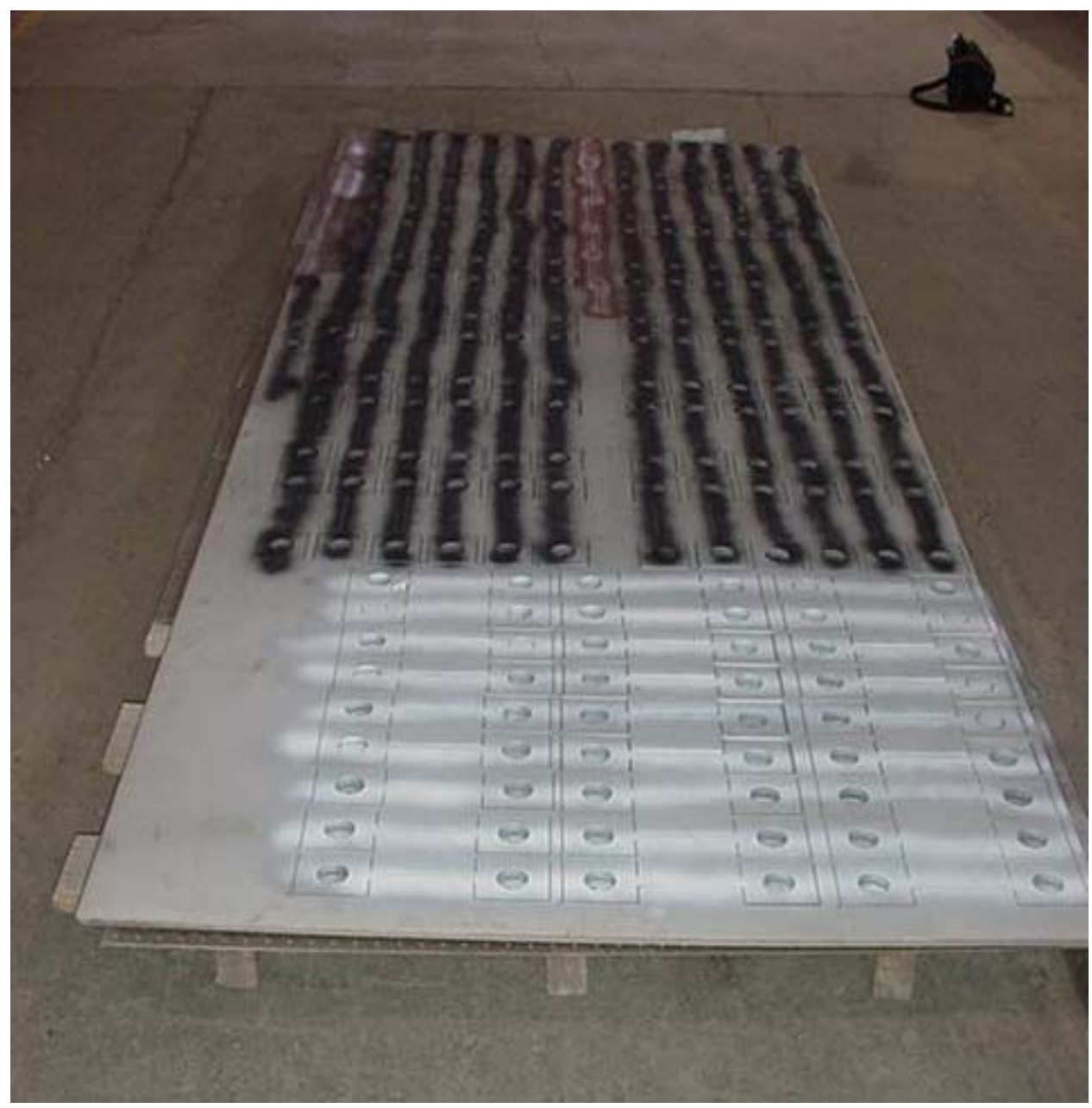

Figure 39. Initial 316L plate water jet cut and test specimens painted. 
The additional geometry testing and associated data evaluation efforts indicated that a minimum gauge length of 3 inches was necessary for a good uniform strain distribution along the gauge length with minimal transition end effects. In addition, with the goal of achieving strain rate tests in the 5 to 10 per second strain rate range, thinner $1 / 4$-inch thick specimens of the same minimum gauge length of 3 inches were deemed necessary. At this time, it was also recognized that a more formal test specimen identification method was needed that would clearly indicate not only the test specimen's generic profile but also the width and thickness of the gauge length. Therefore, an identifier format of ' $\mathrm{X}-\mathrm{N}-\mathrm{N}$ ' was adopted. The $\mathrm{X}$ would be an alpha character that could specify generic geometry designations or profiles (e.g., $\mathrm{A}, \mathrm{D}$, etc), the first $\mathrm{N}$ was a numeric value that indicated the gauge width nominally measured in eights of an inch, and the second $\mathrm{N}$ (the last character) was also a numeric character that indicated the gauge thickness also nominally measured in eights of an inch. Hence, D-4-4 indicated a D profile with a $1 / 2$-inch gauge width and a $1 / 2$-inch gauge thickness. Similarly, A-2-2 indicated an A profile with a 1/4-inch gauge width and a $1 / 4$-inch gauge thickness. Use of the original ' $A$ ' geometry identifier was continued in testing records for material impact tests already completed. However, any material impact testing performed after November 2005 using the older 'A' test specimens would refer to those test specimens as having an A-4-4 geometry.

Figures 40 and 41 illustrate the geometries for the 3 -inch gauge length test specimens cut from $1 / 2$-inch plate material (D-4-4 specimens) and $1 / 4$-inch plate material (D-2-2 specimens), respectively. The material was identified in Section 5.1.2.

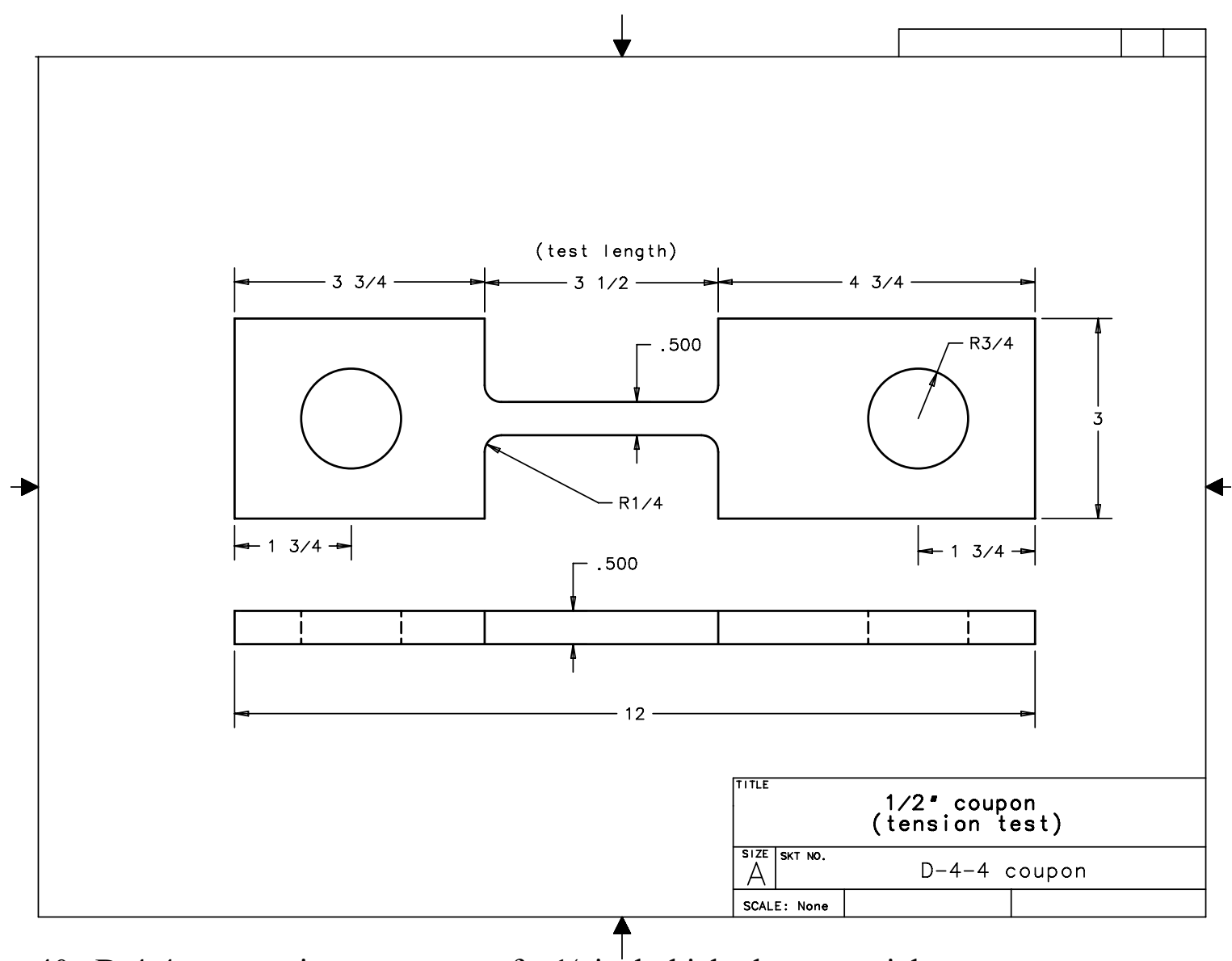

Figure 40. D-4-4 test specimen geometry for $1 / 2$-inch thick plate material. 


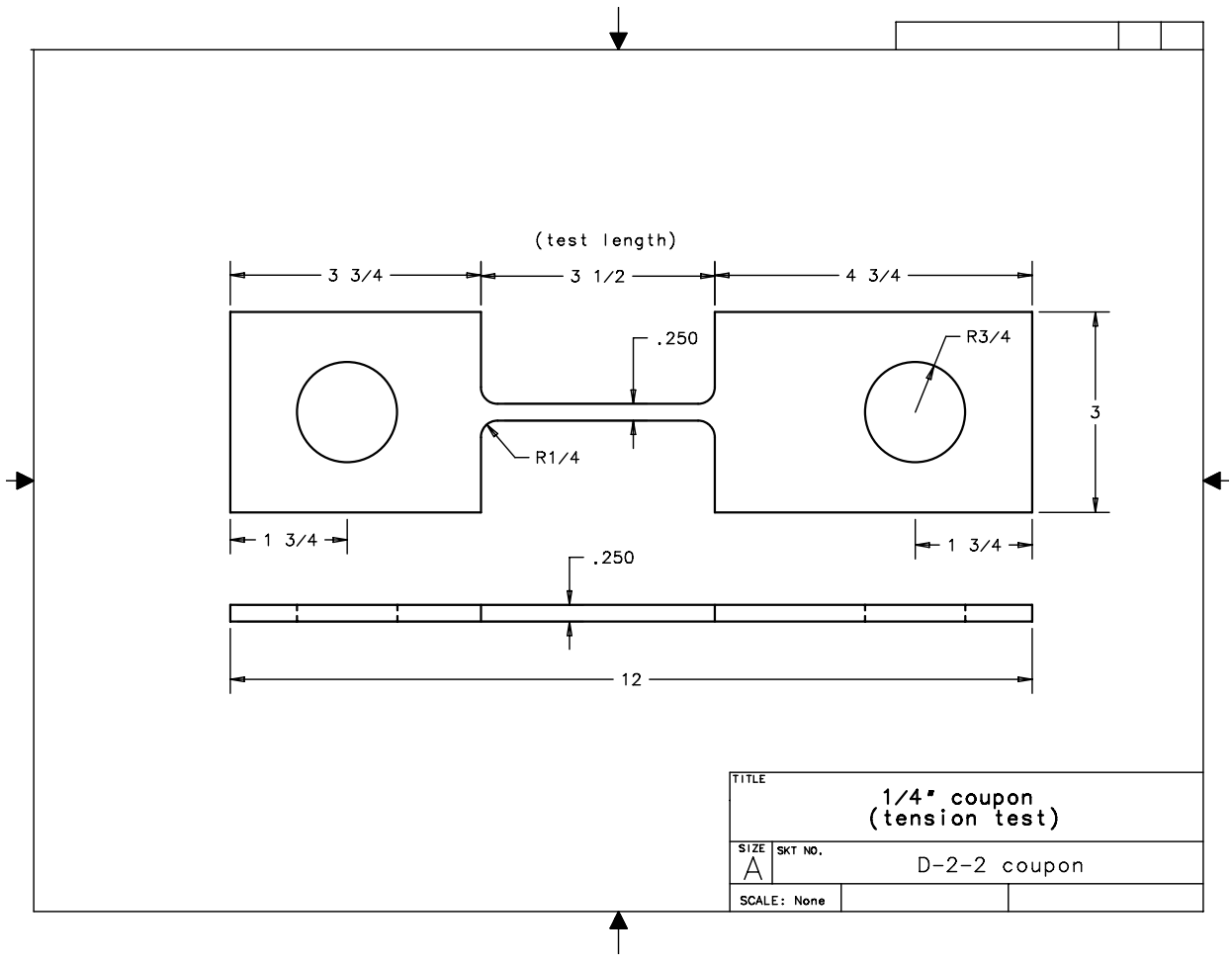

Figure 41. D-2-2 test specimen geometry for $1 / 4$-inch thick plate material.

Finally, it was also decided to try a longer gauge length for the $1 / 4$-inch thickness plates, similar to the 'A' geometry. Therefore, an A-2-2 test specimen geometry was used to evaluate its effectiveness at achieving low strain rates in the 5 per second range. Figure 42 illustrates this test specimen geometry.

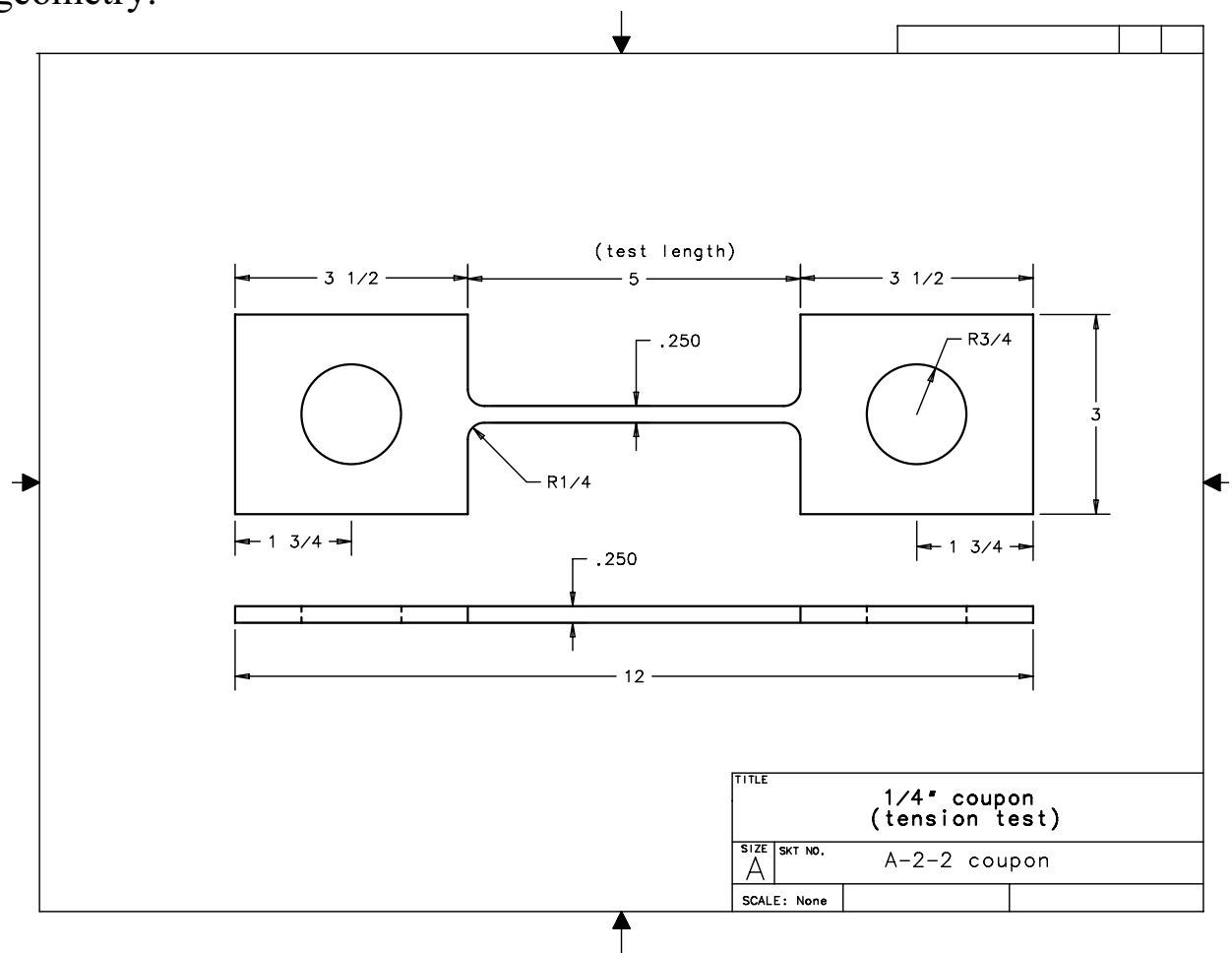

Figure 42. A-2-2 test specimen geometry for $1 / 4$-inch thick plate material. 
Figures 14 and 15, in additional to illustrating the material blanks cut for quasi-static testing, show how the above impact test specimens were water jet cut from the 'auxiliary' plate material. Figures 16 and 17 have previously provided illustrations on how the welded plates were water jet cut to obtain impact test specimens along with the material necessary for quasi-static tensile testing. Figure 43 provides a clear indication of how six typical material impact test specimens (four base and two welded material test specimens), were water jet cut from a single welded plate. All of the impact test specimens from the 'auxiliary' plates and the welded plates were longitudinally (parallel with the mill rolling direction) oriented.

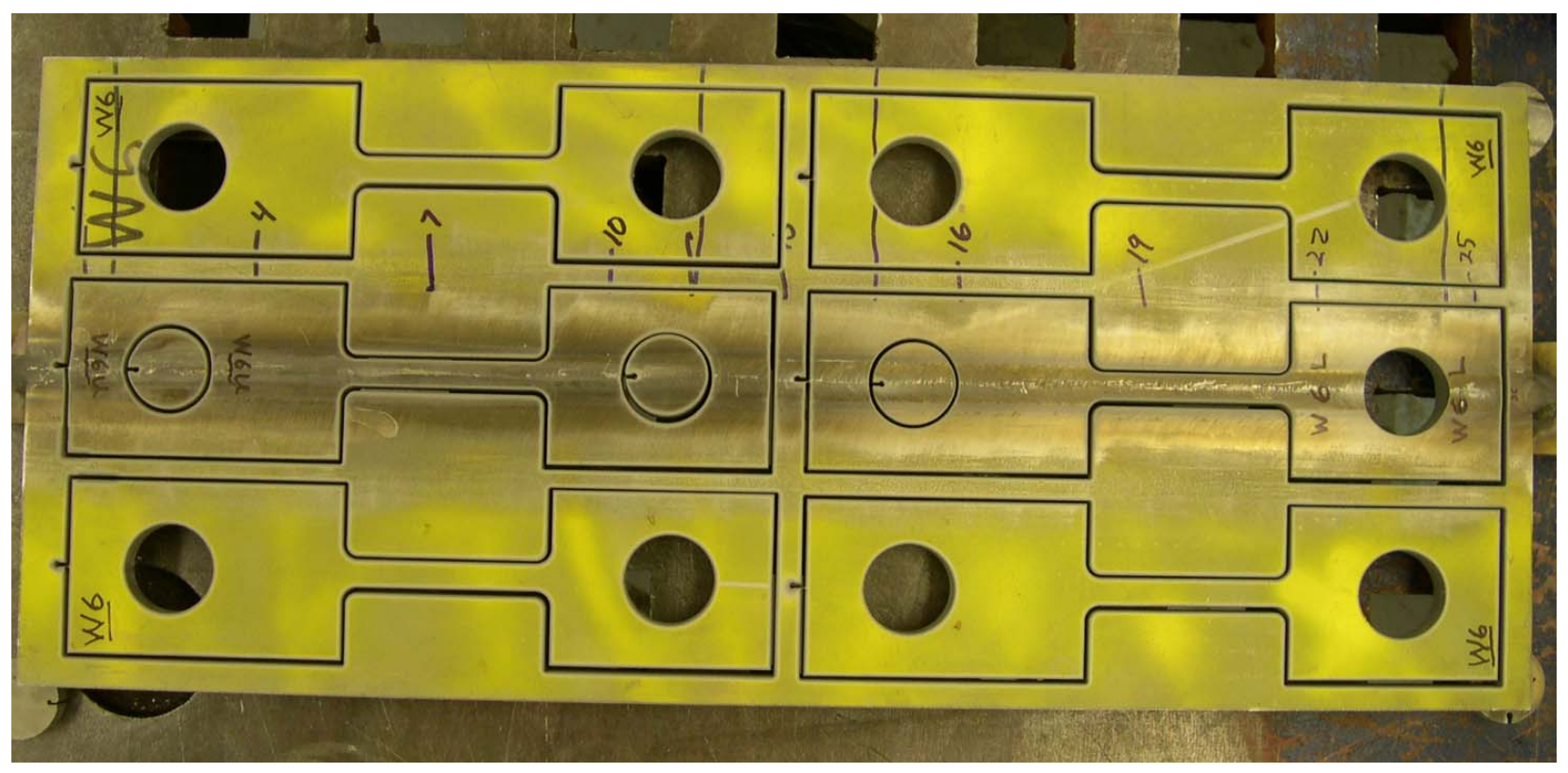

Figure 43. Material impact test specimens (D-4-4) water jet cut from welded plate W6.

Note that the base material test specimens were ready for pre-test inspection directly after removal from the plates. On the other hand, the welded material test specimens required additional machining to remove the weld crowns and achieve a square cross section along the entire gauge length. Figure 44 illustrates what a typical welded material impact test specimen square cross section would look like. Included in the test material are weld material, base material, the interface, and heat-affected zone material.

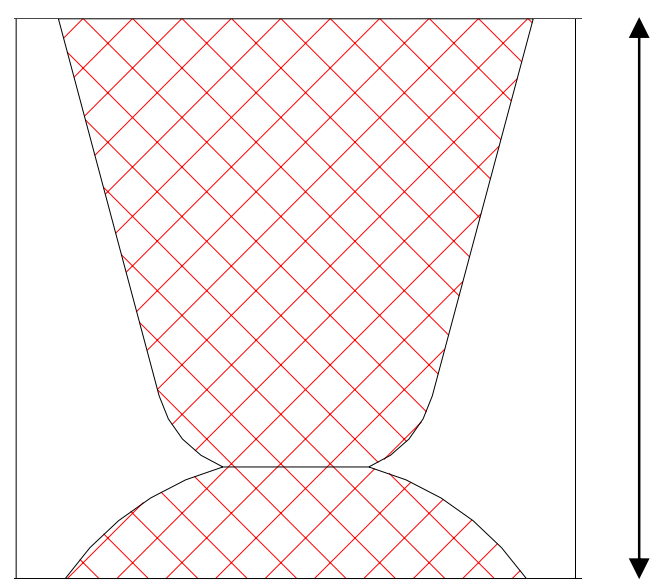

Direction of plate thickness.

Figure 44. Cross-section of welded material test specimen showing weld material (cross-hatched) and base metal (not cross-hatched) within the square test specimen cross-section profile. 


\subsubsection{Pre-Test Dimensional Measurements}

Prior to impact testing, the uniformity and acceptability of each test specimen was determined by NSNFP test personnel using specially developed go/no go gages and marking gages followed by detailed measurements with a calibrated caliper.

The first step was to assess the overall geometry of the test specimen. Even though the gauge length dimensions were of primary importance, it was still deemed appropriate to have nearly identical test specimens. This was determined using a go/no go gage. A go/no go gage is a plate with the test specimen maximum and minimum-tolerance shape step-machined into it. The dimensions checked using these go/no go gages were considered 'important" in order to achieve overall test specimen uniformity and so the maximum tolerances were established at \pm 0.100 inches. The fabrication of the go/no go gage reflected these tolerances. Figure 45 illustrates this type of profile check go/no go gage with the 'important' dimensions blanked out for determination by the INL dimensional inspector. If an actual test specimen dimension is too large, it will not fit into the gage (can't go past the Level 1, identified on Figure 45). If an actual test specimen dimension is too small, it will fall past the minimum tolerance step when inserted into the gage (past Level 2 - the next step down). A dimensionally acceptable test specimen will fit into the gage but will not fall past the Level 2 step.

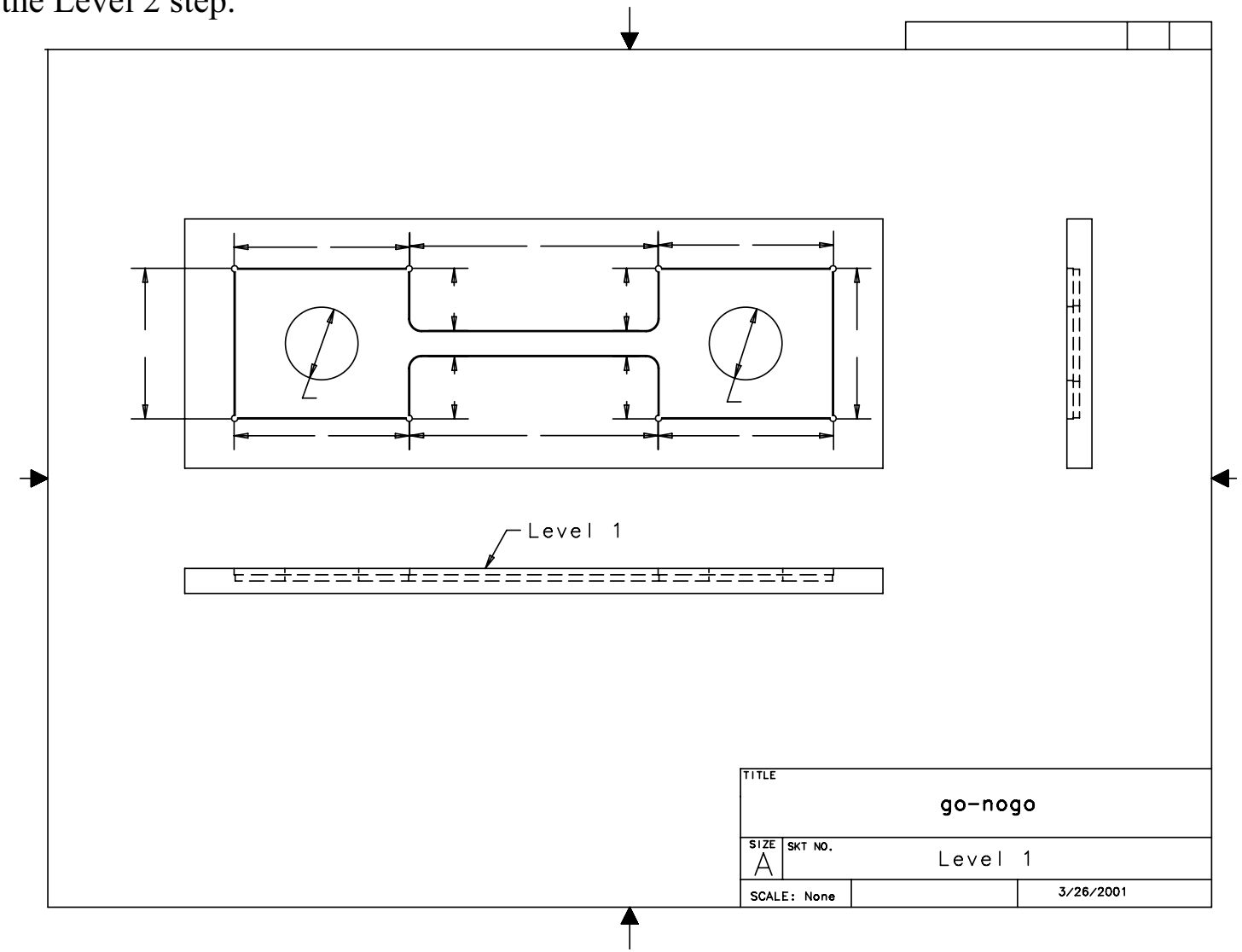

Figure 45. Typical go/no go gage for overall geometry checks of impact test specimens.

Special care was taken to examine the test specimen as it rested on Level 2 of the go/no go gage. The test specimen might not fall past Level 2 if the go/no go gage had a minimal number of locations (potentially just two small points) where the test specimen could rest. Therefore, each test specimen was carefully inspected as it rested in the go/no go gage, looking for gaps around the periphery. 
After determining if the test specimen's overall geometry was acceptable, the width and thickness of the entire gauge length was checked. This also was determined with a go/no go gage. Figure 46 is the fabrication sketch of one of the go/no go gages used to determine the geometry acceptance of the gauge length. This go/no go gage was inserted onto the gauge length portion of the test specimen as fully as possible (down to the first machined step), moving the gage along the entire length for the dimension being measured. Insertion past the outer surface and down to the first machined step was required or the test specimen would be rejected. If the test specimen could be fully inserted to the first step, the measurement was deemed acceptable. However, insertion beyond the opening of the first step would cause the test specimen to be rejected since this would indicate a too small dimension. Since these measurements were along the gauge length, these measurements were considered 'critical' for accurate strain measurements and so the maximum tolerances were established at \pm 0.020 inches. If acceptable, the test specimen was marked with its unique test specimen identifier.

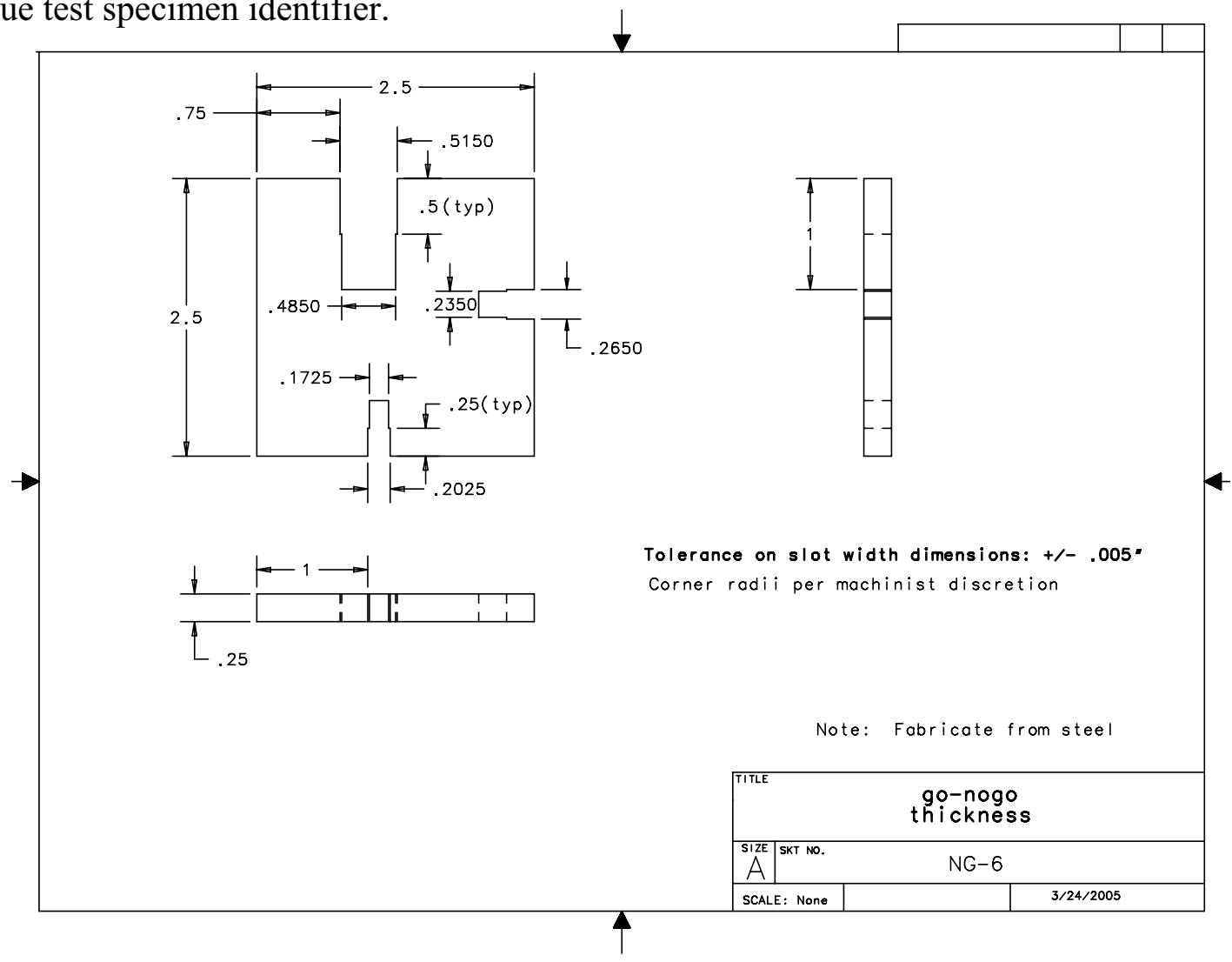

Figure 46. Typical go/no go gage for width and thickness checks.

Next, as part of the pre-test checking process, pre-defined punch guide holes (also considered critical dimensions) were established with separate marking gages (see Figure 47 with critical dimensions blanked out for determination by a qualified dimensional inspector), allowing each test specimen to be consistently marked with a punch. Finally, after punch marking and identifying those marks with alpha characters starting with ' $A$ '(see Figure 48 for a marking example), calipers with points were then used to measure the pre-test distances between the punch marks. A second pair of calibrated calipers were then used to measure the widths (front and back) and thicknesses at intermediate points (e.g., points B and C for D-2-2 and D-4-4 geometries). Acceptance of test specimen critical width dimensions were based on the average of front and back width values. The distance between the two outer-most punch marks defined the test specimen's gauge length. These punch mark lengths and width and thickness measurements along the inner 
gauge length were recorded on the specimen data sheets [see Appendix D for a representative data sheet (page 1 for pre-test data) and see NSNFP Lab Notebook Binder Volumes 2 and 3 for all the actual pre-test specimen data].

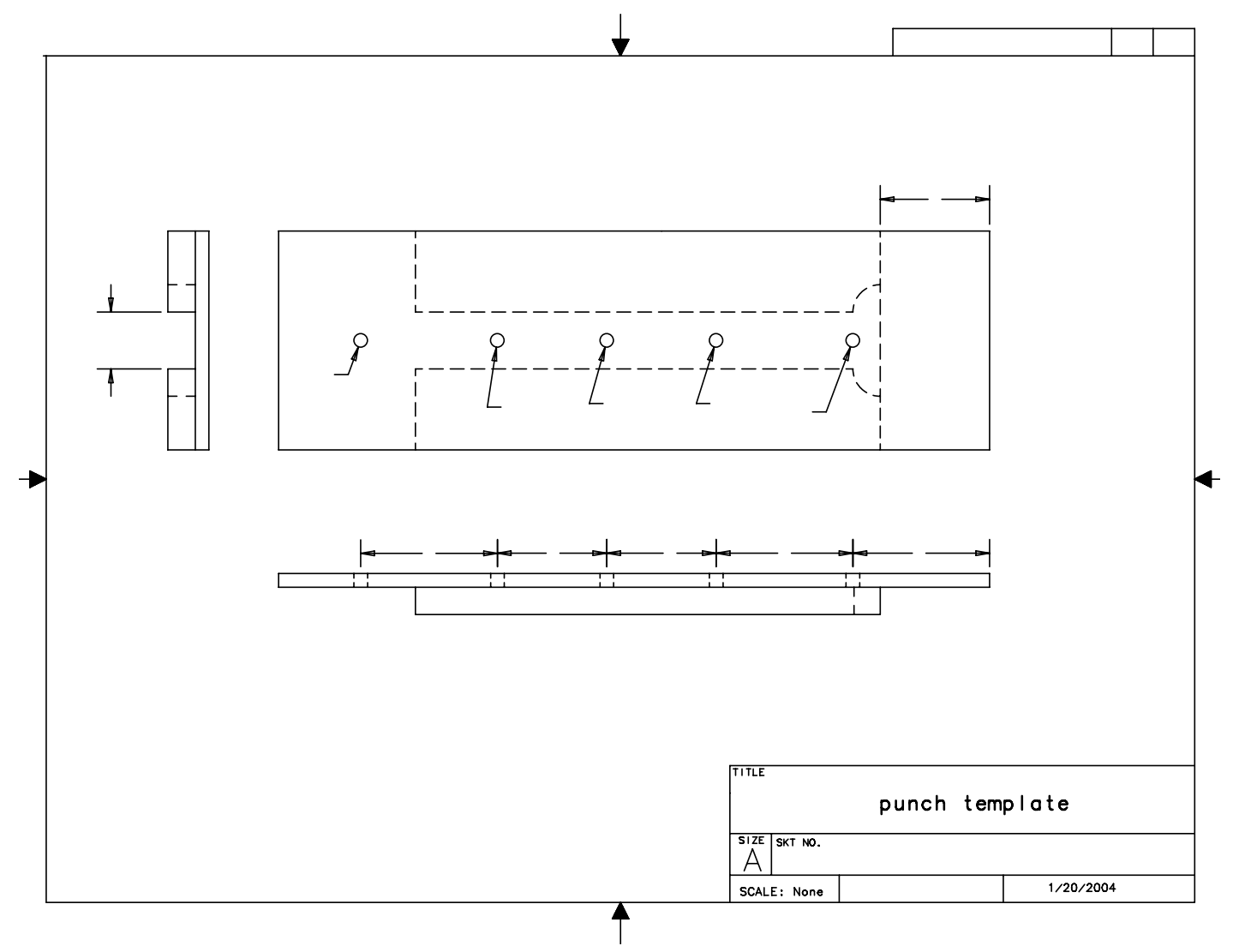

Figure 47. Typical punching gage for 'A' (or A-4-4) test specimens.

Fabrication of these go/no go gages and marking gages were not considered a qualityaffecting activity since they were dimensionally checked by an INL qualified dimensional inspector after fabrication and prior to use. After the gages were measured by the qualified dimensional inspector, NSNFP test personnel determined whether or not the go/no go gages were within acceptable tolerances $( \pm 0.100$ inches for important dimensions, \pm 0.020 inches for critical dimensions). Appropriate gages were used for each different test specimen geometry used for final material impact testing. Dimensional inspections of the gages were made by the qualified dimensional inspector following the completion of each phase of testing. Dimensional inspections of the go/no go and marking gages performed at the completion of prior testing phases were considered as the 'prior to use' dimensional inspection for the next testing phase. As part of a final closeout, the INL Standards and Calibration Laboratory measured these go/no go gages. From their independent measurements, it was determined that the gages were still within the acceptable tolerances for both important and critical dimensions.

\subsubsection{Final Pre-Test Preparations}

The final step of the pre-test preparations was to visibly mark each test specimen so that high-speed digital imagery could be used to perform motion analysis of the impact event. Figure 48 illustrates these marking along with the test specimen's identifier in the format of $304 \mathrm{~L}-\mathrm{XXX}$ or $316 \mathrm{~L}-\mathrm{XXX}$ where $\mathrm{XXX}$ is the unique test specimen number. 


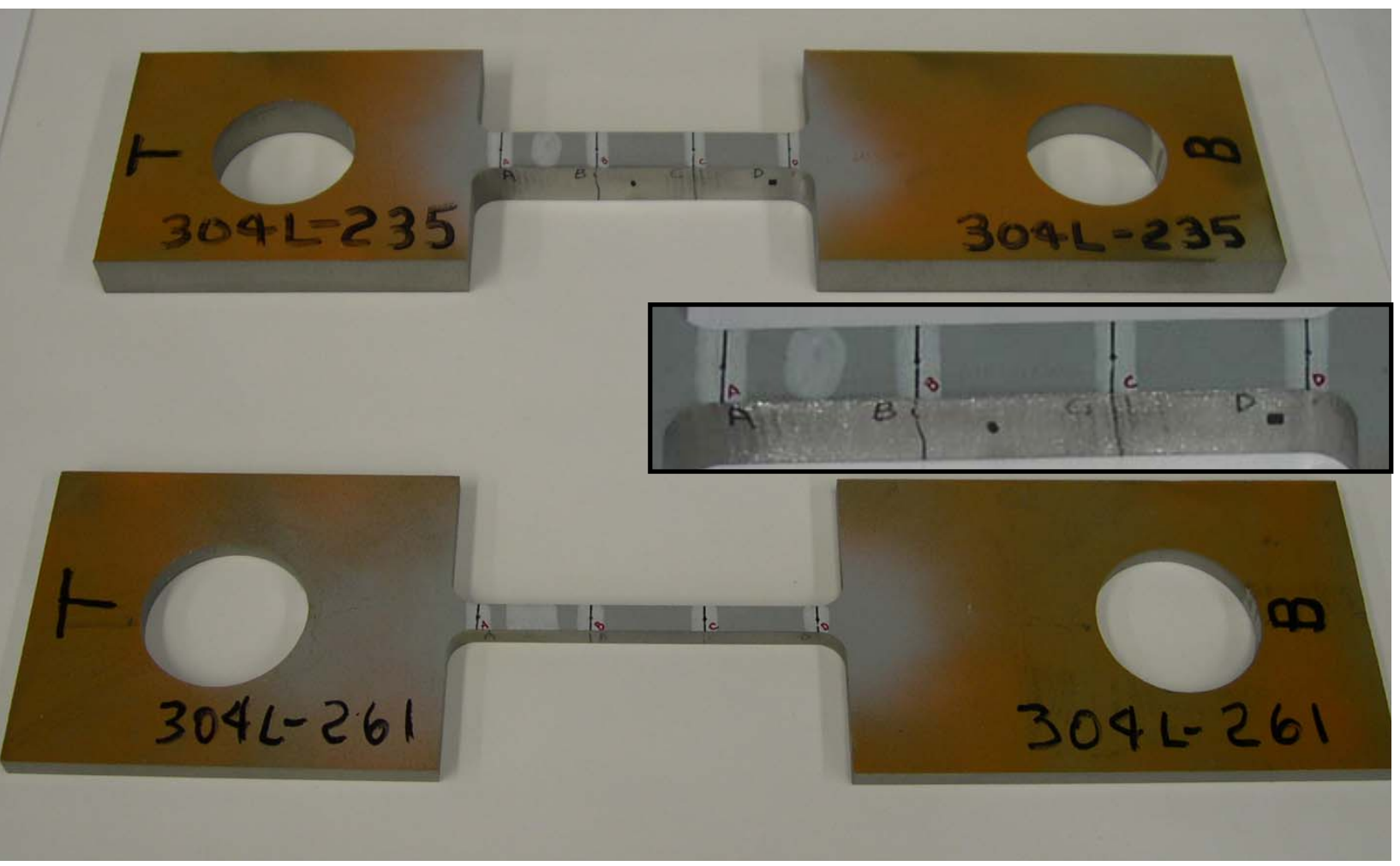

Figure 48. Typical marked material impact test specimens (with close-up picture of gauge length highlighting punch mark identifiers).

\subsection{Impact Test Procedure}

Actual impact testing began once the test specimens were measured and marked to assure acceptable test specimen geometry, that pre-test gauge lengths and cross-sections were measured, and specimen identification was clear and unique. All specimen measurements were taken using calibrated measuring devices (see Report CD-R, File 3). The generic test procedure is very similar for all of the material impact tests performed.

Step 1: First, the desired test weight (or pig) is selected and that weight is loaded into the ITM, above the tensile test fixture. The drop height has already been established (through preliminary analytical estimates, engineering judgment, or from the findings of prior ITM tests) in an attempt to achieve the desired strain rate and strain in the test specimen.

Step 2: The room temperature impact testing process continues with the insertion of a room temperature soaked test specimen into the tensile test fixture. For the other temperature conditions $\left(-20{ }^{\circ} \mathrm{F}, 300{ }^{\circ} \mathrm{F}\right.$, and $\left.600{ }^{\circ} \mathrm{F}\right)$, the test specimens are soaked to their necessary pre-test temperatures prior to insertion into the tensile test fixture (cold) or prior to impact testing (hot) as discussed in the next Section 6.4.

Step 3: The drop weight is positioned at the predetermined drop height (measured using a tape measure) in order to achieve the desired impact velocity and impact energy. High-speed digital camera settings and lighting are already established but final checks are made to assure operability.

Step 4: When test preparations are complete, data recordings are started [for accelerometers and the velocimeter (if desired)] and the electronic drop hook is tripped, allowing the drop weight to fall under the influence of gravity. 
Step 5: Following conclusion of the material impact test, high-speed digital camera data is evaluated to determine if an adequate strain rate has been achieved. Pertinent information concerning the test (date, test number, drop weight used, drop height, temperature, test specimen number, etc.) was recorded in the NSNFP Lab Notebook.

Weight measurements of the drop weights used in the tests were initially determined with 500 and 5000 pound calibrated load cells (see Report CD-R, File 3) and marked with the measured weight (see Figure 49). These marked weights included the weight of the rigging (approximately 5.7 pounds) necessary to interface with the electronic drop hook. After the completion of impact testing, the weights were weighed by the INL Standards and Calibration Laboratory using a device that was significantly more accurate than the load cells. Appendix E provides detailed comparisons of the weight measurements taken using both devices. For the weights used for the impact testing reported herein, the comparisons were within one pound for all individual weights less than 600 pounds and the single remaining largest weight (labeled ' $A$ ' and initially weighed at 1097 pounds) measured 10 pounds lighter, resulting in less than a $1 \%$ variation. Hence, the test weight data used throughout the testing effort was considered acceptable.

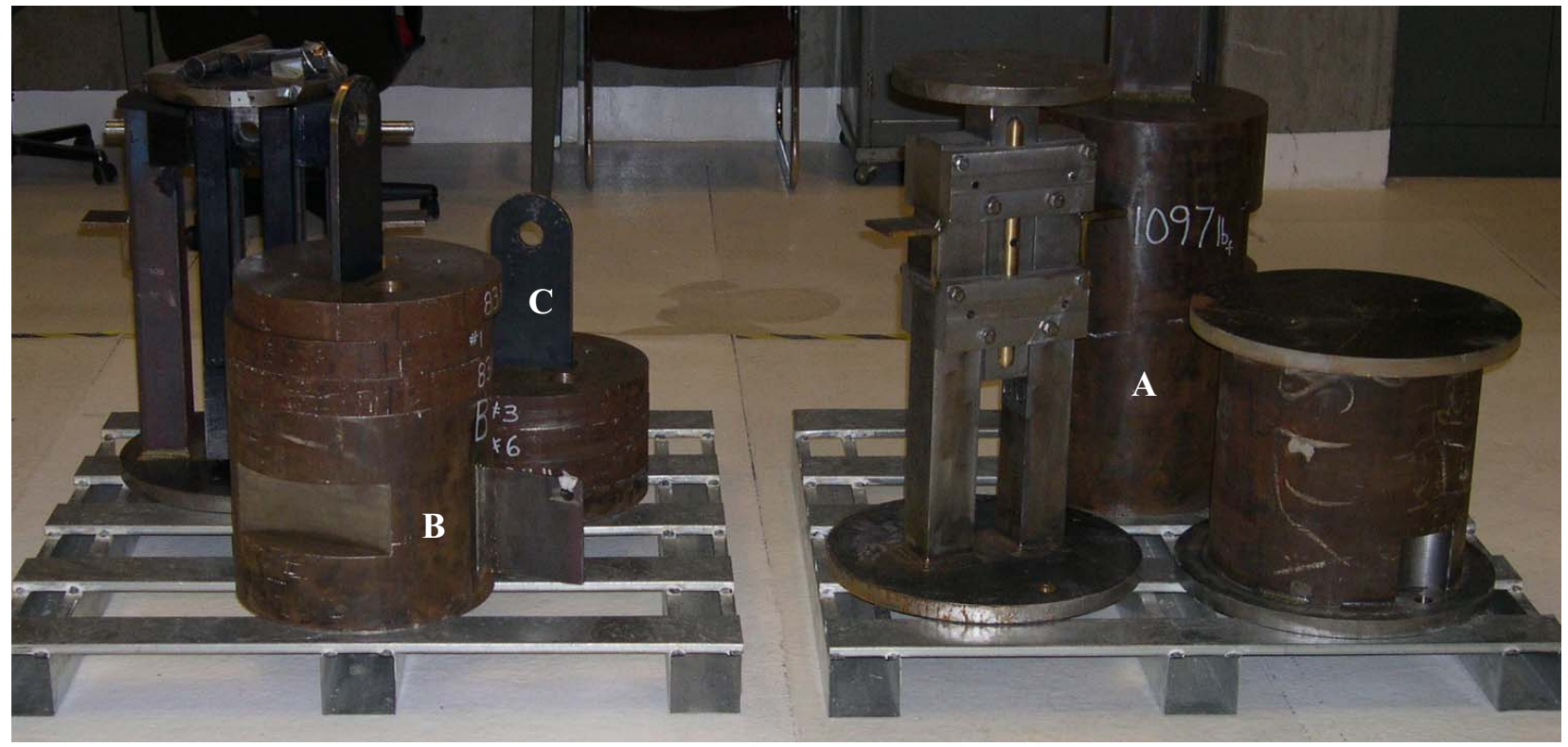

Figure 49. ITM test weights ' $B$ ', $C$ ', and ' $A$ ' (left to right) and disk weights \#1 through \#6 (on ' $B$ ' and ' $C$ ') along with the tensile (back left on left pallet), shear (front left on right pallet), and bending (front right on right pallet) test fixtures.

Details regarding data acquisition can be found in Section 6.5 and certain aspects of recording the necessary test data did affect the impact test procedure. Accelerometer output from preliminary ITM tests in early 2004 yielded indications of high frequency responses believed associated with metal-to-metal contact of the drop weight and impact plate. Depending on the stiffness of the system and the proximity of the transducers, metal-to-metal impact can excite high frequency (but low energy) transducer resonances or 'ringing'. Subsequent ITM tests, and all tests reported herein, incorporated a $1 / 2$-inch thick Buna-N-Rubber (Durometer hardness of approximately $60 \mathrm{~A}$, somewhat harder than tire treads) pad laid onto the impact surface of the impact driver to reduce the ringing (and to prevent lateral slippage/sliding at the interface). Test results obtained with and without the pad showed no significant change in test specimen strains. 
The early ITM tests attempted to use the accelerometer data to determine the strain rate response of each test specimen. However, when applying various filtering techniques to the accelerometer data to reduce higher frequency noise and lower frequency drift, it was noticed that the time content was being altered. Rather than having to address that adverse consequence, highspeed digital camera results were utilized. This device not only visually recorded the impact event but it also permitted the determination of the deformation or strain history, from which the test specimen's strain rate could be calculated. Acceleration data was no longer needed for qualityaffecting data purposes. However, acceleration data was still recorded during impact tests in case future insights of specific test responses needed to be ascertained.

A velocimeter was installed on the ITM even though the INL Standards and Calibration Laboratory determined that the device could not be calibrated within their system. The decision was made that the velocimeter could not provide qualified data. However, the velocimeter data could be used for confirmatory purposes. There was an initial concern that the drop weight might possibly rub along the guide pipe, slowing the drop weight and reducing the final impact velocity. The velocimeter data could be used to support the contention that the drop weight (pig) did not lose any measurable velocity during the drop event. The actual ITM installation and alignment was very accurate and the guide pipe was vertically positioned. No rubbing noises could be heard nor measured by the accelerometers during any of the material impact tests. Measurements from the velocimeter (for over 250 impact tests) confirmed that the final impact velocity matched the velocity magnitude calculated using the simple equation of motion for a free fall of a body under the influence of gravity:

$$
\mathrm{v}=\sqrt{2 \mathrm{gh}}
$$

where:

$$
\begin{aligned}
& \mathrm{v}=\text { velocity at impact (in./sec.) } \\
& \mathrm{g}=\text { acceleration of gravity }\left(386.4 \mathrm{in.} / \mathrm{sec}^{2}{ }^{2}\right) \\
& \mathrm{h}=\text { drop height (in.). }
\end{aligned}
$$

Even after performing numerous material impact tests, the NSNFP test personnel were vigilant in monitoring data accuracy and constantly looking for improvements. In mid-June 2006, during impact tests using lighter drop weights (less than 800 pounds), a questionable response was noticed in the deformation history. A potential cause of this odd response was thought to be a slight drag from the velocimeter (as its line was rolling out) that might be tipping the drop weight and altering its direct, flat impact onto the test fixture. It appeared that lighter weights were more susceptible to this potential occurrence. Limited testing was performed that indicated there might be some small affects beyond the variability of the material properties. Therefore, the decision was made to immediately stop using the velocimeter in order to eliminate any potential concerns about its possible affect on the impact tests. In order to reevaluate past impact tests, limited testing was performed using the heavier 1097 pound drop weight (labeled 'A'). No significant variation was seen in this comparison impact testing when the velocimeter was and was not attached to the drop weight. Therefore, only past impact tests that used a drop weight equal to or greater than 1097 pounds (that had the velocimeter attached) would be considered valid.

The material impact testing performed (for acceptable impact tests) limited the maximum strains to below the uniform strain limit, such that necking of the test specimens was not expected to occur. This is a strain limit that most component designs would not want to exceed in pure tension due to impending stability concerns if the through-wall strain levels exceeded this value. 
The impact test procedure also needed to reflect an adequate number of impact tests to be performed and an acceptable tolerance on the test results obtained. At the onset of material impact testing in 2004, the goal was to achieve three valid impact tests at certain strain rates (called target strain rates) identified in the Test Plan. Typically, multiple impact tests were performed in order to achieve the desired strain rates. This was necessary due to variations in material properties and the nonlinear responses of the test specimens, making initial response predictions difficult. It was hoped that the test specimen inelastic strains would vary significantly between 0.1 and the uniform strain limit for the three tests conducted at each target strain rate. With a reasonable spread in maximum strain achieved for the three tests at the same strain rate, it would then be possible to generate an elevated true stress-strain curve reflecting the average of those three target strain rate tests. Obviously, a tight tolerance on the strain rate was needed in order to generate an elevated true stress-strain curve that reflected the target strain rate. Therefore, it became necessary to define an acceptable tolerance on the strain rates achieved. For target strain rates above 20 per second, a tolerance of \pm 2 per second was established. For target strain rates of 10 per second and below, an initial tolerance of \pm 2 per second was established but was later tightened to \pm 1 per second for the associated impact tests reported herein. The goal was to develop a sufficient number of these elevated true stress-strain curves such that the structural analyst could adequately define material responses for a drop event. While this was adequate for initial impact testing and establishing performance characteristics of the test specimens, numerous impact tests were not being utilized.

After contemplating various approaches to increase the use of all data from valid impact tests, it was decided to still attempt to achieve the target strain rates identified in the Test Plan. For base material, three distinct impact tests were attained for each target strain rate. For welded material (due to a limited number of available test specimens), only two impact tests per target strain rate were attained. Impact testing still had to be performed at some strain rate levels and achieving the target strain rates satisfied the Test Plan requirement. This would also still permit the generation of elevated true stress-strain curves at specific target strain rates if deemed pertinent. However, finding a way to use all of the available valid impact test data was still needed. The NSNFP test personnel determined that if factors (constant values that quantified the strain rate effects for impact tests) could be calculated efficiently, then factor versus strain rate curves could be generated. This would incorporate all valid impact testing results. Hence, this approach was adopted.

\subsection{Achieving Impact Temperature Conditions}

Room temperature impact testing results and engineering judgment were combined to determine that only the D-2-2 and the D-4-4 test specimen geometries would be needed to achieve the desired strain rates for the cold and elevated temperature impact testing. Limiting the number of test specimen geometries minimized the amount of temperature baseline testing needed to establish the parameters necessary to achieve adequate impact temperature conditions. If this initial assessment proved wrong, additional temperature baseline testing would be performed for additional test specimen geometries. However, the impact testing indeed demonstrated that these two test specimen geometries were sufficient to allow all of the target strain rates to be achieved.

\subsubsection{Room Temperature Testing}

Considering all of the room temperature material impact testing completed, the room temperatures ranged from $52{ }^{\circ} \mathrm{F}$ to $85^{\circ} \mathrm{F}$. The locations where the material impact testing was performed were in two older facilities that had limited temperature controls during the fall, winter, 
spring, and summer seasons. However, this range of room temperatures is still considered acceptable. Performing the room temperature impact testing did not require establishing any specific release times for the drop hook. The impact tests were performed when test preparations were complete and the NSNFP test personnel were ready.

\subsubsection{Elevated Temperature Testing}

The NSNFP assigned the task of performing strain rate impact testing at elevated temperatures of $300{ }^{\circ} \mathrm{F}$ and $600{ }^{\circ} \mathrm{F}$ for both base and welded material. The initial question was how to achieve the test specimen heating process. Heating the entire test fixture and test specimen to $600{ }^{\circ} \mathrm{F}$ was not considered wise when repeatedly impacting the test fixture (made of A36 carbon steel) with weights up to 1600 pounds. This would probably deform the test fixture too much for future use. Heating the test specimens in an oven and then loading them into the test fixture would be possible but the process of handling a hot test specimen in a short enough time interval to maintain proper temperature conditions did not seem reasonable. Open flame heating was considered too dangerous. Electric heat guns (focused on heating the test specimen itself while in the test fixture) were chosen as the best option.

Multiple heating setups were tested before effective heating processes were proven viable for both the D-4-4 and the D-2-2 test specimens. The D-4-4 and D-2-2 test specimens used for temperature baseline testing had five equally spaced holes for thermocouples to be embedded into the central volume of the test specimen along its gauge length (Figure 50 illustrates the D-2-2 temperature baseline test specimen). Preliminary baseline testing (not documented in the NSNFP Lab Notebook) tried different numbers of electric heat guns, different heat gun positions, different heat gun settings, and different heating time intervals. In addition, it was recognized during the preliminary testing that heat shields or reflectors were needed to provide additional local heating control. Two heat shields (for front and back) were developed for the D-4-4 and D-2-2 specimen testing and another unique pair were created for the D-2-2 specimen testing at $600{ }^{\circ} \mathrm{F}$ (see Figure 51 for a picture of each heat shield geometry). Finally, for the D-2-2 baseline specimen testing, it was recognized that the thinner gauge length lost heat much quicker that the D-4-4 specimen. In order to better protect the D-2-2 specimen, a 'cradle' (see Figure 52) was fabricated that would essentially insulate the D-2-2 specimen test length on three sides (while still leaving viewing room for the high-speed camera). Hence, the preliminary testing permitted a large variety of heating methods to be tried and adjusted before the final (or near final) test setup was established. At this stage, documentation of the temperature baseline testing commenced in the NSNFP Lab Notebook.

The goal of the temperature baseline testing was to demonstrate the validity of the proposed heating process for both the $300{ }^{\circ} \mathrm{F}$ and $600{ }^{\circ} \mathrm{F}$ testing efforts and to demonstrate that it was repeatable. The test process approach required that the test specimens be overheated in order to allow time for test preparations (e.g., removing heating equipment for a clear camera view) to occur while the test specimen was cooling down to the target temperature. Therefore, the heating process also had to determine at what time interval (following the heat guns being turned off) the impact test could commence (see Section 6.4.2.1). 


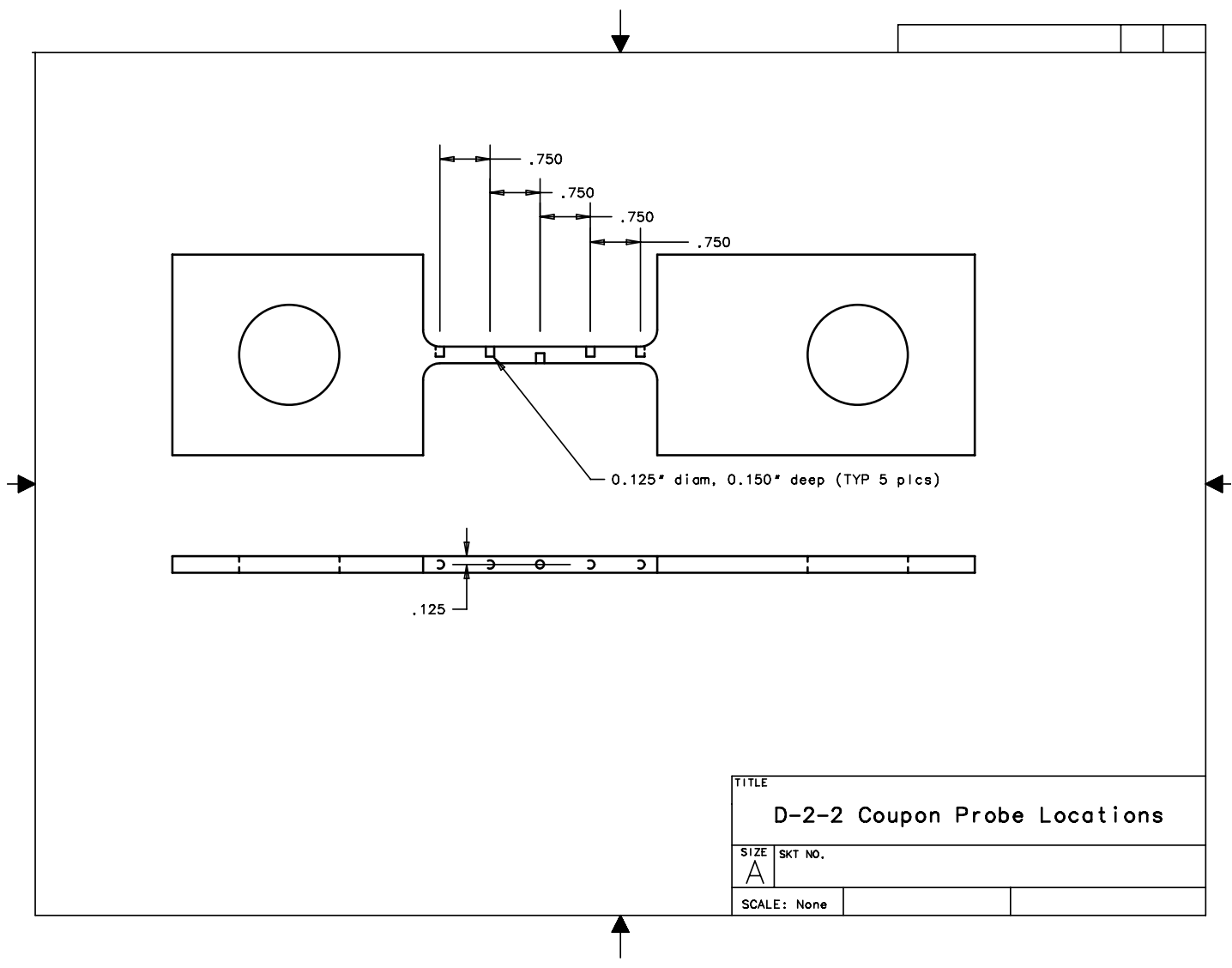

Figure 50. Temperature baseline testing specimen D-2-2 showing thermocouple hole locations.

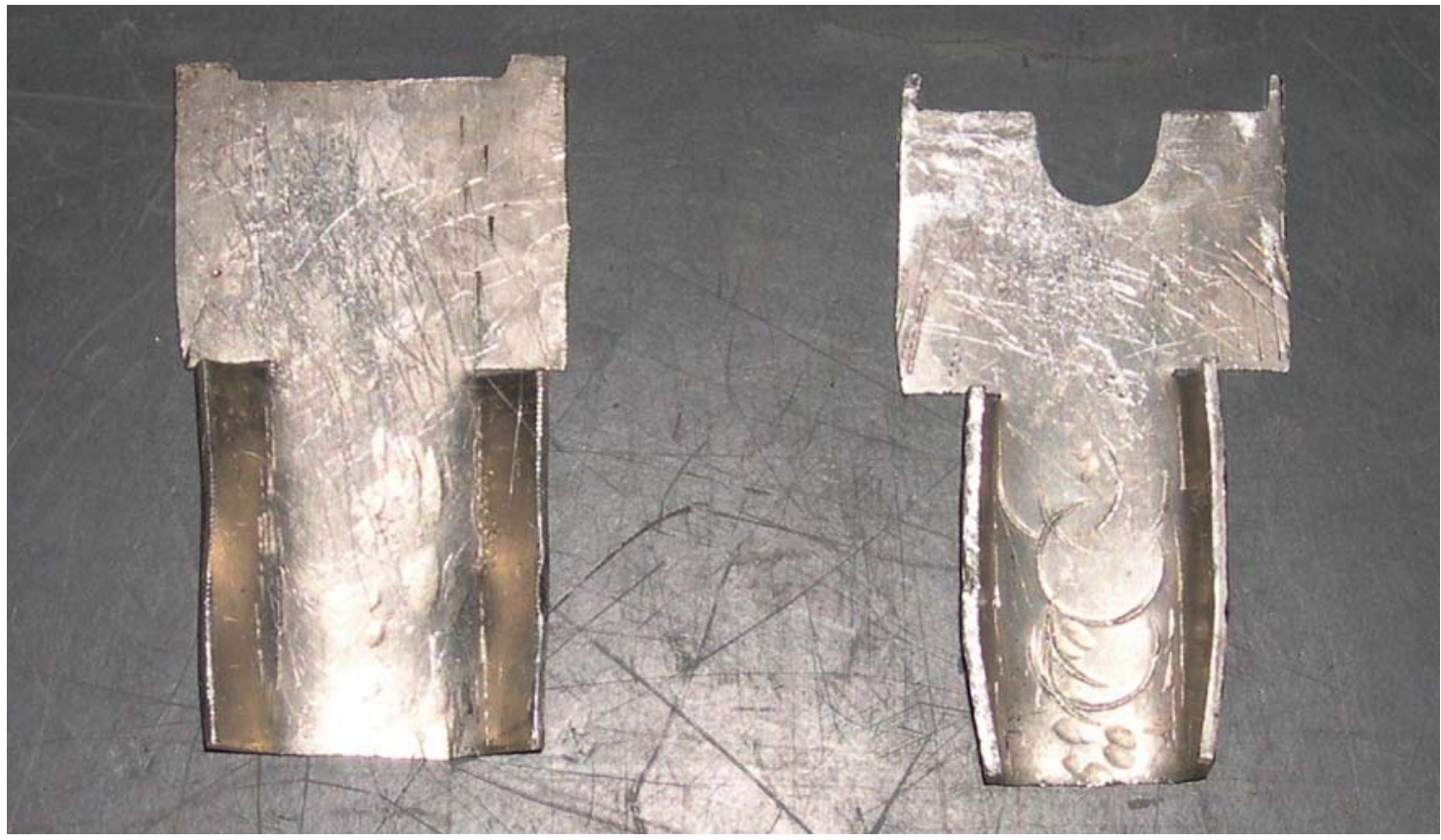

Figure 51. Heat shields for all test specimens (left) except D-2-2 test specimens at $600^{\circ} \mathrm{F}$ (right). 


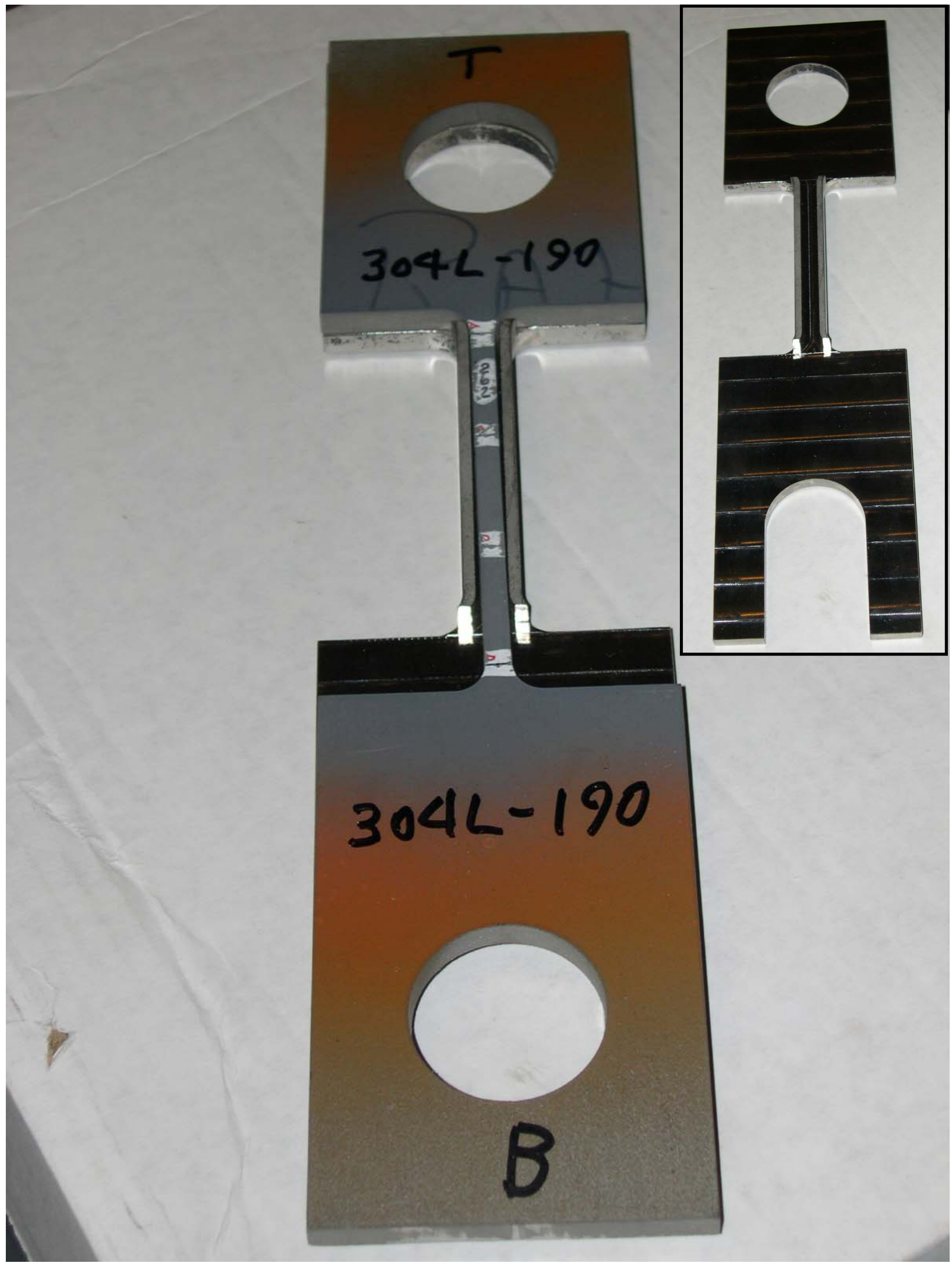

Figure 52. D-2-2 cradle holding an impacted test specimen (upper right insert is of cradle alone). 
The final heating configuration consisted of four heat guns. The heat guns were symmetrically placed, two in the front and two in the back, as illustrated in Figure 53. The bottom heat guns had three-inch long nozzle extenders and were positioned into the slot cut into the lower cross-member and pushed fully forward. This alignment centered the directed heat onto a spot approximately 1 -inch below the 3 -inch wide shoulder transition, onto the large bottom holder area. The top heat guns were positioned so that the nozzles were in contact with the bottom surface of the upper cross-member and pushed fully forward. This alignment centered the directed heat onto a spot approximately $1 / 2$-inch below the 3 -inch wide shoulder transition, onto the gauge length. Once an acceptable heating level was achieved, the barrels on the heat guns were marked to establish that particular heat gun setting (no gradations existed on the heat guns so marking was necessary in order to reset the heat gun settings). Table 8 indicates the heat gun barrel marking used.

Table 8. Heat gun barrel markings used for elevated temperature impact testing.

\begin{tabular}{|c|c|c|c|}
\hline \multicolumn{2}{|c|}{ Test Specimen Geometry } & $300^{\circ} \mathrm{F}$ Testing & $600^{\circ} \mathrm{F}$ Testing \\
\hline \multirow{2}{*}{ D-2-2 } & Top Guns & \multirow{2}{*}{ L-L } & \multirow{2}{*}{ J-J } \\
\hline & Bottom Guns & & \\
\hline \multirow{2}{*}{ D-4-4 } & Top Guns & D-D & \multirow{2}{*}{ E-E } \\
\hline & Bottom Guns & $\mathrm{H}-\mathrm{H}$ & \\
\hline
\end{tabular}

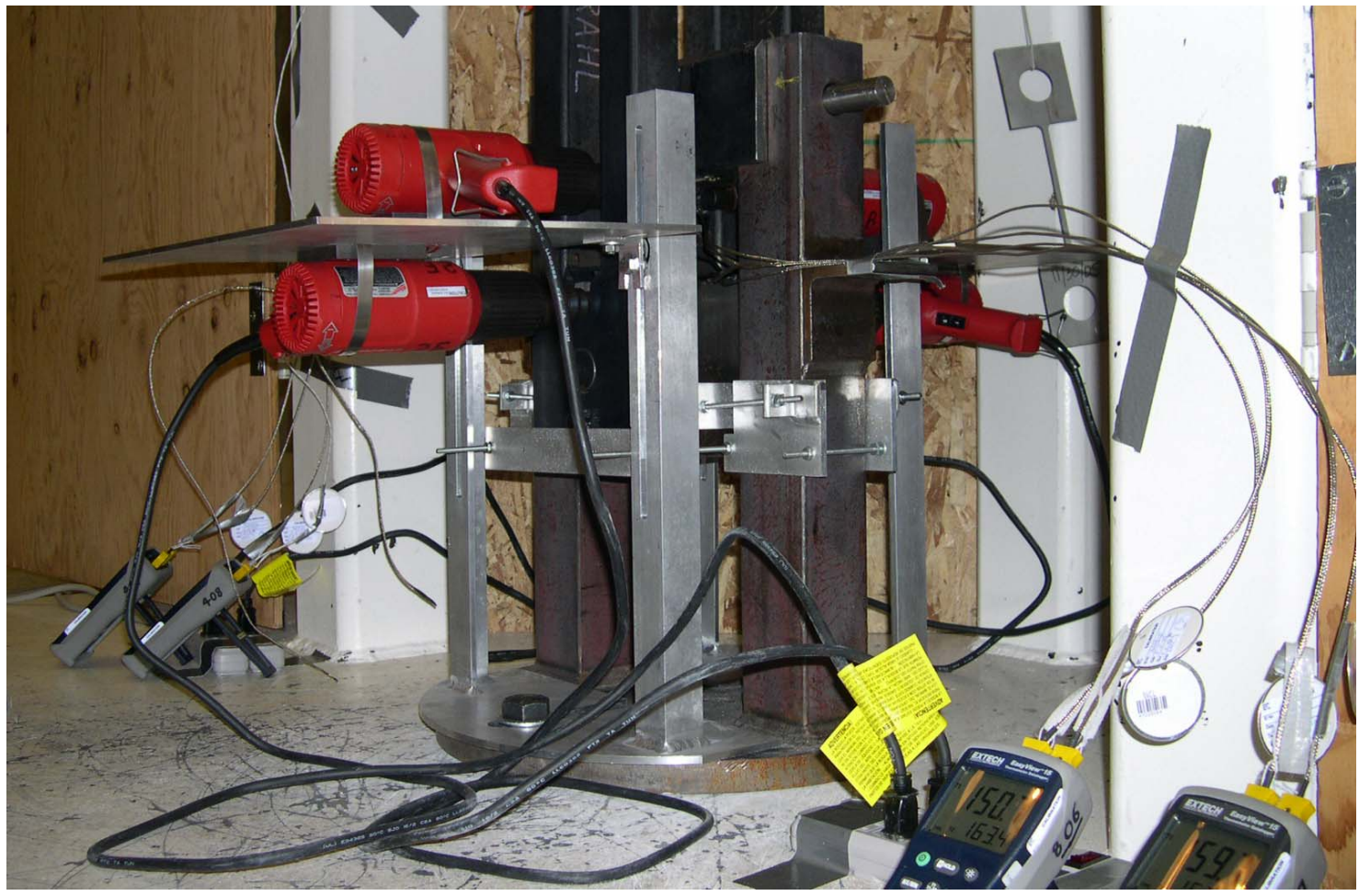

Figure 53. Temperature baseline testing setup showing four heat guns in position.

The heat shields were placed on top of the lower cross-member, bridging across the slot cut, and pressed up against the test specimen, front and back. Constant monitoring during the temperature baseline testing (and during the heating process for impact testing) was necessary to make sure these heat shields did not vibrate (due to operation of the heat guns) out of position 
during the heating process. The heat shields allowed the heating process to concentrate more heat into the bottom holder areas of the test specimens, minimizing heat loss through those large areas while the notches permitted hot air to rise and bathe the gauge length. Overall, much improved temperature distributions were measured throughout the gauge length with the heat shields in place.

In order to achieve acceptable test specimen temperature tolerances, a very prescriptive heatup process was used. The settings for the heat guns, marked during baseline testing, were achieved by adjusting to a full power setting and then reducing the setting down to the desired power level marking at the start of every day of elevated temperature testing. As indicated above, five thermocouple readouts (at 1.5 second intervals) were recorded (at three second intervals) for each temperature baseline test performed. Achieving consistent timing of the heating cycle durations was also considered vitally important in order to achieve consistency in the heating process (Section 6.4.2.1 explains the timing aspects in more detail). Every temperature baseline test performed as a basis test is included in NSNFP Lab Notebook Binder Volume 4. As can be seen in Figure 54, a representative D-2-2 test specimen was heated until a steady-state condition was achieved, and then the heat guns were turned off (after 25 minutes of heating as monitored on the digital timer). Thermocouple data was continuously recorded after the heat guns were turned off so that the test specimen cooldown (toward the target impact temperature of $600{ }^{\circ} \mathrm{F}$ in this specific case) could be monitored. Figure 55 illustrates the associated enlargement of the cooldown process (also contained in the NSNFP Lab Notebook Binder Volume 4). As can be seen, 18 seconds after the heat guns were turned off, the maximum temperature was $626^{\circ} \mathrm{F}$ and the minimum temperature was $578^{\circ} \mathrm{F}$.

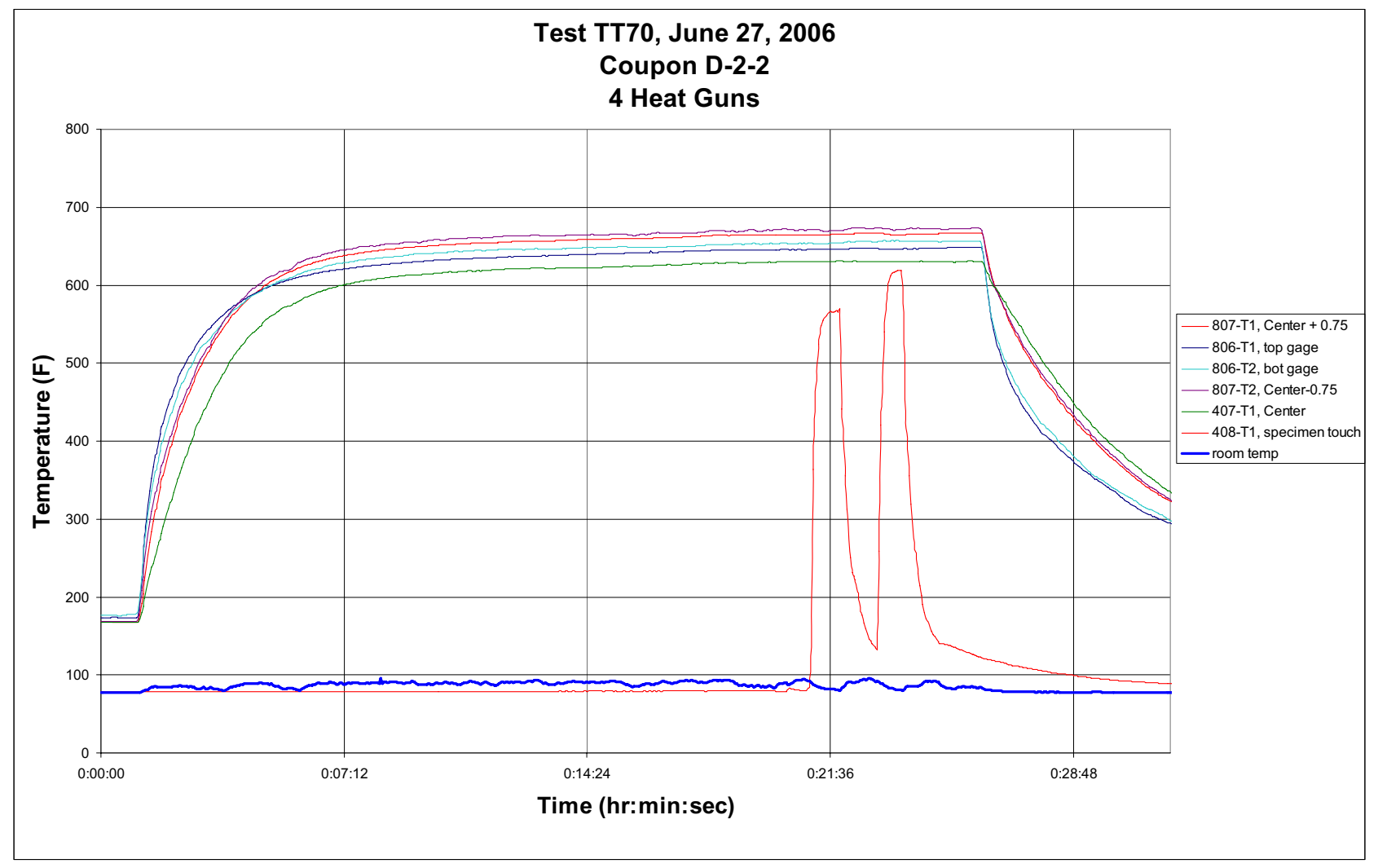

Figure 54. Representative temperature baseline test showing heat-up, steady-state, and the cooldown following the heat guns being turned off after 25 minutes of heating. 


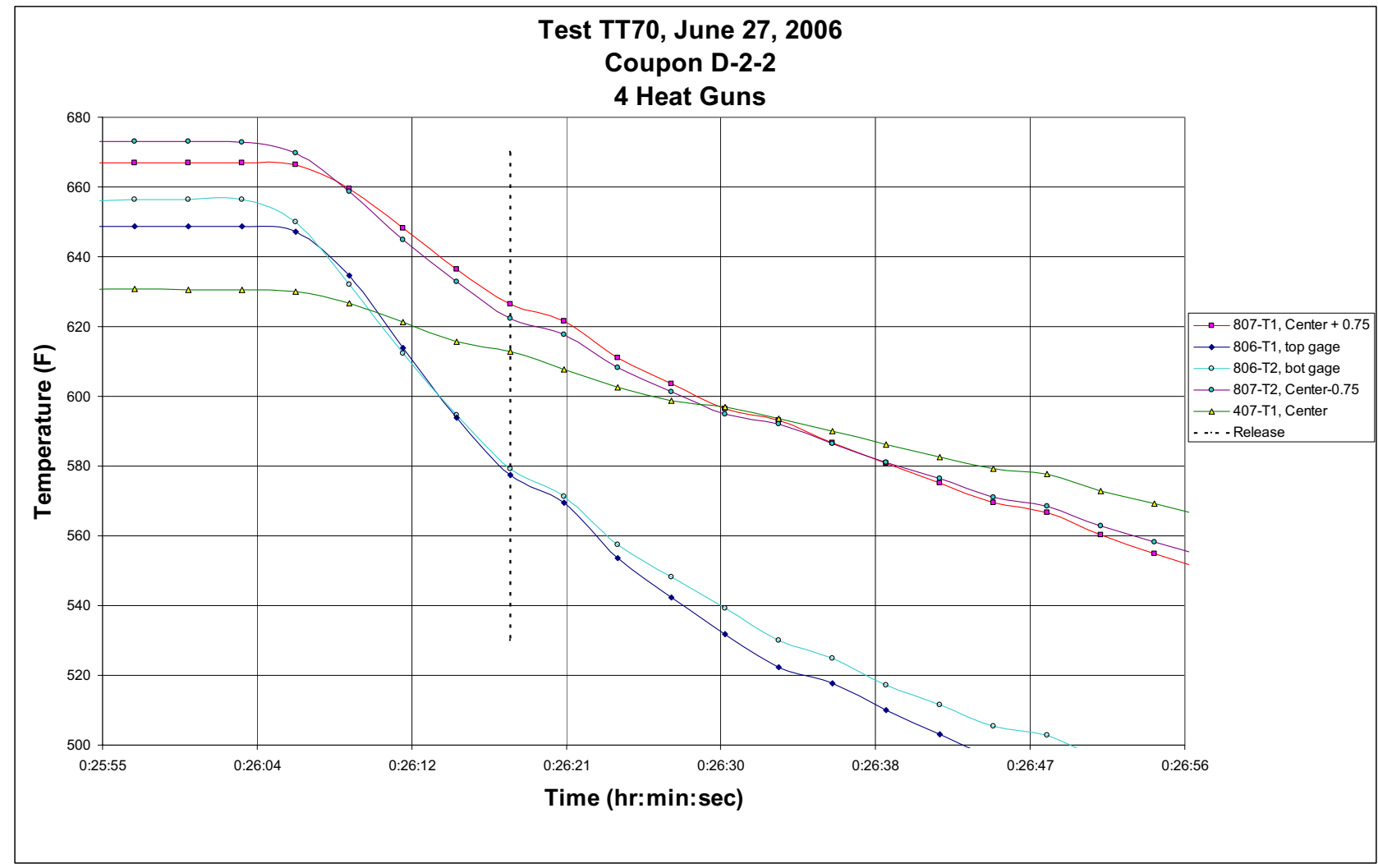

Figure 55. Representative cooldown with release time of 18 seconds identified by vertical dashed line showing temperature range of 578 to $626^{\circ} \mathrm{F}$.

It was recognized that heat gun settings and time duration alone were not sufficient to justify the acceptable heating of the test specimens for the actual impact testing. Therefore, it was decided that actual temperature measurements of each test specimen before impact testing at pre-established times (see Section 6.4.2.1) near the end of the heating process should be performed to gain further confirmation that each heat-up cycle was acceptable and following the baseline testing parameters. The initial assumption during temperature baseline testing was that the temperature at the center portion of the gauge length would be sufficient to judge the adequacy of the test specimen temperature and the heating process. Early on in the temperature baseline testing, test specimen measurements of the hot spot where the top heat guns were directed onto the gauge length were monitored to determine just how hot those locations became. However, during heat gun failure testing (see Section 6.4.2.3), it was determined that another temperature measurement near the bottom punch mark of the test specimen was needed to assure proper heat gun performance during the heating cycle. Therefore, after the heat gun failure testing, it became routine during temperature baseline testing to measure the temperatures of the test specimen (D-4-4 specimen on the side) or test specimen holder (D-2-2 cradle on the side) at the center and at the bottom punch mark locations. A thermocouple was used for these temperature measurements. The temperature baseline testing established the timing for the measurements and the acceptable ranges for these measured test specimen temperatures [Figure 54 illustrates a bottom temperature was measured first $\left(570^{\circ} \mathrm{F}\right)$ and then a center position $\left(619^{\circ} \mathrm{F}\right)$ temperature measurement was taken]. Table 9 indicates the acceptable ranges of these two test specimen temperatures (based on the multiple temperature baseline tests performed) as well as the ranges of temperatures achieved during actual material impact testing. All material impact tests conformed to the test specimen temperature measurement tolerances established. 
Table 9. Measured test specimen temperature ranges during baseline and impact testing.

\begin{tabular}{|c|c|c|c|c|c|}
\hline \multirow{2}{*}{$\begin{array}{c}\text { Data } \\
\text { Recorded }\end{array}$} & \multirow{2}{*}{$\begin{array}{l}\text { Measurement } \\
\text { Location }\end{array}$} & \multicolumn{2}{|c|}{$300^{\circ} \mathrm{F}$ Testing } & \multicolumn{2}{|c|}{$600^{\circ} \mathrm{F}$ Testing } \\
\hline & & D-2-2 & D-4-4 & D-2-2 & D-4-4 \\
\hline \multirow{2}{*}{$\begin{array}{c}\text { During } \\
\text { Baseline } \\
\text { Testing } \\
\end{array}$} & Bottom & 270 to $320^{\circ} \mathrm{F}$ & 280 to $320^{\circ} \mathrm{F}$ & 540 to $630^{\circ} \mathrm{F}$ & 570 to $620^{\circ} \mathrm{F}$ \\
\hline & Center & 280 to $320^{\circ} \mathrm{F}$ & 285 to $320^{\circ} \mathrm{F}$ & 585 to $635^{\circ} \mathrm{F}$ & 580 to $635^{\circ} \mathrm{F}$ \\
\hline \multirow{2}{*}{$\begin{array}{l}\text { During } \\
\text { Impact } \\
\text { Testing }\end{array}$} & Bottom & 270 to $314{ }^{\circ} \mathrm{F}$ & 282 to $321{ }^{\circ} \mathrm{F}^{*}$ & 545 to $611^{\circ} \mathrm{F}$ & 572 to $607^{\circ} \mathrm{F}$ \\
\hline & Center & 283 to $307^{\circ} \mathrm{F}$ & 286 to $317^{\circ} \mathrm{F}$ & 585 to $627^{\circ} \mathrm{F}$ & 580 to $592{ }^{\circ} \mathrm{F}$ \\
\hline
\end{tabular}

Note that early on in the impact testing, efforts to measure the D-4-4 test specimens proved difficult. The measured temperatures were unexpectedly low. After various attempts, including performing heat-up testing with the thermocouple instrumented baseline test specimen again, it was recognized that the impact test specimens, since they were water jet cut, had a rougher surface on the sides where the temperature measurements were taken whereas the baseline test specimens had smoother machined surfaces. (For D-2-2 testing, a cradle was used for baseline testing and impact testing and the cradle side surfaces were machined smooth.) Therefore, the side surfaces on the impact test specimens where the temperature measurements were to be taken were locally polished in order to improve the thermocouple contact. This greatly improved the impact test specimen temperature measuring process. For each successful heat-up cycle, the confirmatory bottom and center test specimen temperature measurements made prior to impact testing were recorded and entered into the lab notebook. If the measured temperatures were not acceptable, the heating process was continued (heat guns turned off at the proper time) but the impact test was not performed.

Two other issues were discussed during preliminary temperature testing and a final decision was made to address each in the temperature baseline testing. The heat-up cycle was very time consuming (see Section 6.4.2.1) with a lot of heat being absorbed by the test fixture. It was believed that another indication of repeatability would be the temperatures of the test fixture, taken before and after each heat-up cycle. Although not expected to be a precise indicator of test specimen temperatures, knowing the generic temperature history of the test fixture throughout the heating process could provide additional confirmation of a proper and repeatable process. Section 6.4.2.2 contains additional information on temperature measurements of the test fixture. In an effort to address potential equipment failure, additional testing was performed to determine if a single heat gun failure could be detected. Section 6.4.2.3 describes how the test specimen pre-impact test temperatures were utilized to help detect a potential heat gun failure.

The NSNFP Lab Notebook provides the overall process and insights related to the qualified temperature baseline testing performed and the associated Binder Volume 4 provides the test specific baseline results (each test geometry at each elevated temperature) as well as testing summaries. A full testing day's worth of temperature baseline testing was achieved and then repeated on another day. In an effort to demonstrate full repeatability, the heat guns were reset prior to a second day of temperature baseline testing. Finally, if any problems arose, it was decided early on that the instrumented test specimen used for the temperature baseline testing could be re-used on impact testing days or other days as necessary to gain insights on a continuing acceptable heat-up 
process. Those types of confirmation checks were made and each confirmed that the heating process was always within stated tolerances. These confirmatory checks are also documented in the NSNFP Lab Notebook Binder Volume 4.

\subsubsection{Heating/Cooldown Durations and Trip Hook Release Times}

The following shows the heat-up and cooldown cycle time intervals used during testing. These intervals were determined during the preliminary testing, used throughout temperature baseline testing, and followed during actual material impact testing at elevated temperatures. The time intervals established between heat guns off and heat guns back on allowed not only for the impact test to be performed but also were established in order to allow adequate time for the determination of the impact test strain rate, permit the test fixture to cooldown for handling purposes, and to allow for sufficient time to change drop weights. All times were determined and followed using a digital timer. A continuous timing sequence was used (see below for temperature specific timing intervals) that began at the start of a test day (heat guns on) and ended with the final material impact test for that day.

\section{Event Timing}

0 min.

12 to $13 \mathrm{~min}$.

14 to $15 \mathrm{~min}$.

$17 \mathrm{~min}$.

Specimen dependent

52 min. or

$1 \mathrm{hr} 22 \mathrm{~min}$. (after third test only)

\section{Event Timing}

First Test of Day:

$0 \mathrm{~min}$.

55 to $56 \mathrm{~min}$.

57 to $58 \mathrm{~min}$.

$60 \mathrm{~min}$.

Specimen dependent

$1 \mathrm{hr} 45 \mathrm{~min}$.

Remaining Four Tests of Day:

$0 \mathrm{~min}$.

20 to $21 \mathrm{~min}$.

22 to $23 \mathrm{~min}$.

$25 \mathrm{~min}$.

Specimen dependent

$1 \mathrm{hr} 15 \mathrm{~min}$.

\section{$\underline{300}{ }^{\circ} \mathrm{F}$ Impact Tests (Six tests maximum per day)}

Start Heat Guns

Bottom Punch Measurement (initially the hot spot)

Centerline Measurement

Heat Guns Off

Drop Weight Released

Heat Guns Back On (repeat above steps for next test)

$\underline{600}{ }^{\circ} \mathrm{F}$ Impact Tests (Five tests maximum per day)

Start Heat Guns

Bottom Punch Measurement (initially the hot spot)

Centerline Measurement

Heat Guns Off

Drop Weight Released

Heat Guns On (go to timing below for remaining tests)

\section{Start Heat Guns}

Bottom Punch Measurement (initially the hot spot)

Centerline Measurement

Heat Guns Off

Drop Weight Released

Heat Guns Back On (repeat above steps for next test) 
In addition, the drop hook release time needed to be established. The baseline testing established the drop hook release times, which were hoped to be less than 30 seconds from turning off the heat guns in order to minimize thermal gradients across the test specimen thickness.

Obviously, the impact time is the most critical time parameter but with different weights resulting in different drop heights, the time between drop hook release and actual impact varied between zero and 1 second. Therefore, if a 1 second long time interval could be determined wherein the worst case temperature values achieved acceptable weighted average temperatures and acceptable maximum and minimum temperatures, then the drop hook should be activated at the start of that 1 second time interval. This is what is documented in NSNFP Lab Notebook Binder Volume 4. The one exception was for the D-4-4 test specimen at $300{ }^{\circ} \mathrm{F}$ temperature. The time at which the measured worst case temperature ranges achieved the minimal temperature ranges ( 22 seconds) was much longer than the other tests (16 to 20 seconds). Therefore, it was decided to not exceed 20 seconds for a trip hook activation time so that any potential thermal gradient effects through the test specimen thickness would be minimized and not become a detrimental issue. Table 10 below summarizes the temperature tolerances achieved during temperature baseline testing for each target temperature for each unique test specimen geometry at the drop hook release time or a one second interval afterwards. These drop hook release times were achieved by the NSNFP test personnel for each material impact test completed.

Table 10. Drop hook release times and associated test specimen temperatures.

\begin{tabular}{|c|c|c|c|c|c|c|}
\hline \multirow[b]{3}{*}{$\begin{array}{c}\text { Target } \\
\text { Temp. } \\
\left({ }^{0} \mathbf{F}\right)\end{array}$} & \multicolumn{6}{|c|}{ Test Specimen Geometry } \\
\hline & \multicolumn{3}{|c|}{ D-2-2 } & \multicolumn{3}{|c|}{ D-4-4 } \\
\hline & $\begin{array}{c}\text { Drop } \\
\text { Hook } \\
\text { Release } \\
\text { Time } \\
\text { (sec.) } \\
\end{array}$ & $\begin{array}{c}\text { Weighted } \\
\text { Avg. } \\
\text { Temp. } \\
\text { Range } \\
\left({ }^{\circ} \text { F) }\right. \\
\end{array}$ & $\begin{array}{c}\text { Max/Min } \\
\text { Temp. } \\
\text { Range } \\
\left({ }^{0} \mathbf{F}\right)\end{array}$ & $\begin{array}{c}\text { Drop } \\
\text { Hook } \\
\text { Release } \\
\text { Time } \\
\text { (sec.) } \\
\end{array}$ & $\begin{array}{c}\text { Weighted } \\
\text { Avg. } \\
\text { Temp. } \\
\text { Range } \\
\text { ('F) } \\
\end{array}$ & $\begin{array}{c}\text { Max/Min } \\
\text { Temp. } \\
\text { Range } \\
\left({ }^{\circ} \mathbf{F}\right)\end{array}$ \\
\hline 300 & 16 & $+5 /-10$ & $\begin{array}{l}+23 / \\
-24\end{array}$ & 20 & $+12 /-7$ & $\begin{array}{c}+18 / \\
-12\end{array}$ \\
\hline 600 & 18 & $+15 /+4$ & $\begin{array}{l}+32 / \\
-32\end{array}$ & 18 & $+8 /-7$ & $\begin{array}{l}+28 \\
-28\end{array}$ \\
\hline : & 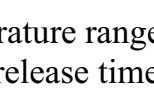 & arval aft & The & $\begin{array}{l}F \text { and } \epsilon \\
\text { ff. }\end{array}$ & & \\
\hline
\end{tabular}

The weighted average temperature covers the entire gauge length whereas the $\mathrm{max} / \mathrm{min}$ temperature ranges are the highest or lowest temperature regardless of specific location. One important point to recognize is that the minimum temperature range typically reflected the temperature measurements made at the extreme ends (top and bottom locations) of the gauge length. This is reasonable due to the heat loss through the pin connected ends (through the top and bottom cross-members) of the test specimen. Note that Table 9 indicates the worst-case temperature tolerances achieved during all of the numerous temperature baseline tests completed. For most of the tests, the weighted average temperature and maximum and minimum temperatures were much closer to the target test temperatures. 


\subsubsection{Test Fixture Temperatures}

Test fixture temperatures were recorded during the temperature baseline testing as well as during the actual material impact tests. Temperature measurements of the upper cross-member (on the top surface centered in front of the slotted opening) and lower cross-member (facing the impact driver, on the right side approximately 2 inches down from the top and 2 inches toward the back) were taken immediately before the heat guns were turned on and approximately one minute after the heat guns were turned off. These temperatures, recorded in the NSNFP Lab Notebook obviously varied somewhat due to variations in the heating process and to varying initial conditions.

Although not considered as significant as the measured test specimen temperatures, this information was considered to provide insights into the overall performance of the heat guns throughout the impact testing effort and to also provide test repeatability insights. Since the start of each day's impact testing could be at a different room temperature than that of the baseline testing, it was decided to look at the temperature changes of the test fixture throughout the multiple heat-up cycles for a full day of testing and see how they compared to the baseline testing data. Variances are those temperature values that were beyond the range of test fixture temperatures established during baseline testing. The variance was considered zero if the change in temperature was within the tolerance achieved during the two days of baseline testing. These variance data are determined in the NSNFP Lab Notebook Binder Volume 4 and are summarized below in Table 11.

Table 11. Test fixture temperature variances.

\begin{tabular}{|c|c|c|c|c|}
\hline \multirow{2}{*}{$\begin{array}{c}\text { Impact Test } \\
\text { Variances From } \\
\text { Temperature } \\
\text { Baseline Testing }\end{array}$} & D-2-2 & D-4-4 & D-2-2 & D-4-4 \\
\cline { 2 - 5 } & $8{ }^{\circ} \mathrm{F}$ & $11^{\circ} \mathrm{F}$ & $24^{\circ} \mathrm{F}$ & $20^{\circ} \mathrm{F}$ \\
\hline $\begin{array}{c}\text { Largest Single Test } \\
\text { Variance }\end{array}$ & $2.4^{\circ} \mathrm{F}$ & $3.7^{\circ} \mathrm{F}$ & $9.3{ }^{\circ} \mathrm{F}$ & $7.0^{\circ} \mathrm{F}$ \\
\hline $\begin{array}{c}\text { Average Variance } \\
\text { of Viable Impact } \\
\text { Tests }\end{array}$ & & & \\
\hline
\end{tabular}

Initial desires were that the worst case variance from that established during temperature baseline testing would be less than $25^{\circ} \mathrm{F}$. This tolerance was achieved. Hence, the test fixture temperature data also confirms an acceptable heating process was used for the elevated temperature material impact testing.

\subsubsection{Heat Gun Failure}

The possibility of heat gun failure during a heat-up process was investigated. Documentation of that effort and the establishment of acceptable temperature range checks is contained in the temperature baseline testing data. Plots in the NSNFP Lab Notebook Binder Volume 4 show temperature time histories of what happened during $300^{\circ} \mathrm{F}$ and $600^{\circ} \mathrm{F}$ baseline testing if a specific heat gun failed. This was achieved by following the established temperature baseline heat-up process (using the instrumented test specimens) until reasonable steady state conditions were achieved and then a heat gun was turned off while the remaining three heat guns 
continued to heat. This was repeated four times until each heat gun in sequence had been turned off. The $300{ }^{\circ} \mathrm{F}$ heat-up process was repeated but it was felt that one test for $600{ }^{\circ} \mathrm{F}$ testing was sufficient since the results were similar to the $300{ }^{\circ} \mathrm{F}$ testing.

The results show that center test specimen measurements accurately indicated a top front or top back heat gun failure. The center temperatures reduced by 28 to $44^{\circ} \mathrm{F}$ for $300{ }^{\circ} \mathrm{F}$ testing and 56 to $74{ }^{\circ} \mathrm{F}$ for $600{ }^{\circ} \mathrm{F}$ testing, a very measurable difference. For a bottom front or bottom back heat gun failure, the center test specimen temperature measurement proved to be inconclusive so measurements of the bottom punch (or base) area were taken and these proved much more insightful. The bottom punch or base temperatures reduced by approximately 42 to $61{ }^{\circ} \mathrm{F}$ for $300^{\circ} \mathrm{F}$ testing and 70 to $132^{\circ} \mathrm{F}$ for $600{ }^{\circ} \mathrm{F}$ testing, again a very measurable difference.

It was decided that in place of hot spot temperature checks, test specimen temperature measurements at the bottom punch mark were necessary to assure that none of the four heat guns failed during the heat-up cycle. Therefore, heat gun failure baseline testing was used to establish acceptable ranges for bottom punch (or base) temperature measurements. The heat-up and cooldown baseline testing mandated higher acceptable temperatures than those determined for proper heat gun performance at the center position. In conclusion, these heat gun failure data were used to assure that heat gun failure would be detected and impact testing would therefore be terminated until a replacement heat gun could be incorporated and validated with additional temperature baseline testing.

\subsubsection{Resulting Test Specimen Temperatures at Impact}

An initial accuracy target of the weighted average test temperature of $\pm 25^{\circ} \mathrm{F}$ was specified in the Test Plan but it was quickly realized that not only should a reasonable weighted average test specimen temperature be achieved but that a limit on the highest and lowest temperatures must also be imposed. Initial desires for acceptable maximum and minimum temperature ranges (within the test specimen gauge length) were $\pm 25^{\circ} \mathrm{F}$ for the $300{ }^{\circ} \mathrm{F}$ testing and $\pm 35^{\circ} \mathrm{F}$ for the $600{ }^{\circ} \mathrm{F}$ testing. As can be seen in the baseline testing information provided in Table 10, these accuracy goals were met. The worst case extremes (of any of the associated baseline tests) were then used to establish the temperature ranges applicable to the heating process used. However, most of the baseline testing results were actually much closer to the target temperatures than the extremes listed.

It was expected that certain variabilities in test conditions could arise for the many anticipated days of actual material impact testing. Therefore, the previously stated temperature ranges achieved during temperature baseline testing (see Table 10) were rounded up to values that would become the stated temperature tolerances achieved during impact testing. These final temperature tolerances are presented in Table 12.

Table 12. Temperature tolerances for material impact testing.

\begin{tabular}{|c|c|c|}
\hline \multirow{2}{*}{$\begin{array}{c}\text { Target Temperature } \\
\left({ }^{\mathbf{0}} \mathbf{F}\right)\end{array}$} & $\begin{array}{c}\text { Weighted Avg. } \\
\text { Temperature Range } \\
\left({ }^{\mathbf{0}} \mathbf{F}\right)\end{array}$ & $\begin{array}{c}\text { Max/Min } \\
\text { Temperature Range } \\
\left({ }^{\mathbf{0}} \mathbf{F}\right)\end{array}$ \\
\hline 300 & $+15 /-10$ & \pm 25 \\
\hline 600 & $+15 /-10$ & \pm 35 \\
\hline
\end{tabular}


In addition to the significant amount of measured temperature data, a thermal analysis of the temperature cooldown of a D-4-4 test specimen was performed to provide more insights into the validity of the measured temperatures and insight on whether significant thermal gradients existed through the thickness during cooldown. This thermal analysis effort, reported in EDF-NSNF-065 (Reference 39) provided the following conclusion:

"The main conclusion, deduced from the comparison of the predictions of the ABAQUS model to the test data for the 300 and $600{ }^{\circ} \mathrm{F}$ tests, is that the thermocouples should accurately represent the transient thermal response of the test coupon during the initial cooldown (i.e., the first 20-30 seconds after the heaters are shut off). Thermocouple lag, or delay, effects were not seen in the data. Also, the temperature distribution across the thickness of the coupon test section was determined to be uniform."

\subsubsection{Cold Temperature Testing}

For the $-20^{\circ} \mathrm{F}$ material impact testing, the decision was made to use a research freezer (with a stated capacity down to $-40^{\circ} \mathrm{F}$ ) to cold-soak the test specimens. Similar to the elevated temperature testing, it was decided to not cold-soak the entire tensile test fixture down to $-20^{\circ} \mathrm{F}$. It was decided to cold-soak each test specimen down to a temperature lower than $-20^{\circ} \mathrm{F}$ and then take the time (while the test specimen was warming) to insert the test specimen into the test fixture and prepare for impact testing.

Preliminary temperature baseline testing determined how much colder than $-20{ }^{\circ} \mathrm{F}$ was necessary to allow sufficient time for placement of the test specimen into the test fixture and prepare for the impact test. A time interval no longer than one minute was thought to be adequate for impact testing once the test specimen had been removed from the research freezer.

Instrumented temperature baseline test specimens [both the D-2-2 (with cradle) and the D-4-4 test specimens as used for the elevated temperature testing] with three thermocouples inserted into the mid-cross section (top punch, bottom punch, and center positions along the gauge length) were used to determine the test specimen temperature responses. Both the D-4-4 and the D-2-2 preliminary temperature results indicated that an initial cold-soak temperature of approximately $-33{ }^{\circ} \mathrm{F}$ was needed. Preliminary testing also indicated that having just a few specimens in the freezer caused the freezer to cycle frequently because it was difficult to keep just air sufficiently cold. Therefore, a thick stainless steel plate was inserted into the freezer so that this denser mass could help the freezer temperature stabilize. This established a more consistent temperature in the freezer and all test specimens were stacked onto this plate to promote more rapid cooling.

Temperature baseline testing for cold temperatures could now proceed with data being recorded in the NSNFP Lab Notebook. In order to simulate impact testing conditions as much as possible, the three thermocouple leads were taped close to the test specimen body so that the specimen could still be inserted into the test fixture while monitoring and recording the temperatures. Timing was monitored using the same digital timer used for the elevated temperature testing. Timing started with the opening of the research freezer. The instrumented test specimen was removed from the freezer, loaded into the test fixture, a one minute pause interval occurred, and then the specimen was returned to the freezer. Rather than directly holding the test specimen, a tab of duct tape was used to hold the test specimen, thus minimizing localized heat gain. Only test specimens that had cold-soaked at least overnight were used to establish the warm-up timing. 
However, other warm-up tests were performed during the remainder of the day once the test specimen had cold-soaked and stabilized to at least a temperature below $-30{ }^{\circ} \mathrm{F}$. These tests, using both test specimen geometries, were used to demonstrate the repeatability of the test process. The NSNFP Lab Notebook Binder Volume 4 contains this repeatability data. These repeatability tests (using the weighted averages of the recorded temperatures) were biased to start at the average temperature of the established starting temperature range. These plots (illustrated in Figure 56 for the D-2-2 test specimen repeatability tests biased to $-33.25^{\circ} \mathrm{F}$ ) show a very tight grouping of curves, confirming a very repeatable warm-up process, especially up to the time that the drop hook was released. The D-4-4 temperature baseline testing results (not shown), reflecting a test specimen with more thermal mass, had an even closer temperature grouping than the D-2-2 results.

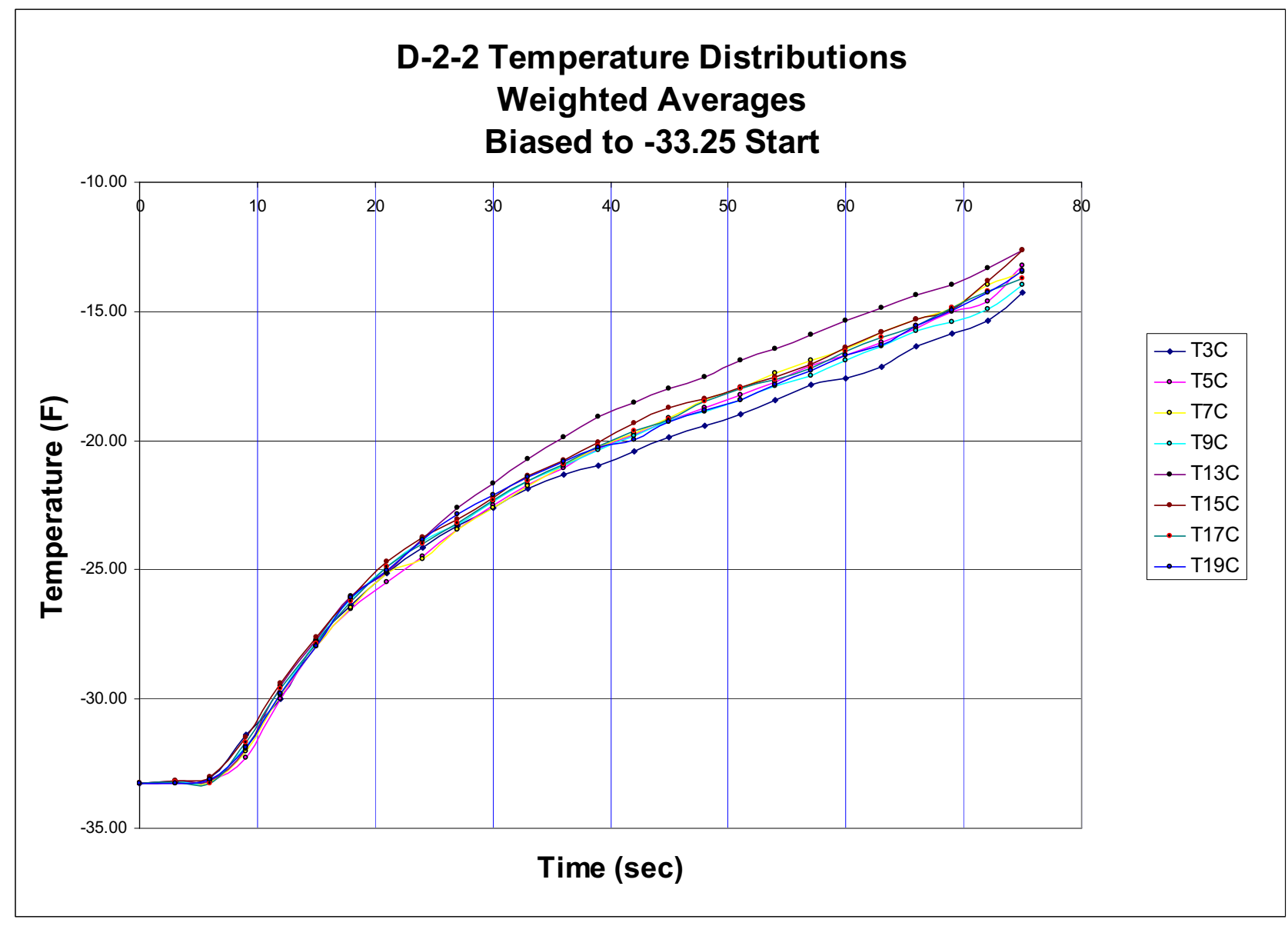

Figure 56. Repeatability tests for D-2-2 test specimen all temperatures biased to start at $-33.25^{\circ} \mathrm{F}$.

As previously mentioned, only the thoroughly cold-soaked test specimens were tested (first tests of the day) to establish the timing for the impact tests. Warm-up tests $1 \mathrm{C}, 11 \mathrm{C}, 24 \mathrm{C}$, and $25 \mathrm{C}$ addressed the D-2-2 specimens and warm-up tests 2C, 12C, 21C, and 23C addressed the D-4-4 specimens. Presentation and evaluation of this data is contained in NSNFP Lab Notebook Binder Volume 4. Figure 57 illustrates the warm-up test results for D-2-2 test specimen at test 25C. Again, note that the D-4-4 test results provided even closer temperature grouping due to the larger thermal mass of the thicker test specimen. 


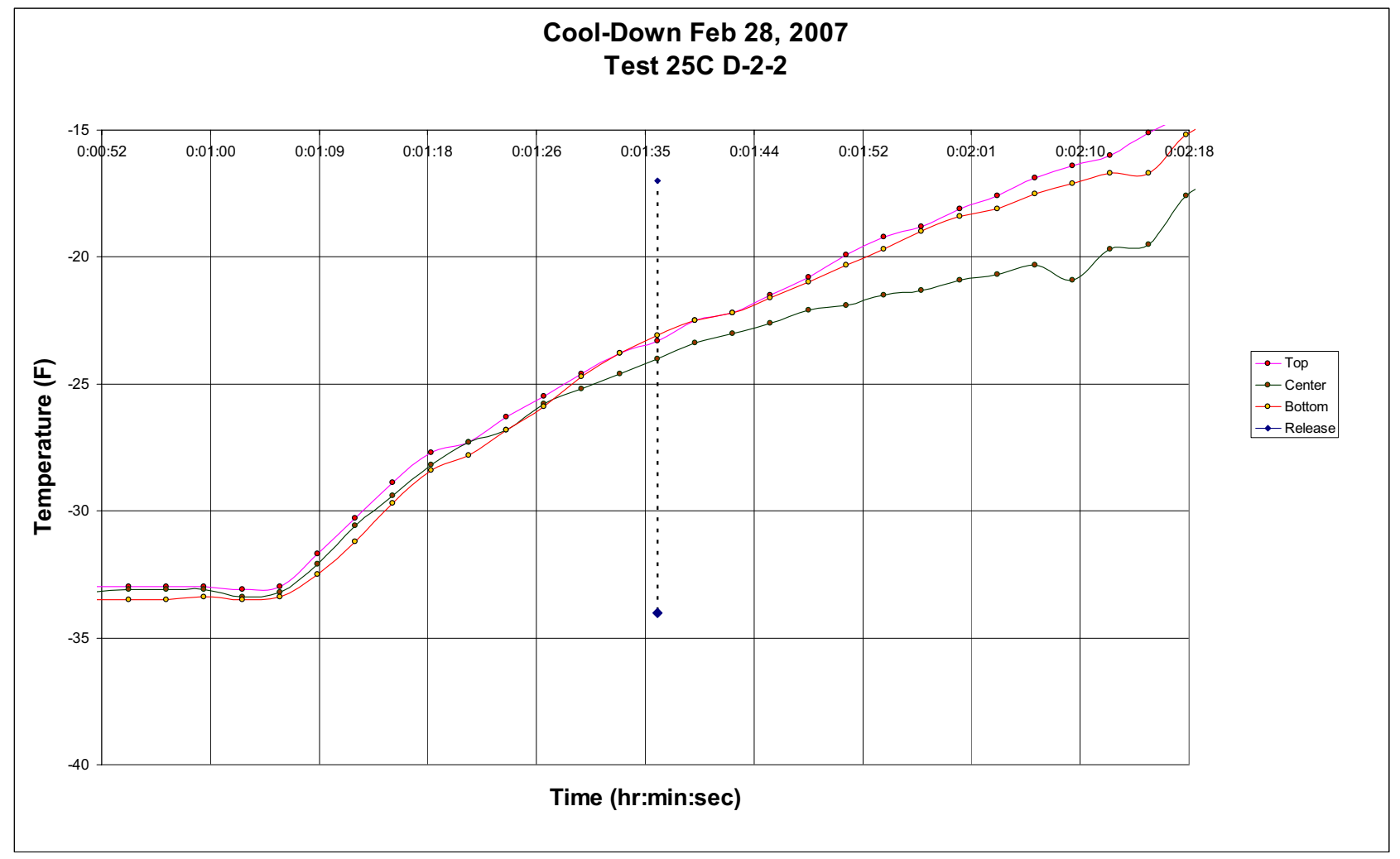

Figure 57. Typical D-2-2 warm-up test from overnight cold-soaked conditions.

Table 13 lists the weighted average temperature and the maximum and minimum temperature ranges determined during the temperature baseline testing. In addition, the averages of the weighted average, maximum, and minimum temperatures for each of the four baseline tests were then determined. From these averages of the averages, constant factor adjustments were made to address the probable temperatures that would be achieved at an anticipated minimum starting temperature and at an anticipated maximum starting temperature. These anticipated starting temperatures became the acceptable starting temperature ranges for cold impact testing. For the D-4-4 specimens, the starting acceptable temperature range for impact testing was -31 to $-34.5^{\circ} \mathrm{F}$. For the D-2-2 specimens, the acceptable starting temperature range for impact testing was -32 to $34.5^{\circ} \mathrm{F}$.

Table 13. Test specimen cold temperature ranges at impact test.

\begin{tabular}{|c|c|c|}
\hline Temperature Parameter & D-2-2 Specimen & D-4-4 Specimen \\
\hline $\begin{array}{c}\text { Weighted Average } \\
\text { Temperature Range at Impact }\end{array}$ & -21.8 to $-23.6^{\circ} \mathrm{F}$ & -20.7 to $-22.1^{\circ} \mathrm{F}$ \\
\hline $\begin{array}{c}\text { Maximum / Minimum } \\
\text { Temperature Range at Impact }\end{array}$ & -19.0 to $-24.3^{\circ} \mathrm{F}$ & -20.5 to $-22.3^{\circ} \mathrm{F}$ \\
\hline
\end{tabular}

Testing was also performed to demonstrate that cradles reused during the test day would not adversely affect the temperatures of D-2-2 test specimens that had cold-soaked overnight. After performing an overnight cold-soaked D-2-2 warm-up test, the cradle was returned to the 
freezer no longer than 3 minutes and 15 seconds after initial opening of the freezer for test specimen removal. After waiting 45 minutes, another overnight cold-soaked test specimen was placed into the cradle. After 15 more minutes of cooling, the center temperature of the coldsoaked test specimen was checked. The D-2-2 test specimen was just as cold as it had been after the overnight cold-soak. Therefore, this same minimal timing for cradle cooling was applied if cradles were to be reused during a single test day. Appropriate time intervals were recorded in the NSNFP Lab Notebook for cradles reused during a single day.

\subsubsection{Trip Hook Release Times}

The established timing interval for the $-20^{\circ} \mathrm{F}$ material impact testing (from freezer opening to release of drop hook) was 36 seconds for the D-2-2 specimens and 51 seconds for the D-4-4 test specimens. Temperature baseline test data can be found in the NSNFP Lab Notebook Binder Volume 4 for the $-20^{\circ} \mathrm{F}$ temperature testing efforts.

\subsubsection{Acceptability of Cold Test Specimen Temperatures at Impact}

Table 14 summarizes the actual measured starting temperature ranges achieved during the $-20{ }^{\circ} \mathrm{F}$ impact testing performed during 2007. These temperature ranges are based on temperature measurements from an instrumented test specimen that was placed inside the freezer during the entire testing sequence. This starting temperature range satisfies both the D-2-2 and the D-4-4 starting temperature range criteria established during temperature baseline testing. The room temperatures during actual impact tests ranged from 66 to $71^{\circ} \mathrm{F}$, very similar to the room temperatures experienced during baseline testing $\left(68\right.$ to $\left.71{ }^{\circ} \mathrm{F}\right)$. In fact, the room temperature during cold impact testing never exceeded the maximum baseline testing room temperature experienced and were within $2^{\circ} \mathrm{F}$ of the minimum room temperature experienced during baseline testing. Hence, the room temperature conditions during actual impact testing had no adverse effect on the timing intervals established for the cold test specimens.

Table 14. Initial temperature ranges for cold material impact testing.

\begin{tabular}{|c|c|}
\hline Test Specimen Geometry & $\begin{array}{c}\text { Initial Temperature } \\
\text { Range }\left({ }^{\mathbf{0}} \mathbf{F}\right)\end{array}$ \\
\hline D-2-2 or D-4-4 & -32.1 to $-33.4^{\circ} \mathrm{F}$ \\
\hline
\end{tabular}

Therefore, the actual temperatures achieved in the test specimens for cold impact testing were expected to have been within the ranges established during temperature baseline testing and shown in Table 13. These narrow temperature ranges were acceptable for impact testing. It is interesting to note that the warmest starting test specimen temperature recorded for impact testing was $-32.1{ }^{\circ} \mathrm{F}$ (compared to an allowable of $-31^{\circ} \mathrm{F}$ ) so the actual temperature ranges would have been even closer than the temperatures predicted in Table 13.

\subsection{Data Acquisition}

This section discusses in more detail the types of data recorded during the actual impact tests. Pre- and post-test dimensional measurements of the test specimens are addressed in Sections 6.2 and 6.7, respectively. 


\subsubsection{High-Speed Digital Camera}

Strain rates vary with time during accidental drops or crash events. Since the ITM reflects a true impact event, the strain rate starts out at a fairly constant value but then dissipates to zero as the impact energy of the dropped weight is transformed into permanent test specimen deformation.

A Photron Fastcam high-speed digital camera was used to record image data of the impact events. The camera was positioned to look directly at the specimen front surface. Displacement histories for test specimen geometry 'A' (A-4-4) punch marks A through D (see Figure 48) were recorded during a drop event. Punch mark $\mathrm{E}$ was not visible to the camera during any impact testing performed prior to cutting the slot into the test fixture's lower crossmember (see Section 6.1). For test specimen geometries A-2-2, D-2-2, and D-4-4 (all tested after November 21, 2005 with the slot already cut), the entire gauge length of the test specimen was visible to the camera. Imaging data were recorded at a frame rate of 3000 frames per second and a resolution of $512 \times 1024$ pixels for the initial strain rate testing performed in 2004. However, starting in early 2005 , the imaging data were recorded at 8000 frames per second at a resolution of $256 \times 1024$ pixels.

Motion analysis of the digital image data was used to determine displacement histories of the camera visible specimen punch marks. Displacement histories of camera visible punch marks on the test specimen were measured directly from the frame exposures. Engineering strain histories were developed from the recorded displacement histories and were converted to true strain histories using the relationship:

$$
\varepsilon_{\text {true }}=\ln \left(1+\varepsilon_{\text {engineering }}\right)
$$

For this strain rate research, the impact test strain rate was defined as that rate of straining occurring early in the specimen response stage where the strain rate is nearly constant with time. Figure 58 illustrates a typical strain history data plot used to determine strain rates. For the test shown, the slope was determined to be a line from the origin through a true strain data point of 0.1558 at time 0.006 seconds. This calculates to be a strain rate of $0.1558 / 0.006=26.0$ per second. Strain rate data were recorded on page 2 of the test data sheets (as shown in the Appendix D sample and contained in the NSNFP Lab Notebook Binder Volumes 2 and 3 for each impact test).

Imagery of the impact event from before impact to after specimen initial rebound was saved to a DVD, typically 1340 frames for each test. (These DVDs are part of the NSNFP Lab Notebook Binder Volume 5 and were submitted to the NSNFP as records.) The displacements of the camera visible punch marks were used to develop strain histories for the specimens by performing motion analysis of the recorded image files. Motion analysis data are contained in the NSNFP Lab Notebook Binder Volume 5 (eight books total). The camera frame rate was calibrated before and after testing to assure accuracy (see Report CD-R, file 3). Motion analysis results (strains) were also compared to test specimen final measured results (strains) to verify accuracy. The camera data were (on average for all 260 impact tests used to calculate factors) within $2.5 \%$ of the measured test specimen strains. This indicates that the strain rates derived from the camera data were accurately determined. Section 7.1 contains camera versus measured strain comparisons for every impact test considered herein. 


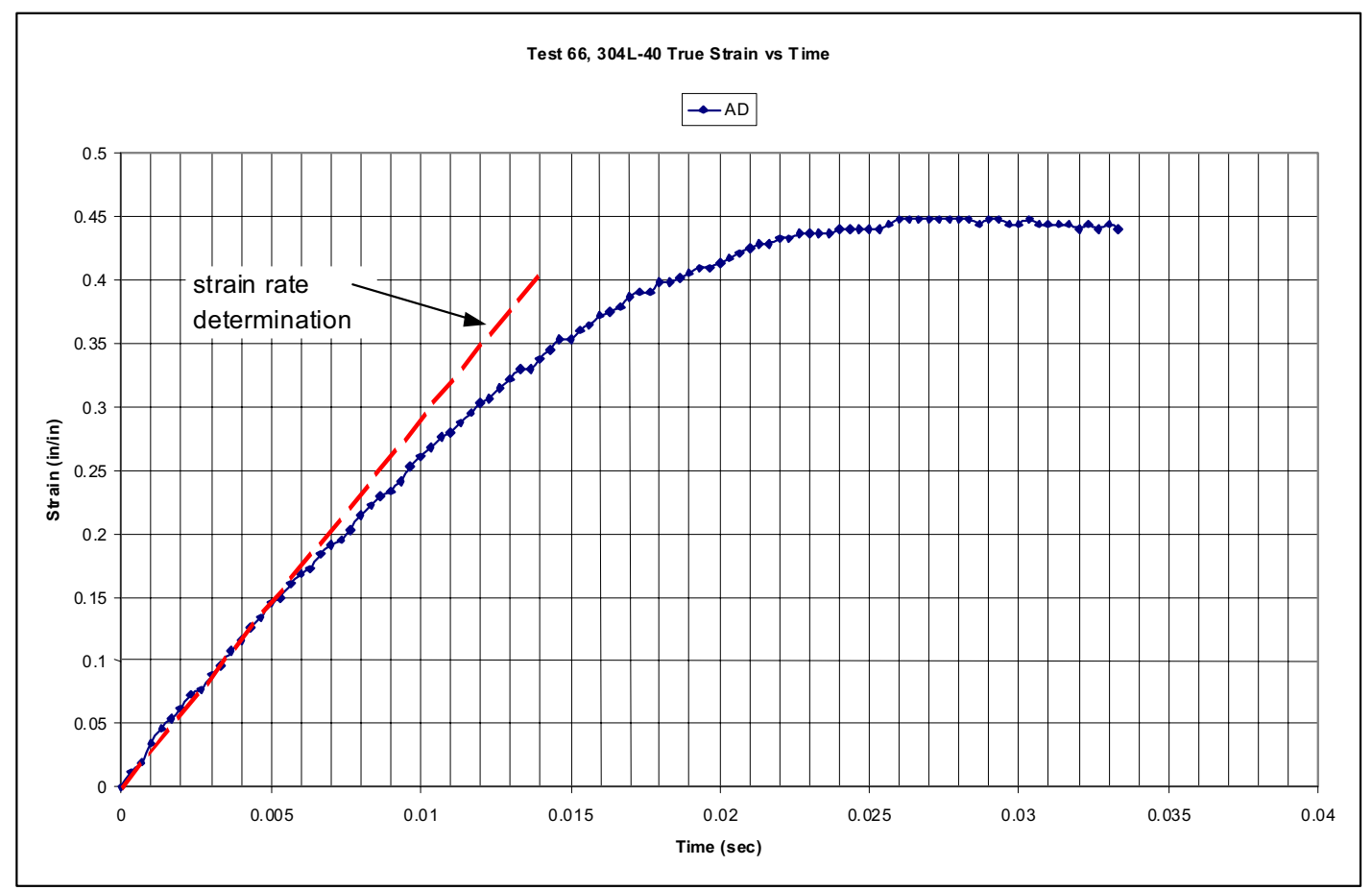

Figure 58. Camera determined true strain history for specimen 304L-40.

\subsubsection{Accelerometer and Velocimeter Data}

During an impact test, test specimen acceleration histories were measured using calibrated $500 \mathrm{~g}$ and $5000 \mathrm{~g}$ accelerometers mounted on the back side of the impact driver lower cross-member. Acceleration histories were recorded on a Data Acquisition System (DAQ) $2000 \mathrm{~A}$ at a rate of 5000 samples per second for 20 seconds. Acceleration data were recorded with the goal of having that additional impact data in case of future test specimen response questions. The raw acceleration data were filtered using a Butterworth bandpass filter. The frequency band used was $2 \mathrm{~Hz}-500 \mathrm{~Hz}$. Integration of this acceleration trace was also performed using DADiSP 2002. Both of these results were recorded on page 2 of the test data sheets for both the 304L and 316L test specimens, located in NSNFP Lab Notebook Binder Volumes 2 and 3 , respectively.

As previously mentioned in Section 6.3, drop weight velocities were initially measured by the attachment of a velocimeter (a device that could not be calibrated at the INL) to the lower end of the drop weight. Velocity histories were recorded on a Data Acquisition System (DAQ) 2000A at a rate of 5000 samples per second for 20 seconds. Prior to mid-June 2006, velocimeter data was recorded and these results can also be found in the NSNFP Lab Notebook Binder Volumes 2 and 3 for those tests where incorporated.

Accelerometer and velocimeter data were recorded as 'data of interest'. The data gathered by these devices supported observations made by the NSNFP test personnel and certain aspects of the camera data. However, they were not used in the development of the factors or the strain rate elevated true stress-strain curves. 


\subsection{Previous ITM Performance}

Having described the ITM, the test specimens, and the impact test methodology used, a brief review of the two locations where the ITM has been used for material impact testing is appropriate. Also discussed herein is the past testing of both longitudinal and transverse oriented test specimens, the results of which were used to establish how test specimens were to be cut from the plate material.

\subsubsection{Test Performance at Different Test Sites}

The initial placement of the ITM at the Material Test Reactor building (RTC-603) at the INL occurred on November 12, 2003. The MTR building had an overhead crane, more than 30 feet of overhead clearance above the ITM, and a robust floor (consisting of a 12-inch thick concrete slab poured over large concrete encased steel beams) with a load rating of 1250 pounds per square foot. Due to building demolition plans, the ITM was then moved to the INL's Critical Infrastructure Test Range Complex (CITRC) Building 613 in late April, 2005. This facility also has an overhead crane, more than 25 feet of overhead clearance above the ITM, and a 4.75-foot thick reinforced concrete floor situated on bedrock that has a posted allowable floor loading of $2500 \mathrm{lb} . / \mathrm{ft}^{2}$. Both locations have strong, rigid floors. However, it was decided to perform confirmatory testing of duplicate impact tests in order to determine if any noticeable change in test specimen response could be detected. Comparisons of these confirmatory impact tests appear in Table 15 below for 304L material and Table 16 below for 316L material. Some of the tests reported below are using different material heats and different test specimen geometries (all of the 304L tests excluding 69 and 172) from another research effort but the comparative insights are still valid.

Table 15. Comparison of 304L strain responses for impact tests performed at different locations.

\begin{tabular}{|c|c|c|c|c|c|}
\hline Test Number & Location & $\begin{array}{c}\text { Drop Weight } \\
\text { (lb.) }\end{array}$ & $\begin{array}{l}\text { Drop Height } \\
\text { (in.) }\end{array}$ & True Strain & $\begin{array}{c}\text { Variation } \\
(\%)\end{array}$ \\
\hline 69 & MTR & \multirow{2}{*}{1513} & \multirow{2}{*}{31} & 0.3242 & \multirow{2}{*}{2.56} \\
\hline 172 & 613 & & & 0.3161 & \\
\hline 91 & MTR & \multirow{2}{*}{1513} & \multirow{2}{*}{14} & 0.4116 & \multirow{2}{*}{2.57} \\
\hline 176 & 613 & & & 0.4013 & \\
\hline 96 & MTR & \multirow{2}{*}{1347} & \multirow{2}{*}{15.75} & 0.4146 & \multirow{2}{*}{9.45} \\
\hline 185 & 613 & & & 0.3788 & \\
\hline 100 & MTR & \multirow{2}{*}{1097} & \multirow{2}{*}{20} & 0.3949 & \multirow{2}{*}{0.92} \\
\hline 193 & 613 & & & 0.3913 & \\
\hline 104 & MTR & \multirow{2}{*}{790} & \multirow{2}{*}{25.375} & 0.3406 & \multirow{2}{*}{0.38} \\
\hline 198 & 613 & & & 0.3393 & \\
\hline & & & & Average & 3.18 \\
\hline
\end{tabular}


Table 16. Comparison of $316 \mathrm{~L}$ strain responses for impact tests performed at different locations.

\begin{tabular}{|c|c|c|c|c|c|}
\hline Test Number & Location & $\begin{array}{c}\text { Drop Weight } \\
\text { (lb.) }\end{array}$ & $\begin{array}{l}\text { Drop Height } \\
\text { (in.) }\end{array}$ & True Strain & $\begin{array}{c}\text { Variation } \\
\text { (\%) }\end{array}$ \\
\hline 24 & MTR & \multirow{2}{*}{1513} & \multirow{2}{*}{36} & 0.3878 & \multirow{2}{*}{2.05} \\
\hline 174 & 613 & & & 0.3959 & \\
\hline 75 & MTR & \multirow{2}{*}{1347} & \multirow{2}{*}{40} & 0.3843 & \multirow{2}{*}{2.19} \\
\hline 184 & 613 & & & 0.3929 & \\
\hline 28 & MTR & \multirow{2}{*}{1097} & \multirow{2}{*}{45} & 0.3493 & \multirow{2}{*}{0.85} \\
\hline 192 & 613 & & & 0.3523 & \\
\hline 49 & MTR & \multirow{2}{*}{790} & \multirow{2}{*}{50} & 0.2661 & \multirow{2}{*}{0.22} \\
\hline 197 & 613 & & & 0.2667 & \\
\hline & & & & Average & 1.33 \\
\hline
\end{tabular}

As can be seen from Tables 15 and 16, the comparisons of identical impact tests at different facilities are extremely close. Even including one set of 304L tests that were within $9.45 \%$ (evidencing material variability), the average variations are very low. Therefore, material impact tests performed at either location can be combined together since the ITM responses are deemed to be facility independent.

\subsubsection{Longitudinal Versus Transverse Specimen Orientation}

One of the initial goals of the material impact testing was to compare impact responses of test specimens that were fabricated reflecting longitudinal (parallel to plate rolling) and transverse (perpendicular to plate rolling) orientations. The first effort was to perform "quasistatic" tensile testing which was previously described in Section 5.0. Both 304L (Heat \#10W8) and 316L (Heat \#09T9) material were tested. The testing consisted of three specimens from each orientation for both materials, resulting in twelve total tests. Table 17 contains the tensile material property results of that testing.

Table 17. Longitudinal and transverse quasi-static tensile test results.

\begin{tabular}{|c|c|c|c|c|c|c|}
\hline Test ID & $\begin{array}{c}\text { Specimen } \\
\text { ID }\end{array}$ & Material & $\begin{array}{c}\text { Heat } \\
\text { Number }\end{array}$ & Orientation & $\begin{array}{c}\text { Elongation } \\
(\%)\end{array}$ & $\begin{array}{c}\text { Ultimate } \\
\text { Load (lb.) }\end{array}$ \\
\hline 03 & MT03 & 304L & $10 \mathrm{~W} 8$ & Longitudinal & 63 & 22,100 \\
\hline 04 & MT04 & 304L & $10 \mathrm{~W} 8$ & Longitudinal & 64.5 & 22,200 \\
\hline 23 & MT23 & 304L & $10 \mathrm{~W} 8$ & Longitudinal & 62 & 22,000 \\
\hline 05 & MT05 & $304 \mathrm{~L}$ & $10 \mathrm{~W} 8$ & Transverse & 62.5 & 22,000 \\
\hline 06 & MT06 & 304L & $10 \mathrm{~W} 8$ & Transverse & 63 & 22,200 \\
\hline 24 & MT24 & 304L & $10 \mathrm{~W} 8$ & Transverse & 59 & 21,800 \\
\hline \hline 11 & MT11 & 316L & 09T9 & Longitudinal & 61 & 20,500 \\
\hline 12 & MT12 & 316L & 09T9 & Longitudinal & 61 & 20,500 \\
\hline 21 & MT21 & 316L & 09T9 & Longitudinal & 59 & 20,400 \\
\hline 09 & MT09 & 316L & 09T9 & Transverse & 58 & 20,700 \\
\hline 10 & MT10 & 316L & 09T9 & Transverse & 60.5 & 20,700 \\
\hline 22 & MT22 & 316L & 09T9 & Transverse & 58 & 20,500 \\
\hline
\end{tabular}


As can be seen, the ultimate load and the elongation results indicate very little difference between the longitudinal and the transverse-oriented test specimens for each material.

The next step was to perform impact tests, using the same material as indicated above. Identical test weights and drop heights were used during the actual impact tests, using both the longitudinal and the transverse-oriented test specimens described in Section 6.2. For 304L, the longitudinal specimens were color coded red and the transverse specimens were color coded light yellow. For 316L, the longitudinal specimens were color coded black and the transverse specimens were color coded white. Drop weights and drop heights were chosen to maximize test specimen strains, purposely challenging floor flexibility in order to maximize any potential facility difference. The results of that comparative testing are summarized in Table 18. The results show that the variations between longitudinally-oriented test specimens and transverseoriented test specimens are insignificant, less than a 3\% variation on average. This is well within the range of material property variations previously discussed. Therefore, based on these comparative results of both quasi-static and impact tensile testing, the decision was made to proceed with material impact testing at varying temperatures with longitudinally oriented test specimens only.

\subsection{Post-Test Dimensional Measurements}

Post-test dimensional measurements were needed to determine the deformation changes so that achieved strains could be calculated for each impact tested specimen.

\subsubsection{Test Specimen Deformations}

After impact testing, appropriate test specimen deformation measurements were taken by NSNFP test personnel. These measurements included the deformed lengths between the punch marks as well as the reduced widths and thicknesses at the same punch locations measured during pre-test measurements. This characterized the post-impact geometry of each test specimen. These measurements were recorded on page 1 of the test data sheet for pre- and postimpact deformation measurements (as representatively shown in Appendix D and contained in the NSNFP Lab Notebook Binder Volumes 2 and 3). With this post-test dimensional data, strains could be calculated and recorded on page 2 of the test data sheet along with the acceleration and velocity traces previously discussed in Section 6.5.2.

After impact testing, the welded material test specimens exhibited the 'orange peel' effect, as did the quasi-static tensile test specimens (see Section 5.5.2). Figure 59 illustrates a welded material test specimen before impact testing (left) and a welded material test specimen after impact testing (right). The rough surface (due to the straining of the irregular grain structure resulting from welding) made post-test width and thickness measurements more difficult to achieve. 
Table 18. Comparison of deformation responses of longitudinal and transverse-oriented test specimens for varying impact tests.

\begin{tabular}{|c|c|c|c|c|c|c|c|c|c|c|c|c|}
\hline $\begin{array}{c}\text { Weight } \\
\text { (lb.) }\end{array}$ & $\begin{array}{c}\text { Drop } \\
\text { Height } \\
\text { (in.) }\end{array}$ & $\begin{array}{l}\text { Test } \\
\text { ID }\end{array}$ & $\begin{array}{l}\text { Specimen } \\
\text { ID }\end{array}$ & Direction & $\begin{array}{c}\text { Gauge } \\
\text { Delta } \\
\text { (in.) }\end{array}$ & $\begin{array}{c}\text { Avg. } \\
\text { Delta } \\
\text { (in.) }\end{array}$ & $\begin{array}{c}\text { Test } \\
\text { ID }\end{array}$ & $\begin{array}{c}\text { Specimen } \\
\text { ID }\end{array}$ & Direction & $\begin{array}{c}\text { Gauge } \\
\text { Delta } \\
\text { (in.) }\end{array}$ & $\begin{array}{c}\text { Avg. } \\
\text { Delta } \\
\text { (in.) }\end{array}$ & $\begin{array}{c}\text { Delta } \\
\text { Ratio } \\
(\%)\end{array}$ \\
\hline \multicolumn{13}{|c|}{ 304L Material } \\
\hline 1513 & 31 & 69 & $304 \mathrm{~L}-43$ & longitudinal & 1.7260 & \multirow{2}{*}{1.7010} & 145 & $304 \mathrm{~L}-111$ & transverse & 1.7220 & \multirow{2}{*}{1.7153} & \multirow{2}{*}{0.992} \\
\hline 1513 & 31 & 172 & $304 \mathrm{~L}-126$ & longitudinal & 1.6760 & & 146 & $304 \mathrm{~L}-112$ & transverse & 1.7085 & & \\
\hline 1347 & 38 & 66 & $304 \mathrm{~L}-40$ & longitudinal & 1.8490 & \multirow{2}{*}{1.8090} & 149 & $304 \mathrm{~L}-113$ & transverse & 1.7795 & \multirow{2}{*}{1.7975} & \multirow{2}{*}{0.994} \\
\hline 1347 & 38 & 167 & $304 \mathrm{~L}-125$ & longitudinal & 1.7690 & & 150 & $304 \mathrm{~L}-114$ & transverse & 1.8155 & & \\
\hline 1097 & 43 & 65 & 304L-39 & longitudinal & 1.6085 & \multirow{2}{*}{1.6055} & 153 & $304 \mathrm{~L}-115$ & transverse & 1.5500 & \multirow{2}{*}{1.5593} & \multirow{2}{*}{0.971} \\
\hline 1097 & 43 & 165 & $304 \mathrm{~L}-124$ & longitudinal & 1.6025 & & 154 & $304 \mathrm{~L}-116$ & transverse & 1.5685 & & \\
\hline 790 & 43 & 58 & $304 \mathrm{~L}-32$ & longitudinal & 1.1025 & \multirow{2}{*}{1.0948} & 157 & $304 \mathrm{~L}-117$ & transverse & 1.0980 & \multirow{2}{*}{1.0990} & \multirow{2}{*}{0.996} \\
\hline 790 & 43 & 162 & $304 \mathrm{~L}-123$ & longitudinal & 1.0870 & & 158 & $304 \mathrm{~L}-118$ & transverse & 1.1000 & & \\
\hline & & & & & & & & & & & Avg. & 0.988 \\
\hline \multicolumn{13}{|c|}{ 316L Material } \\
\hline 1513 & 36 & 24 & $316 \mathrm{~L}-8$ & longitudinal & 2.1325 & \multirow{3}{*}{2.1325} & 147 & $316 \mathrm{~L}-35$ & transverse & 2.2090 & \multirow{3}{*}{2.1473} & \multirow{3}{*}{0.993} \\
\hline 1513 & 36 & 173 & $316 \mathrm{~L}-52$ & longitudinal & Necked & & 148 & $316 \mathrm{~L}-36$ & transverse & 2.1070 & & \\
\hline 1513 & 36 & 174 & $316 \mathrm{~L}-53$ & longitudinal & Necked & & 175 & $316 \mathrm{~L}-46$ & transverse & 2.1260 & & \\
\hline 1347 & 40 & 25 & $316 \mathrm{~L}-9$ & longitudinal & 2.0725 & \multirow{4}{*}{2.1155} & 151 & $316 \mathrm{~L}-37$ & transverse & 2.0140 & \multirow{4}{*}{2.0740} & \multirow{4}{*}{0.980} \\
\hline 1347 & 40 & 166 & $316 \mathrm{~L}-49$ & longitudinal & Broke & & 152 & $316 \mathrm{~L}-38$ & transverse & 2.1290 & & \\
\hline 1347 & 40 & 184 & $316 \mathrm{~L}-54$ & longitudinal & 2.1630 & & 168 & $316 \mathrm{~L}-44$ & transverse & 2.0790 & & \\
\hline 1347 & 40 & 75 & $316 \mathrm{~L}-28$ & longitudinal & 2.1110 & & - & - & - & - & & \\
\hline 1097 & 45 & 28 & $316 \mathrm{~L}-12$ & longitudinal & 1.8795 & \multirow{4}{*}{1.8824} & 155 & 316L-39 & transverse & 1.8030 & \multirow{4}{*}{1.8050} & \multirow{4}{*}{0.959} \\
\hline 1097 & 45 & 164 & $316 \mathrm{~L}-48$ & longitudinal & 1.8735 & & 156 & $316 \mathrm{~L}-40$ & transverse & 1.8265 & & \\
\hline 1097 & 45 & 192 & $316 \mathrm{~L}-55$ & longitudinal & 1.8960 & & 163 & $316 L-43$ & transverse & 1.7855 & & \\
\hline 1097 & 45 & 29 & 316L-13 & longitudinal & 1.8805 & & - & - & - & - & & \\
\hline 790 & 50 & 49 & $316 \mathrm{~L}-23$ & longitudinal & 1.3720 & \multirow{3}{*}{1.3910} & 159 & 316L-41 & transverse & 1.3815 & \multirow{3}{*}{1.3547} & \multirow{3}{*}{0.974} \\
\hline 790 & 50 & 161 & $316 \mathrm{~L}-47$ & longitudinal & 1.4255 & & 160 & $316 \mathrm{~L}-42$ & transverse & 1.3650 & & \\
\hline 790 & 50 & 197 & $316 \mathrm{~L}-56$ & longitudinal & 1.3755 & & 199 & $316 \mathrm{~L}-57$ & transverse & 1.3175 & & \\
\hline \multirow[t]{2}{*}{1347} & 34 & 169 & $316 \mathrm{~L}-50$ & longitudinal & 1.7625 & 1.7625 & 171 & 316L-45 & transverse & 1.7955 & 1.7925 & 0.981 \\
\hline & & & & & & & & & & & Avg. & 0.978 \\
\hline
\end{tabular}




\subsubsection{Certified Dimensional Inspector Validations}

The NSNFP test personnel measured the post-test impact test specimens. As a means of checking the post-test measurements and to add validity to all dimensional measurements performed by NSNFP test personnel, an INL qualified dimensional inspector also measured the deformed test specimens. Page 3 of the test specimen data sheets contains the results of those independent measurements. NSNFP Lab Notebook Binder Volumes 2 and 3 contain the test data sheets and these confirmatory measurements. All dimensions measured by the INL dimensional inspector validated the NSNFP test personnel measurements. None of the post-test measurements differed by more than $0.75 \%$ (INL compared to NSNFP test personnel). Appendix F contains qualification documentation for the INL dimensional inspector.

The INL qualified dimensional inspector also measured the go/no go gages periodically or on an as-needed basis when newer devices completed fabrication and needed to be verified before use. This activity was previously discussed in Section 6.2.1. Documentation of the measurements made by the INL qualified dimensional inspector on the go/no go gages is contained in the NSNFP Lab Notebook Binder Volume 1.

\subsection{Closeout Calibration}

Calibrated measuring and test equipment were used for measuring all quality-affecting data. In order to demonstrate the calibration history of the measuring and test equipment used, the Report CD-R (file 3) contains the INL Calibration and Standards Laboratory calibration sheets for all of the devices used for the time intervals when the device was used for this strain rate research effort. The applicable measuring and test equipment used in this strain rate research effort also received a closeout calibration. The closeout calibration indicated all measuring and test equipment were acceptable.

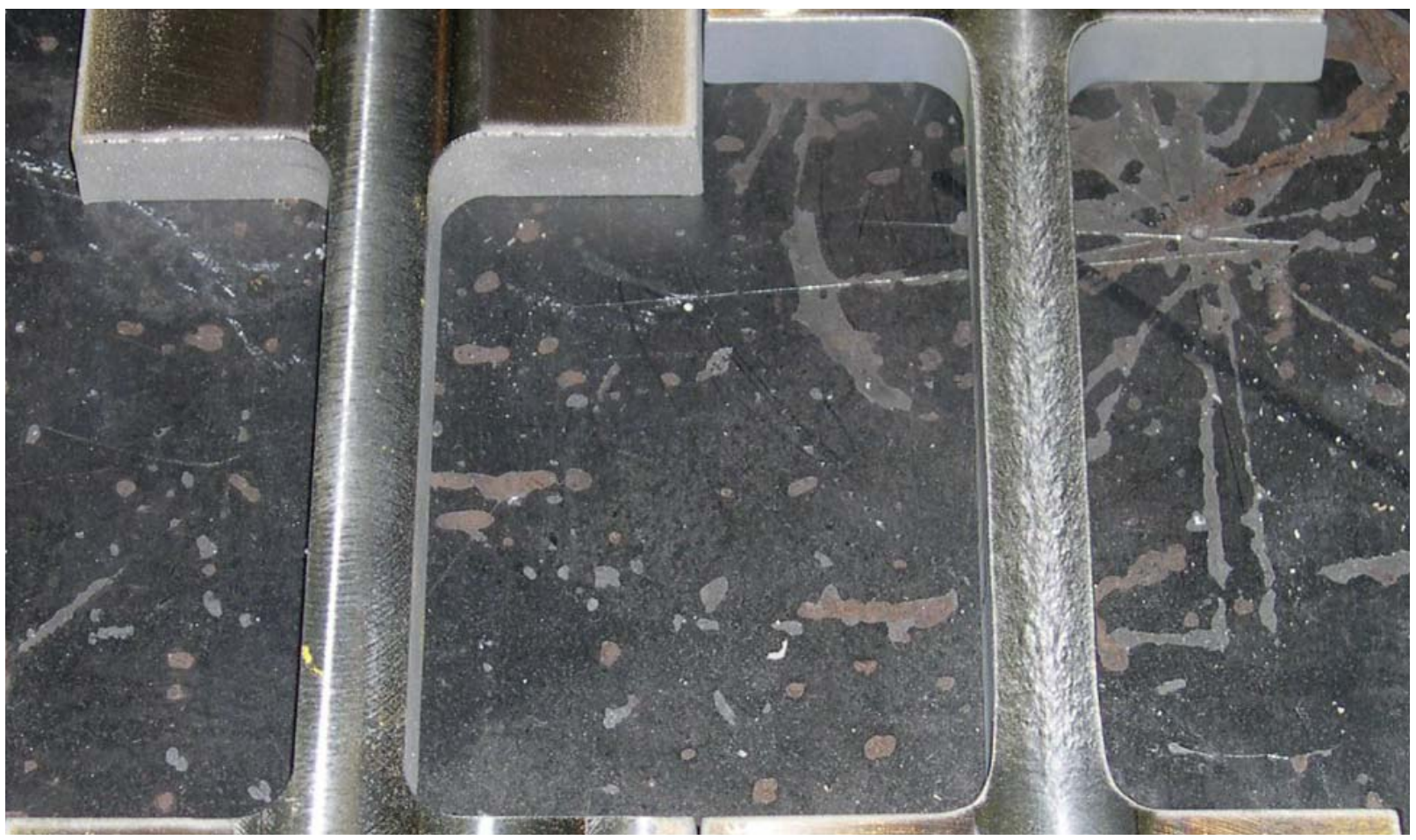

Figure 59. 'Orange peel' effect in welded material impact test specimen (right). 


\section{TEST RESULTS: DEVELOPMENT OF FACTORS AND STRAIN RATE ELEVATED TRUE STRESS-STRAIN CURVES}

The data needed to justify the definition of material responses considering strain rate effects were obtained using the ITM. By using a combination of different weights and different drop heights, varying strain levels and strain rates were achieved. The energy input in straining the test specimen was known from the input test variables of mass (drop weight and impact driver) and impact velocity (of drop weight). The total test energy also included the work done elongating the test specimen. At a given test temperature, specimen displacement histories were measured. These test inputs and outputs are used to determine test specimen strain, rate of straining, and a 'factor' (derived from the test energy) that can be applied to the appropriate quasi-static true stress-strain curve to generate a corresponding strain rate elevated true stressstrain curve.

A brief literature search (References 40 and 41) indicated that the shape of strain rate elevated true stress-strain curves for stainless steels relative to the quasi-static shape are similar. Two potential options that preserve this curve shape are (1) shifting the curve upward (the addition of a constant to each point) or (2) factoring (multiplication of each stress point by a constant). Both techniques utilize the established shape of the quasi-static curve as determined from tensile tests as the starting point. Since the literature was inconsistent as to a specific shape of strain rate elevated curves, variations in curve shape were initially addressed by evaluating both a factored and a shifted technique (Reference 42). These early evaluation efforts (up to the uniform strain limit) indicated less than a 3\% difference between the two techniques. The 'factored' approach was the simplest for structural analysts to apply since the area under the quasi-static stress-strain curve did not have to be determined as it would be if using the shifted approach. One only need to multiply the stress values by the strain rate factor to attain the strainrate elevated stress-strain curve. Therefore, the 'factored' approach was adopted for this study.

\subsection{Development of Factors}

Each unique dynamic impact test performed results in a strain rate 'factor' corresponding to the particular test material, heat, specimen geometry, temperature, and strain rate achieved in the test. By performing a sufficient number of impact tests using various weights dropped from a variety of heights, a plot of the strain rate factor versus strain rate can be generated for a particular type of material, heat, and temperature.

A total impact energy approach was used that considers the test specimen strain energy. Strain energy is the energy required to strain (deform) a volume of material a specified amount. It is equivalent to the area under the stress-strain curve up to a specified strain level. Remember that the goal of the ITM testing was to limit strains to below the uniform strain limit. For this approach, the quasi-static true stress-strain curve is determined and the area under that curve up to the strain level of interest is evaluated. The strain level of interest is that strain achieved in an actual impact test specimen at a given strain rate. It is acknowledged that energy loses may exist in the transfer of energy from the drop weight to the specimen. However, loses are believed small. Knowing the energy input to the specimen during the impact test and assuming the shape for the strain rate elevated true stress-strain curve being generated, the corresponding true stress 
value can be established by bounding the input energy density (area under the stress-strain curve) to the value of true strain achieved in the impact test.

The energy input to the specimen is determined by applying conservation of momentum theory to the total impact energy assuming an inelastic impact. The total impact energy applied to specimen deformation is calculated as follows:

$$
\mathrm{E}_{\text {total }}=1 / 2 m v^{2}+w \Delta
$$

where: $\quad 1 / 2 m v^{2}$ is the kinetic energy of the combined mass (drop weight +impact driver) and $w \Delta \quad$ is the potential energy due to deformation of the specimen.

$$
\begin{array}{ll}
m= & \text { mass }=m_{\text {drop weight }}+m_{\text {impact driver }} \\
w= & \text { weight }=w_{\text {drop weight }}+w_{\text {impact driver }} \\
\Delta= & \text { elongation of test specimen } \\
v= & \text { velocity of the combined mass (drop weight }+ \text { impact driver }) \\
v= & \left(m_{\text {drop weight }}\right)\left(v_{\text {impact }}\right) / m \text { (conservation of momentum) } \\
v_{\text {impact }} & \text { impact velocity of the drop weight } \\
& =\sqrt{2 \mathrm{gh}} \quad \text { where } \mathrm{g} \text { is the acceleration of gravity and } \mathrm{h} \text { is the drop height }
\end{array}
$$

The total impact energy approach assumes that the area under the strain rate elevated true stress-strain curve (up to the strain value achieved in the test specimen) equals the total impact energy per material volume used to dynamically strain the test specimen during the ITM impact test. The units for total impact energy are in.-lb. The area under a material stress-strain curve has the units of psi (stress) per in./in. (strain), or in.-lb. per cubic inch, or strain energy density. The area under the strain rate elevated true stress-strain curve up to the magnitude of the overall average strain achieved in the test specimen is determined by dividing the total impact energy $\left(\mathrm{E}_{\text {total }}\right)$ by the material volume absorbing the impact energy (volume of test specimen material strained).

The volume of material strained during the dynamic impact test was the specimen gauge length volume plus a portion of the transition region volume. Because all strain energy density needed to be addressed, it was also necessary to determine the distribution of strain in the test specimen transition regions. Strains would not be expected to be uniform or of a magnitude equal to the overall average strain in the gauge length. They would likely vary from the overall average strain value at the gauge end of the transition to near zero at the large end of the transition region. The transition region strain distribution and material volumes were determined using dynamic simulations of the ITM impact tests in the computer program ABAQUS/Explicit. Finite element models of the test specimens used and the associated ITM impact driver mass were generated. Test specimen material properties were based on the quasi-static true stress strain curves developed for each particular material and heat. The resulting transition region strain distribution and material volume results from these computer simulations were incorporated into the procedure for determining test specimen strain energy densities and strain rate factors (see Report CD-R, file 2B).

The actual process of determining the factor values involves an iterative integration of the true stress-strain curves. At a given magnitude of overall average strain, the applicable (material, 
heat and temperature dependent) quasi-static true stress strain curve must be elevated such that the strain energy density represented by the area under the resulting curve matches the energy density from the impact test (input energy and volume of material strained). In this process the magnitude of overall average strain being used must match the magnitude achieved in the impact test. The factor is then determined as the ratio of the area under the elevated curve to that under the quasi-static curve both determined up to the same magnitude of the overall average strain. The corresponding strain rate is that resulting directly from the impact test being evaluated.

This process was accomplished using the computer program DADiSP. Knowing the quasi-static stress-strain curve shape and the area required under the curve at a given strain level, the factor value can be 'estimated', the resulting stress-strain curve plotted and integrated to see if the area matches that required. An improved estimate is made of the factor value, if necessary, and the process iterates to a final, acceptable value.

\subsubsection{Development of Spreadsheets}

In practice, a 'reverse' process was employed for quickly determining the factor for a given set of three impact test parameters: (1) the total impact energy $\left(E_{\text {total }}\right),(2)$ the overall average strain achieved (OAS), and (3) the gauge volume $(\mathrm{GV})$. The total energy $\left(\mathrm{E}_{\text {total }}\right)$ is defined above in Section 7.1. The overall average strain (OAS) is the average true strain through the gauge length resulting from the impact test and is determined from the measured data recorded on the specimen data sheets following the test. The gauge volume $(\mathrm{GV})$ is the volume of material within the gauge length strained as a result of the impact test and is also determined from the test specimen measured and recorded data. These three impact test parameters are presented in Tables 19 through 22 for the 304L impact tests at the temperatures considered and Tables 23 through 26 for the 316L impact tests at the temperatures considered. In these tables, the 'True Strain' column is OAS, the 'Total Energy' column is $\mathrm{E}_{\text {total, }}$ and the 'Test Specimen Volume' column is GV.

Rather than directly calculating the factor for each unique set of test parameters using the iterative integration approach (a time consuming effort), a series of worksheets and spreadsheets were developed for a broad range of specified factors and overall average strains that bounded those expected from the actual impact testing. The iterative integration approach was performed only once for each set of unique material properties. This 'pre-solving' approach saved time. Using this set of worksheets and spreadsheets and a given set of three impact test parameters, the corresponding factor could be quickly 'interpolated' from the bounding results. A discussion of the development of the worksheets and spreadsheets is presented in the following paragraphs.

For a given material type (304L or 316L), heat (base and welded material), and temperature, a series of factored true stress-strain curves is generated using the appropriate digitized quasi-static true stress-strain curve and a range of bounding factors and overall average strains. For this work, factors ranged from 1.0 to 2.0 in six increments and overall average strain values ranged from 0.01 to 0.45 in nine increments. A DADiSP worksheet was employed for this effort. The quasi-static true stress-strain curve is first factored. The area under the resulting true stress-strain curve up to the limit of each overall average strain value is determined for each factor. The resulting set of values $(6 \times 9=54)$ of 'area under the curve' (units of in.-lb./in. ${ }^{3}$ ) and corresponding true overall average strain values are input to a Material Curve Excel spreadsheet 
(see upper left hand corner of Figure 60). The DADiSP worksheets used for the work performed in this report are contained on the Report CD-R (file 2A).

Table 19. Selected impact test parameters and factors for $304 \mathrm{~L}$ at $-20^{\circ} \mathrm{F}$ conditions.

\begin{tabular}{|c|c|c|c|c|c|c|c|c|c|}
\hline $\begin{array}{l}\text { Test } \\
\text { ID }\end{array}$ & $\begin{array}{c}\text { Test } \\
\text { Specimen } \\
\text { Geometry }\end{array}$ & $\begin{array}{c}\% \\
\text { Diff. }\end{array}$ & $\begin{array}{c}\text { True } \\
\text { Strain } \\
\text { Rate } \\
\left(\text { sec. }^{-1}\right)\end{array}$ & $\begin{array}{c}\text { True } \\
\text { Strain }\end{array}$ & $\begin{array}{c}\text { Test } \\
\text { Specimen } \\
\text { Identifier }\end{array}$ & $\begin{array}{c}\text { Material } \\
\text { Heat } \\
\text { Number }\end{array}$ & $\begin{array}{c}\text { Total } \\
\text { Energy } \\
\text { (in.-lb.) }\end{array}$ & $\begin{array}{c}\text { Test } \\
\text { Specimen } \\
\text { Volume } \\
{\text { (in. }{ }^{3} \text { ) }}^{\text {ald }}\end{array}$ & Factor \\
\hline 432 & D-2-2 & -0.5 & 8.9 & 0.1168 & $304 \mathrm{~L}-261$ & $64 \mathrm{~A} 1$ & 2273 & 0.1887 & 1.436 \\
\hline 434 & D-2-2 & -3.2 & 11.4 & 0.2377 & $304 \mathrm{~L}-262$ & $64 \mathrm{~A} 1$ & 5066 & 0.1875 & 1.214 \\
\hline 445 & D-2-2 & -0.9 & 7.5 & 0.1190 & $304 \mathrm{~L}-289$ & $64 \mathrm{~A} 1$ & 2327 & 0.1878 & 1.443 \\
\hline 436 & D-2-2 & -2.5 & 5.5 & 0.0813 & $304 \mathrm{~L}-263$ & $64 \mathrm{~A} 1$ & 1466 & 0.1872 & 1.447 \\
\hline 453 & D-2-2 & -4.1 & 5.4 & 0.0613 & $304 \mathrm{~L}-292$ & $64 \mathrm{~A} 1$ & 1179 & 0.1893 & 1.582 \\
\hline 455 & D-2-2 & -5.4 & 11.3 & 0.1784 & $304 L-293$ & 64A1 & 3559 & 0.1878 & 1.285 \\
\hline 449 & D-2-2 & -3.8 & 13.4 & 0.2286 & $304 \mathrm{~L}-264$ & 64A1 & 4963 & 0.1860 & 1.269 \\
\hline 489 & D-2-2 & -2.6 & 15.4 & 0.2648 & $304 \mathrm{~L}-311$ & $64 \mathrm{~A} 1$ & 5962 & 0.1851 & 1.231 \\
\hline 438 & D-4-4 & -2.9 & 23.7 & 0.1496 & $304 \mathrm{~L}-235$ & $72 \mathrm{~K} 9$ & 14793 & 0.7599 & 1.556 \\
\hline 442 & D-4-4 & -3.9 & 29.5 & 0.2019 & $304 \mathrm{~L}-288$ & $72 \mathrm{~K} 9$ & 22294 & 0.7545 & 1.537 \\
\hline 443 & D-4-4 & -1.6 & 28.4 & 0.3209 & $304 \mathrm{~L}-290$ & $72 \mathrm{~K} 9$ & 36872 & 0.7584 & 1.252 \\
\hline 457 & D-4-4 & -4.7 & 19.9 & 0.1596 & $304 \mathrm{~L}-294$ & $72 \mathrm{~K} 9$ & 17024 & 0.7635 & 1.627 \\
\hline 459 & D-4-4 & -0.9 & 28.9 & 0.2677 & $304 \mathrm{~L}-295$ & $72 \mathrm{~K} 9$ & 29456 & 0.7638 & 1.316 \\
\hline 477 & D-4-4 & -3.4 & 19.4 & 0.1203 & $304 \mathrm{~L}-296$ & $72 \mathrm{~K} 9$ & 12643 & 0.7593 & 1.794 \\
\hline 496 & D-4-4 & -2.5 & 35.7 & 0.3166 & $304 \mathrm{~L}-298$ & $72 \mathrm{~K} 9$ & 37656 & 0.7569 & 1.308 \\
\hline 451 & D-2-2 & -1.5 & 9.7 & 0.1474 & $304 \mathrm{~L}-291$ & 485896 & 2951 & 0.1872 & 1.293 \\
\hline 462 & D-2-2 & -5.1 & 10.0 & 0.1860 & $304 L-303$ & 485896 & 4073 & 0.1911 & 1.268 \\
\hline 466 & D-2-2 & -4.2 & 10.9 & 0.1265 & $304 \mathrm{~L}-304$ & 485896 & 2467 & 0.1914 & 1.297 \\
\hline 470 & D-2-2 & -1.5 & 15.3 & 0.2590 & $304 \mathrm{~L}-305$ & 485896 & 5931 & 0.1803 & 1.202 \\
\hline 485 & D-2-2 W & -3.4 & 10.8 & 0.1243 & $304 L-308$ & 485896 & 2457 & 0.1896 & 1.437 \\
\hline 490 & D-2-2 W & -3.6 & 10.5 & 0.1451 & $304 L-309$ & 485896 & 2940 & 0.1911 & 1.404 \\
\hline 464 & D-4-4 & -3.2 & 23.1 & 0.1825 & $304 \mathrm{~L}-300$ & $54 \mathrm{M} 7$ & 17128 & 0.7545 & 1.422 \\
\hline 468 & D-4-4 & -4.7 & 22.6 & 0.1472 & $304 \mathrm{~L}-301$ & $54 \mathrm{M} 7$ & 13193 & 0.7620 & 1.469 \\
\hline 481 & D-4-4 & -6.5 & 23.5 & 0.1209 & $304 \mathrm{~L}-312$ & $54 \mathrm{M} 7$ & 11481 & 0.7698 & 1.652 \\
\hline 487 & D-4-4 W & -2.3 & 20.8 & 0.1220 & $304 \mathrm{~L}-284$ & $54 \mathrm{M} 7$ & 13109 & 0.7602 & 1.518 \\
\hline 491 & D-4-4 W & -1.4 & 22.5 & 0.1556 & $304 \mathrm{~L}-285$ & $54 \mathrm{M} 7$ & 17005 & 0.7521 & 1.477 \\
\hline
\end{tabular}


Table 20. Selected impact test parameters and factors for 304L at room temperature conditions.

\begin{tabular}{|c|c|c|c|c|c|c|c|c|c|}
\hline $\begin{array}{l}\text { Test } \\
\text { ID }\end{array}$ & $\begin{array}{l}\text { Test } \\
\text { Specimen } \\
\text { Geometry }\end{array}$ & $\begin{array}{c}\% \\
\text { Diff. }\end{array}$ & $\begin{array}{c}\text { True } \\
\text { Strain } \\
\text { Rate } \\
\left(\text { sec. }^{-1}\right)\end{array}$ & $\begin{array}{c}\text { True } \\
\text { Strain }\end{array}$ & $\begin{array}{c}\text { Test } \\
\text { Specimen } \\
\text { Identifier }\end{array}$ & $\begin{array}{c}\text { Material } \\
\text { Heat } \\
\text { Number }\end{array}$ & $\begin{array}{c}\text { Total } \\
\text { Energy } \\
\text { (in.-lb.) }\end{array}$ & $\begin{array}{c}\text { Test } \\
\text { Specimen } \\
\text { Volume } \\
{\text { (in. }{ }^{3} \text { ) }}^{\text {and }}\end{array}$ & Factor \\
\hline 63 & A & 2.0 & 21.8 & 0.2536 & 304L-37 & $10 \mathrm{~W} 8$ & 32448 & 1.1399 & 1.343 \\
\hline 64 & $\mathrm{~A}$ & 0.7 & 22.8 & 0.2753 & $304 \mathrm{~L}-38$ & $10 \mathrm{~W} 8$ & 37278 & 1.1457 & 1.376 \\
\hline 65 & $\mathrm{~A}$ & -6.1 & 24.9 & 0.3054 & $304 \mathrm{~L}-39$ & $10 \mathrm{~W} 8$ & 42171 & 1.1615 & 1.335 \\
\hline 66 & A & -5.9 & 26.0 & 0.3438 & $304 \mathrm{~L}-40$ & $10 \mathrm{~W} 8$ & 47602 & 1.1556 & 1.287 \\
\hline 69 & A & -9.4 & 25.2 & 0.3242 & $304 \mathrm{~L}-43$ & $10 \mathrm{~W} 8$ & 44528 & 1.1556 & 1.305 \\
\hline 134 & A & -3.1 & 24.3 & 0.3971 & $304 \mathrm{~L}-48$ & 10W8 & 57402 & 1.1412 & 1.284 \\
\hline 135 & A & -1.7 & 26.4 & 0.4138 & 304L-105 & 10W8 & 60274 & 1.1547 & 1.257 \\
\hline 136 & A & 1.1 & 27.5 & 0.4282 & $304 \mathrm{~L}-106$ & 10W8 & 63128 & 1.1511 & 1.257 \\
\hline 165 & A & -3.6 & 25.8 & 0.3051 & $304 \mathrm{~L}-124$ & 10W8 & 42163 & 1.1543 & 1.345 \\
\hline 167 & A & -4.3 & 25.9 & 0.3305 & $304 \mathrm{~L}-125$ & $10 \mathrm{~W} 8$ & 47479 & 1.1520 & 1.360 \\
\hline 172 & A & -2.3 & 24.9 & 0.3161 & $304 \mathrm{~L}-126$ & $10 \mathrm{~W} 8$ & 44442 & 1.1331 & 1.375 \\
\hline 250 & A-2-2 & -2.3 & 5.9 & 0.1191 & $304 \mathrm{~L}-180$ & 64A1 & 3023 & 0.2858 & 1.307 \\
\hline 253 & A-2-2 & 2.7 & 5.9 & 0.1501 & $304 \mathrm{~L}-181$ & 64A1 & 3928 & 0.2849 & 1.275 \\
\hline 247 & D-2-2 & -2.5 & 12.8 & 0.2439 & 304L-183 & 64A1 & 4805 & 0.1920 & 1.219 \\
\hline 249 & D-2-2 & -0.4 & 13.3 & 0.2841 & 304L-184 & 64A1 & 5830 & 0.1926 & 1.200 \\
\hline 252 & D-2-2 & -2.0 & 11.2 & 0.2797 & $304 \mathrm{~L}-185$ & 64A1 & 5678 & 0.1911 & 1.203 \\
\hline 259 & D-2-2 & 0.0 & 10.6 & 0.1908 & 304L-189 & 64A1 & 3616 & 0.1911 & 1.274 \\
\hline 262 & D-2-2 & -3.8 & 10.6 & 0.2236 & $304 \mathrm{~L}-190$ & 64A1 & 4381 & 0.1899 & 1.261 \\
\hline 294 & D-2-2 & -4.3 & 5.3 & 0.0766 & 304L-204 & 64A1 & 1242 & 0.1905 & 1.366 \\
\hline 305 & D-2-2 & -1.6 & 10.9 & 0.2745 & $304 \mathrm{~L}-207$ & 64A1 & 5310 & .1869 & 1.179 \\
\hline 312 & D-2-2 & -1.8 & 9.6 & 0.1348 & 304L-209 & 64A1 & 2335 & .1869 & 1.307 \\
\hline 246 & D-4-4 & -0.9 & 27.2 & 0.2691 & $304 \mathrm{~L}-175$ & $\mathrm{~K} 9$ & 26423 & .7695 & 1.456 \\
\hline 248 & D-4-4 & -0.8 & 27.4 & 0.2696 & $304 \mathrm{~L}-176$ & $\mathrm{~K} 9$ & 26589 & .7692 & 1.462 \\
\hline 251 & D-4-4 & -3.1 & 26.2 & 0.3117 & 304L-177 & $72 \mathrm{~K} 9$ & 31434 & 0.7680 & 1.416 \\
\hline 254 & D-4-4 & -2.2 & 29.2 & 0.3658 & 304L-178 & $72 \mathrm{~K} 9$ & 37194 & 0.7794 & 1.317 \\
\hline 258 & D-4-4 & -1.1 & 27.1 & 0.2785 & 304L-179 & $72 \mathrm{~K} 9$ & 27874 & 0.7737 & 1.458 \\
\hline 260 & D-4-4 & -1.9 & 27.0 & 0.2793 & $304 \mathrm{~L}-186$ & $72 \mathrm{~K} 9$ & 29285 & 0.7734 & 1.527 \\
\hline 261 & D-4-4 & -2.4 & 26.8 & 0.2910 & $304 \mathrm{~L}-187$ & $72 \mathrm{~K} 9$ & 30008 & 0.7716 & 1.473 \\
\hline 288 & D-4-4 & -4.3 & 24.5 & 0.2163 & 304L-202 & $72 \mathrm{~K} 9$ & 19624 & 0.7674 & 1.456 \\
\hline 289 & D-4-4 & -3.6 & 23.7 & 0.2026 & 304L-201 & $72 \mathrm{~K} 9$ & 17922 & 0.7653 & 1.454 \\
\hline 290 & D-4-4 & -3.2 & 22.1 & 0.1936 & 304L-203 & $72 \mathrm{~K} 9$ & 17179 & 0.7707 & 1.469 \\
\hline 301 & D-4-4 & -6.3 & 32.6 & 0.3329 & $304 \mathrm{~L}-215$ & $72 \mathrm{~K} 9$ & 33299 & 0.7647 & 1.373 \\
\hline 302 & D-4-4 & -4.1 & 29.3 & 0.3081 & $304 \mathrm{~L}-216$ & $72 \mathrm{~K} 9$ & 29669 & 0.7572 & 1.377 \\
\hline 313 & D-4-4 & -4.0 & 24.0 & 0.1806 & $304 \mathrm{~L}-217$ & $72 \mathrm{~K} 9$ & 16492 & 0.7560 & 1.573 \\
\hline 314 & D-4-4 & 2.1 & 22.4 & 0.1578 & $304 \mathrm{~L}-218$ & $72 \mathrm{~K} 9$ & 14821 & 0.7719 & 1.650 \\
\hline 315 & D-4-4 & -2.6 & 29.1 & 0.2380 & $304 \mathrm{~L}-219$ & $72 \mathrm{~K} 9$ & 22427 & 0.7629 & 1.472 \\
\hline 316 & D-4-4 & 0.8 & 27.0 & 0.1629 & $304 \mathrm{~L}-220$ & $72 \mathrm{~K} 9$ & 14788 & 0.7563 & 1.611 \\
\hline 317 & D-4-4 & -2.7 & 21.6 & 0.1201 & $304 \mathrm{~L}-221$ & $72 \mathrm{~K} 9$ & 9880 & 0.7608 & 1.575 \\
\hline 348 & D-2-2 & 1.3 & 10.5 & 0.1460 & $304 \mathrm{~L}-225$ & 485896 & 2531 & 0.1833 & 1.191 \\
\hline 355 & D-2-2 & -3.0 & 9.9 & 0.1720 & $304 \mathrm{~L}-244$ & 485896 & 3299 & 0.1935 & 1.203 \\
\hline 360 & D-2-2 & -2.7 & 10.1 & 0.2227 & $304 \mathrm{~L}-245$ & 485896 & 4299 & 0.1890 & 1.155 \\
\hline 379 & $\mathrm{D}-2-2 \mathrm{~W}$ & -0.1 & 9.6 & 0.1621 & $304 \mathrm{~L}-272$ & 485896 & 3250 & 0.1926 & 1.301 \\
\hline 403 & $\mathrm{D}-2-2 \mathrm{~W}$ & -3.2 & 8.2 & 0.1306 & $304 \mathrm{~L}-275$ & 485896 & 2479 & 0.1800 & 1.374 \\
\hline 413 & $\mathrm{D}-2-2 \mathrm{~W}$ & -3.6 & 8.1 & 0.1156 & $304 \mathrm{~L}-276$ & 485896 & 2430 & 0.1917 & 1.469 \\
\hline 349 & D-4-4 & -0.7 & 23.9 & 0.1824 & $304 \mathrm{~L}-226$ & $54 \mathrm{M} 7$ & 14349 & 0.7317 & 1.469 \\
\hline 354 & D-4-4 & -1.0 & 21.9 & 0.1302 & $304 \mathrm{~L}-227$ & 54M7 & 9905 & 0.7485 & 1.535 \\
\hline 356 & D-4-4 & 0.6 & 23.0 & 0.2118 & $304 \mathrm{~L}-248$ & $54 \mathrm{M} 7$ & 17147 & 0.7470 & 1.411 \\
\hline 381 & D-4-4 W & -1.4 & 22.4 & 0.1834 & $304 \mathrm{~L}-273$ & $54 \mathrm{M} 7$ & 17016 & 0.7506 & 1.321 \\
\hline 401 & D-4-4 W & 0.7 & 20.3 & 0.1528 & $304 \mathrm{~L}-274$ & $54 \mathrm{M} 7$ & 14245 & 0.7377 & 1.398 \\
\hline
\end{tabular}


Table 21. Selected impact test parameters and factors for $304 \mathrm{~L}$ at $300{ }^{\circ} \mathrm{F}$ conditions.

\begin{tabular}{|c|c|c|c|c|c|c|c|c|c|}
\hline $\begin{array}{l}\text { Test } \\
\text { ID }\end{array}$ & $\begin{array}{c}\text { Test } \\
\text { Specimen } \\
\text { Geometry }\end{array}$ & $\begin{array}{c}\% \\
\text { Diff. }\end{array}$ & $\begin{array}{c}\text { True } \\
\text { Strain } \\
\text { Rate } \\
\left(\text { sec. }^{-1}\right)\end{array}$ & $\begin{array}{c}\text { True } \\
\text { Strain }\end{array}$ & $\begin{array}{c}\text { Test } \\
\text { Specimen } \\
\text { Identifier }\end{array}$ & $\begin{array}{c}\text { Material } \\
\text { Heat } \\
\text { Number }\end{array}$ & $\begin{array}{c}\text { Total } \\
\text { Energy } \\
\text { (in.-lb.) }\end{array}$ & $\begin{array}{c}\text { Test } \\
\text { Specimen } \\
\text { Volume } \\
{\left.\text { (in. }{ }^{3}\right)}^{\text {and }}\end{array}$ & Factor \\
\hline 274 & D-4-4 & 1.2 & 34.7 & 0.2961 & 304L-196 & $72 \mathrm{~K} 9$ & 21555 & 0.7656 & 1.258 \\
\hline 285 & D-4-4 & -0.4 & 25.3 & 0.2785 & $304 \mathrm{~L}-200$ & $72 \mathrm{~K} 9$ & 19928 & 0.7701 & 1.256 \\
\hline 327 & D-4-4 & -0.7 & 27.5 & 0.2570 & $304 \mathrm{~L}-208$ & $72 \mathrm{~K} 9$ & 18043 & 0.7692 & 1.267 \\
\hline 329 & D-4-4 & -3.3 & 24.1 & 0.2167 & $304 \mathrm{~L}-222$ & $72 \mathrm{~K} 9$ & 14713 & 0.7587 & 1.310 \\
\hline 331 & D-4-4 & -1.7 & 22.5 & 0.1876 & $304 \mathrm{~L}-223$ & $72 \mathrm{~K} 9$ & 12697 & 0.7746 & 1.336 \\
\hline 339 & D-4-4 & -4.1 & 19.2 & 0.1181 & $304 \mathrm{~L}-229$ & $72 \mathrm{~K} 9$ & 7476 & 0.7530 & 1.451 \\
\hline 340 & D-4-4 & -0.5 & 23.9 & 0.1441 & $304 \mathrm{~L}-230$ & $72 \mathrm{~K} 9$ & 9139 & 0.7446 & 1.396 \\
\hline 341 & D-4-4 & 0.4 & 22.6 & 0.1269 & $304 \mathrm{~L}-233$ & $72 \mathrm{~K} 9$ & 8297 & 0.7557 & 1.467 \\
\hline 376 & D-4-4 & -3.4 & 21.6 & 0.2118 & $304 \mathrm{~L}-232$ & $72 \mathrm{~K} 9$ & 14463 & 0.7674 & 1.312 \\
\hline 321 & D-2-2 & -3.1 & 10.6 & 0.1806 & $304 \mathrm{~L}-210$ & $64 \mathrm{~A} 1$ & 2493 & 0.1863 & 1.191 \\
\hline 324 & D-2-2 & -0.1 & 8.5 & 0.1575 & $304 \mathrm{~L}-211$ & $64 \mathrm{~A} 1$ & 2185 & 0.1869 & 1.238 \\
\hline 367 & D-2-2 & -8.4 & 5.3 & 0.1238 & $304 \mathrm{~L}-239$ & $64 \mathrm{~A} 1$ & 1684 & 0.1881 & 1.282 \\
\hline 370 & D-2-2 & -2.6 & 5.3 & 0.1083 & $304 \mathrm{~L}-240$ & $64 \mathrm{~A} 1$ & 1185 & 0.1869 & 1.069 \\
\hline 383 & D-2-2 & -2.9 & 6.7 & 0.1089 & $304 \mathrm{~L}-242$ & $64 \mathrm{~A} 1$ & 1264 & 0.1893 & 1.120 \\
\hline 385 & D-2-2 & -7.6 & 4.4 & 0.0770 & $304 \mathrm{~L}-243$ & $64 \mathrm{~A} 1$ & 893 & 0.1896 & 1.219 \\
\hline 386 & D-2-2 & -1.8 & 9.1 & 0.1861 & $304 \mathrm{~L}-260$ & $64 \mathrm{~A} 1$ & 2542 & 0.1860 & 1.171 \\
\hline 397 & D-2-2 & 0.6 & 10.6 & 0.2003 & $304 \mathrm{~L}-214$ & $64 \mathrm{~A} 1$ & 2757 & 0.1863 & 1.154 \\
\hline 388 & D-2-2 & -1.9 & 10.4 & 0.2064 & $304 \mathrm{~L}-246$ & 485896 & 3103 & 0.1848 & 1.164 \\
\hline 396 & D-2-2 & -2.8 & 9.1 & 0.1717 & $304 \mathrm{~L}-268$ & 485896 & 2639 & 0.1851 & 1.245 \\
\hline 398 & D-2-2 & -1.3 & 10.9 & 0.1775 & $304 \mathrm{~L}-270$ & 485896 & 2640 & 0.1917 & 1.156 \\
\hline 428 & D-2-2 W & -1.7 & 9.9 & 0.1761 & $304 \mathrm{~L}-283$ & 485896 & 2965 & 0.1947 & 1.265 \\
\hline 430 & D-2-2 W & -0.8 & 10.9 & 0.1599 & $304 \mathrm{~L}-281$ & 485896 & 2578 & 0.2019 & 1.189 \\
\hline 377 & D-4-4 & -2.1 & 22.5 & 0.2382 & $304 \mathrm{~L}-251$ & $54 \mathrm{M} 7$ & 15230 & 0.7443 & 1.308 \\
\hline 405 & D-4-4 & -1.7 & 22.5 & 0.1936 & $304 \mathrm{~L}-254$ & $54 \mathrm{M} 7$ & 12203 & 0.7464 & 1.374 \\
\hline 407 & D-4-4 & -0.9 & 21.7 & 0.1370 & $304 \mathrm{~L}-255$ & $54 \mathrm{M} 7$ & 7921 & 0.7368 & 1.409 \\
\hline 512 & D-4-4 & -1.4 & 18.6 & 0.1636 & $304 \mathrm{~L}-249$ & $54 \mathrm{M} 7$ & 10032 & 0.7488 & 1.400 \\
\hline 513 & D-4-4 W & 1.1 & 21.0 & 0.1562 & $304 \mathrm{~L}-286$ & $54 \mathrm{M} 7$ & 12073 & 0.7548 & 1.369 \\
\hline 516 & D-4-4 W & 1.1 & 20.7 & 0.1917 & $304 \mathrm{~L}-321$ & $54 \mathrm{M} 7$ & 13898 & 0.7512 & 1.242 \\
\hline
\end{tabular}


Author: D. K. Morton and R. K. Blandford

Date: March 2008

Reviewed By: S. D. Snow

EDF-NSNF-082 Page 87 of 118

Table 22. Selected impact test parameters and factors for $304 \mathrm{~L}$ at $600{ }^{\circ} \mathrm{F}$ conditions.

\begin{tabular}{|c|c|c|c|c|c|c|c|c|c|}
\hline $\begin{array}{l}\text { Test } \\
\text { ID }\end{array}$ & $\begin{array}{c}\text { Test } \\
\text { Specimen } \\
\text { Geometry }\end{array}$ & $\begin{array}{c}\% \\
\text { Diff. }\end{array}$ & $\begin{array}{c}\text { True } \\
\text { Strain } \\
\text { Rate } \\
\left(\text { sec. }^{-1}\right)\end{array}$ & $\begin{array}{c}\text { True } \\
\text { Strain }\end{array}$ & $\begin{array}{c}\text { Test } \\
\text { Specimen } \\
\text { Identifier }\end{array}$ & $\begin{array}{c}\text { Material } \\
\text { Heat } \\
\text { Number }\end{array}$ & $\begin{array}{l}\text { Total } \\
\text { Energy } \\
\text { (in.-lb.) }\end{array}$ & $\begin{array}{c}\text { Test } \\
\text { Specimen } \\
\text { Volume } \\
{\text { (in. }{ }^{3} \text { ) }}^{\text {and }}\end{array}$ & Factor \\
\hline 333 & D-4-4 & -0.5 & 22.9 & 0.2147 & $304 \mathrm{~L}-224$ & $72 \mathrm{~K} 9$ & 12477 & 0.7704 & 1.228 \\
\hline 335 & D-4-4 & -0.3 & 21.6 & 0.1332 & $304 \mathrm{~L}-228$ & $72 \mathrm{~K} 9$ & 6913 & 0.7566 & 1.292 \\
\hline 417 & D-4-4 & -0.4 & 21.4 & 0.2536 & $304 \mathrm{~L}-234$ & $72 \mathrm{~K} 9$ & 14666 & 0.7593 & 1.169 \\
\hline 509 & D-4-4 & -3.4 & 16.8 & 0.1533 & $304 \mathrm{~L}-299$ & $72 \mathrm{~K} 9$ & 8353 & 0.7698 & 1.281 \\
\hline 297 & D-2-2 & 3.9 & 4.7 & 0.1123 & $304 \mathrm{~L}-205$ & $64 \mathrm{~A} 1$ & 1160 & 0.1899 & 1.095 \\
\hline 344 & D-2-2 & -1.9 & 10.9 & 0.2481 & $304 \mathrm{~L}-212$ & $64 \mathrm{~A} 1$ & 2966 & 0.1881 & 1.014 \\
\hline 347 & D-2-2 & -1.2 & 8.2 & 0.1776 & $304 \mathrm{~L}-213$ & $64 \mathrm{~A} 1$ & 2165 & 0.1875 & 1.151 \\
\hline 361 & D-2-2 & -11.2 & 4.6 & 0.1098 & $304 \mathrm{~L}-236$ & $64 \mathrm{~A} 1$ & 1099 & 0.1887 & 1.074 \\
\hline 364 & D-2-2 & -4.4 & 5.0 & 0.1065 & $304 \mathrm{~L}-237$ & $64 \mathrm{~A} 1$ & 1041 & 0.1890 & 1.056 \\
\hline 365 & D-2-2 & -6.6 & 9.9 & 0.2305 & $304 \mathrm{~L}-238$ & $64 \mathrm{~A} 1$ & 2755 & 0.1860 & 1.050 \\
\hline 410 & D-2-2 & -3.0 & 10.7 & 0.1913 & $304 \mathrm{~L}-241$ & $64 \mathrm{~A} 1$ & 2211 & 0.1899 & 1.054 \\
\hline 389 & D-2-2 & -0.7 & 8.4 & 0.2006 & $304 \mathrm{~L}-247$ & 485896 & 2612 & 0.1848 & 1.062 \\
\hline 391 & D-2-2 & -3.2 & 9.7 & 0.2505 & $304 \mathrm{~L}-266$ & 485896 & 3320 & 0.1836 & 1.023 \\
\hline 392 & D-2-2 & -3.5 & 8.1 & 0.1931 & $304 \mathrm{~L}-267$ & 485896 & 2725 & 0.1896 & 1.135 \\
\hline 408 & D-2-2 & -2.4 & 9.5 & 0.2456 & $304 \mathrm{~L}-269$ & 485896 & 3548 & 0.1911 & 1.079 \\
\hline 412 & D-2-2 & -3.5 & 9.8 & 0.1476 & $304 \mathrm{~L}-271$ & 485896 & 1819 & 0.1965 & 1.022 \\
\hline 424 & D-2-2 W & -4.8 & 9.2 & 0.1443 & $304 \mathrm{~L}-279$ & 485896 & 1811 & 0.1944 & 1.120 \\
\hline 506 & D-2-2 W & 1.4 & 8.6 & 0.1805 & $304 \mathrm{~L}-282$ & 485896 & 2165 & 0.1896 & 1.039 \\
\hline 395 & D-4-4 & -2.3 & 21.0 & 0.1514 & $304 \mathrm{~L}-253$ & $54 \mathrm{M} 7$ & 7759 & 0.7731 & 1.262 \\
\hline 415 & D-4-4 & -1.4 & 21.7 & 0.2170 & $304 \mathrm{~L}-258$ & $54 \mathrm{M} 7$ & 12168 & 0.7587 & 1.255 \\
\hline 419 & D-4-4 & 0.1 & 21.5 & 0.2587 & $304 \mathrm{~L}-259$ & $54 \mathrm{M} 7$ & 14692 & 0.7599 & 1.194 \\
\hline 423 & D-4-4 W & -2.9 & 20.3 & 0.1991 & $304 \mathrm{~L}-278$ & $54 \mathrm{M} 7$ & 12104 & 0.7299 & 1.146 \\
\hline 507 & D-4-4 W & 1.1 & 19.1 & 0.1978 & $304 \mathrm{~L}-320$ & $54 \mathrm{M} 7$ & 11591 & 0.7314 & 1.103 \\
\hline
\end{tabular}


Table 23. Selected impact test parameters and factors for $316 \mathrm{~L}$ at $-20^{\circ} \mathrm{F}$ conditions.

\begin{tabular}{|c|c|c|c|c|c|c|c|c|c|}
\hline $\begin{array}{l}\text { Test } \\
\text { ID }\end{array}$ & $\begin{array}{c}\text { Test } \\
\text { Specimen } \\
\text { Geometry }\end{array}$ & $\begin{array}{c}\% \\
\text { Diff. }\end{array}$ & $\begin{array}{c}\text { True } \\
\text { Strain } \\
\text { Rate }^{-1} \\
\left(\text { sec. }^{-1}\right)\end{array}$ & $\begin{array}{c}\text { True } \\
\text { Strain }\end{array}$ & $\begin{array}{c}\text { Test } \\
\text { Specimen } \\
\text { Identifier }\end{array}$ & $\begin{array}{c}\text { Material } \\
\text { Heat } \\
\text { Number }\end{array}$ & $\begin{array}{c}\text { Total } \\
\text { Energy } \\
\text { (in.-lb.) }\end{array}$ & $\begin{array}{c}\text { Test } \\
\text { Specimen } \\
\text { Volume } \\
{\left.\text { (in. }{ }^{3}\right)}^{\text {and }}\end{array}$ & Factor \\
\hline 437 & D-4-4 & -2.5 & 23.7 & 0.1565 & $316 \mathrm{~L}-115$ & $67 \mathrm{~K} 0$ & 14657 & 0.7494 & 1.367 \\
\hline 439 & D-4-4 & -1.9 & 29.2 & 0.2145 & $316 \mathrm{~L}-125$ & $67 \mathrm{~K} 0$ & 21705 & 0.7494 & 1.350 \\
\hline 441 & D-4-4 & -2.8 & 20.4 & 0.1066 & $316 \mathrm{~L}-126$ & $67 \mathrm{~K} 0$ & 9824 & 0.7599 & 1.459 \\
\hline 444 & D-4-4 & -2.9 & 28.3 & 0.3365 & $316 \mathrm{~L}-180$ & $67 \mathrm{~K} 0$ & 35635 & 0.7635 & 1.185 \\
\hline 458 & D-4-4 & 0.7 & 19.7 & 0.1528 & $316 \mathrm{~L}-184$ & $67 \mathrm{~K} 0$ & 14423 & 0.7527 & 1.381 \\
\hline 460 & D-4-4 & -1.9 & 31.8 & 0.3011 & $316 \mathrm{~L}-185$ & $67 \mathrm{~K} 0$ & 32198 & 0.7548 & 1.262 \\
\hline 478 & D-4-4 & -2.0 & 16.7 & 0.1074 & 316L-186 & $67 \mathrm{~K} 0$ & 9784 & 0.7551 & 1.448 \\
\hline 497 & D-4-4 & -1.1 & 39.1 & 0.4101 & $316 \mathrm{~L}-188$ & $67 \mathrm{~K} 0$ & 45885 & 0.7506 & 1.171 \\
\hline 431 & D-2-2 & -2.7 & 9.7 & 0.1104 & $316 \mathrm{~L}-111$ & $76 \mathrm{H} 3$ & 2252 & 0.1941 & 1.349 \\
\hline 433 & D-2-2 & -3.1 & 8.6 & 0.1652 & $316 \mathrm{~L}-160$ & $76 \mathrm{H} 3$ & 3606 & 0.1902 & 1.334 \\
\hline 435 & D-2-2 & -5.4 & 6.5 & 0.1042 & 316L-161 & $76 \mathrm{H} 3$ & 1904 & 0.1896 & 1.250 \\
\hline 446 & D-2-2 & -2.9 & 5.3 & 0.0770 & $316 \mathrm{~L}-164$ & $76 \mathrm{H} 3$ & 1445 & 0.1881 & 1.378 \\
\hline 456 & D-2-2 & -1.3 & 10.8 & 0.1678 & $316 \mathrm{~L}-183$ & $76 \mathrm{H} 3$ & 3510 & 0.1884 & 1.284 \\
\hline 448 & D-2-2 & -5.4 & 13.0 & 0.2223 & $316 \mathrm{~L}-163$ & $76 \mathrm{H} 3$ & 5050 & 0.1866 & 1.295 \\
\hline 450 & D-2-2 & -2.1 & 14.7 & 0.2702 & $316 \mathrm{~L}-162$ & $76 \mathrm{H} 3$ & 6220 & 0.1881 & 1.218 \\
\hline 452 & D-2-2 & -2.9 & 11.3 & 0.1723 & 316L-181 & $48 \mathrm{R} 8$ & 3298 & 0.1830 & 1.147 \\
\hline 465 & D-2-2 & -5.0 & 10.1 & 0.1463 & 316L-195 & $48 \mathrm{R} 8$ & 2947 & 0.1863 & 1.238 \\
\hline 473 & D-2-2 & -4.5 & 10.0 & 0.1934 & 316L-197 & $48 \mathrm{R} 8$ & 4115 & 0.1896 & 1.194 \\
\hline 461 & D-2-2 & -4.6 & 10.7 & 0.1225 & 316L-194 & $48 \mathrm{R} 8$ & 2293 & 0.1836 & 1.216 \\
\hline 475 & D-2-2 & -3.5 & 17.2 & 0.3062 & 316L-198 & $48 \mathrm{R} 8$ & 6994 & 0.1821 & 1.148 \\
\hline 492 & D-2-2 W & -3.2 & 10.0 & 0.1166 & 316L-199 & $48 \mathrm{R} 8$ & 2273 & 0.1929 & 1.347 \\
\hline 486 & D-2-2 W & 0.0 & 10.2 & 0.1392 & $316 \mathrm{~L}-174$ & $48 \mathrm{R} 8$ & 2914 & 0.2007 & 1.340 \\
\hline 463 & D-4-4 & -5.2 & 23.7 & 0.2148 & 316L-191 & 230468 & 18687 & 0.7554 & 1.384 \\
\hline 467 & D-4-4 & -4.7 & 24.5 & 0.1708 & 316L-192 & 230468 & 13912 & 0.7485 & 1.437 \\
\hline 471 & D-4-4 & -6.8 & 21.5 & 0.1444 & $316 \mathrm{~L}-193$ & 230468 & 11912 & 0.7641 & 1.517 \\
\hline 482 & D-4-4 & -5.3 & 19.4 & 0.1183 & 316L-201 & 230468 & 9875 & 0.7482 & 1.672 \\
\hline 484 & D-4-4 & -1.2 & 23.1 & 0.1336 & 316L-203 & 230468 & 10713 & 0.7374 & 1.566 \\
\hline 488 & D-4-4 W & 2.0 & 21.0 & 0.1306 & $316 \mathrm{~L}-178$ & 230468 & 11865 & 0.7191 & 1.427 \\
\hline 493 & D-4-4 W & 0.0 & 22.9 & 0.1927 & 316L-179 & 230468 & 18578 & 0.7266 & 1.376 \\
\hline
\end{tabular}


Table 24. Selected impact test parameters and factors for $316 \mathrm{~L}$ at room temperature conditions.

\begin{tabular}{|c|c|c|c|c|c|c|c|c|c|}
\hline $\begin{array}{c}\text { Test } \\
\text { ID }\end{array}$ & $\begin{array}{c}\text { Test } \\
\text { Specimen } \\
\text { Geometry }\end{array}$ & $\begin{array}{c}\% \\
\text { Diff. }\end{array}$ & $\begin{array}{c}\text { True } \\
\text { Strain } \\
\text { Rate }^{-1} \\
\left(\text { sec. }^{-1}\right)\end{array}$ & $\begin{array}{c}\text { True } \\
\text { Strain }\end{array}$ & $\begin{array}{c}\text { Test } \\
\text { Specimen } \\
\text { Identifier }\end{array}$ & $\begin{array}{c}\text { Material } \\
\text { Heat } \\
\text { Number }\end{array}$ & $\begin{array}{c}\text { Total } \\
\text { Energy } \\
\text { (in.-lb.) }\end{array}$ & $\begin{array}{c}\text { Test } \\
\text { Specimen } \\
\text { Volume } \\
{\left.\text { (in. }{ }^{3}\right)}^{\text {and }}\end{array}$ & Factor \\
\hline 23 & A & -2.9 & 24.1 & 0.3743 & $316 \mathrm{~L}-7$ & 09T9 & 49097 & 1.1286 & 1.292 \\
\hline 24 & $\mathrm{~A}$ & -4.3 & 25.9 & 0.3878 & $316 \mathrm{~L}-8$ & 09T9 & 51928 & 1.1525 & 1.274 \\
\hline 25 & $\mathrm{~A}$ & -4.0 & 24.4 & 0.3788 & $316 \mathrm{~L}-9$ & 09T9 & 50302 & 1.1448 & 1.284 \\
\hline 26 & $\mathrm{~A}$ & -3.5 & 24.0 & 0.3710 & $316 \mathrm{~L}-10$ & 09T9 & 47867 & 1.1102 & 1.295 \\
\hline 27 & A & 0.4 & 25.8 & 0.3660 & $316 \mathrm{~L}-11$ & 09T9 & 47325 & 1.1079 & 1.308 \\
\hline 28 & $\mathrm{~A}$ & -5.5 & 25.2 & 0.3493 & $316 \mathrm{~L}-12$ & 09T9 & 44386 & 1.1115 & 1.305 \\
\hline 30 & A & -5.6 & 14.0 & 0.1293 & $316 \mathrm{~L}-14$ & 09T9 & 13856 & 1.1421 & 1.451 \\
\hline 31 & A & -8.4 & 16.9 & 0.1647 & $316 \mathrm{~L}-15$ & 09T9 & 17824 & 1.1534 & 1.364 \\
\hline 32 & A & -2.9 & 18.4 & 0.1975 & $316 \mathrm{~L}-16$ & 09T9 & 21780 & 1.1151 & 1.365 \\
\hline 51 & $\mathrm{~A}$ & -6.3 & 26.2 & 0.3043 & $316 \mathrm{~L}-25$ & 09T9 & 38433 & 1.1358 & 1.337 \\
\hline 75 & $\mathrm{~A}$ & -4.3 & 25.8 & 0.3843 & $316 \mathrm{~L}-28$ & 09T9 & 50361 & 1.1457 & 1.258 \\
\hline 76 & $\mathrm{~A}$ & -2.9 & 27.2 & 0.2877 & $316 \mathrm{~L}-29$ & 09T9 & 35273 & 1.1489 & 1.309 \\
\hline 164 & A & -0.4 & 26.5 & 0.3472 & $316 \mathrm{~L}-48$ & 09T9 & 44378 & 1.1205 & 1.305 \\
\hline 169 & A & -1.2 & 24.3 & 0.3300 & $316 \mathrm{~L}-50$ & 09T9 & 42758 & 1.1228 & 1.346 \\
\hline 170 & A & -1.7 & 21.8 & 0.2688 & $316 \mathrm{~L}-51$ & 09T9 & 31579 & 1.0998 & 1.338 \\
\hline 184 & A & -1.5 & 25.8 & 0.3929 & $316 \mathrm{~L}-54$ & 09T9 & 50441 & 1.0926 & 1.279 \\
\hline 192 & $\mathrm{~A}$ & 0.0 & 27.1 & 0.3523 & $316 \mathrm{~L}-55$ & 09T9 & 44407 & 1.1142 & 1.287 \\
\hline 229 & A & -1.1 & 20.4 & 0.2510 & $316 \mathrm{~L}-61$ & 09T9 & 29325 & 1.1016 & 1.359 \\
\hline 239 & A-2-2 & -5.4 & 7.3 & 0.1910 & $316 \mathrm{~L}-75$ & $76 \mathrm{H} 3$ & 5313 & 0.2768 & 1.287 \\
\hline 240 & A-2-2 & -0.4 & 6.0 & 0.1508 & $316 \mathrm{~L}-76$ & $76 \mathrm{H} 3$ & 3936 & 0.2808 & 1.267 \\
\hline 241 & A-2-2 & -2.0 & 4.9 & 0.1186 & $316 \mathrm{~L}-77$ & $76 \mathrm{H} 3$ & 2981 & 0.2786 & 1.301 \\
\hline 237 & $\mathrm{D}-2-2$ & -3.8 & 8.5 & 0.2038 & $316 \mathrm{~L}-71$ & $76 \mathrm{H} 3$ & 3844 & 0.1869 & 1.256 \\
\hline 238 & D-2-2 & 1.3 & 10.6 & 0.2639 & $316 \mathrm{~L}-72$ & $76 \mathrm{H} 3$ & 5241 & 0.1860 & 1.226 \\
\hline 242 & D-2-2 & 0.1 & 10.3 & 0.1968 & $316 \mathrm{~L}-73$ & $76 \mathrm{H} 3$ & 3644 & 0.1839 & 1.265 \\
\hline 293 & D-2-2 & 3.3 & 12.0 & 0.2249 & $316 \mathrm{~L}-78$ & $76 \mathrm{H} 3$ & 4246 & 0.1845 & 1.236 \\
\hline 295 & D-2-2 & -2.6 & 5.9 & 0.0812 & $316 \mathrm{~L}-79$ & $76 \mathrm{H} 3$ & 1262 & 0.1878 & 1.280 \\
\hline 303 & D-2-2 & 1.3 & 5.7 & 0.0908 & 316L-97 & $76 \mathrm{H} 3$ & 1513 & 0.1920 & 1.313 \\
\hline 306 & D-2-2 & -3.5 & 9.3 & 0.1323 & $316 \mathrm{~L}-98$ & $76 \mathrm{H} 3$ & 2326 & 0.1929 & 1.270 \\
\hline 230 & D-4-4 & -3.4 & 29.2 & 0.3422 & $316 \mathrm{~L}-62$ & $67 \mathrm{~K} 0$ & 32526 & 0.7455 & 1.292 \\
\hline 231 & D-4-4 & -2.7 & 30.5 & 0.3532 & $316 \mathrm{~L}-63$ & $67 \mathrm{~K} 0$ & 34796 & 0.7500 & 1.316 \\
\hline 232 & D-4-4 & -3.4 & 28.0 & 0.2913 & $316 \mathrm{~L}-64$ & $67 \mathrm{~K} 0$ & 28413 & 0.7536 & 1.392 \\
\hline 233 & D-4-4 & -2.6 & 30.2 & 0.3322 & $316 \mathrm{~L}-65$ & $67 \mathrm{~K} 0$ & 32356 & 0.7533 & 1.326 \\
\hline 276 & D-4-4 & -5.5 & 33.4 & 0.3017 & $316 \mathrm{~L}-83$ & $67 \mathrm{~K} 0$ & 27125 & 0.7347 & 1.298 \\
\hline 277 & D-4-4 & 0.9 & 32.3 & 0.3031 & $316 \mathrm{~L}-84$ & $67 \mathrm{~K} 0$ & 27131 & 0.7347 & 1.290 \\
\hline 278 & D-4-4 & -2.0 & 29.7 & 0.3204 & $316 \mathrm{~L}-85$ & $67 \mathrm{~K} 0$ & 28557 & 0.7353 & 1.258 \\
\hline 279 & D-4-4 & -3.8 & 28.9 & 0.3128 & $316 \mathrm{~L}-86$ & $67 \mathrm{~K} 0$ & 28521 & 0.7404 & 1.290 \\
\hline 280 & D-4-4 & 3.0 & 27.6 & 0.3095 & $316 \mathrm{~L}-87$ & $67 \mathrm{~K} 0$ & 28503 & 0.7431 & 1.304 \\
\hline 291 & D-4-4 & -0.8 & 22.0 & 0.1811 & $316 \mathrm{~L}-91$ & $67 \mathrm{~K} 0$ & 14550 & 0.7446 & 1.344 \\
\hline 292 & D-4-4 & 0.0 & 23.3 & 0.2032 & $316 \mathrm{~L}-94$ & $67 \mathrm{~K} 0$ & 16757 & 0.7368 & 1.348 \\
\hline 304 & D-4-4 & -2.4 & 29.3 & 0.3910 & 316L-95 & $67 \mathrm{~K} 0$ & 36038 & 0.7404 & 1.197 \\
\hline 307 & D-4-4 & -1.9 & 27.5 & 0.2290 & $316 \mathrm{~L}-103$ & $67 \mathrm{~K} 0$ & 19849 & 0.7473 & 1.349 \\
\hline 308 & D-4-4 & 0.3 & 22.8 & 0.1481 & $316 \mathrm{~L}-104$ & $67 \mathrm{~K} 0$ & 13834 & 0.7479 & 1.643 \\
\hline 309 & D-4-4 & -0.9 & 23.7 & 0.1828 & 316L-105 & $67 \mathrm{~K} 0$ & 15226 & 0.7476 & 1.385 \\
\hline 310 & D-4-4 & -1.3 & 22.4 & 0.1713 & $316 \mathrm{~L}-106$ & $67 \mathrm{~K} 0$ & 14709 & 0.7446 & 1.459 \\
\hline 311 & D-4-4 & 0.1 & 29.0 & 0.2428 & $316 \mathrm{~L}-107$ & $67 \mathrm{~K} 0$ & 21808 & 0.7524 & 1.364 \\
\hline 318 & D-4-4 & -2.5 & 21.7 & 0.1138 & $316 \mathrm{~L}-108$ & $67 \mathrm{~K} 0$ & 9864 & 0.7371 & 1.649 \\
\hline 350 & D-2-2 & -1.9 & 10.2 & 0.1491 & $316 \mathrm{~L}-127$ & $48 \mathrm{R} 8$ & 2701 & 0.1947 & 1.285 \\
\hline 357 & D-2-2 & -2.6 & 9.8 & 0.1928 & $316 \mathrm{~L}-128$ & 48R8 & 3391 & 0.1917 & 1.177 \\
\hline 359 & D-2-2 & -3.6 & 10.4 & 0.2627 & $316 \mathrm{~L}-136$ & $48 \mathrm{R} 8$ & 4728 & 0.1848 & 1.129 \\
\hline 380 & $\mathrm{D}-2-2 \mathrm{~W}$ & -1.5 & 10.8 & 0.1914 & $316 \mathrm{~L}-165$ & $48 \mathrm{R} 8$ & 3385 & 0.1854 & 1.313 \\
\hline 404 & D-2-2 W & -2.9 & 11.9 & 0.1581 & 316L-168 & 48R8 & 2732 & 0.1950 & 1.278 \\
\hline 414 & D-2-2 W & -6.0 & 9.6 & 0.1505 & $316 \mathrm{~L}-169$ & $48 \mathrm{R} 8$ & 2707 & 0.1923 & 1.364 \\
\hline 351 & D-4-4 & -0.4 & 24.6 & 0.1973 & $316 \mathrm{~L}-137$ & 230468 & 14323 & 0.7728 & 1.351 \\
\hline 352 & D-4-4 & 1.6 & 21.4 & 0.1760 & $316 \mathrm{~L}-138$ & 230468 & 12178 & 0.7467 & 1.381 \\
\hline 353 & D-4-4 & 0.0 & 20.5 & 0.1381 & $316 \mathrm{~L}-139$ & 230468 & 8624 & 0.7359 & 1.361 \\
\hline 358 & D-4-4 & -2.0 & 21.8 & 0.2069 & $316 \mathrm{~L}-142$ & 230468 & 14671 & 0.7524 & 1.331 \\
\hline 382 & D-4-4 W & 0.1 & 20.4 & 0.1729 & $316 \mathrm{~L}-166$ & 230468 & 14514 & 0.7422 & 1.306 \\
\hline 402 & D-4-4 W & 1.3 & 21.8 & 0.1470 & $316 \mathrm{~L}-167$ & 230468 & 12080 & 0.7461 & 1.311 \\
\hline
\end{tabular}


Table 25. Selected impact test parameters and factors for $316 \mathrm{~L}$ at $300^{\circ} \mathrm{F}$ conditions.

\begin{tabular}{|c|c|c|c|c|c|c|c|c|c|}
\hline $\begin{array}{l}\text { Test } \\
\text { ID }\end{array}$ & $\begin{array}{c}\text { Test } \\
\text { Specimen } \\
\text { Geometry }\end{array}$ & $\begin{array}{c}\% \\
\text { Diff. }\end{array}$ & $\begin{array}{c}\text { True } \\
\text { Strain } \\
\text { Rate } \\
\left(\text { sec. }^{-1}\right)\end{array}$ & $\begin{array}{c}\text { True } \\
\text { Strain }\end{array}$ & $\begin{array}{c}\text { Test } \\
\text { Specimen } \\
\text { Identifier }\end{array}$ & $\begin{array}{c}\text { Material } \\
\text { Heat } \\
\text { Number }\end{array}$ & $\begin{array}{l}\text { Total } \\
\text { Energy } \\
\text { (in.-lb.) }\end{array}$ & $\begin{array}{c}\text { Test } \\
\text { Specimen } \\
\text { Volume } \\
{\text { (in. }{ }^{3} \text { ) }}^{\text {and }}\end{array}$ & Factor \\
\hline 284 & D-4-4 & -1.3 & 23.3 & 0.2589 & $316 \mathrm{~L}-88$ & $67 \mathrm{~K} 0$ & 17964 & 0.7467 & 1.213 \\
\hline 286 & D-4-4 & -0.3 & 21.9 & 0.2331 & 316L-89 & $67 \mathrm{~K} 0$ & 15964 & 0.7395 & 1.245 \\
\hline 287 & D-4-4 & -0.8 & 22.5 & 0.2313 & 316L-90 & $67 \mathrm{~K} 0$ & 15490 & 0.7416 & 1.217 \\
\hline 328 & D-4-4 & 0.3 & 25.4 & 0.2271 & $316 \mathrm{~L}-112$ & $67 \mathrm{~K} 0$ & 15385 & 0.7551 & 1.216 \\
\hline 330 & D-4-4 & -0.2 & 21.6 & 0.1689 & $316 \mathrm{~L}-113$ & $67 \mathrm{~K} 0$ & 11995 & 0.7587 & 1.369 \\
\hline 337 & D-4-4 & -2.3 & 25.4 & 0.1590 & $316 \mathrm{~L}-120$ & $67 \mathrm{~K} 0$ & 10378 & 0.7500 & 1.290 \\
\hline 338 & D-4-4 & -0.9 & 23.0 & 0.1258 & $316 \mathrm{~L}-121$ & $67 \mathrm{~K} 0$ & 8495 & 0.7380 & 1.432 \\
\hline 511 & D-4-4 & -2.3 & 16.6 & 0.1312 & $316 \mathrm{~L}-189$ & $67 \mathrm{~K} 0$ & 8018 & 0.7554 & 1.255 \\
\hline 320 & D-2-2 & -0.5 & 9.7 & 0.1610 & 316L-99 & $76 \mathrm{H} 3$ & 2424 & 0.1911 & 1.266 \\
\hline 322 & D-2-2 & -1.8 & 11.4 & 0.2156 & $316 \mathrm{~L}-100$ & $76 \mathrm{H} 3$ & 3224 & 0.1932 & 1.156 \\
\hline 323 & D-2-2 & -0.6 & 10.4 & 0.1745 & $316 \mathrm{~L}-101$ & $76 \mathrm{H} 3$ & 2553 & 0.1929 & 1.196 \\
\hline 366 & D-2-2 & -2.9 & 4.0 & 0.0978 & $316 \mathrm{~L}-133$ & $76 \mathrm{H} 3$ & 1198 & 0.1887 & 1.165 \\
\hline 368 & D-2-2 & -4.4 & 4.9 & 0.1144 & $316 \mathrm{~L}-134$ & $76 \mathrm{H} 3$ & 1628 & 0.1890 & 1.307 \\
\hline 369 & D-2-2 & 4.2 & 5.5 & 0.1043 & $316 \mathrm{~L}-135$ & $76 \mathrm{H} 3$ & 1302 & 0.1896 & 1.166 \\
\hline 384 & D-2-2 & -2.2 & 4.1 & 0.0694 & $316 \mathrm{~L}-158$ & $76 \mathrm{H} 3$ & 862 & 0.1890 & 1.274 \\
\hline 387 & D-2-2 & -1.0 & 9.6 & 0.1981 & $316 \mathrm{~L}-159$ & $76 \mathrm{H} 3$ & 2950 & 0.1872 & 1.213 \\
\hline 325 & D-2-2 & -4.4 & 9.0 & 0.1614 & $316 \mathrm{~L}-116$ & $48 \mathrm{R} 8$ & 2300 & 0.1821 & 1.184 \\
\hline 399 & D-2-2 & -3.7 & 9.4 & 0.1776 & $316 \mathrm{~L}-153$ & $48 \mathrm{R} 8$ & 2640 & 0.1869 & 1.176 \\
\hline 400 & D-2-2 & -0.3 & 10.7 & 0.2250 & $316 \mathrm{~L}-154$ & $48 \mathrm{R} 8$ & 3312 & 0.1878 & 1.086 \\
\hline 429 & D-2-2 W & -1.6 & 10.3 & 0.1697 & $316 \mathrm{~L}-177$ & $48 \mathrm{R} 8$ & 2614 & 0.2010 & 1.150 \\
\hline 495 & D-2-2 W & -3.6 & 11.2 & 0.2064 & $316 \mathrm{~L}-200$ & $48 \mathrm{R} 8$ & 2931 & 0.1899 & 1.071 \\
\hline 342 & D-4-4 & -2.8 & 23.6 & 0.1683 & $316 \mathrm{~L}-118$ & 230468 & 9102 & 0.7491 & 1.228 \\
\hline 378 & D-4-4 & 2.0 & 21.7 & 0.2654 & $316 \mathrm{~L}-145$ & 230468 & 16128 & 0.7398 & 1.208 \\
\hline 406 & D-4-4 & 2.1 & 22.5 & 0.2216 & $316 \mathrm{~L}-147$ & 230468 & 12621 & 0.7401 & 1.202 \\
\hline 515 & D-4-4 W & -2.8 & 24.8 & 0.1871 & $316 \mathrm{~L}-205$ & 230468 & 12499 & 0.7257 & 1.236 \\
\hline 514 & D-4-4 W & -0.2 & 20.9 & 0.2153 & $316 \mathrm{~L}-206$ & 230468 & 14014 & 0.7098 & 1.197 \\
\hline
\end{tabular}


Table 26. Selected impact test parameters and factors for $316 \mathrm{~L}$ at $600^{\circ} \mathrm{F}$ conditions.

\begin{tabular}{|c|c|c|c|c|c|c|c|c|c|}
\hline $\begin{array}{l}\text { Test } \\
\text { ID }\end{array}$ & $\begin{array}{c}\text { Test } \\
\text { Specimen } \\
\text { Geometry }\end{array}$ & $\begin{array}{c}\% \\
\text { Diff. }\end{array}$ & $\begin{array}{c}\text { True } \\
\text { Strain } \\
\text { Rate } \\
\text { (sec. }^{-1} \text { ) } \\
\end{array}$ & $\begin{array}{c}\text { True } \\
\text { Strain }\end{array}$ & $\begin{array}{c}\text { Test } \\
\text { Specimen } \\
\text { Identifier }\end{array}$ & $\begin{array}{c}\text { Material } \\
\text { Heat } \\
\text { Number }\end{array}$ & $\begin{array}{c}\text { Total } \\
\text { Energy } \\
\text { (in.-lb.) }\end{array}$ & $\begin{array}{c}\text { Test } \\
\text { Specimen } \\
\text { Volume } \\
{\text { (in. }{ }^{3} \text { ) }}^{\text {nolume }} \\
\end{array}$ & Factor \\
\hline 296 & D-2-2 & 0.2 & 5.0 & 0.0940 & $316 \mathrm{~L}-92$ & $76 \mathrm{H} 3$ & 965 & 0.1947 & 1.017 \\
\hline 300 & D-2-2 & 2.2 & 10.2 & 0.2384 & 316L-96 & $76 \mathrm{H} 3$ & 3144 & 0.1929 & 1.023 \\
\hline 343 & D-2-2 & -1.7 & 9.7 & 0.2020 & $316 \mathrm{~L}-102$ & $76 \mathrm{H} 3$ & 2668 & 0.1941 & 1.071 \\
\hline 345 & D-2-2 & -5.4 & 11.7 & 0.2042 & $316 \mathrm{~L}-129$ & $76 \mathrm{H} 3$ & 2576 & 0.1899 & 1.041 \\
\hline 346 & D-2-2 & -1.3 & 9.5 & 0.1734 & $316 \mathrm{~L}-130$ & $76 \mathrm{H} 3$ & 2149 & 0.1896 & 1.073 \\
\hline 362 & D-2-2 & -8.7 & 5.1 & 0.1196 & $316 \mathrm{~L}-131$ & $76 \mathrm{H} 3$ & 1323 & 0.1902 & 1.054 \\
\hline 363 & D-2-2 & -10.0 & 5.3 & 0.1018 & $316 \mathrm{~L}-132$ & $76 \mathrm{H} 3$ & 1156 & 0.1890 & 1.136 \\
\hline 319 & D-4-4 & -0.6 & 23.6 & 0.1780 & 316L-109 & $67 \mathrm{~K} 0$ & 10028 & 0.7485 & 1.171 \\
\hline 332 & D-4-4 & -0.6 & 20.9 & 0.1873 & 316L-119 & $67 \mathrm{~K} 0$ & 10788 & 0.7506 & 1.177 \\
\hline 334 & D-4-4 & 0.3 & 23.2 & 0.1517 & $316 \mathrm{~L}-114$ & $67 \mathrm{~K} 0$ & 8060 & 0.7593 & 1.138 \\
\hline 418 & D-4-4 & -1.8 & 20.7 & 0.2269 & $316 \mathrm{~L}-124$ & $67 \mathrm{~K} 0$ & 13132 & 0.7596 & 1.105 \\
\hline 390 & D-2-2 & -1.4 & 9.7 & 0.2292 & $316 \mathrm{~L}-140$ & $48 \mathrm{R} 8$ & 2982 & 0.1977 & 1.034 \\
\hline 409 & D-2-2 & -1.3 & 9.1 & 0.2205 & $316 \mathrm{~L}-155$ & $48 \mathrm{R} 8$ & 2839 & 0.1875 & 1.091 \\
\hline 411 & D-2-2 & -1.4 & 10.7 & 0.2041 & $316 \mathrm{~L}-157$ & $48 \mathrm{R} 8$ & 2497 & 0.1869 & 1.066 \\
\hline 425 & D-2-2 W & -0.1 & 9.0 & 0.1781 & $316 \mathrm{~L}-173$ & $48 \mathrm{R} 8$ & 2405 & 0.1956 & 1.137 \\
\hline 505 & D-2-2 W & -2.5 & 8.3 & 0.1943 & $316 \mathrm{~L}-176$ & $48 \mathrm{R} 8$ & 2349 & 0.1965 & 0.991 \\
\hline 394 & D-4-4 & 0.5 & 22.4 & 0.2396 & $316 \mathrm{~L}-146$ & 230468 & 12171 & 0.7461 & 1.138 \\
\hline 416 & D-4-4 & -1.3 & 21.9 & 0.1666 & $316 \mathrm{~L}-148$ & 230468 & 7998 & 0.7281 & 1.242 \\
\hline 420 & D-4-4 & -0.3 & 20.5 & 0.2705 & $316 \mathrm{~L}-152$ & 230468 & 13817 & 0.7206 & 1.131 \\
\hline 508 & D-4-4 W & -0.8 & 19.1 & 0.2011 & 316L-204 & 230468 & 11139 & 0.7365 & 1.053 \\
\hline 510 & D-4-4 W & -2.2 & 21.4 & 0.2010 & $316 \mathrm{~L}-171$ & 230468 & 11472 & 0.7341 & 1.088 \\
\hline
\end{tabular}




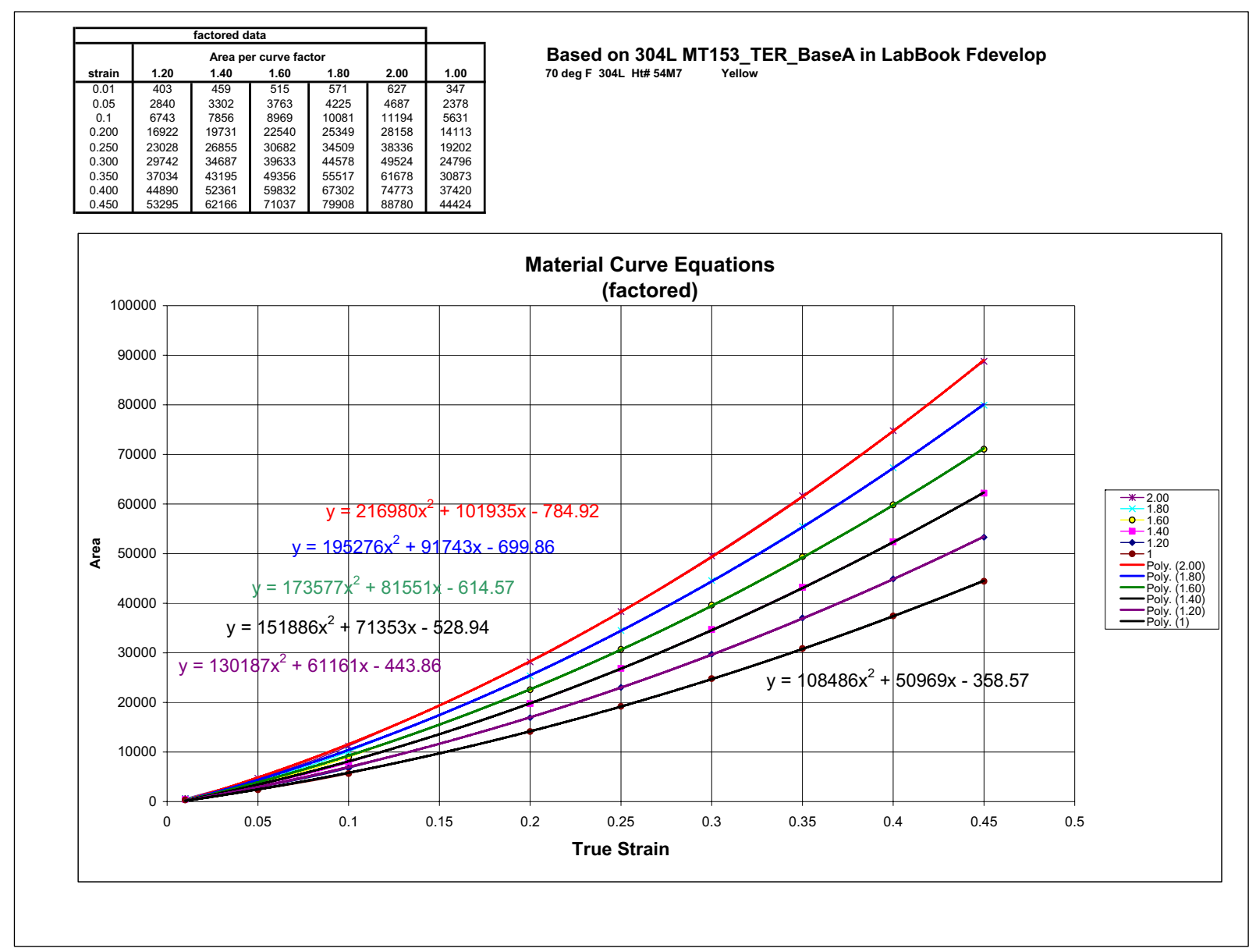

Figure 60. Excel Material Curve spreadsheet, 304L, heat 54M7, 1/2-inch base material at room temperature. 
Material curve equations are developed next in an Excel spreadsheet using the 'area under the curve' (in.-lb./in. ${ }^{3}$ ) and overall average strain values determined in the DADiSP worksheets for the specified factors and strain limits. These material curves are material type (304L or 316L), heat (base and welded material), and temperature specific. The Material Curve Excel spreadsheet for $304 \mathrm{~L}$, heat $54 \mathrm{M} 7$, base material, at $70^{\circ} \mathrm{F}$ is shown in Figure 60 . In the Excel spreadsheet, the 54 'area under the curve' values are input versus factor and overall average strain values and are then plotted [area (y coordinate) versus true strain (x coordinate)] and fit with a $2^{\text {nd }}$ order polynomial. The equation for the curve is then determined for each factor. This equation provides the relationship between the area under the factored true stress strain curve (energy density) up to a given strain limit. The Material Curve spreadsheets used for the work performed herein are contained on the Report CD-R (file 2D).

The strain distribution through the transition regions was based on the overall average strain in the gauge length and the ABAQUS/Explicit predictions by applying the ratio of the overall average strain to the corresponding value used in the computer simulations. The volume of transition region material strained to these distributions was also based on the ABAQUS/Explicit model that incorporated nominal specimen dimensions. An Excel spreadsheet was used to determine the strain and volume distributions from ABAQUS/Explicit output coordinates and coordinate displacements. The spreadsheets for the specimen geometries used for the work reported herein are contained on the Report CD-R (file 2D).

The resulting material curve equations are input into a final Excel spreadsheet (see Figure 61 for a representative example) to determine the specific factor value for a given strain rate impact test using the overall average strain (OAS), gauge volume $(\mathrm{GV})$, and test total impact energy ( $\left.E_{\text {total }}\right)$ parameters. The final spreadsheet used to calculate the elevated strain rate factor for a specific impact test is material type (304L or $316 \mathrm{~L})$, heat (base and welded material), temperature, and geometry specific. The spreadsheet is material, heat, and temperature specific because it utilizes the derived material curve equations to determine appropriate energies. The spreadsheet is geometry dependent because it utilizes the ABAQUS/Explicit predicted strain and material volume distributions in the transition regions to determine appropriate energies. Representative spreadsheets for all the materials, temperatures, and specimen geometries used for the work performed herein are provided on the Report CD-R (file 2D). Also contained on the Report CD-R (file 2D) are the calculated factors. NSNFP Lab Notebook Binder Volume 7 also contains the resulting factors along with details of the associated test conditions and parameters. These factors are presented in this report in Tables 19 through 22 for the 304L impact tests at the temperatures considered and Tables 23 through 26 for the $316 \mathrm{~L}$ impact tests at the temperatures considered.

\subsubsection{Checking of Spreadsheets}

Once the Excel spreadsheets were developed, they were thoroughly checked in accordance with NSNFP Procedure 19.01 for verification of routines and macros within exempt commercial software. The spreadsheets were assigned the unique identifier NSNF/MED/017, Revision 1 by the NSNFP Document Control Coordinator and were submitted to NSNFP Document Control. Checking and verification of the spreadsheets is documented on the Signature Sheet contained in Appendix B. Verification of the DADiSP routines used in this process is documented in Appendix A. 

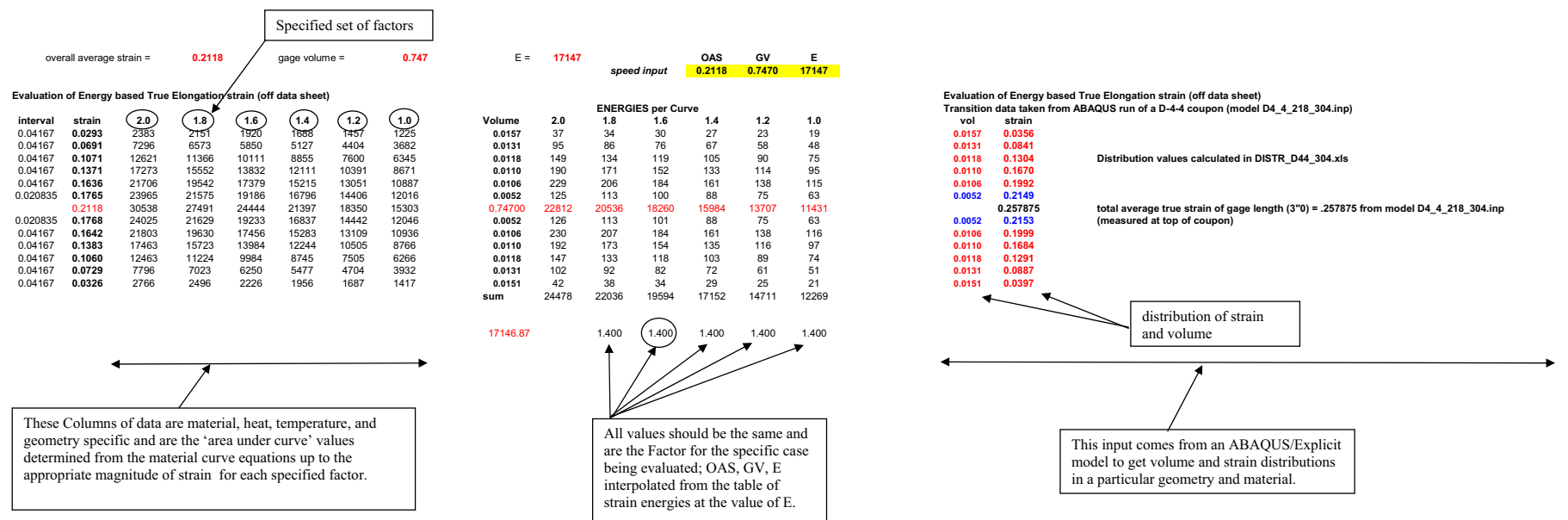

Figure 61. Excel Spreadsheet for Final Factor Determination, Test \#356, 304L, Heat 54M7, 1/2-Inch Base Material at $70^{\circ} \mathrm{F}$. 


\subsection{Strain Rate Elevated True Stress-Strain Curves}

For each successful strain rate test, an associated strain rate factor was determined as described in Section 7.1. For each of the materials (304L or 316L) investigated, the factors were plotted versus strain rate and fitted with a linear curve. These plots are shown in Figures 62 through 69 for the two materials and four temperatures tested. The results shown in these figures for a particular material and temperature include all material heats, both base and weld metal, and various specimen geometries (A and D profiles in $1 / 2$-inch and $1 / 4$-inch thicknesses). Given the relatively limited strain rate range studied to date, a linear fit of all of the material and temperature related results was considered to best trend the material data. It is recognized that, at this time, the majority of the linear fit curves do not pass through the coordinate point $(0.0,1.0)$, representing a factor of one at a strain rate of zero (quasi-static conditions), as would be expected. This may be attributed to a lack of data at higher strain rates and/or a need for a higher order curve fit. With the data currently limited to strain rates of just 40 per second or lower (depending on temperature), a higher order fit is no easier justified and the linear fit is adequate at this time for trending. The data point $(0.0,1.0)$ was added to the strain rate data when establishing the linear curve fits shown in the figures.

For a particular material (304L or 316L) and chosen temperature, the strain rate elevated true stress-strain curve can be developed up to the uniform strain limit from the factor predicted by the linear curve fit at the strain rate of interest. Using the corresponding material and temperature quasi-static true stress-strain curve, the strain rate elevated curve is developed by multiplying the appropriate factor times the true stress coordinates of the quasi-static true stressstrain curve.

Strain rate elevated true stress-strain curves for 304L and 316L materials developed using the linear curve fit relationships at various strain rates and temperatures are illustrated in Figures 70 through 79 (with strains up to their respective uniform strain limit). The 304L curves shown were based on the quasi-static true stress strain curve for $1 / 2$-inch thick, 304L, heat $54 \mathrm{M} 7$, base material at the indicated temperature. The $316 \mathrm{~L}$ curves shown were based on the quasi-static true stress-strain curve for $1 / 2$-inch thick, $316 \mathrm{~L}$, heat 230468 , base material at the indicated temperature. The quasi-static true stress-strain curves for all materials, heats, and temperatures can be found on the Report CD-R (files 1A and 1B).

Figures 70 through 74 illustrate the strain rate elevated true stress-strain curves for 304L stainless steel at 0 (quasi-static results), 5, 10, 22, and 25 per second strain rates at -20 , room, 300 , and $600{ }^{\circ} \mathrm{F}$ temperatures respectively. Figures 75 through 79 illustrate the same information but for $316 \mathrm{~L}$ material. 


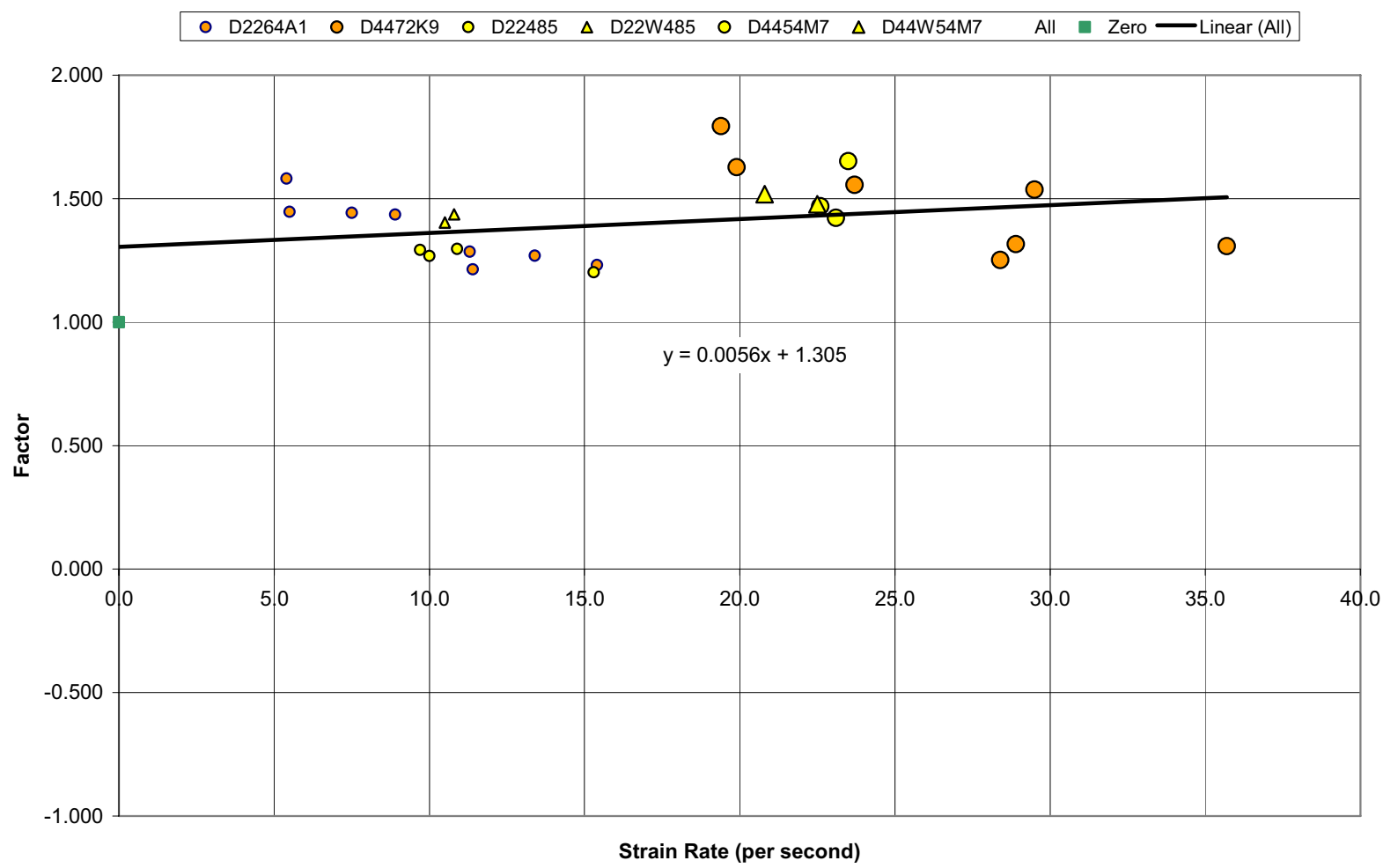

Figure 62. Factor versus strain rate curve at $-20^{\circ} \mathrm{F}$ for $304 \mathrm{~L}$.

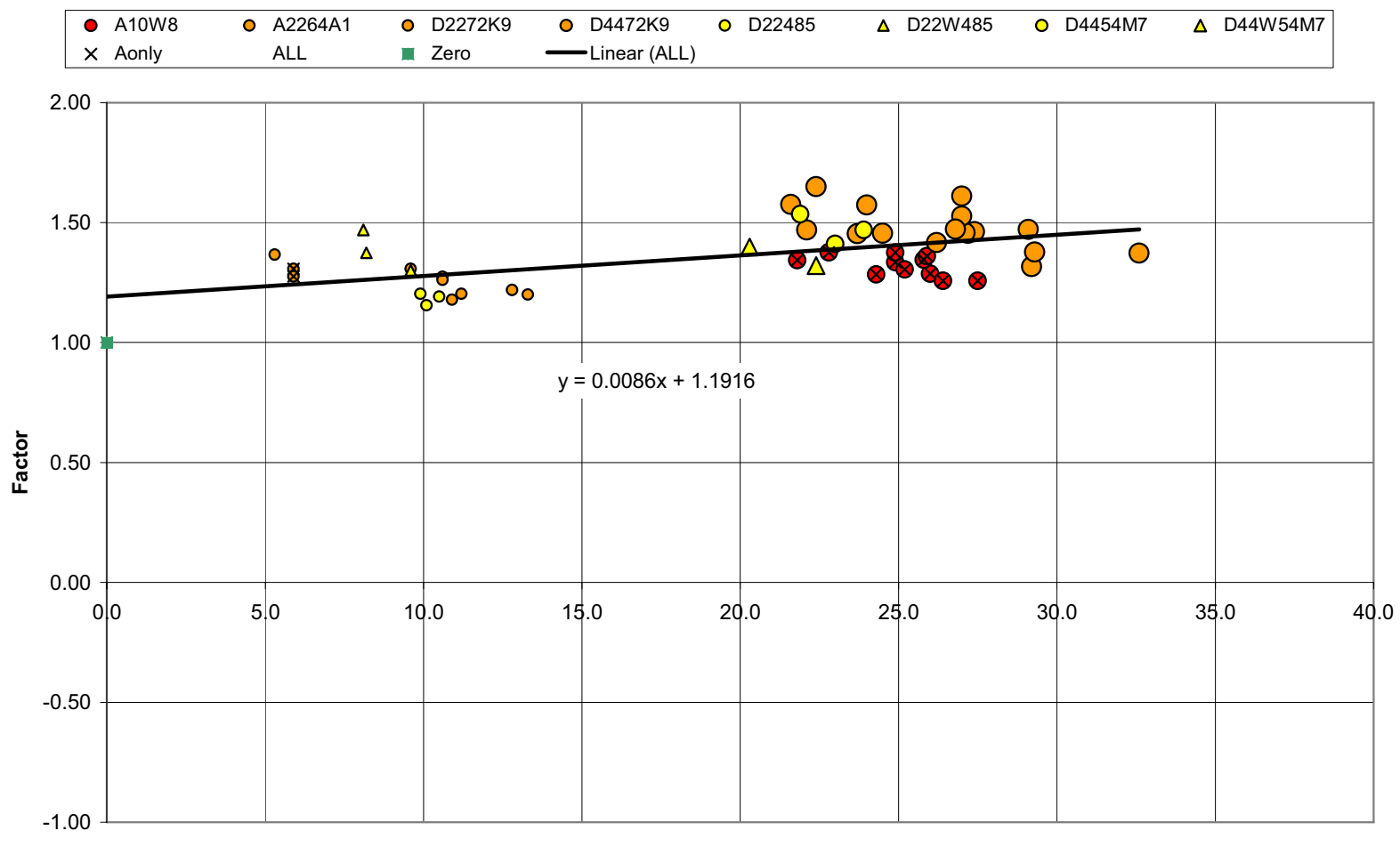

Strain Rate (per second)

Figure 63. Factor versus strain rate curve at room temperature for 304L. 


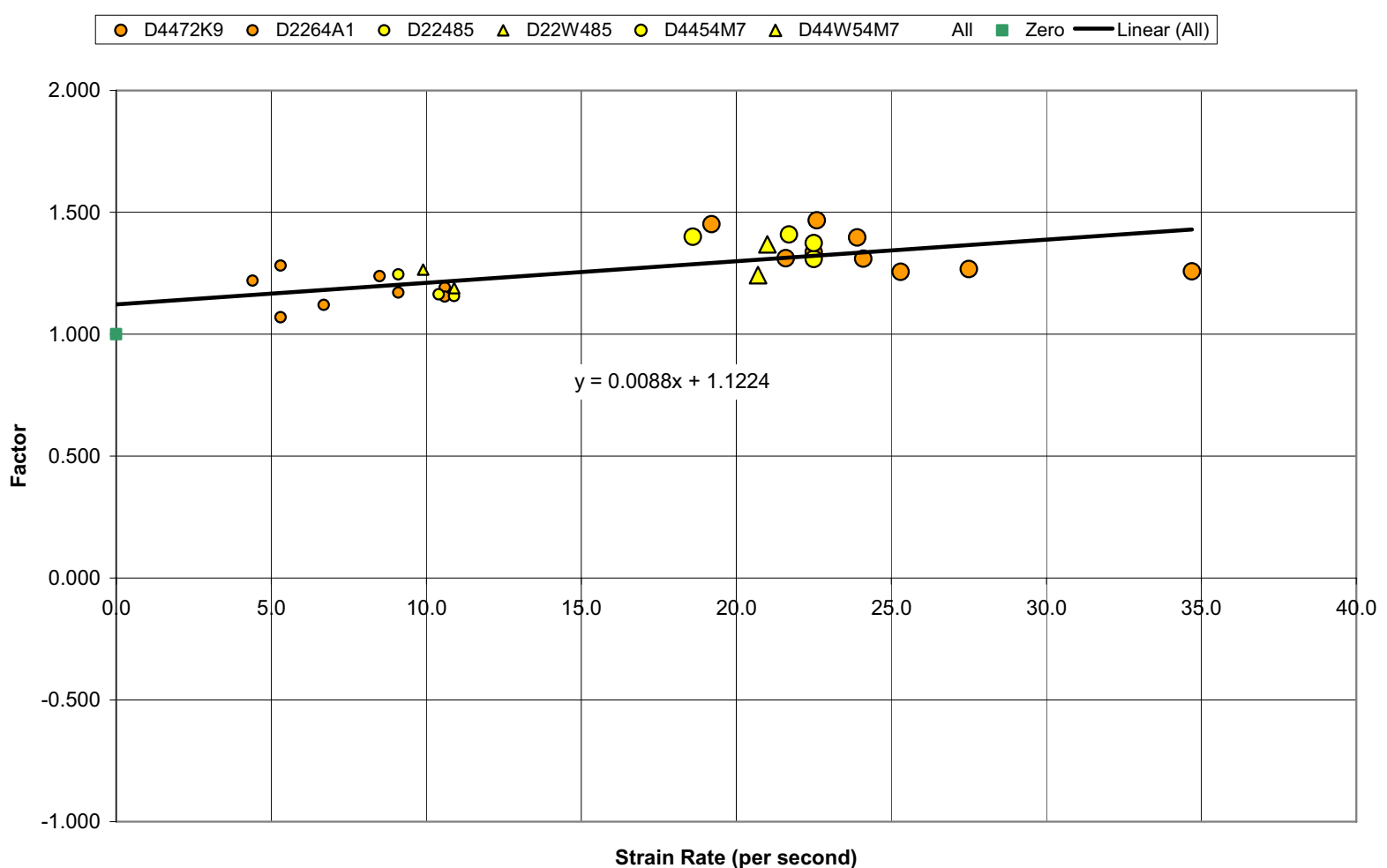

Figure 64. Factor versus strain rate curve at $300^{\circ} \mathrm{F}$ for $304 \mathrm{~L}$.

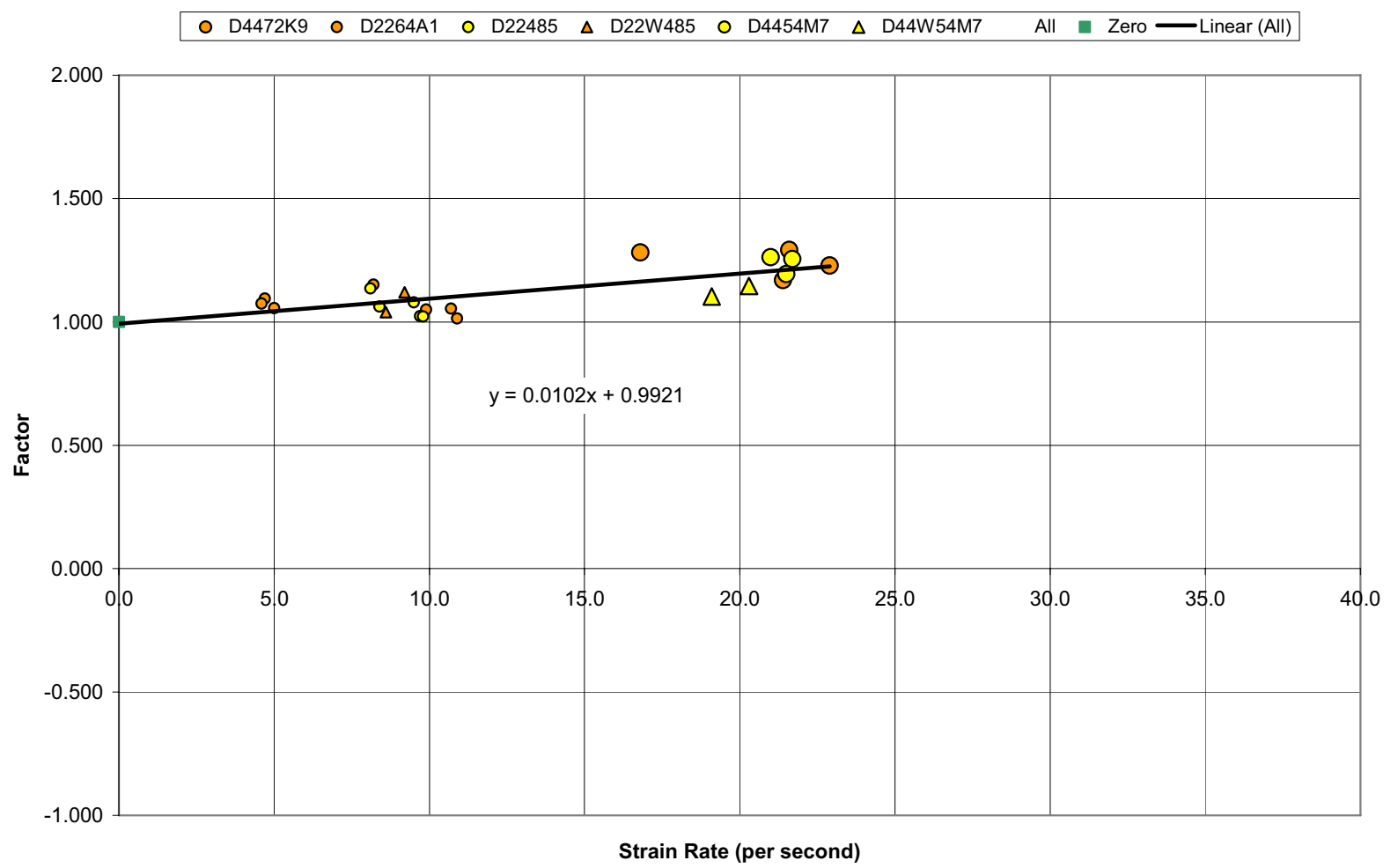

Figure 65. Factor versus strain rate curve $600^{\circ} \mathrm{F}$ for $304 \mathrm{~L}$. 


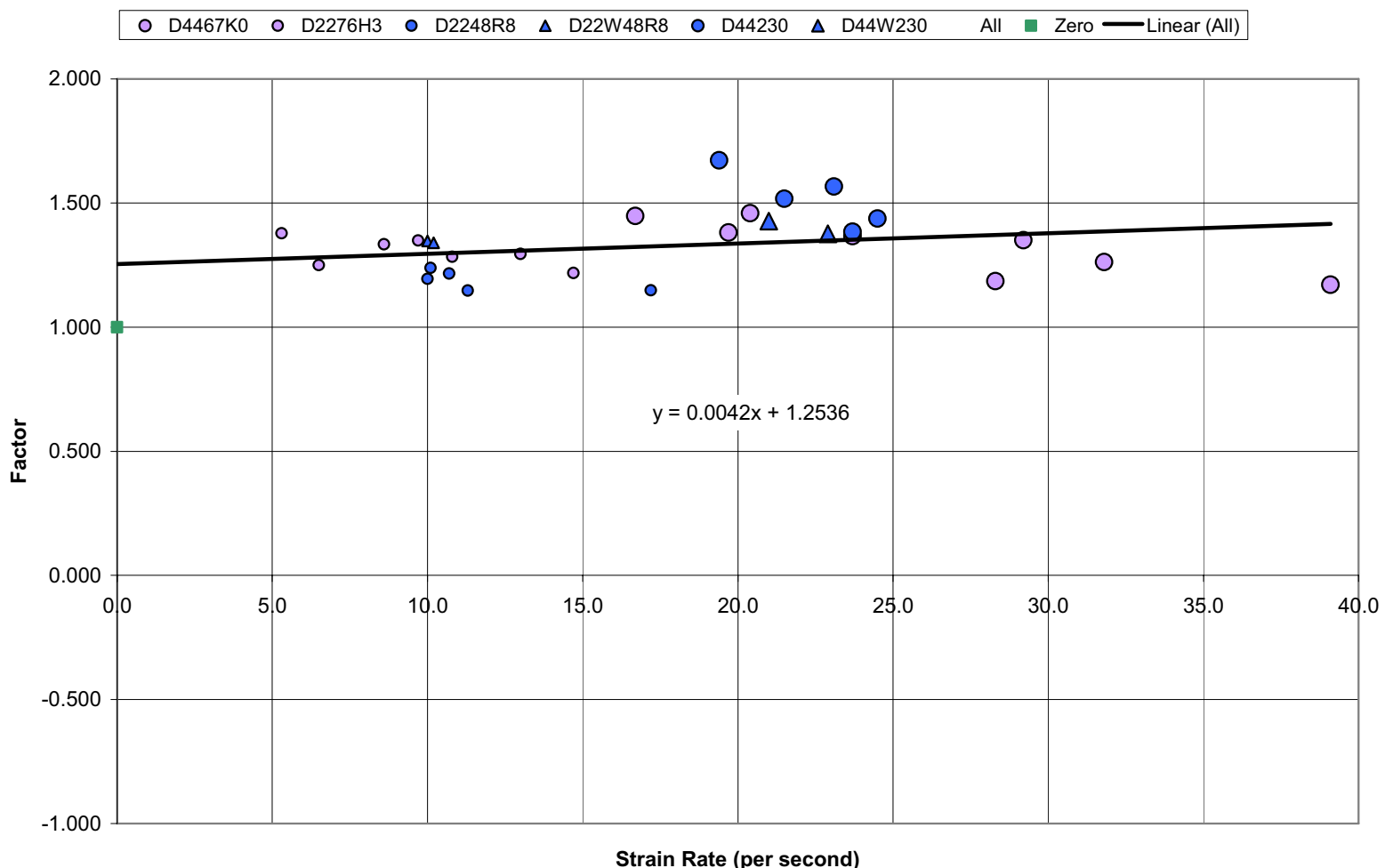

Figure 66 . Factor versus strain rate curve at $-20^{\circ} \mathrm{F}$ for $316 \mathrm{~L}$.

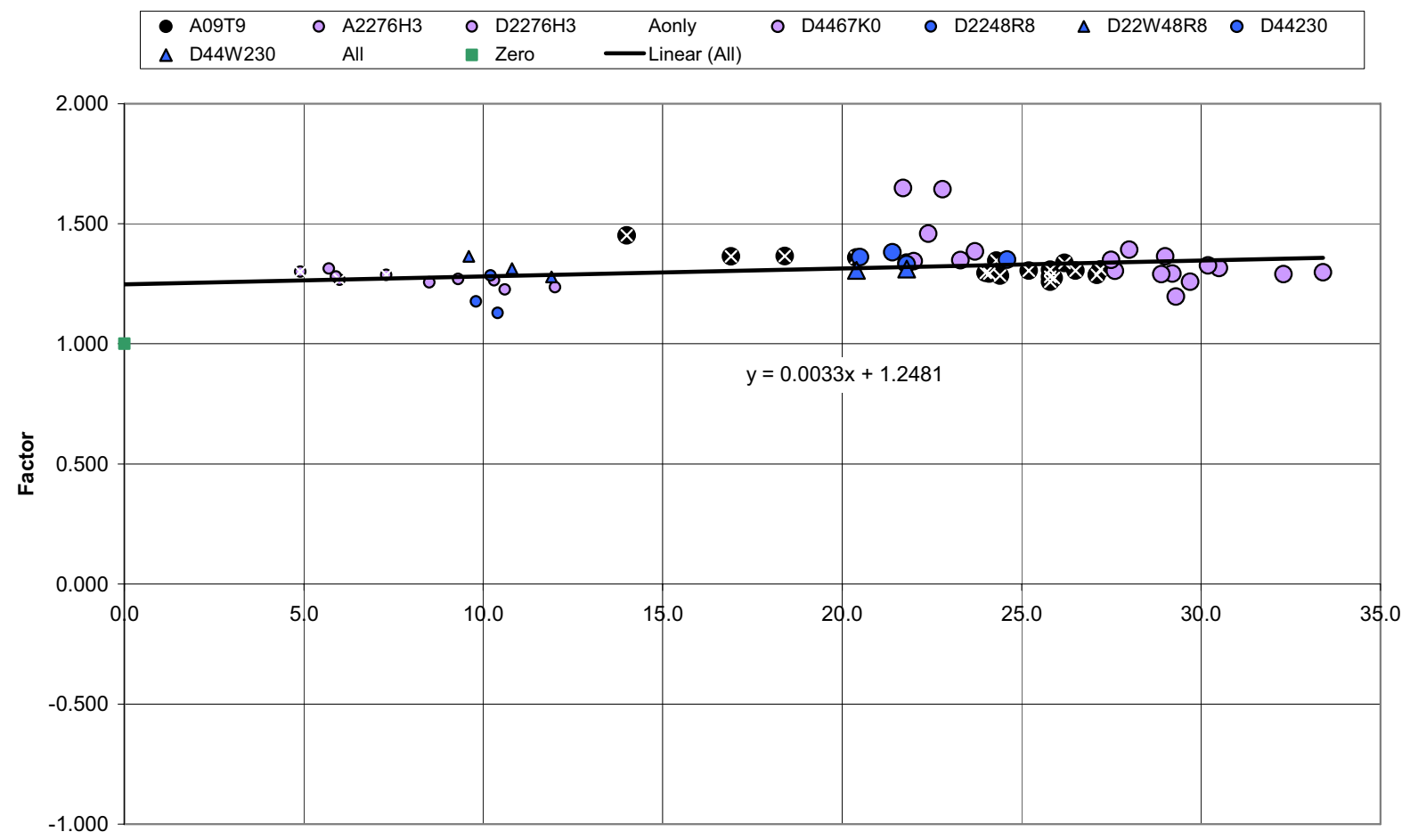

Strain Rate (per second)

Figure 67. Factor versus strain rate curve at room temperature for 316L. 


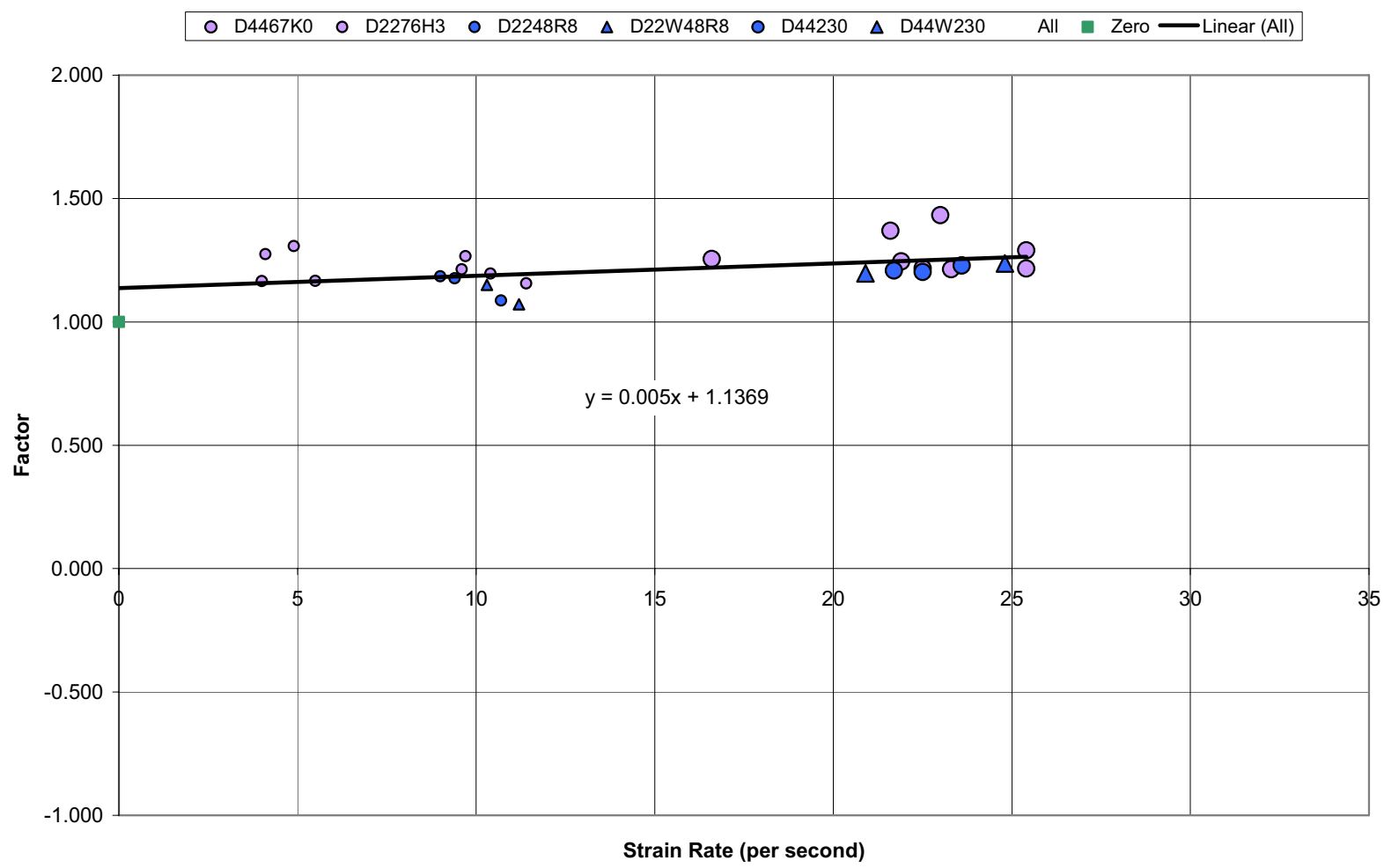

Figure 68 . Factor versus strain rate curve at $300^{\circ} \mathrm{F}$ for $316 \mathrm{~L}$.

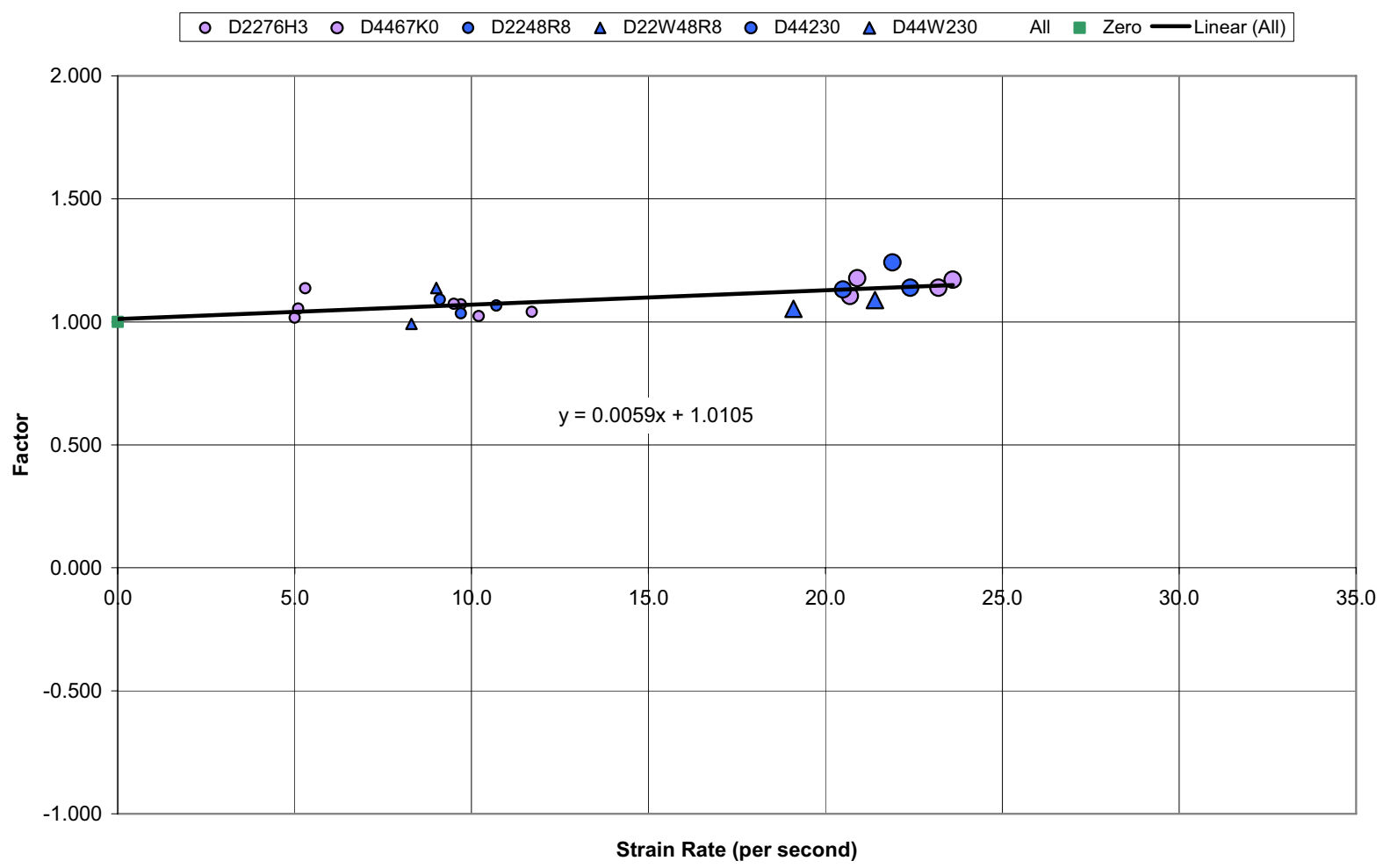

Figure 69. Factor versus strain rate curve at $600^{\circ} \mathrm{F}$ for $316 \mathrm{~L}$. 


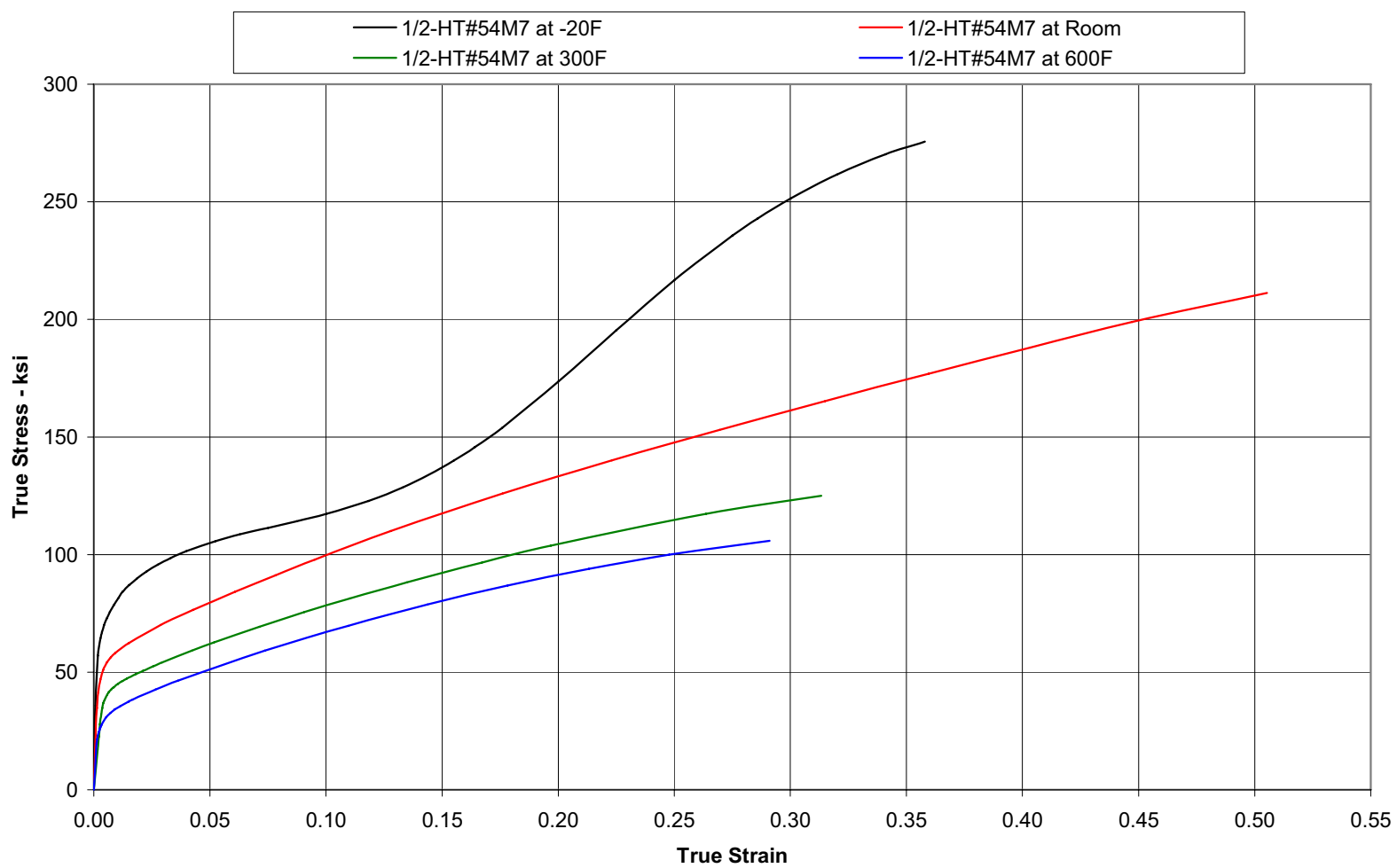

Figure 70 . 304L heat 54M7 true stress-strain curve at 22/second strain rate at varying temperatures.

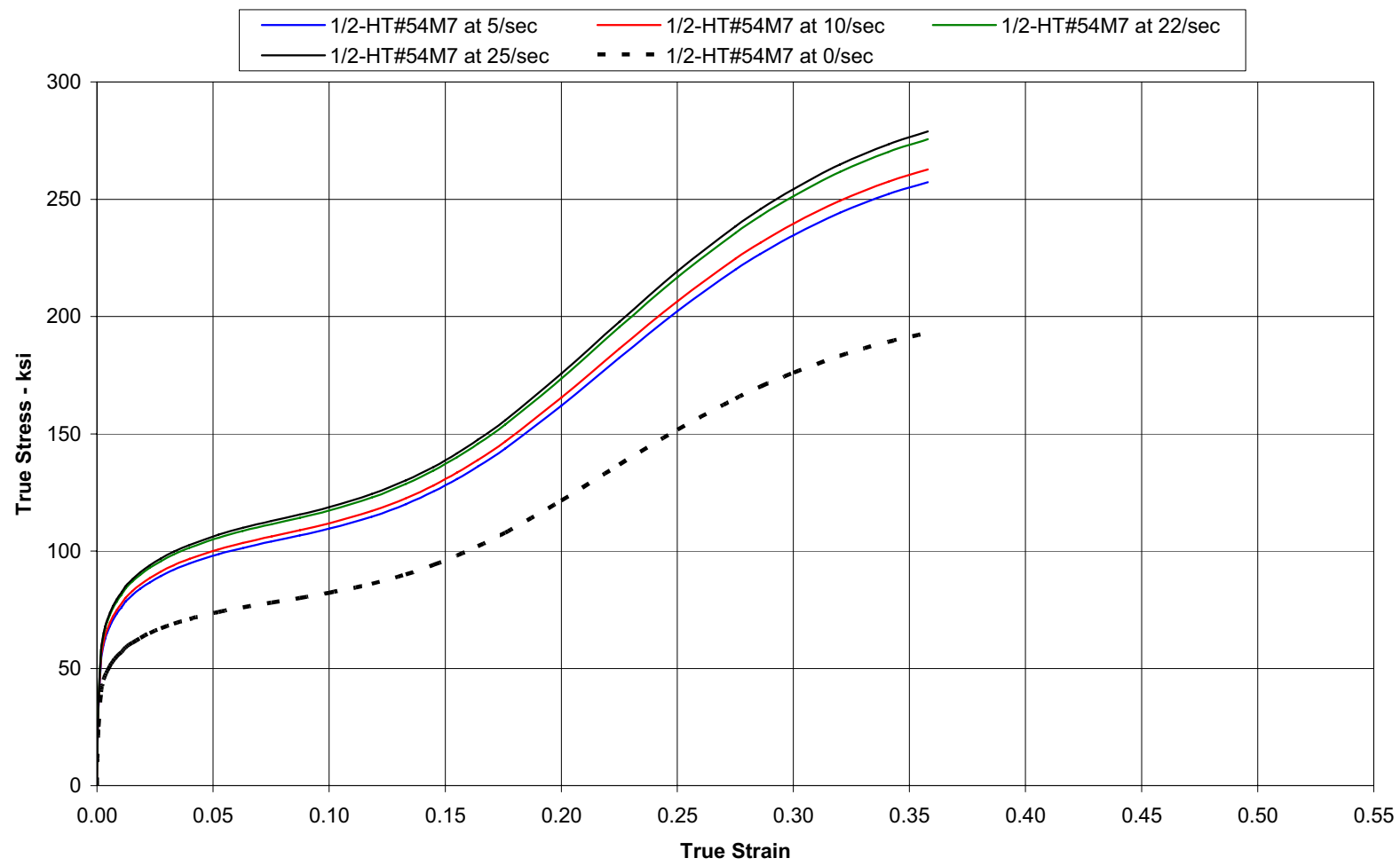

Figure $71.304 \mathrm{~L}$ heat $54 \mathrm{M} 7$ true stress-strain curve at $-20{ }^{\circ} \mathrm{F}$ at varying strain rates. 


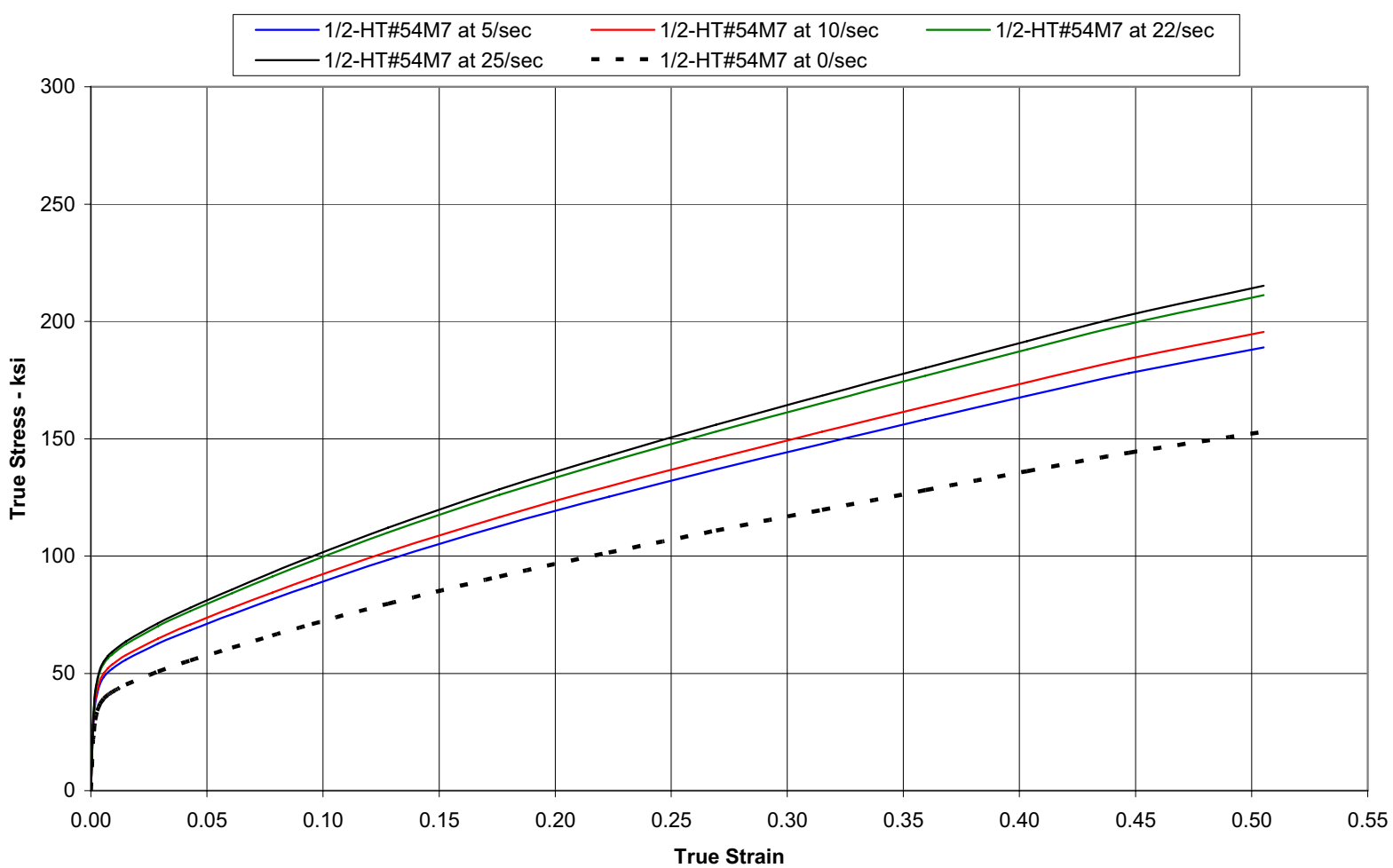

Figure $72.304 \mathrm{~L}$ heat $54 \mathrm{M} 7$ true stress-strain curve at room temperature at varying strain rates.

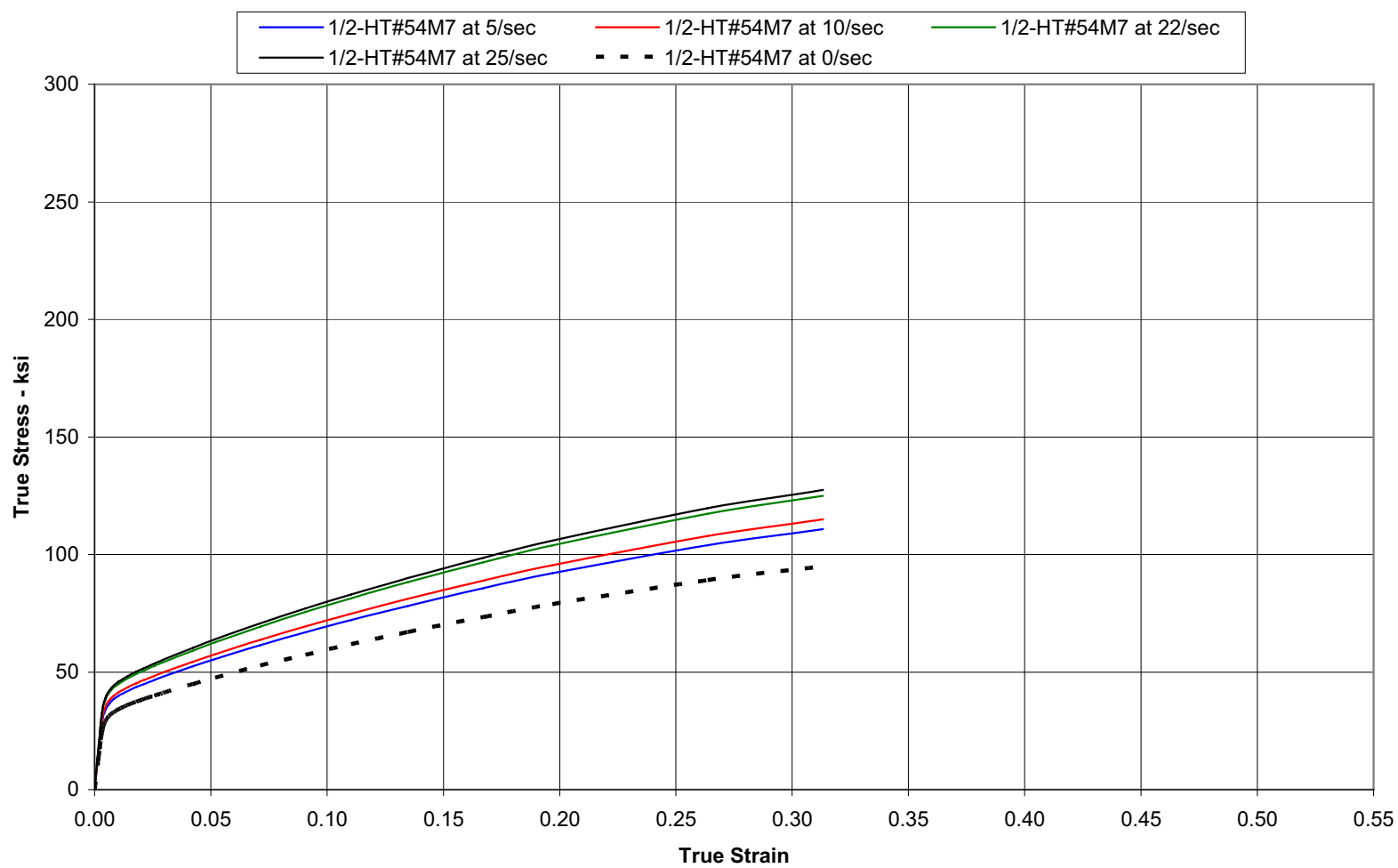

Figure 73. 304L heat $54 \mathrm{M} 7$ true stress-strain curve at $300{ }^{\circ} \mathrm{F}$ at varying strain rates. 


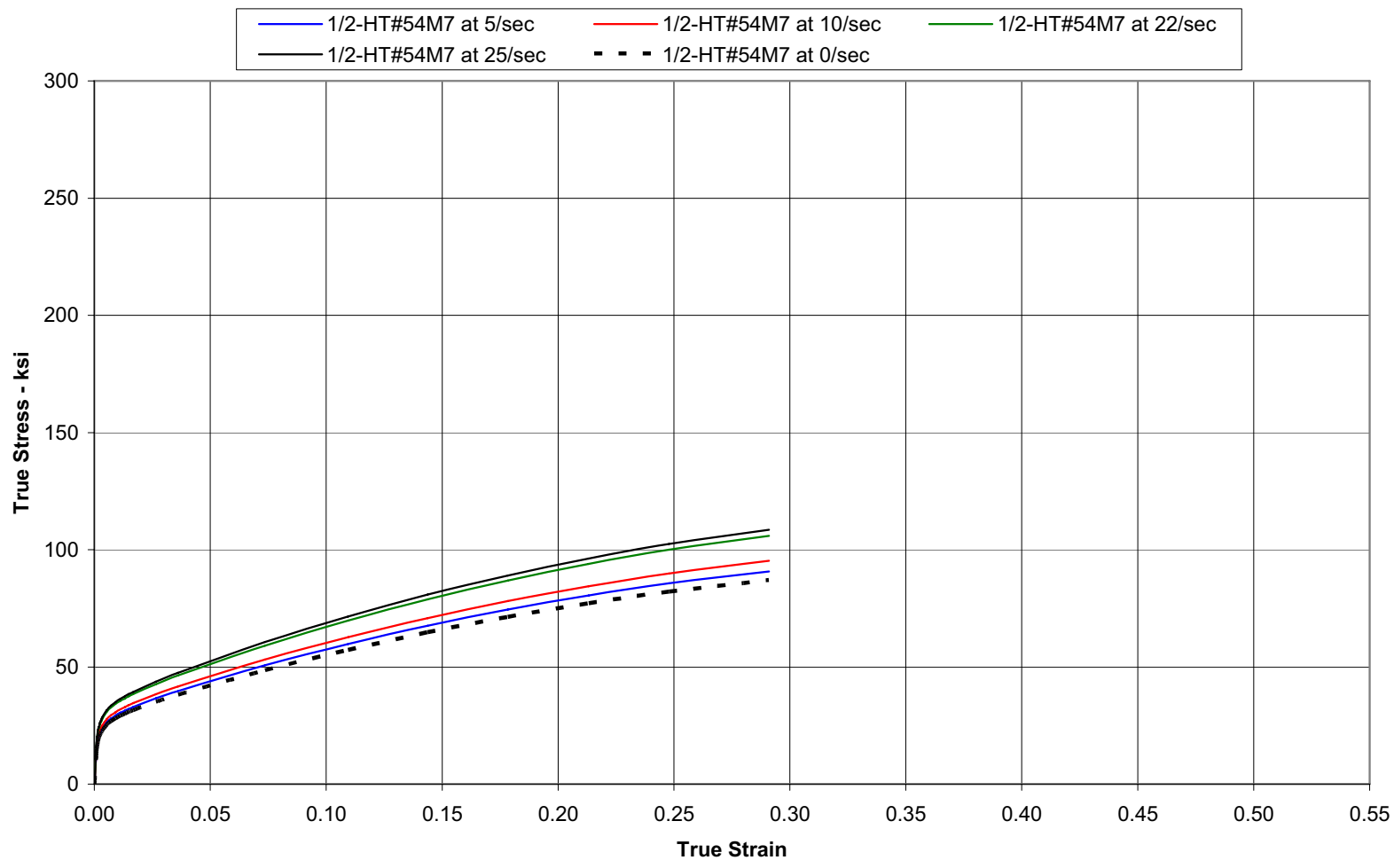

Figure $74.304 \mathrm{~L}$ heat $54 \mathrm{M} 7$ true stress-strain curve at $600^{\circ} \mathrm{F}$ at varying strain rates.

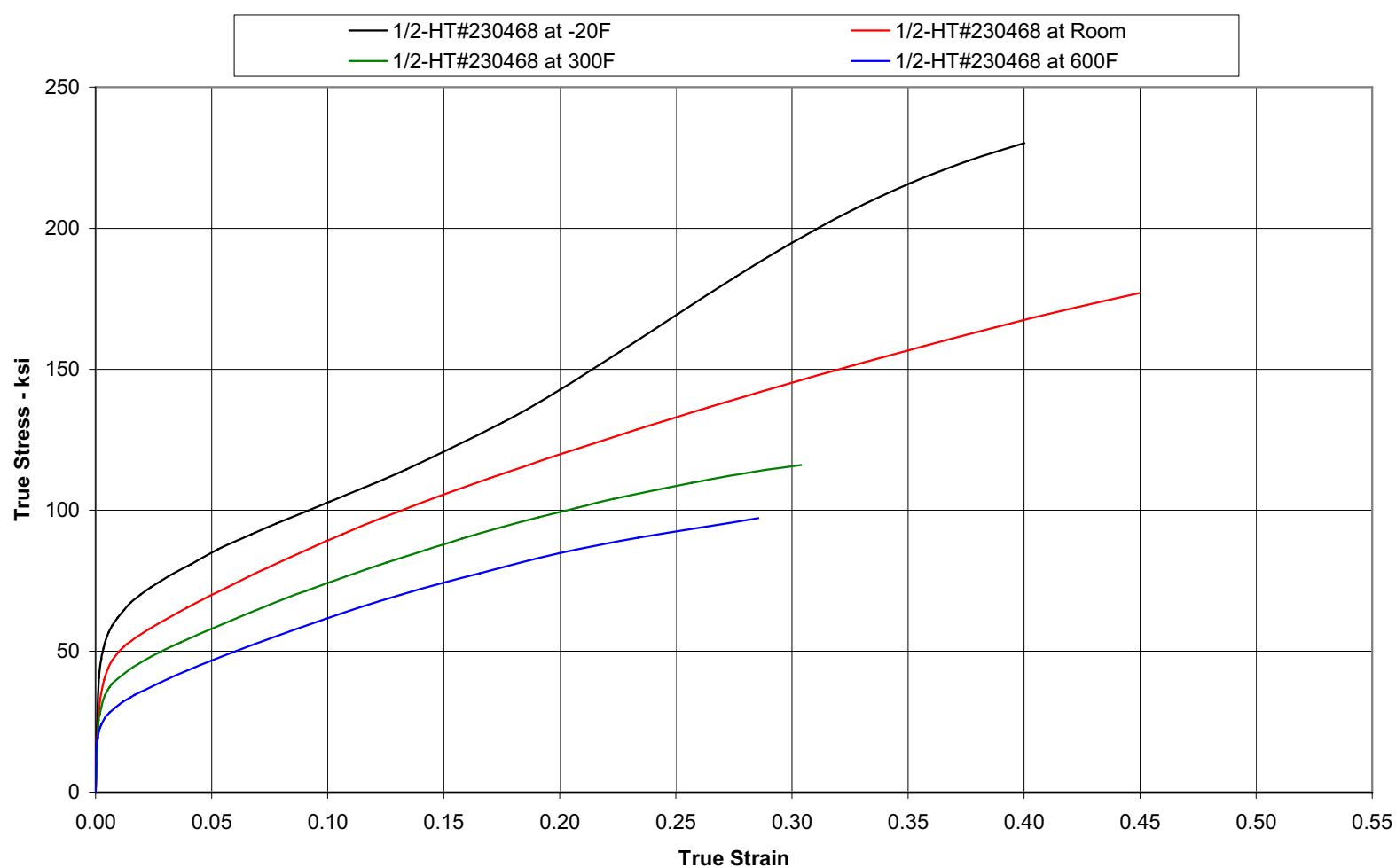

Figure $75.316 \mathrm{~L}$ heat 230468 true stress-strain curve at $22 /$ second strain rate at varying temperatures. 


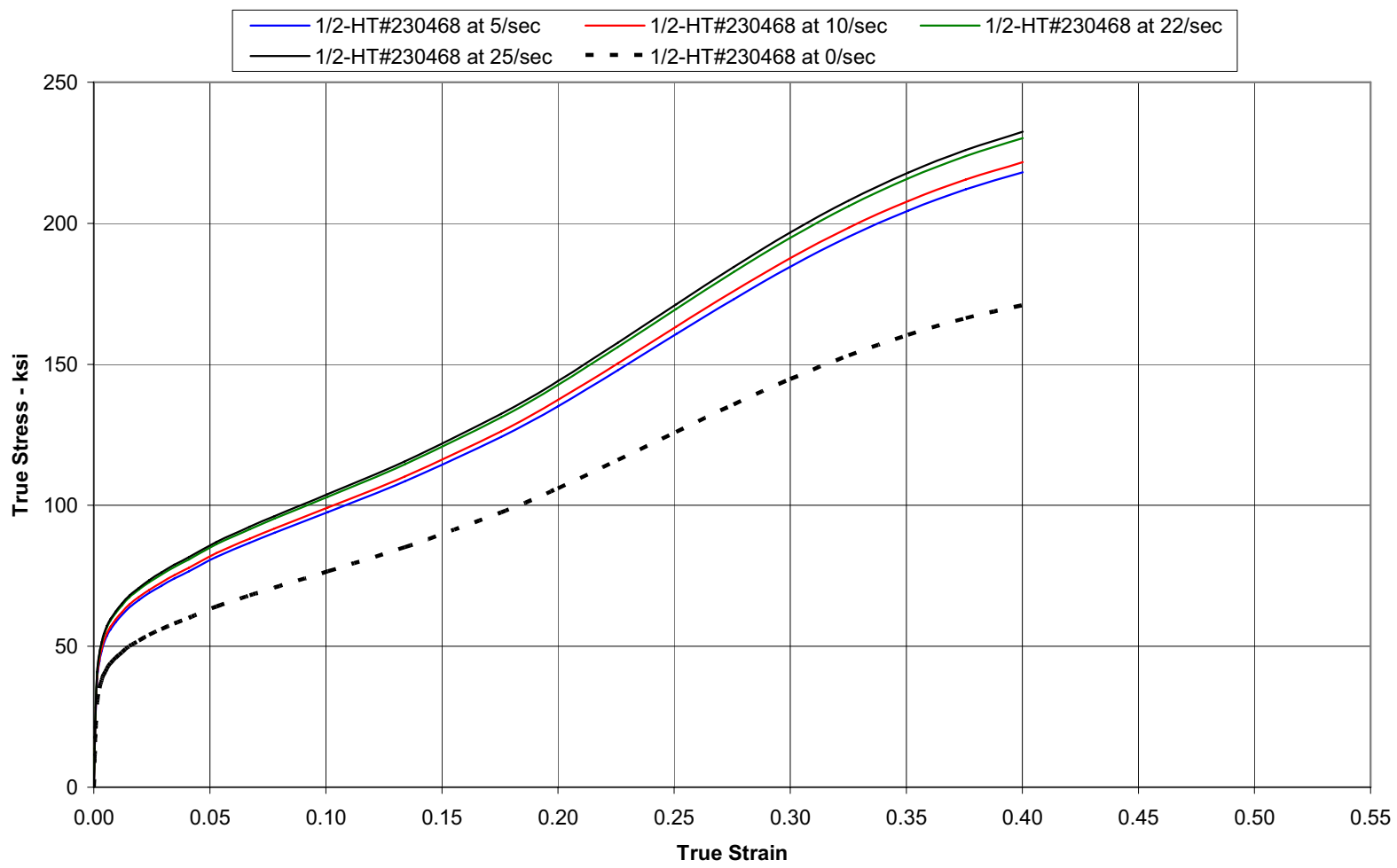

Figure 76 . $316 \mathrm{~L}$ heat 230468 true stress-strain curve at $-20{ }^{\circ} \mathrm{F}$ at varying strain rates.

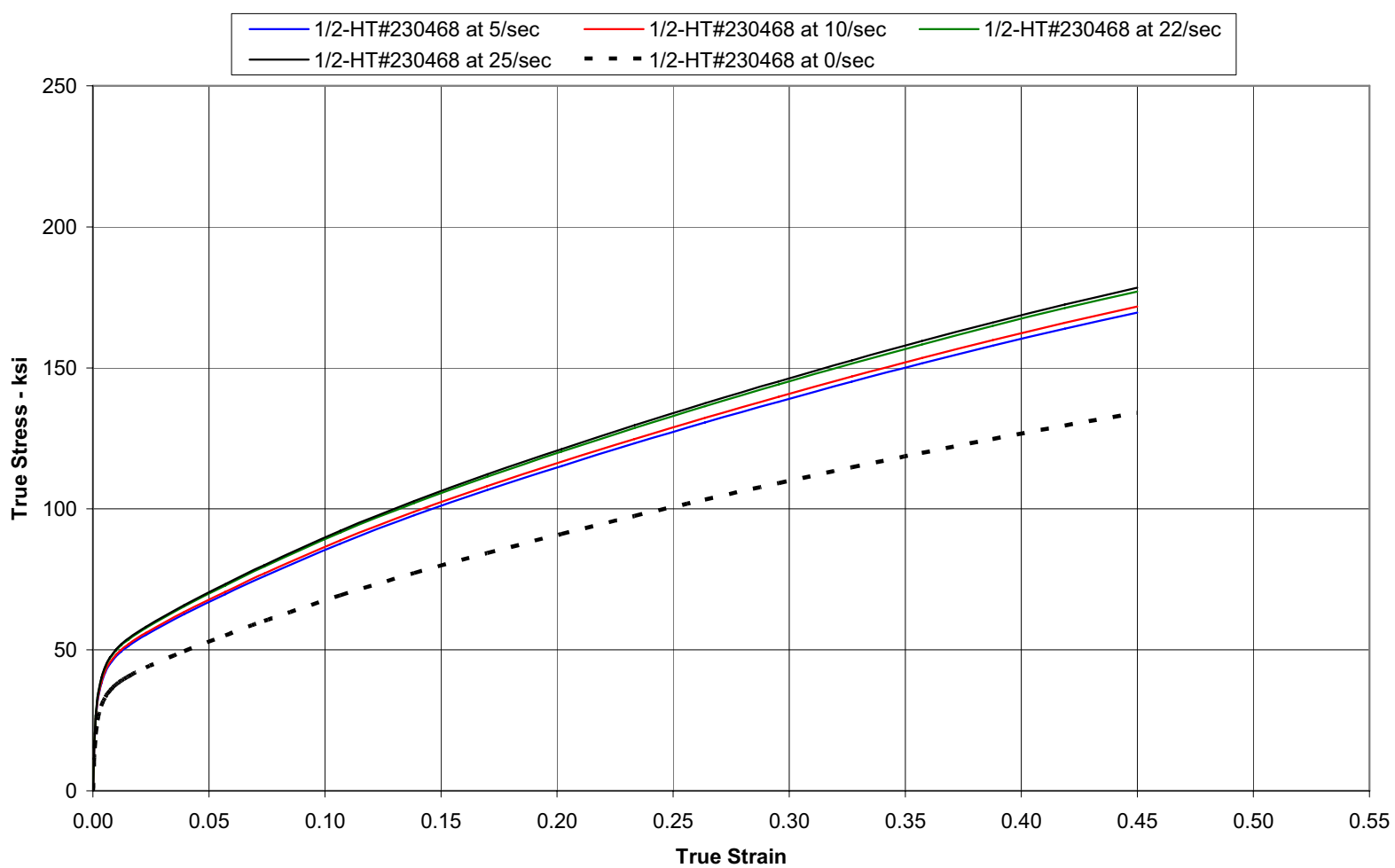

Figure 77 . $316 \mathrm{~L}$ heat 230468 true stress-strain curve at room temperature at varying strain rates. 


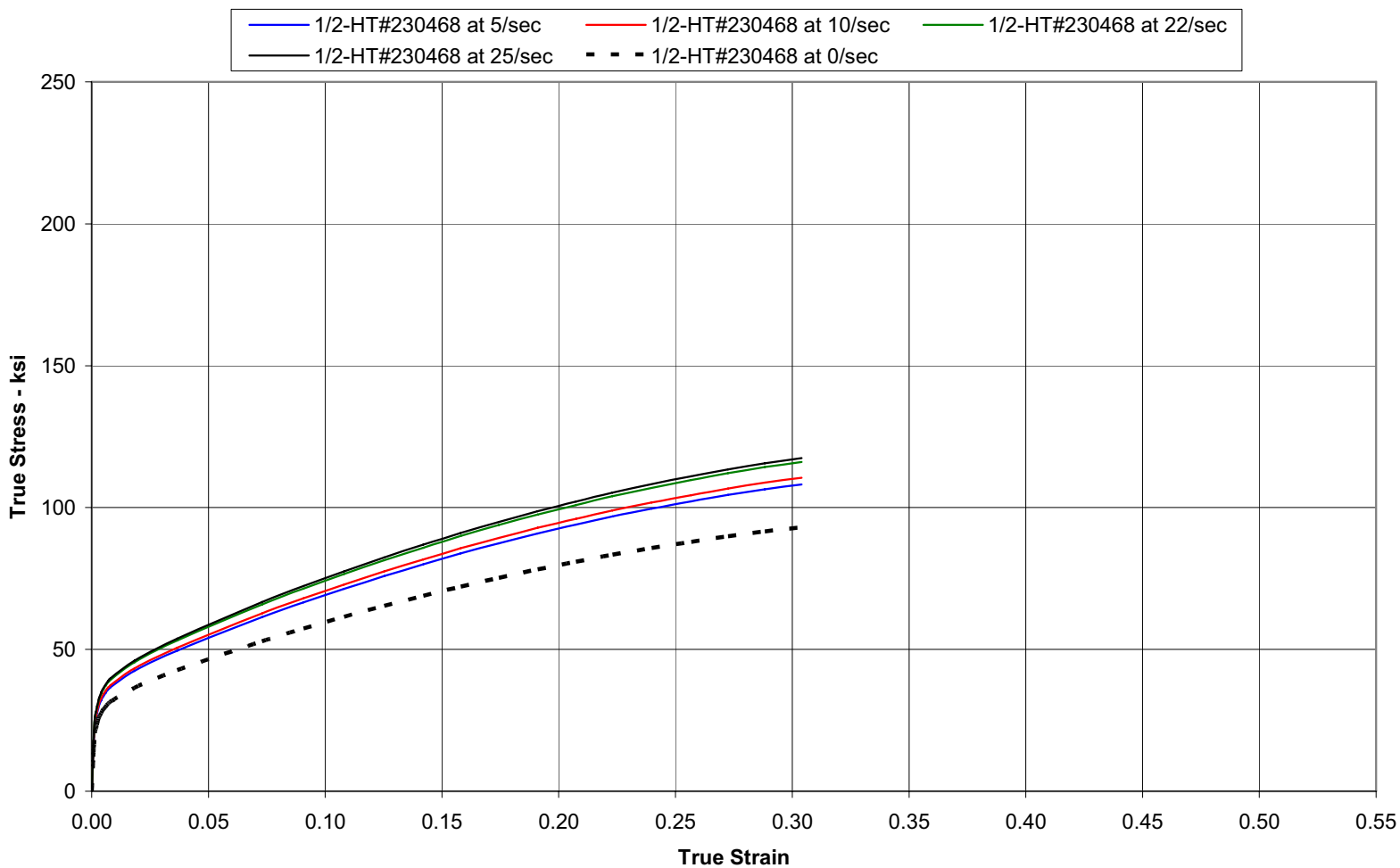

Figure 78. $316 \mathrm{~L}$ heat 230468 true stress-strain curve at $300{ }^{\circ} \mathrm{F}$ at varying strain rates.

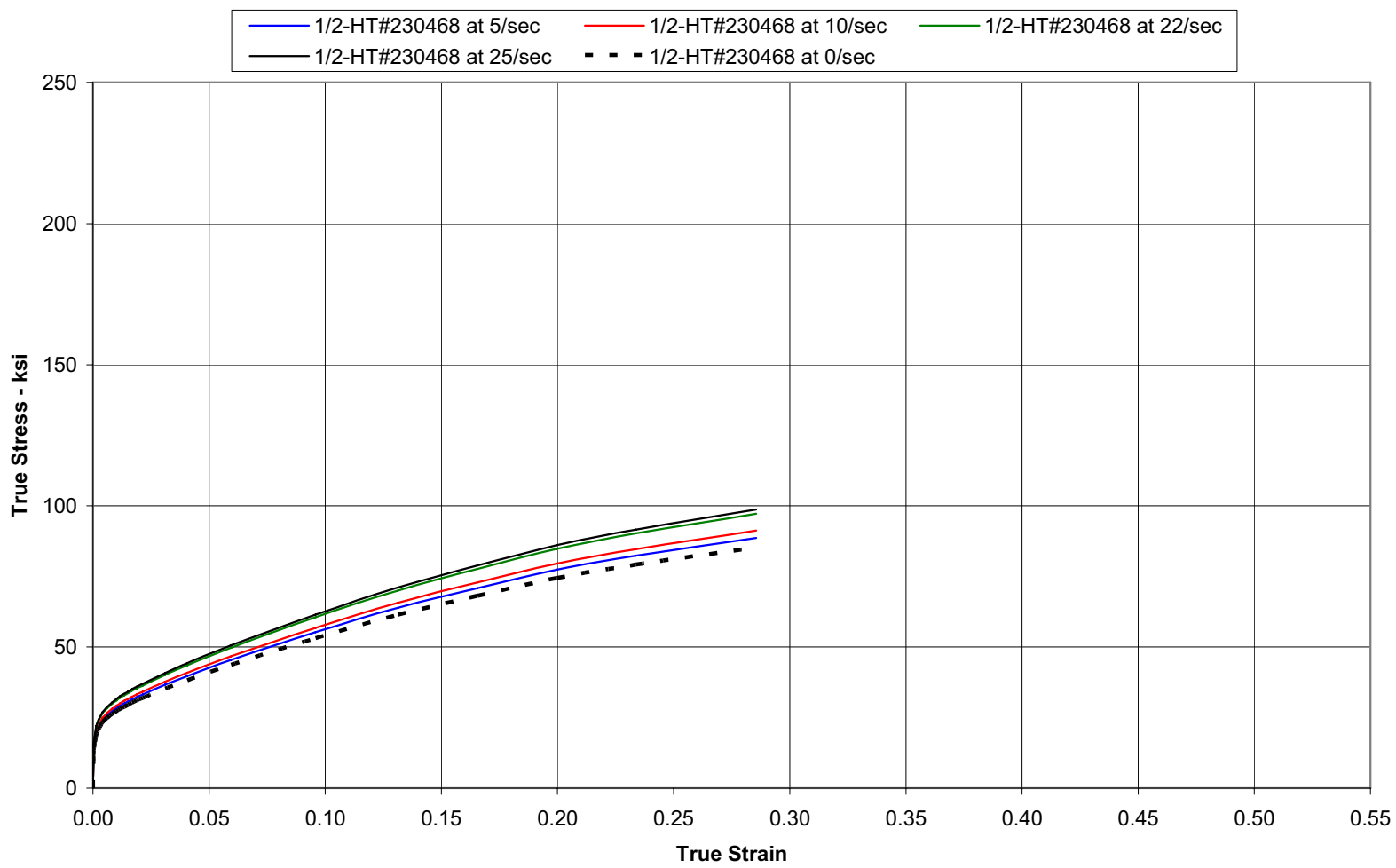

Figure 79. 316L heat 230468 true stress-strain curve at $600{ }^{\circ} \mathrm{F}$ at varying strain rates. 
Although this testing program did not investigate the entire strain rate range of interest (up to 300 per second), certain important insights can be observed by evaluating the findings to date. The strain rate elevated true stress-strain curves (Figures 70 through 79) clearly illustrate that increasing strain rates result in increased (higher strength) true stress-strain curves (factors are positive and increasing with increasing strain rate). It is expected that this trend would continue, possibly to a limit, as higher strain rates are investigated. However, actual magnitudes and rates of change beyond those considered herein cannot be quantified without further testing.

Comparing 304L versus 316L curves, the increased capacity to absorb impact energy appears more significant in the 304L than in the 316L material. Figures 70 and 75 illustrate how the strain rate elevated true stress-strain curves vary with temperature at a strain rate of 22 per second. These two figures both indicate that at the same strain rate, increasing temperature decreases the strain rate gain in strength. This is shown more clearly by the listing of factors (calculated from each appropriate curve fit) in Table 27 where the magnitudes decrease as the temperatures increase.

Table 27. Factors for specified strain rates.

\begin{tabular}{|c|c|c|c|c|}
\hline $\begin{array}{c}\text { Strain } \\
\text { rate } \\
\text { (per sec.) }\end{array}$ & $\begin{array}{c}\mathbf{- 2 0} \\
{ }^{\mathbf{}} \mathbf{F}\end{array}$ & $\begin{array}{c}\text { Room } \\
\text { Temperature }\end{array}$ & $\begin{array}{c}\mathbf{3 0 0} \\
{ }^{\mathbf{0}} \mathbf{F}\end{array}$ & $\begin{array}{c}\mathbf{6 0 0} \\
{ }^{\mathbf{}} \mathbf{F}\end{array}$ \\
\hline 5 & 1.333 & 1.235 & 1.166 & 1.043 \\
\hline 10 & 1.361 & 1.278 & 1.210 & 1.094 \\
\hline 22 & 1.428 & 1.381 & 1.316 & 1.217 \\
\hline 25 & 1.445 & 1.407 & 1.342 & 1.247 \\
\hline \multicolumn{5}{|c|}{31 L Stainless Steel } \\
\hline 5 & 1.275 & 1.265 & 1.162 & 1.040 \\
\hline 10 & 1.296 & 1.281 & 1.187 & 1.070 \\
\hline 22 & 1.346 & 1.321 & 1.247 & 1.140 \\
\hline 25 & 1.359 & 1.331 & 1.262 & 1.158 \\
\hline
\end{tabular}




\section{USING RESULTS: ABAQUS/EXPLICIT ANALYSES USING STRAIN RATE ELEVATED TRUE STRESS-STRAIN CURVES}

With the strain rate factors and strain rate elevated true stress strain curves developed (within the specified strain rate range), it is appropriate to investigate the actual validity of these impact test results. As discussed in Section 1 of this report:

"The test data developed can be used to establish an analysis methodology that can then be applied in analytical simulations to more accurately predict the deformation and resulting material straining in the components being evaluated that are subject to dynamic, impulsive loads."

Forty finite element analyses were performed of various impact tests using the fully dynamic, inelastic analysis software ABAQUS/Explicit, Version 6.6-3. Material properties were input as either non-factored (the quasi-static true stress-strain curve) or factored true stress-strain curves (reflecting strain rate effects as quantified herein using the appropriate curve fit data). The true stress-strain curves input to each analysis reflected the proper material heat (either base or welded material) at the proper temperature, as described in Sections 5 and 6. For the factored true stress-strain input, two strain rate elevated true stress strain curves were input into the finite element model. The first true stress-strain curve had a zero strain rate designated and the second curve had an upper bound (typically 30 per second) strain rate designated. The factors applied were the factors resulting from the curve fits identified on the appropriate factor versus strain rate curves presented in Section 7, even if the factor was not unity at zero strain rate. Linear interpolation of the material properties for strain rates between these two bounding strain rate points was used.

Due to symmetry in two planes, a quarter-model of the test specimen was created (see Figure 80) with mass from the impact driver appropriately applied. Model restraint was provided by fixing the upper cross-member pin in space and by applying plane symmetry boundary restraints to the specimen and lower cross-member pin. To initiate a test simulation, the model mass representing the drop weight was given an initial velocity equal to the drop weight's impact velocity. The analyses were run for a time period of approximately 0.030 seconds, which was determined from the actual testing to be sufficient to capture the full downward motion of the test specimen. Nominal dimensions for the test specimen geometry were used (just like a typical design analysis approach), rather than test specimen specific dimensions based on pre-test measurements.

Table 28 provides a summary of all forty analyses performed, grouped by temperature and strain rate. Percent difference comparisons using non-factored and factored analysis results are made to the actual resulting gauge length axial deformations (for the temperatures considered) at the target strain rates of 10 and 22 per second. In Table 28, the plus values indicate over-prediction and the negative values indicate under-prediction. The Table 28 results clearly indicate that the strain rate adjusted (factored) material input yields more accurate analysis predictions than when just the quasi-static (non-factored) true stress-strain curves are used. Considerable error (over 40\%) results when just the quasi-static true stress-strain curves are used, indicating that strain rate effects are real and significant. As expected, all of the analysis results using the non-factored input over-predicted the axial deformation. Without 
elevating the true stress-strain curve, a higher strain prediction results in order to equate the impact test's strain energy density with the area under the defined stress-strain curve. The factored material input analyses had estimates above and below the actual deformation, anticipated considering material property and test specimen geometry variabilities.

In general terms, the analysis results show significant improvement for all temperatures except for the $600{ }^{\circ} \mathrm{F}$ results. Seven out of the ten $600^{\circ} \mathrm{F}$ analyses performed had more accurate results using the factored input but three tests (\#391, \#508, and \#394) had higher percent differences. The percentage variation at $600^{\circ} \mathrm{F}$ between non-factored and factored input is reduced due to the lower magnitude of strain rate factors, especially at the strain rates of 5 and 10 per second. These associated factors are less than 1.10, clearly within the variability of plate material properties. Table 29 provides more detailed test and analysis comparison results for each impact test analytically considered, with the shaded portions reflecting the lower strain rate analysis results. Appendix G contains the names and dates of the ABAQUS/Explicit models used for this comparative evaluation. This information is being provided in accordance with NSNFP Procedure 19.03 (Reference 43). The strain rate data quantified herein has indeed provided an improved analysis methodology for dynamic, impulsive events.

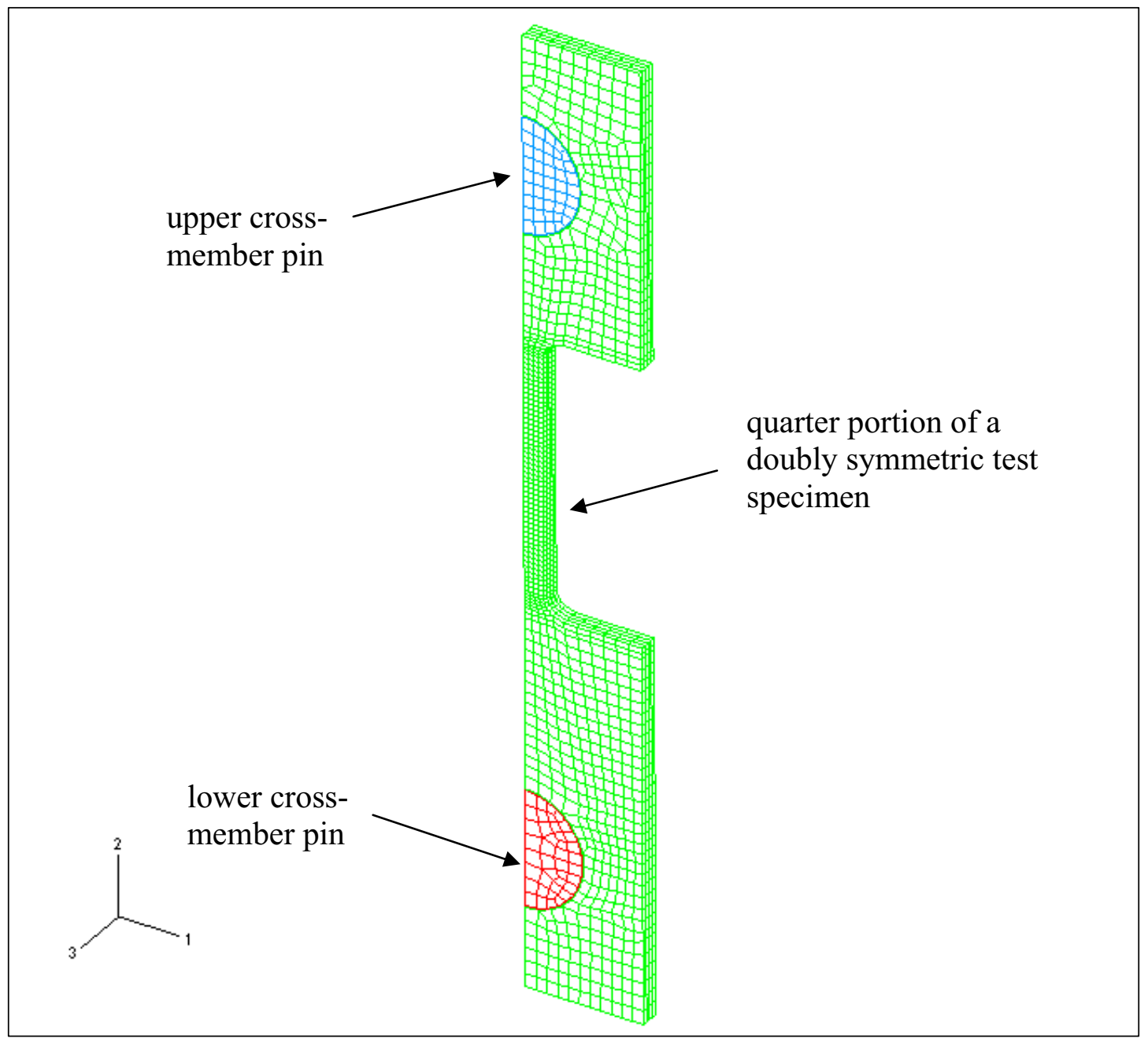

Figure 80. ABAQUS/Explicit symmetric model of impact test specimen. 
Table 28. Summary of comparisons of analytical results using non-factored and factored input to actual impact test deformations.

\begin{tabular}{|c|c|c|c|c|}
\hline \multirow{2}{*}{ Temperature } & \multicolumn{4}{|c|}{$\begin{array}{c}\text { Percent Difference Comparisons Between Actual Test Results } \\
\text { and ABAQUS/Explicit Calculated Results (\%) }\end{array}$} \\
\cline { 2 - 5 } & \multicolumn{2}{|c|}{ Non-Factored } & \multicolumn{2}{c|}{ Factored } \\
\cline { 2 - 5 } & SR=10 & SR=22 & SR=10 & SR=22 \\
\hline$-20{ }^{\circ} \mathrm{F}$ & +24.8 to +40.7 & +25.2 to +36.9 & -6.2 to +10.6 & -3.6 to +6.3 \\
\hline Room & +22.6 to +33.3 & +21.4 to +34.8 & -5.5 to +4.4 & -4.5 to +4.0 \\
\hline $300^{\circ} \mathrm{F}$ & +11.4 to +34.7 & +8.9 to +24.1 & -7.8 to +12.7 & -9.4 to -0.3 \\
\hline $600^{\circ} \mathrm{F}$ & +2.6 to +12.0 & +2.0 to +12.4 & -5.7 to +5.9 & -7.6 to -1.8 \\
\hline $\begin{array}{l}\text { Positive table values indicate over-predicted deformations and negative table values indicate under- } \\
\text { predicted deformations, when compared to actual test results. } \\
\text { SR }- \text { strain rate }\left(\text { sec }^{-1}\right)\end{array}$
\end{tabular}


Table 29. Comparison of ABAQUS/Explicit predictions using non-factored and factored input to test deformations of impact tests.

\begin{tabular}{|c|c|c|c|c|c|c|c|c|c|c|c|c|c|}
\hline \multirow[b]{2}{*}{ Material } & \multirow{2}{*}{$\begin{array}{c}\text { Temp. } \\
\text { (F) }\end{array}$} & \multirow{2}{*}{$\begin{array}{c}\text { Strain } \\
\text { Rate }^{-1} \\
\left(\text { sec. }^{-1}\right)\end{array}$} & \multirow{2}{*}{$\begin{array}{l}\text { Specimen } \\
\text { Geom. }\end{array}$} & \multirow{2}{*}{$\begin{array}{c}\text { Drop } \\
\text { Weight } \\
\text { (lb.) }\end{array}$} & \multirow{2}{*}{$\begin{array}{c}\text { Drop } \\
\text { Height } \\
\text { (in.) }\end{array}$} & \multirow{2}{*}{$\begin{array}{l}\text { Test } \\
\text { No. }\end{array}$} & \multirow{2}{*}{$\begin{array}{c}\text { Test } \\
\text { Specimen } \\
\text { No. }\end{array}$} & \multirow{2}{*}{$\begin{array}{c}\text { Gauge } \\
\text { Deform. } \\
\text { (in.) }\end{array}$} & \multirow{2}{*}{$\begin{array}{c}\text { Material } \\
\text { Test } \\
\text { Used }\end{array}$} & \multicolumn{2}{|c|}{ Without Factors } & \multicolumn{2}{|c|}{ With Factors } \\
\hline & & & & & & & & & & $\begin{array}{c}\text { ABAQUS } \\
\text { Deform. (in.) }\end{array}$ & $\begin{array}{c}\text { Percent } \\
\text { Difference }\end{array}$ & $\begin{array}{c}\text { ABAQUS } \\
\text { Deform. (in.) }\end{array}$ & $\begin{array}{c}\text { Percent } \\
\text { Difference }\end{array}$ \\
\hline \multirow{20}{*}{$304 \mathrm{~L}$} & \multirow{5}{*}{-20} & 9.7 & D-2-2 & 1097 & 2.5 & 451 & 304L-291 & 0.4775 & 55 & 0.6096 & $27.7 \%$ & 0.4523 & $5.3 \%$ \\
\hline & & 8.9 & D-2-2 & 790 & 3.0 & 432 & 304L-261 & 0.3710 & 13 & 0.5152 & $38.9 \%$ & 0.3751 & $1.1 \%$ \\
\hline & & 22.5 & D-4-4W & 1097 & 17.5 & 491 & $304 \mathrm{~L}-285$ & 0.5060 & $183 \mathrm{~W}$ & 0.6929 & $36.9 \%$ & 0.5071 & $0.3 \%$ \\
\hline & & 22.6 & D-4-4 & 790 & 20.0 & 468 & $304 \mathrm{~L}-301$ & 0.4760 & 156 & 0.6184 & $29.9 \%$ & 0.4795 & $0.7 \%$ \\
\hline & & 19.9 & D-4-4 & 1097 & 17.5 & 457 & 304L-294 & 0.5210 & 106 & 0.7067 & $35.6 \%$ & 0.5528 & $6.1 \%$ \\
\hline & \multirow{5}{*}{ Room } & 9.9 & D-2-2 & 1097 & 2.75 & 355 & $304 \mathrm{~L}-244$ & 0.5660 & 47 & 0.7183 & $26.9 \%$ & 0.5590 & $1.2 \%$ \\
\hline & & 9.6 & D-2-2 & 790 & 3.0 & 312 & 304L-209 & 0.4340 & 2 & 0.5727 & $31.9 \%$ & 0.4533 & $4.4 \%$ \\
\hline & & 22.4 & D-4-4W & 1097 & 17.375 & 381 & $304 \mathrm{~L}-273$ & 0.6050 & $177 \mathrm{~W}$ & 0.7701 & $27.3 \%$ & 0.5777 & $4.5 \%$ \\
\hline & & 23.9 & D-4-4 & 790 & 21.625 & 349 & $304 \mathrm{~L}-226$ & 0.6005 & 153 & 0.7652 & $27.4 \%$ & 0.5933 & $1.2 \%$ \\
\hline & & 22.1 & D-4-4 & 1097 & 17.5 & 290 & $304 \mathrm{~L}-203$ & 0.6415 & 113 & 0.8648 & $34.8 \%$ & 0.6674 & $4.0 \%$ \\
\hline & \multirow{5}{*}{300} & 10.4 & D-2-2 & 1097 & 2.375 & 388 & $304 \mathrm{~L}-246$ & 0.6865 & 50 & 0.8244 & $20.1 \%$ & 0.6765 & $1.5 \%$ \\
\hline & & 10.6 & D-2-2 & 790 & 3.0 & 321 & $304 \mathrm{~L}-210$ & 0.5955 & 5 & 0.7174 & $20.5 \%$ & 0.5972 & $0.3 \%$ \\
\hline & & 20.7 & D-4-4W & 1097 & 14.0 & 516 & 304L-321 & 0.6335 & $171 \mathrm{~W}$ & 0.7836 & $23.7 \%$ & 0.6047 & $4.5 \%$ \\
\hline & & 22.5 & D-4-4 & 790 & 18.188 & 405 & $304 \mathrm{~L}-254$ & 0.6420 & 146 & 0.7807 & $21.6 \%$ & 0.6303 & $1.8 \%$ \\
\hline & & 21.6 & D-4-4 & 1097 & 14.5 & 376 & 304L-232 & 0.7090 & 109 & 0.8797 & $24.1 \%$ & 0.7067 & $0.3 \%$ \\
\hline & \multirow{5}{*}{600} & 9.7 & D-2-2 & 1097 & 2.375 & 391 & $304 \mathrm{~L}-266$ & 0.8550 & 53 & 0.8773 & $2.6 \%$ & 0.8067 & $5.7 \%$ \\
\hline & & 10.7 & D-2-2 & 790 & 2.5 & 410 & $304 \mathrm{~L}-241$ & 0.6325 & 8 & 0.6812 & $7.7 \%$ & 0.6366 & $0.6 \%$ \\
\hline & & 19.1 & D-4-4W & 1097 & 11.5 & 507 & $304 \mathrm{~L}-320$ & 0.6560 & $179 \mathrm{~W}$ & 0.7065 & $7.7 \%$ & 0.6066 & $7.5 \%$ \\
\hline & & 21.7 & D-4-4 & 790 & 18.0 & 415 & $304 \mathrm{~L}-258$ & 0.7285 & 151 & 0.8139 & $12.4 \%$ & 0.7151 & $1.8 \%$ \\
\hline & & 21.4 & D-4-4 & 1097 & 14.5 & 417 & $304 \mathrm{~L}-234$ & 0.8665 & 111 & 0.9289 & $7.2 \%$ & 0.8066 & $6.9 \%$ \\
\hline \multirow{20}{*}{$316 \mathrm{~L}$} & \multirow{5}{*}{-20} & 10.1 & D-2-2 & 1097 & 2.5 & 465 & $316 \mathrm{~L}-195$ & 0.4745 & 42 & 0.5924 & $24.8 \%$ & 0.4453 & $6.2 \%$ \\
\hline & & 9.7 & D-2-2 & 790 & 3.0 & 431 & $316 \mathrm{~L}-111$ & 0.3500 & 26 & 0.4925 & $40.7 \%$ & 0.3873 & $10.6 \%$ \\
\hline & & 22.9 & D-4-4W & 1097 & 19.0 & 493 & 316L-179 & 0.6390 & $181 \mathrm{~W}$ & 0.8003 & $25.2 \%$ & 0.6163 & $3.6 \%$ \\
\hline & & 21.5 & D-4-4 & 790 & 18.0 & 471 & 316L-193 & 0.4675 & 141 & 0.6218 & $33.0 \%$ & 0.4968 & $6.3 \%$ \\
\hline & & 19.7 & D-4-4 & 1097 & 14.75 & 458 & 316L-184 & 0.4965 & 125 & 0.6286 & $26.6 \%$ & 0.4904 & $1.2 \%$ \\
\hline & \multirow{5}{*}{ Room } & 9.8 & D-2-2 & 1097 & 2.75 & 357 & $316 \mathrm{~L}-128$ & 0.6380 & 33 & 0.7824 & $22.6 \%$ & 0.6029 & $5.5 \%$ \\
\hline & & 9.3 & D-2-2 & 790 & 3.0 & 306 & 316L-98 & 0.4250 & 17 & 0.5666 & $33.3 \%$ & 0.4393 & $3.4 \%$ \\
\hline & & 20.4 & D-4-4W & 1097 & 14.75 & 382 & $316 \mathrm{~L}-166$ & 0.5675 & $167 \mathrm{~W}$ & 0.7126 & $25.6 \%$ & 0.5498 & $3.1 \%$ \\
\hline & & 21.4 & D-4-4 & 790 & 18.25 & 352 & $316 \mathrm{~L}-138$ & 0.5765 & 138 & 0.6997 & $21.4 \%$ & 0.5635 & $2.2 \%$ \\
\hline & & 22.0 & D-4-4 & 1097 & 14.75 & 291 & 316L-91 & 0.5955 & 128 & 0.7335 & $23.2 \%$ & 0.5815 & $2.4 \%$ \\
\hline & \multirow{5}{*}{300} & 10.7 & D-2-2 & 1097 & 2.5 & 400 & $316 \mathrm{~L}-154$ & 0.7575 & 35 & 0.8439 & $11.4 \%$ & 0.6986 & $7.8 \%$ \\
\hline & & 9.7 & D-2-2 & 790 & 3.0 & 320 & 316L-99 & 0.5255 & 19 & 0.7078 & $34.7 \%$ & 0.5920 & $12.7 \%$ \\
\hline & & 20.9 & D-4-4W & 1097 & 14.0 & 514 & 316L-206 & 0.7230 & $161 \mathrm{~W}$ & 0.8118 & $12.3 \%$ & 0.6547 & $9.4 \%$ \\
\hline & & 22.5 & D-4-4 & 790 & 18.688 & 406 & 316L-147 & 0.7440 & 131 & 0.8103 & $8.9 \%$ & 0.6773 & $9.0 \%$ \\
\hline & & 21.9 & D-4-4 & 1097 & 16.0 & 286 & $316 \mathrm{~L}-89$ & 0.7865 & 120 & 0.9208 & $17.1 \%$ & 0.7474 & $5.0 \%$ \\
\hline & & 9.7 & $\mathrm{D}-2-2$ & 1097 & 2.125 & 390 & $316 \mathrm{~L}-140$ & 0.7735 & 37 & 0.8667 & $12.0 \%$ & 0.8189 & $5.9 \%$ \\
\hline & & 9.5 & D-2-2 & 790 & 2.5 & 346 & $316 \mathrm{~L}-130$ & 0.5690 & 22 & 0.6227 & $9.4 \%$ & 0.5913 & $3.9 \%$ \\
\hline & 600 & 19.1 & D-4-4W & 1097 & 11.0 & 508 & 316L-204 & 0.6675 & $164 \mathrm{~W}$ & 0.6854 & $2.7 \%$ & 0.6169 & $7.6 \%$ \\
\hline & & 22.4 & D-4-4 & 790 & 17.875 & 394 & $316 \mathrm{~L}-146$ & 0.8120 & 135 & 0.8286 & $2.0 \%$ & 0.7561 & $6.9 \%$ \\
\hline & & 20.7 & D-4-4 & 1097 & 13.0 & 418 & $316 \mathrm{~L}-124$ & 0.7640 & 123 & 0.8073 & $5.7 \%$ & 0.7367 & $3.6 \%$ \\
\hline
\end{tabular}




\section{OBSERVATIONS FROM TEST RESULTS}

A total of 260 dynamic impact tensile tests of $304 \mathrm{~L}$ and $316 \mathrm{~L}$ stainless steels were used in this report to calculate strain rate factors for the strain rate range of 4 to 40 per second. More than 160 quasi-static tensile tests were also performed to establish stress-strain relationships of the materials used. This section discusses several observations related to this large population of tests.

\subsection{Quasi-Static Tensile Testing}

The quasi-static tensile testing performed for this research effort produced results that were correct, as evidence in Section 5.5. However, additional discussion is needed to more fully explain how the uniform strain limits were determined.

The text book explanation for determining the uniform strain limit of typical steels would indicate that it is the strain at which the tensile stress is at its maximum (ultimate tensile strength or UTS). However, with these stainless steels, the quasi-static engineering curves did not have a significant 'hump' shape (as seen in Figure 2) but were relatively flat for a significant strain range. This is illustrated in Figure 81.

Figure 81 illustrates how the maximum UTS value [the red dot that is less than $0.25 \%$ higher in strength than the adjacent blue (left) and black (right) square boxes] would lead the text book engineer to pick 0.43 engineering strain as the uniform strain limit. In reality, the onset of significant necking is actually closer to the black square box value of 0.47 engineering strain (if not a little higher). Typical accuracy tolerances for these tensile test machines is $\pm 0.5 \%$ of the load (which carries over to stress accuracy). Attempts to indicate that the maximum UTS can be so precisely determined within a few psi is not appropriate. Since this research effort was interested in accurately defining the strain energy density for each material at the onset of significant necking, the higher uniform strain limit value would have been chosen. In Section 5.5, Table 7 lists the uniform strain limits chosen for use in this research effort.

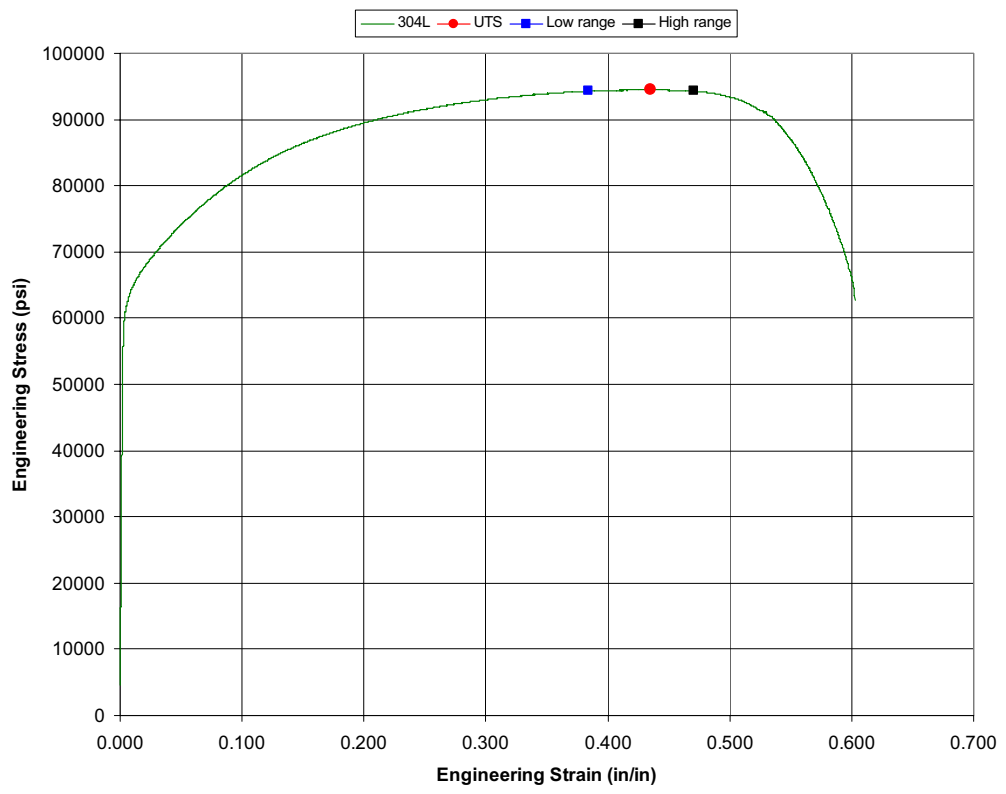

Figure 81. Engineering plot of 304L material exhibiting flat response near UTS. 


\subsection{Impact Tensile Testing}

A number of significant insights were gained from the impact testing performed for factor determination. A more thorough understanding of what strain rates are achievable with various test specimen geometries was a significant step forward for test planning purposes. However, two specific issues, (1) impact test anomalies and (2) base versus welded material responses, are pertinent to this report and are discussed in further detail below.

\subsubsection{Impact Test Anomalies}

Ten impact tests were able to achieve strains beyond the established uniform strain limit (see Table 7) yet did not exhibit any signs of necking. Discarding those instances where that strain exceedance was $5 \%$ or less (attempting to determine a trend by focusing on extreme indicators), only three impact tests remain. With strains exceeding their established uniform strain limits by $8.7 \%, 8.7 \%$, and $17.3 \%$, these three 'high indicator' $316 \mathrm{~L}$ tests $(\# 326$, \#375, and $\# 422$ ) did not provide clear indications that the uniform strain limit increases with increasing strain rate.

On the other hand, there were a total of four impact tests where the strain achieved was below the established uniform strain limit and the test specimen either necked or broke. Again discarding those tests that had strains greater than $95 \%$ of their uniform strain limit (attempting to determine a trend by focusing on extreme indicators), two 316L tests remain [\#427 (welded) and \#469] that necked at strains of $90.8 \%$ and $77.5 \%$ of their established uniform strain limits. These 'low indicator' tests were surprises from the perspective that the material failed earlier than anticipated, especially Test \#469 that necked at 3/4 of the uniform strain limit. However, there was no clear indication that the uniform strain limit decreases with increasing strain rate.

These 'high' and 'low' test anomalies highlight the probabilistic nature of testing that should not be unexpected. Even though material variability has an effect on the impact test results and the uniform strain limit, the impact testing performed herein at strain rates below 40 per second did not provide clear indications that the uniform strain limit varies with strain rate.

\subsubsection{Base Versus Welded Material Responses}

Prior drop testing experience of full-scale Department of Energy spent nuclear fuel canisters (References 44, 45, and 46) indicated there was no significant variation in the deformation responses of the canister wall when impact occurred directly onto a canister weld. A limited number of impact tests of welded material at elevated temperatures were performed prior to the completion of that material's quasi-static tensile testing. These first impact tests used the same drop weight and drop height as was used for the base material. The resulting strain rate responses of the welded material test specimens appeared to be very similar to the base material. However, some of the welded material test specimens necked or broke where the base material test specimens had not. The conclusion reached was that the welded material had a lower uniform strain limit and fracture strain than the base material. After completion of the quasistatic tensile testing, this indeed turned out to be the case.

Figures 82 and 83 show, for 304L and 316L respectively, quasi-static tensile test results of base and welded materials at $300^{\circ} \mathrm{F}$ temperature conditions. These representative engineering stress-strain plots illustrate that the uniform strain limit and failure strain for the welded material 
are lower than the associated base material. Figures 84 and 85 are comparative strain history plots of 304L and 316L base and welded material impact tests performed at $-20^{\circ} \mathrm{F}$. These impact tests used the same drop weight, drop height, and test specimen geometry. These plots illustrate how similar the base and welded material were in terms of strain rate response. The plots also show that the welded material absorbs the impact energy with a lower maximum strain than the base material (i.e., welded material is stronger than base material). However, as discussed above, the welds fail at lower strain levels than the base material (i.e., welded material is less ductile than the base material).

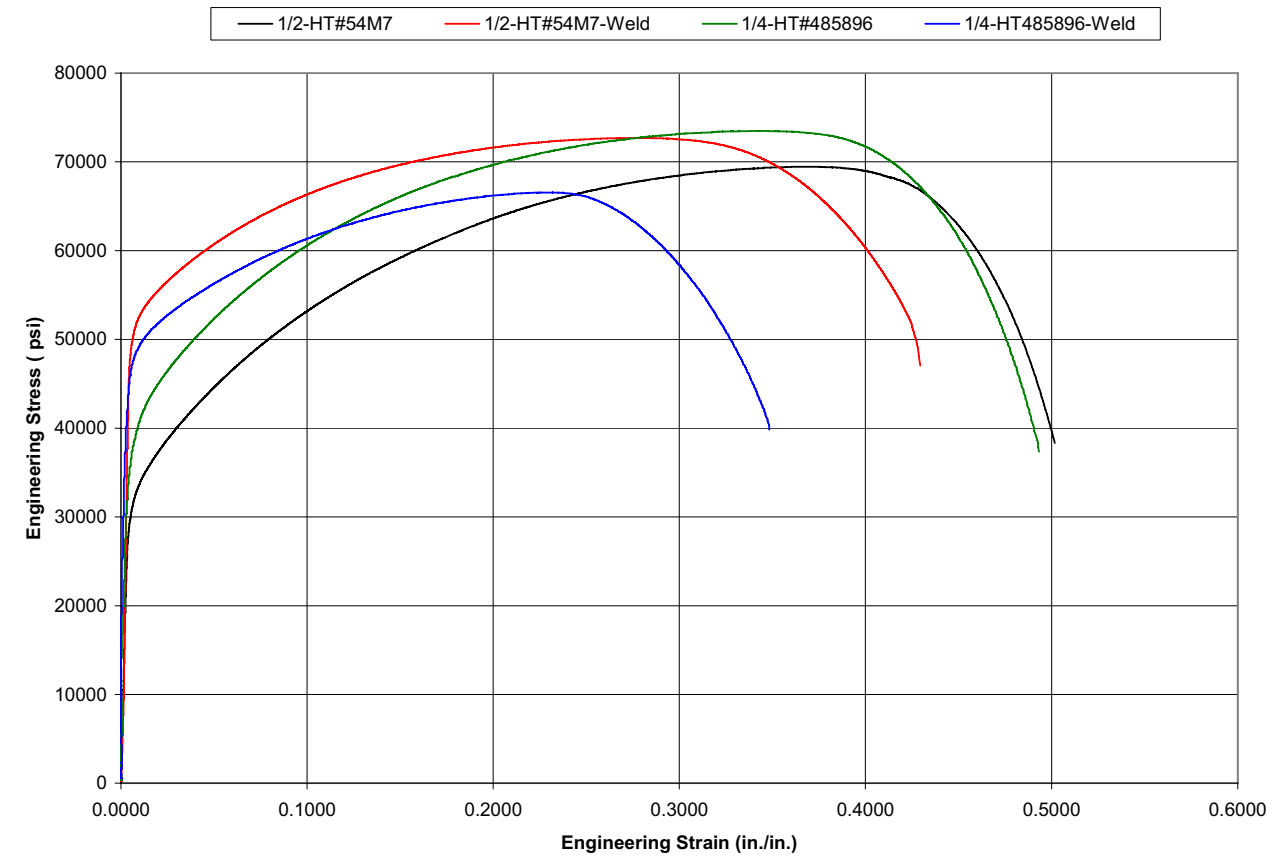

Figure 82. Quasi-static tensile test results for $304 \mathrm{~L}$ base and welded material at $300^{\circ} \mathrm{F}$.

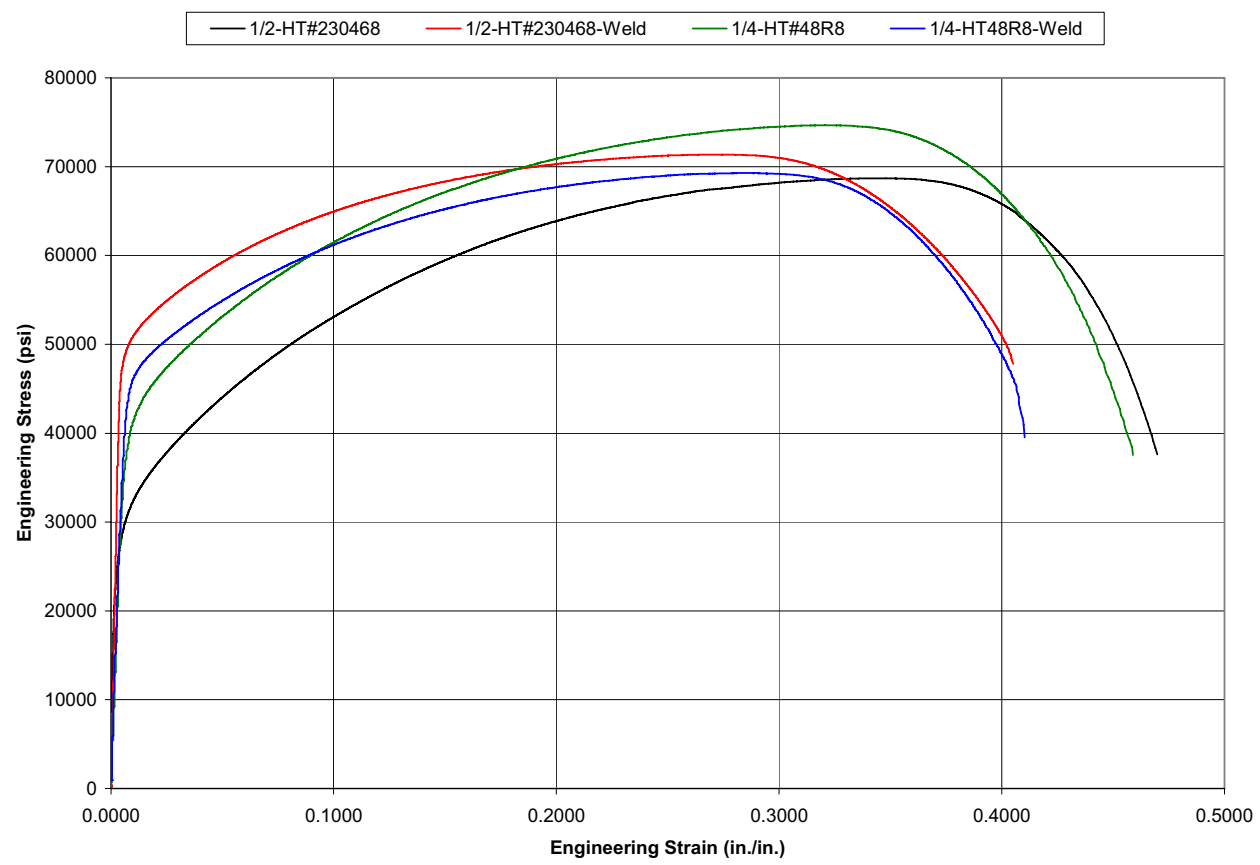

Figure 83. Quasi-static tensile test results for $316 \mathrm{~L}$ base and welded material at $300^{\circ} \mathrm{F}$. 


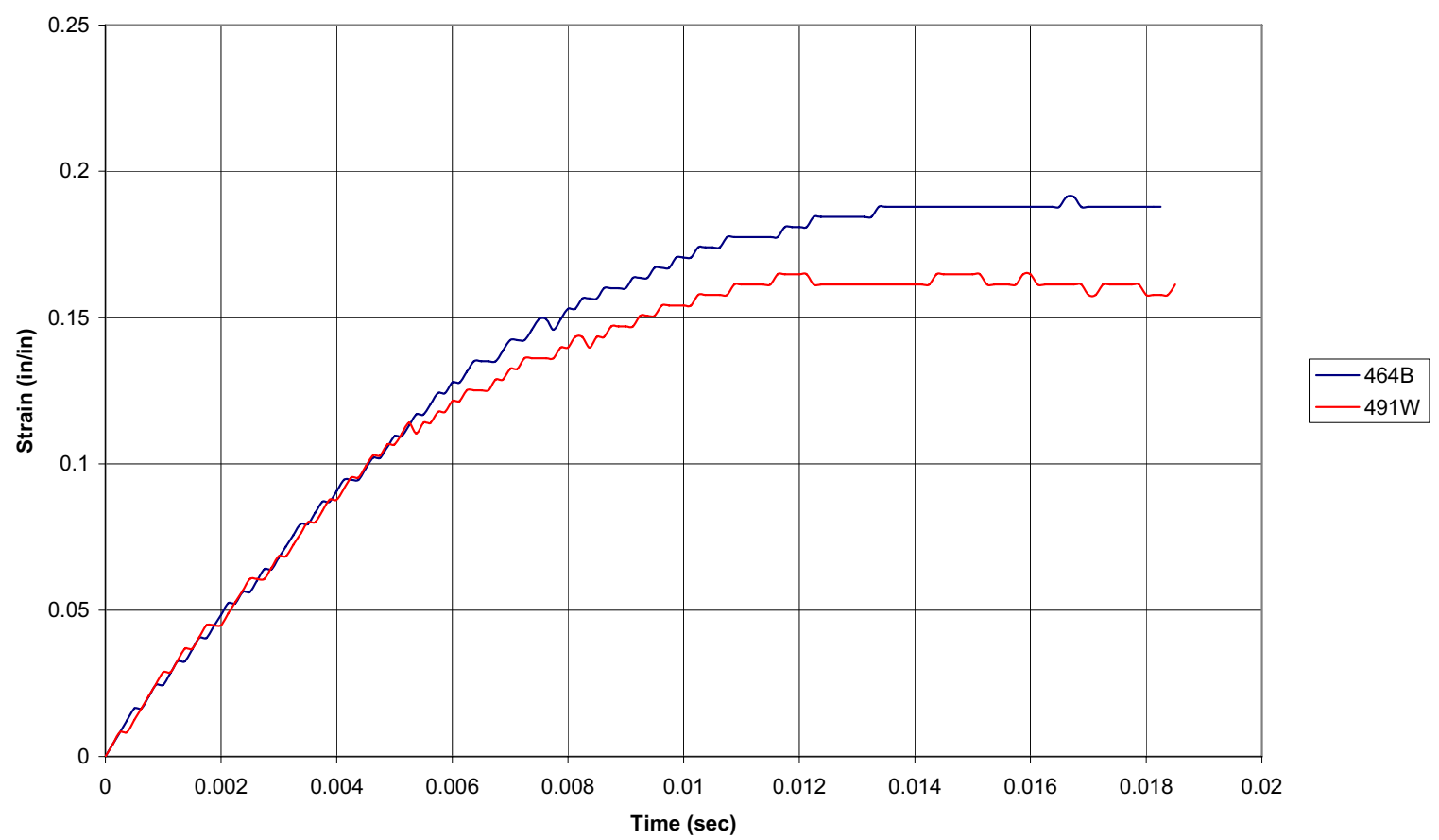

Figure 84. Comparison of base and welded 304L material to identical impact tests at $-20^{\circ} \mathrm{F}$.

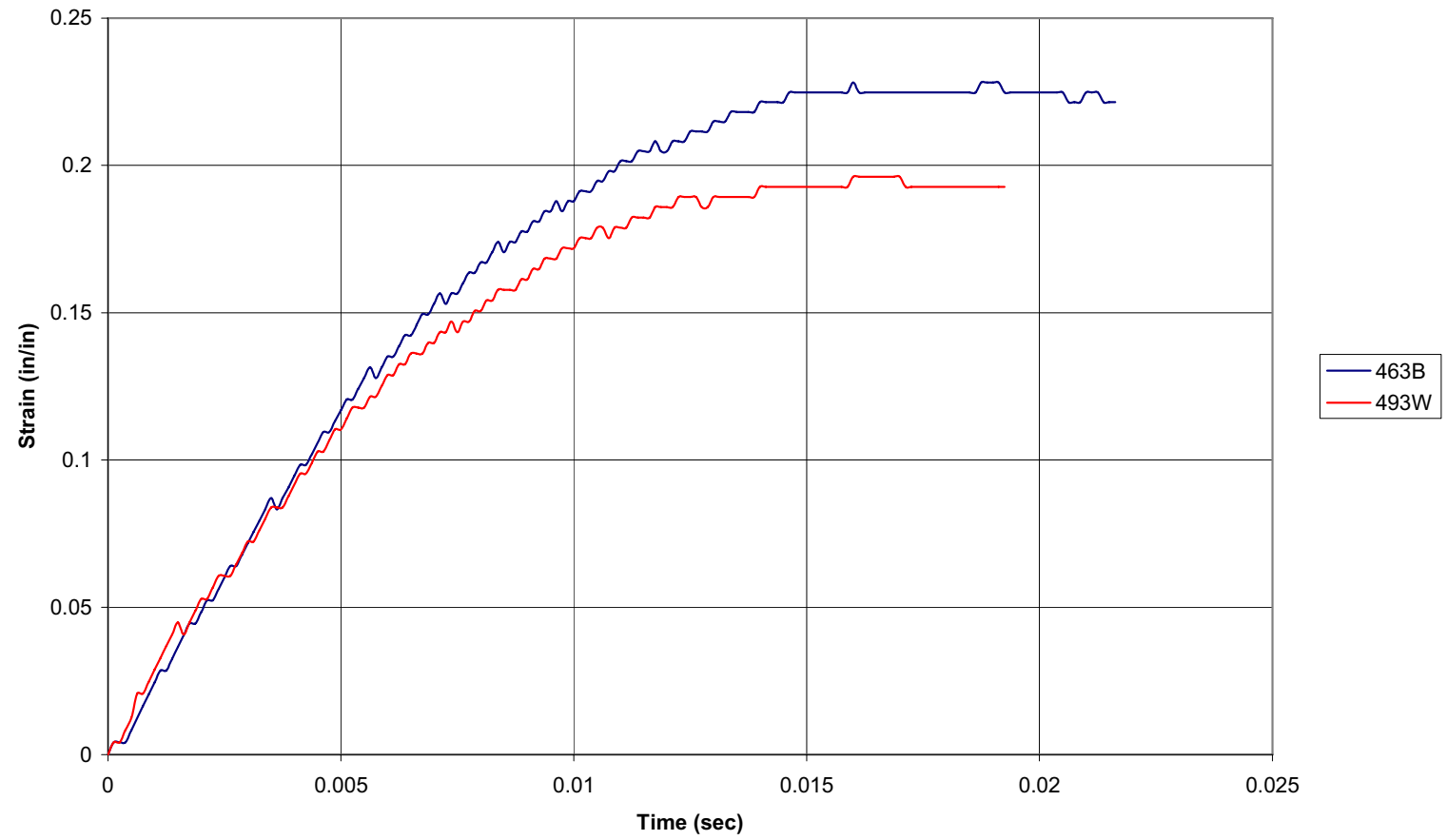

Figure 85. Comparison of base and welded $316 \mathrm{~L}$ material to identical impact tests at $-20^{\circ} \mathrm{F}$. 
Based on the strain rate range achieved herein, the welded material test specimens responded very similar to the base material test specimens. Therefore, one would expect the strain rate factors to be similar. This also was the case, as evidenced by the factor versus strain rate curves (Figures 62 through 69). As can be seen, the welds (identified as triangular-shaped data points) are consistent with the base material data. This permits the structural analyst to use the same strain rate factor data for both base and weld materials when incorporating strain rate effects into finite element models. However, the structural analyst must be fully aware that the welds have a lower uniform strain limit and failure strain and this must be correctly incorporated into the acceptance criteria that the structural analyst is employing.

\subsection{Factors and Strain Rate Elevated True Stress-Strain Curves Insights}

It is important to recognize that the factor versus strain rate curves (Figures 62 through 69) reflect multiple heats and different test specimen geometries. Considering the variability of material properties of all of the test specimens used, the consistency of the curves is quite striking. However, it is too early to engage in discussions on how the formulation of these strain rate test results compare to a characterization of strain rate dependent material behavior (material constitutive equation such as the Cowper-Symonds equation) until strain rate data at higher ranges (up to 300 per second) become available. 


\section{CONCLUSIONS}

Strain rate effects in the range of 4 to 40 per second for tensile loading of $304 \mathrm{~L}$ and $316 \mathrm{~L}$ stainless steel materials were successfully quantified at the INL using a large drop weight test machine and a total energy analysis approach. By incorporating the strain rate elevated true stress-strain material curves into an inelastic finite element computer program as the defined material input, significant improvement in the accuracy of the computer analyses was attained. However, additional impact testing is necessary to achieve higher strain rates (up to 300 per second) before complete definition of strain rate effects can be made for accidental drop events and other similar energy-limited impulsive loads.

The results of this material impact testing effort can be used to support the development of strain-based acceptance criteria for national codes and standards use. As documented by this research effort, in addition to quantifying the strain rate effects, the following items may prove useful to codes and standards developers: (1) the effects of strain rate decrease with increasing temperature, (2) base and welded materials appear to behave similarly during impact testing, though welded materials have lower uniform strain and failure strain limits, and (3) the uniform strain limits for both welded material and base material do not appear to vary from the values established during quasi-static tensile testing for the strain rate range discussed herein. In addition to the need for impact tensile testing research at higher strain rates, bending response impact testing would be very beneficial in establishing maximum viable thru-wall and surface strain limits.

This research approach, using impact testing and a total energy analysis methodology to quantify strain rate effects, can be applied to many other materials used in government and industry. 


\section{REFERENCES}

The references listed below were the most current used for this research task but earlier versions in effect at the time of use were used as appropriate.

1. American Society of Mechanical Engineers, Boiler and Pressure Vessel Code, Section III, Division 1, Appendix F, 2007 Edition.

2. Department of Energy, Quality Assurance Requirements and Description, DOE/RW-0333P, Revision 17, May 8, 2006.

3. Department of Energy, National Spent Nuclear Fuel Program, NSNFP Quality Assurance Program Plan, DOE/SNF/QAPP-001, Revision 3, April 14, 2006.

4. Department of Energy, National Spent Nuclear Fuel Program, Review and Approval of NSNFP Internal Documents, NSNFP 6.01, Revision 12, August 1, 2005.

5. Department of Energy, National Spent Nuclear Fuel Program, Program Procedure, Managing Document Control and Distribution, NSNFP 6.03, Revision 2, October 22, 2004.

6. Department of Energy, National Spent Nuclear Fuel Program, Program Procedure, Engineering Documentation, NSNFP 3.04, Revision 6, May 12, 2007.

7. Department of Energy, National Spent Nuclear Fuel Program, Program Procedure, Testing, NSNFP 11.01, Revision 3, May 12, 2007.

8. Department of Energy, National Spent Nuclear Fuel Program, Program Procedure, Acquiring Government Sector Services, NSNFP 4.02, Revision 1, October 22, 2004.

9. Department of Energy, National Spent Nuclear Fuel Program, Program Procedure, Personnel Indoctrination and Proficiency Training, NSNFP 2.04, Revision 8, June 29, 2007.

10. Department of Energy, National Spent Nuclear Fuel Program, Program Procedure, Software Control, NSNFP 19.01, Revision 4, August 1, 2005.

11. Department of Energy, National Spent Nuclear Fuel Program, Task Management Agreement for the Canister RemoteWeld/Repair System, DOE/SNF/TMA-009, Revision 1, February, 2005.

12. Department of Energy, National Spent Nuclear Fuel Program, Task Management Agreement for Transportation \& Packaging Tasks to be Performed by the INL M\&O Contractor, DOE/SNF/TMA-013, Revision 1, February 2006.

13. Department of Energy, National Spent Nuclear Fuel Program, Test Plans for the Department of Energy Spent Nuclear Fuel Canister and Basket Development Project, DOE/SNF/PP-039, Revision 8, June 2007.

14. INL Welding Laboratory Notebooks \#628 (No. 1), \#684 (No. 2), and \#969 (No.3), "FY2005 Welding and Weld Examination Services for Material Impact Testing" and associated files containing radiographs, radiograph reader sheets, project explanations, etc., (NSNFP Record).

15. ASTM A370-06, 2006, Standard Test Methods and Definitions for Mechanical Testing of Steel Products, ASTM International, Inc., West Conshohocken, PA. 
16. National Spent Nuclear Fuel Program, Planning/QA Program Applicability Evaluation, PAE-010, Revision 4, September 28, 2006.

17. INL Laboratory Notebook LAB 771, "NSNFP Testing Alloy 3xx Stainless Steel”, (NSNFP Record).

18. I-DEAS 10 NX Series, Unigraphics Solutions, Inc., 2002.

19. ABAQUS/Explicit, Version 6.6-3, ABAQUS, Inc., Providence, RI, 2006.

20. DADiSP 2002, The DADiSP Worksheet 2002, Data Analysis and Display Software, DSP Development Corporation, One Kendall Square, Cambridge, Ma., Version 6.0, NI NK B07, April 11, 2003.

21. Collection of Excel spreadsheets identified under NSNF/MED/017, Revision 1, (NSNFP Record).

22. Department of Energy, National Spent Nuclear Fuel Program, Software Report For ABAQUS/Explicit Version 6.6-3, DOE/SNF/REP-107, Revision 0, November 2006.

23. ABAQUS Example Problems Manual, Version 6.6, ABAQUS, Inc., Providence, RI, 2006.

24. ASM International, Atlas of Stress-Strain Curves, Material Park: ASM International, Second Edition, 2002.

25. P. W. Bridgman, The Stress Distribution at the Neck of a Tension Specimen, Transactions of the A. S. M., Twenty-fifth Annual Convention, Chicago, Illinois, October 18-22, 1943.

26. Norman E. Dowling, Mechanical Behavior of Materials, Upper Saddle River: Prentice-Hall Inc., Second Edition, 1999, Appendix B.

27. William D. Callister, Jr., Materials Science and Engineering - An Introduction, New York: John Wiley \& Sons, Inc., 1985.

28. H. E. McCoy, Jr. and R. D. Waddell, Mechanical Properties of Several Products from a Single Heat of Type 304 Stainless Steel, Journal of Engineering Materials and Technology, October 1975, p. 343.

29. W. F. Simmons and H. C. Cross, Report on the Elevated-Temperature Properties of Stainless Steels, ASTM Spec. Tech. Pub. No. 124, 1952.

30. J. B. Conway, R. H. Stentz, and J. T. Berling, Fatigue, Tensile, and Relaxation Behavior of Stainless Steels, Technical Information Center, USAEC, 1975, p. 213.

31. Bettis Plant Materials Manual, Westinghouse Electric Corp., Standards Engineering Section, May 1957. As published in Aerospace Structural Metals Handbook, Vol. 2, Code 1303, CINDAS/USAF CRDA Handbooks Operation, Purdue University, 1995, P. 13.

32. R. K. Blandford, D. K. Morton, S. D. Snow, and T. E. Rahl, Tensile Stress-Strain Results for 304L and 316L Stainless Steel Plate at Temperature, PVP2007-26096, Proceedings of the 2007 ASME Pressure Vessels and Piping Conference, San Antonio, Texas, July 20-26, 2007.

33. American Society of Mechanical Engineers, Boiler and Pressure Vessel Code, Section II, Part A, Specification SA-240/SA-240M, 2004 Edition.

34. INL Weld Manual, Volumes 1 and 1A, Welding Procedure Specifications, Revision 48, April $18,2005$. 
35. INL Procedure, Radiographic Examination, TPR-4970, Revision 1, January 27, 2005.

36. LabVIEW Software, Version 7.0, National Instruments, Inc., Austin TX, 2006.

37. Report CD-R (contained herein this report), generated March 2008.

38. NSNFP Laboratory Notebook NSNF/SN/04.01, "NSNFP Material Strain Rate Testing", Volumes I, II, and III and associated binders (Volumes 1 through 8), (NSNFP Record).

39. J. E. Fisher, Thermal Analysis of NSNFP Strain Rate Test Coupon Heating Tests, EDFNSNF-065, Revision 0, August 22, 2006.

40. G. Solomos, et. al., Strain Rate Effects of Nuclear Steels in Room and Higher Temperatures, Transactions of SMiRT 16, Paper \#1356, Washington, DC, August 2001.

41. Woei-Shyan Lee, et. al., The Effects of Strain Rate and Welding Current Mode on the Dynamic Impact Behavior of Plasma-Arc-Welded 304L Stainless Steel Weldments, Metallurgical and Materials Transactions A, Volume 35A, pp. 1501-1515, May 2004.

42. R. K. Blandford and T. E. Rahl, FY 2004 Material Strain Rate Testing, EDF-NSNF-042, Revision 2, April 19, 2005.

43. Department of Energy, National Spent Nuclear Fuel Program, Program Procedure, Control of the Electronic Management of Information, NSNFP 19.03, Revision 1, October 22, 2004.

44. D. K. Morton, S. D. Snow, and T. E. Rahl, FY1999 Drop Testing Report for the 18-Inch Standardized DOE SNF Canister, EDF-NSNF-007, Revision 2, September 5, 2002.

45. D. K. Morton and S. D. Snow, Drop Testing Representative 24-Inch Diameter Idaho Spent Fuel Project Canisters, EDF-NSNF-045, Revision 0, January 28, 2005.

46. D. K. Morton and S. D. Snow, Drop Testing Representative Multi-Canister Overpacks, EDFNSNF-047, Revision 0, January 28, 2005. 


\section{Appendix A}

\section{DADiSP Integration Verification}




\section{A1. OBJECTIVE}

The objective of this appendix is to verify the integration function used in the computer code DADiSP for accuracy. Verification will be accomplished by solving two problems using DADiSP and comparing the DADiSP solutions with the known classical solutions.

\section{A2. KNOWN SOLUTION SAMPLE PROBLEMS}

\section{A2.1 Area of a Triangle}

The first sample problem chosen for which a known solution (solved by classical methods) exists is a triangle. The particular one used is shown graphically in Figure A1. The area is calculated using classical methods as follows:

$$
\text { Area }=\frac{b \times h}{2}=\frac{1 \times 2}{2}=1
$$

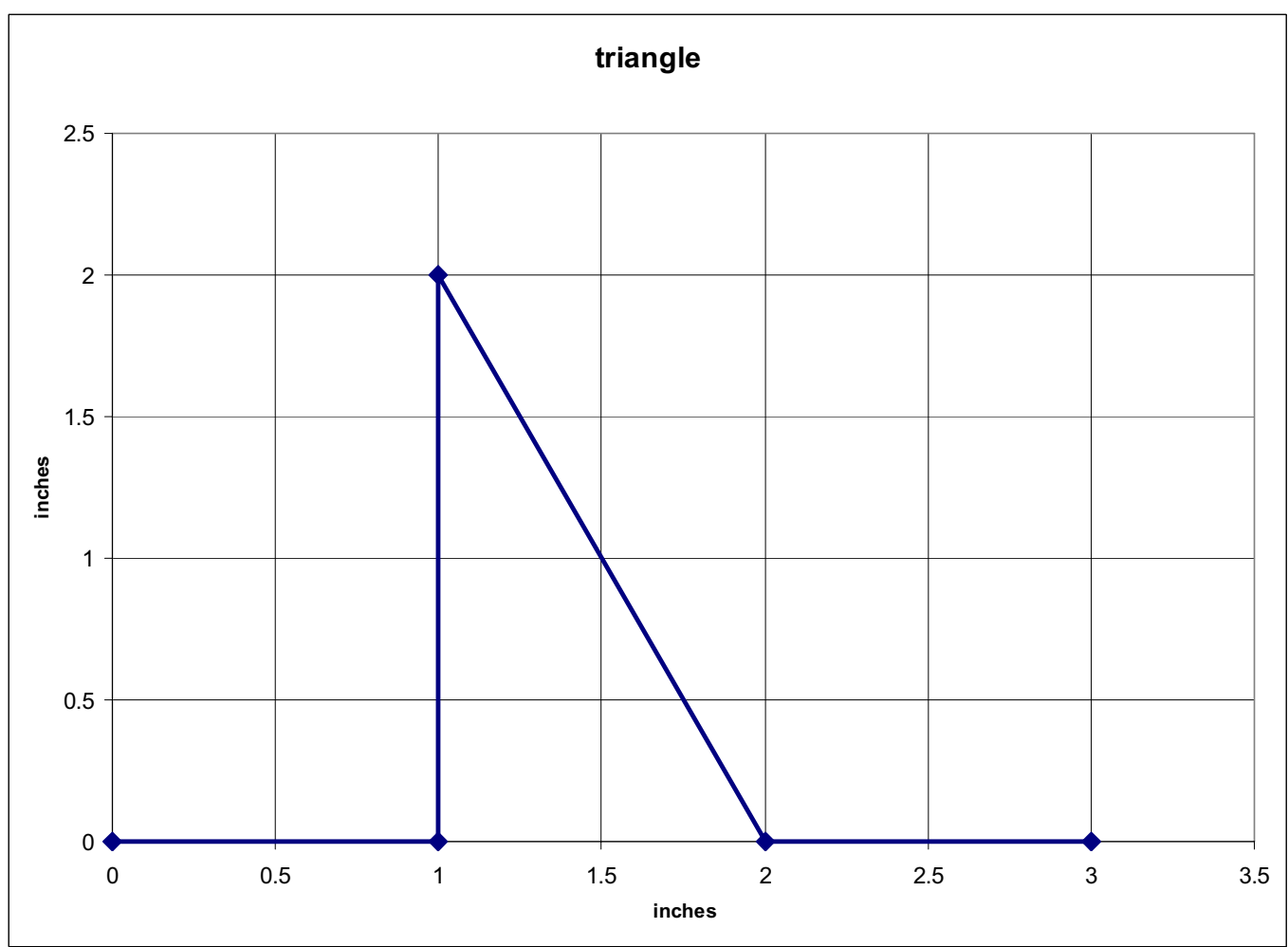

Figure A1. Sample Problem \#1 - Triangle.

Figure A2 is the problem defined in DADiSP with Figure A3 showing the execution of the integration function of DADiSP. Note the final integration value of 1 which agrees with the classical solution. 


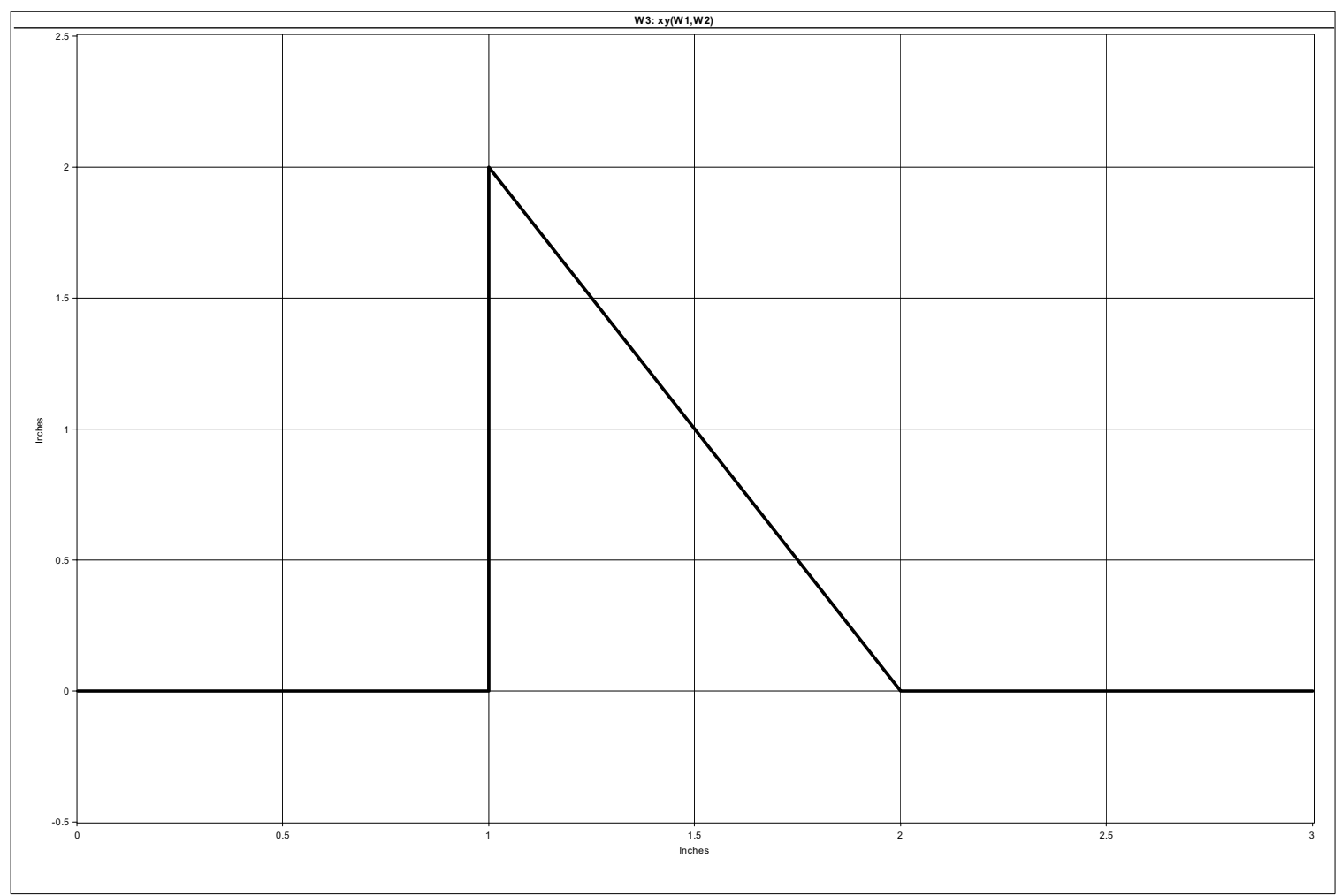

Figure A2. Problem \#1 Definition in DADiSP.

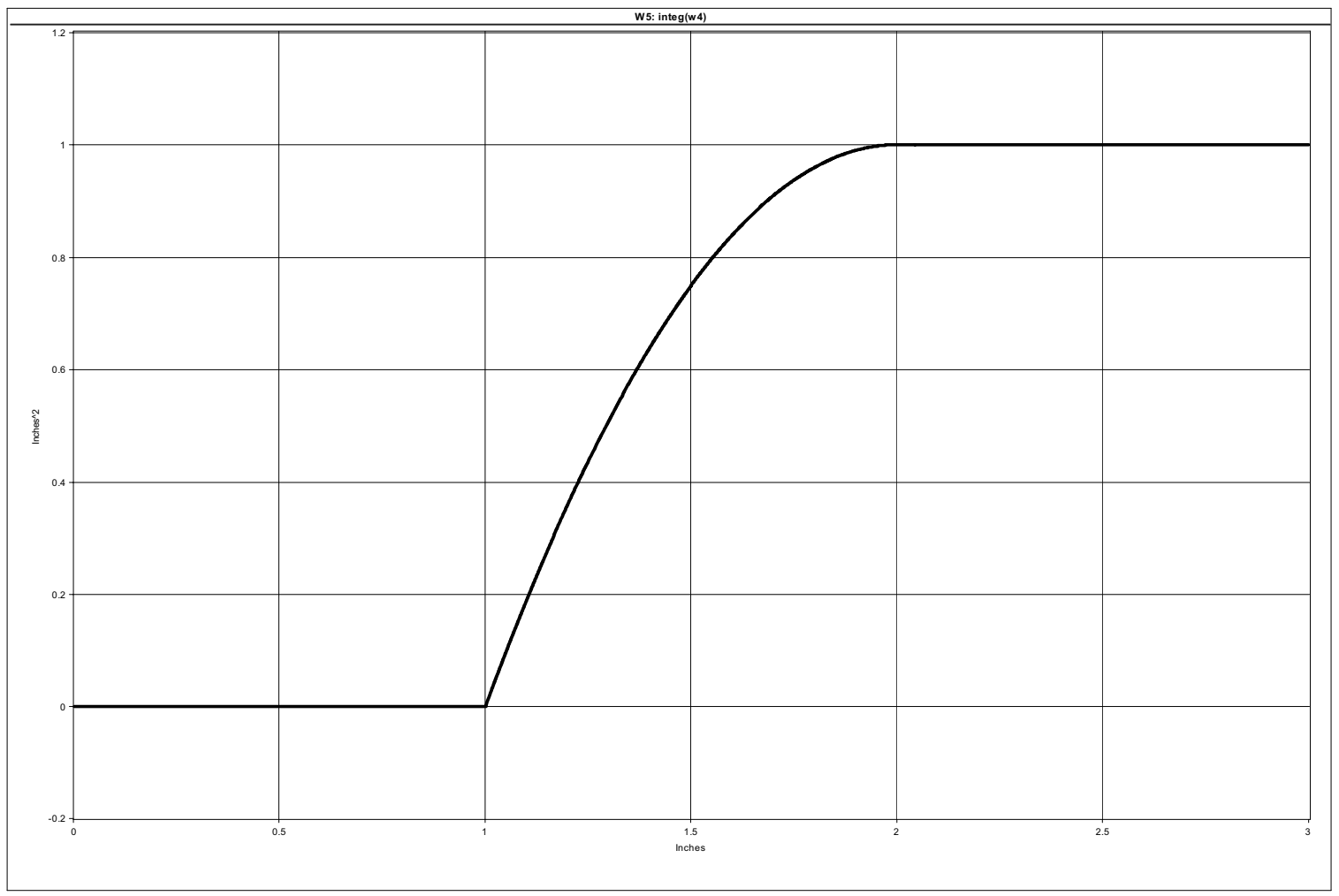

Figure A3. DADiSP Integration Plot of Problem \#1. 


\section{A2.2 Area of a Quarter Circle}

The second sample problem chosen for which a known solution (solved by classical methods) exists is a quarter circle of radius 2 inches. It is shown graphically in Figure A4. The area is calculated using classical methods as follows:

$$
\text { Area }=\frac{\pi \times r^{2}}{4}=\frac{\pi \times 2^{2}}{4}=3.14159
$$

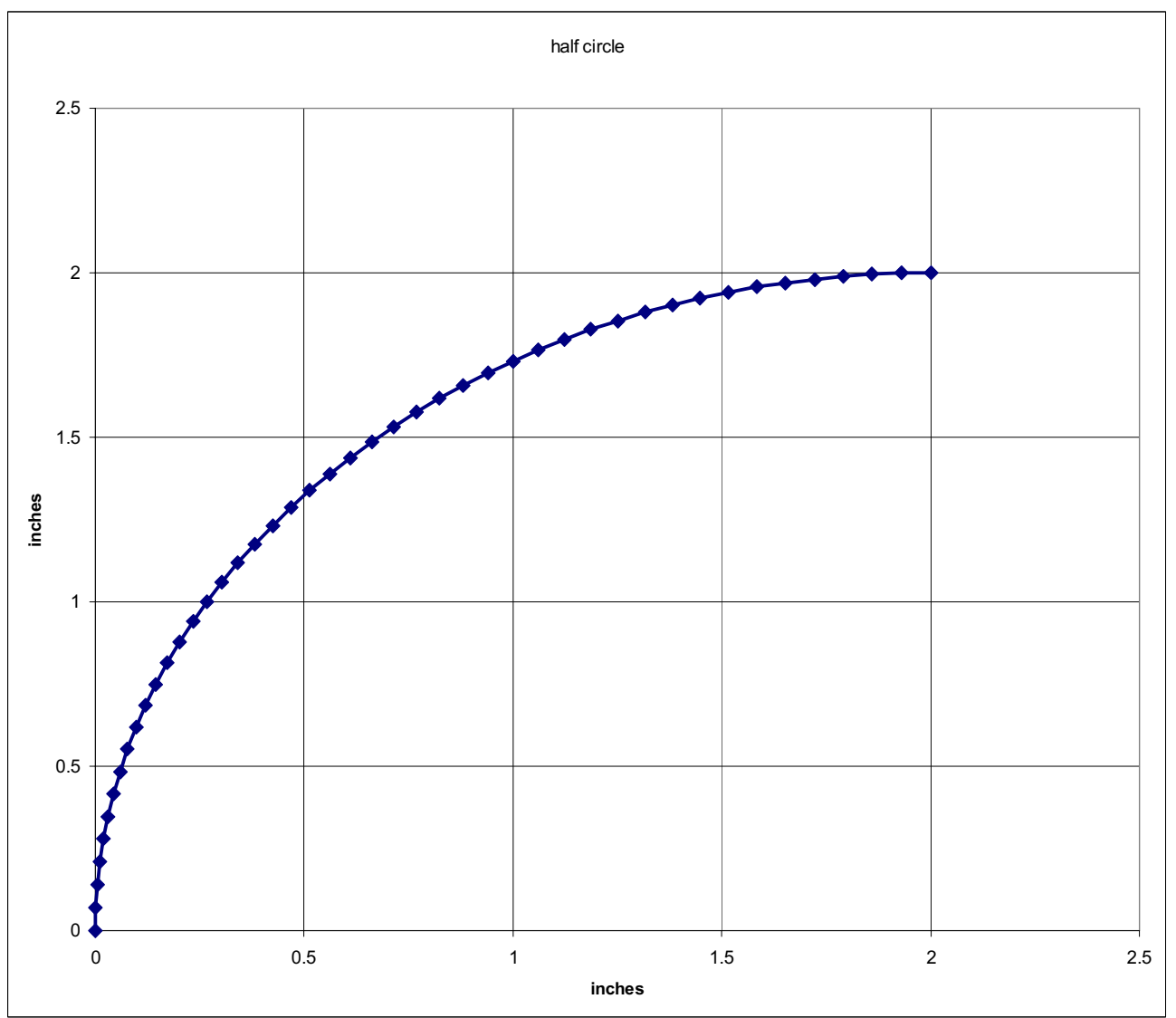

Figure A4. Sample Problem \#2 - Quarter Circle.

Figure A5 is the problem defined in DADiSP with Figure A6 showing the execution of the integration function of DADiSP. Note the final integration value of 3.14096 as a percentage of the classical solution is:

$$
\frac{3.14096}{3.14159} \times 100=99.98 \%
$$

The data points of Figure A4 are tabulated in Table A1. 


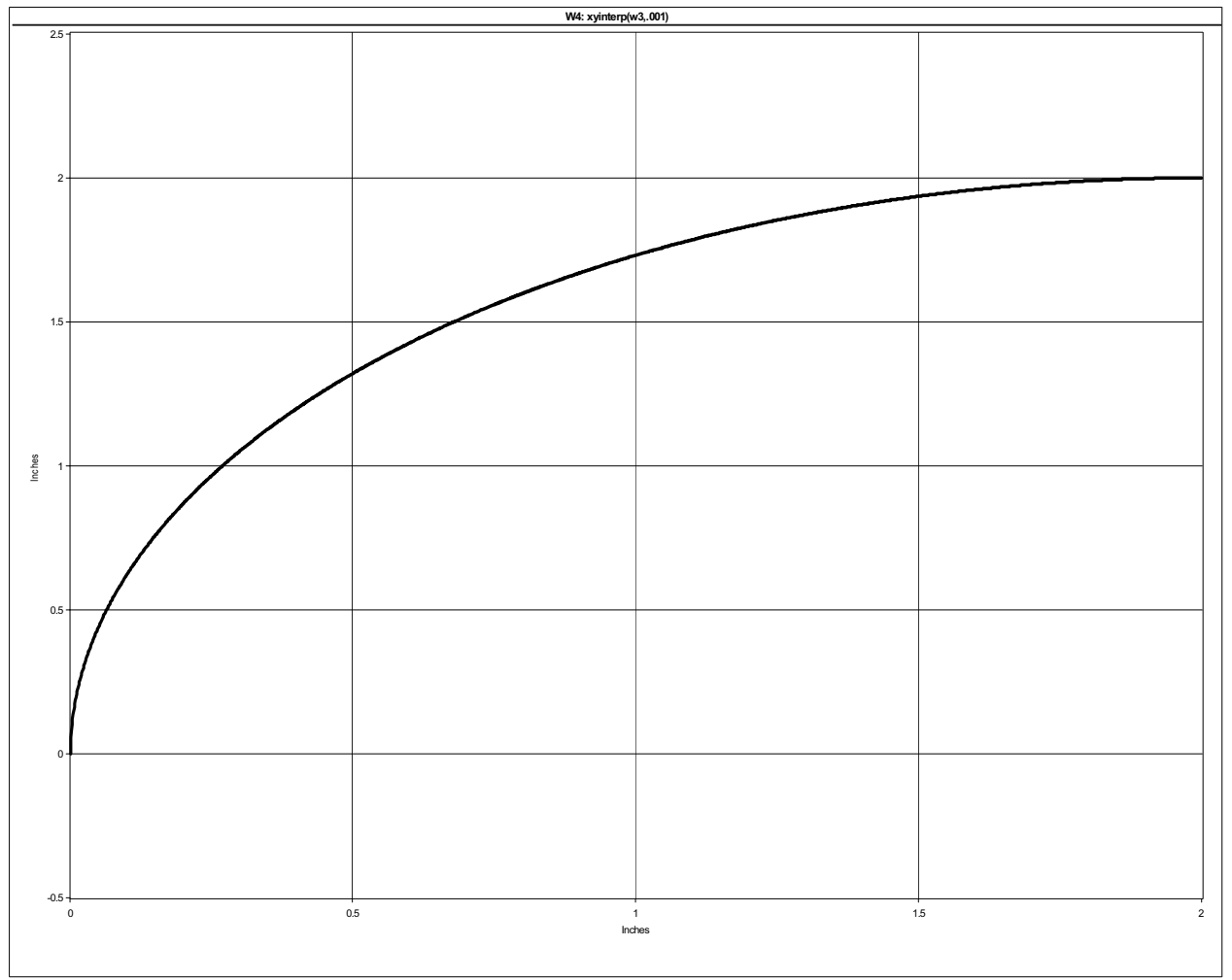

Figure A5. Problem \#2 Definition in DADiSP.

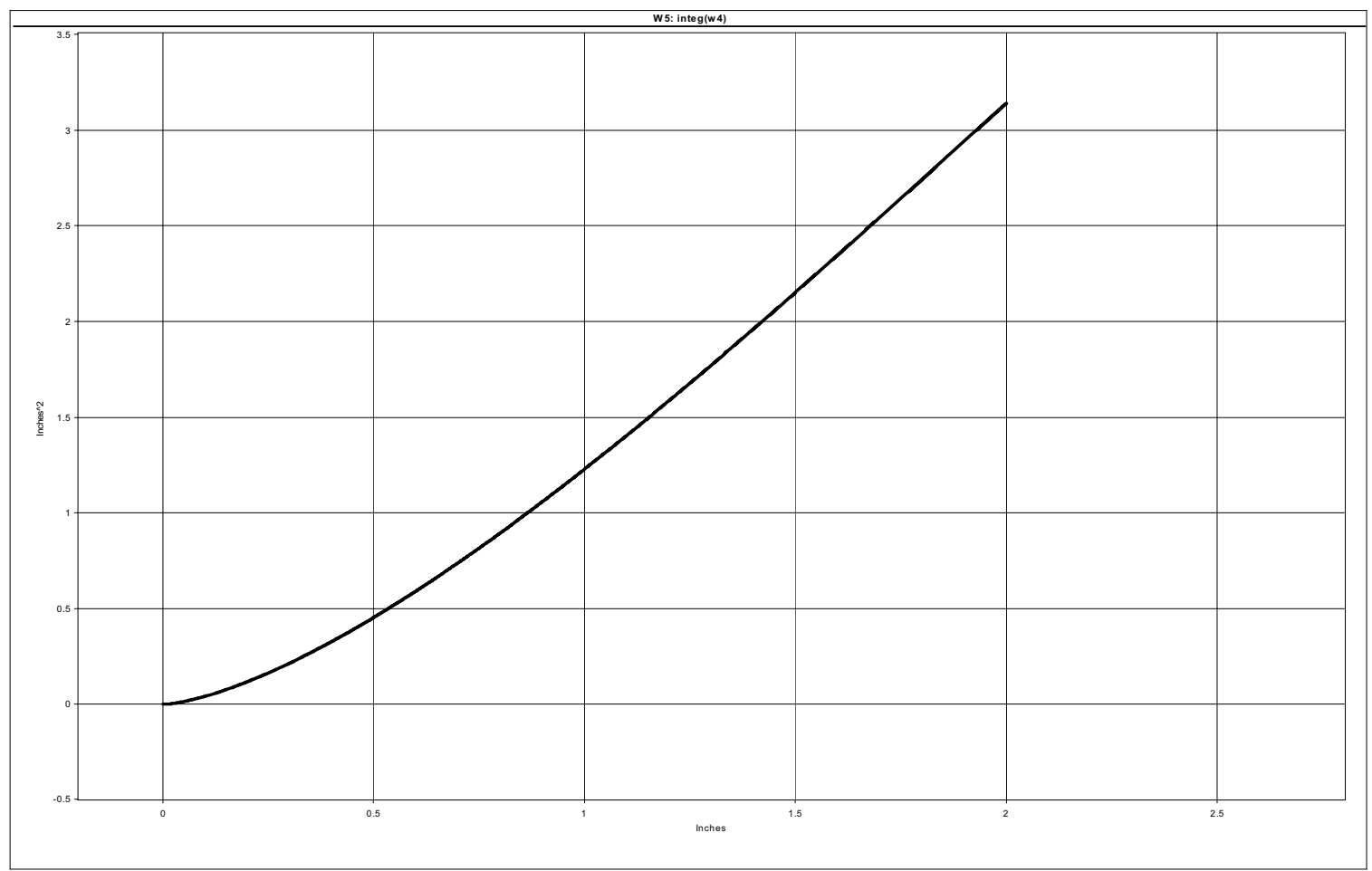

Figure A6. DADiSP Integration Plot of Problem \#2. 
Table A1. XY values of Figure A4.

\begin{tabular}{|c|c|}
\hline x-value & $y$-value \\
\hline 0 & 0 \\
\hline 0.001218 & 0.069799 \\
\hline 0.004872 & 0.139513 \\
\hline 0.010956 & 0.209057 \\
\hline 0.019464 & 0.278346 \\
\hline 0.030384 & 0.347296 \\
\hline 0.043705 & 0.415823 \\
\hline 0.059409 & 0.483844 \\
\hline 0.077477 & 0.551275 \\
\hline 0.097887 & 0.618034 \\
\hline 0.120615 & 0.68404 \\
\hline 0.145632 & 0.749213 \\
\hline 0.172909 & 0.813473 \\
\hline 0.202412 & 0.876742 \\
\hline 0.234105 & 0.938943 \\
\hline 0.267949 & 1 \\
\hline 0.303904 & 1.059839 \\
\hline 0.341925 & 1.118386 \\
\hline 0.381966 & 1.175571 \\
\hline 0.423978 & 1.231323 \\
\hline 0.467911 & 1.285575 \\
\hline 0.51371 & 1.338261 \\
\hline 0.56132 & 1.389317 \\
\hline 0.610683 & 1.43868 \\
\hline 0.661739 & 1.48629 \\
\hline 0.714425 & 1.532089 \\
\hline 0.768677 & 1.576022 \\
\hline 0.824429 & 1.618034 \\
\hline 0.881614 & 1.658075 \\
\hline 0.940161 & 1.696096 \\
\hline 1 & 1.732051 \\
\hline 1.061057 & 1.765895 \\
\hline 1.123258 & 1.797588 \\
\hline 1.186527 & 1.827091 \\
\hline 1.250787 & 1.854368 \\
\hline 1.31596 & 1.879385 \\
\hline 1.381966 & 1.902113 \\
\hline 1.448725 & 1.922523 \\
\hline 1.516156 & 1.940591 \\
\hline 1.584177 & 1.956295 \\
\hline 1.652704 & 1.969616 \\
\hline 1.721654 & 1.980536 \\
\hline 1.790943 & 1.989044 \\
\hline 1.860487 & 1.995128 \\
\hline 1.930201 & 1.998782 \\
\hline 2 & 2 \\
\hline
\end{tabular}




\section{Appendix B}

\section{Engineering Signoffs for Spreadsheet Calculations}




\section{Signature Sheet}

\section{Verification of Excel Routines and Macros Identified in NSNF/MED/017, Rev 1}

The purpose of this signature sheet is to document verification of certain software routines and macros within exempt commercial software as required by NSNFP Procedure 19.01, Revision 4, Section III, A. The applicable routines and macros were generated using Microsoft Office Excel 2003 (11.8169.8172) SP3 software and are uniquely identified by the NSNFP Document Control Coordinator (DCC) as NSNF/MED/017, Revision 1.

The Excel software was used to generate spreadsheets containing equations, routines, and macros used to manipulate, convert, calculate, and present raw strain rate testing related data into meaningful results. The following 'verifier' signatures indicate independent verification by checking, inspection, and/or alternate calculation that the spreadsheet equations, routines, and macros calculate correct results:

\begin{tabular}{|c|c|c|c|c|}
\hline \multirow{2}{*}{ IDENTIFIER } & \multirow{2}{*}{ PERFORMER } & \multicolumn{2}{|c|}{ VERIFIER SIGNATURE } & \multirow{2}{*}{ DATE } \\
\hline & & PRINT & SIGN & \\
\hline $\begin{array}{l}\text { Spreadsheets A_304L } \\
\text { Material Static True Stress } \\
\text { Strain }\end{array}$ & T.E. Rahl & $\begin{array}{l}\text { R.K. } \\
\text { Blandford }\end{array}$ & & $3 / 17 / 2008$ \\
\hline $\begin{array}{l}\text { Spreadsheets B_316L } \\
\text { Material Static True Stress } \\
\text { Strain }\end{array}$ & T.E. Rahl & $\begin{array}{l}\text { R.K. } \\
\text { Blandford }\end{array}$ & & 3) $17 / 2008$ \\
\hline $\begin{array}{l}\text { Spreadsheets C_Calibration } \\
\text { of Static Test Data }\end{array}$ & T. E. Rahl & $\begin{array}{l}\text { R.K. } \\
\text { Blandford }\end{array}$ & & $3 / 17 / 2005$ \\
\hline $\begin{array}{l}\text { Spreadsheets D_Strain } \\
\text { Rate Specimen Strain } \\
\text { Distribution }\end{array}$ & T. E. Rahl & $\begin{array}{l}\text { R.K } \\
\text { Blandford }\end{array}$ & & $3 / 12 / 2008$ \\
\hline $\begin{array}{l}\text { Spreadsheets E_Material } \\
\text { Curve Equations }\end{array}$ & T. E. Rahl & $\begin{array}{l}\text { R.K. } \\
\text { Blandford }\end{array}$ & & $3 / 17 / 2000$ \\
\hline $\begin{array}{l}\text { Spreadsheets F_Strain } \\
\text { Rate Test Factor Evaluation }\end{array}$ & T. E. Rahl & $\begin{array}{l}\text { R.K. } \\
\text { Blandford }\end{array}$ & & $3 / 12 / 2008$ \\
\hline $\begin{array}{l}\text { Spreadsheets G_Strain } \\
\text { Rate Test Summary Tables }\end{array}$ & D. K. Morton & $\begin{array}{l}\text { R.K } \\
\text { Blandford }\end{array}$ & & $3 / 17 / 2008$ \\
\hline
\end{tabular}




\section{Appendix C}

\section{INL Welding Procedure S2.0}


UELOING PRDCEDURE SPECIFICATION KUABER: $\$ 2.0$

PAGE 1 of 2 REVISION NUMBER: 11

PQR: See Notes *t WELDING PROCESS(ES): GTAW

DATE: $03 / 24 / 92$

TYPE(S): Hanua 1

SCOPE: This welding procedure specification must be used in conjuction with the Idaho Matianal Engineering Laboratory's Welding Manual. This welding procedure specification meets the requirements of the ASHE \& \& PV Code Section LX, 1986 edition up to and including AB7 addenda.

This specification is to be used for welding austenitic stainless steel.

JOIMTS (QN-402)

DETAILS

JOINT DESIGY; Grooves and Fillets

BACKING MATERIAL (TYPE):

$3 X X$ stainless steel, if required

MONMETALLIC/NONFUSING METAL RETAINERS: None

See IKEL Welding Manual

BASE MATERIALS (QN-403)

GENERALL CLASS; 3XX stainless steel

P NO.: 8 To P NO.: 8

SPECIFICATION TYPE AND GRADE:

TO SPECIFICATION TYPE AND GRADE:

CHENICAL ANALYSIS AMO MECH.PROP.:

TO CHEMICAL AMALYSIS AMO MECH. PROP.:

THICKNESS RANGE:

BASE MATERIAL - GROOVE: 0.020 to 8.0 in.(note 2)

FILLET: Al1

PIPE DIA, RAMGE:

BASE MATERIAL - GROOVE: A11

FILLET: Al1

SINGLE PASS THICKNESS LIMIT: less than $1 / 2$ in.

FILLER METALS (ON-404)

SPECIFICATIOK ND. (SFA): A/SFA 5.9

AWS NO. (CLASS): See note 1

F NO.: 6

A NO.: 8

NOMINAL CHEMICAL COMPOSITION:

SIZE OF FILLER METALS: 0.125 in. max.

DEPOSITED WELD METAL

THIOKNESS RANGE:

GROOVE: 0.020 to 8.00 . in.

FILLET: A11

CONSUMABLE INSERT: None

SUPPLEMENTAL FILLER/PONOER: Kone

SOLIO/TUQULAR/FLUX CONERED (GMAW): $\mathrm{n} / \mathrm{a}$

POSITION (QN-405)

POSITION(S) OF GRODVE: A11

PREHEAT (QN-406)

VERTICAL WELOING PROGRESSION: Up

PREHEAT TEMP. (ain.): $50 \mathrm{~F}$

POSITION(S) OF FILLET: A11

INTERPASS TEMP. (max.): $350 \mathrm{~F}$

PREHEAT MAINTEMANCE: As requited 
WELDING PROCEDURE SPECIFICATION NUMBER: $\$ 2.0$

POSTWEL D HEAT TREATMENT (QW-407)

TEMP. RAMGE: None

TIME RANGE: None
REVISIOY NO: : 11

PAGE: 2 of 2

ELECTRICAL CHARACTERISTICS (OW-409)

CURRENT TYPE: Direct POLARITY: Straight

ANPS: 10 to $200^{*}$ VOL.TS: 8 to $16^{*}$

TUMGSTEN ELECTRODE SIZE AND TYPE: AWS A5.12 ENTh-2 0.125 in. max.

MODE OF TRANSFER FOR GMAU: $n / a$

ELECTROOE WIRE FEED SPEED RAMGE: $\mathrm{n} / \mathrm{a}$

PULSING: 0ptiona 1

TECHNIQUE $(O W-410)$

STRIMG OR WEAVE BEAD: Both

GAS CUP SIZE: $0.375 \mathrm{in}$. min.

INITIAL AND INTERPASS CLEANING: Clean with alcohol, acetone, or approved cleaners prior to

welding. Grinding and/or wire brushing is permitted.

METHOO OF BACKGOUGING: Grinding, filing, or machining

OSCILLATION: 0.50 in. max.

CONTACT TUBE TO WORK DISTANCE: a/a

MLLTIPLE OR SINGLE PASS (per side): Either

MLLTIPLE CR SIMGLE ELECTRODES: Single

TRAVEL, SPEED (ipm): 1 to 10

PE, MING: Not allowed

ADDITIONAL NOTES:

1) Suggested filler materials: For type 304 use 308 filler, 304L use 308L filler, 316 use $316 \mathrm{filler}, 316 \mathrm{~L}$ use $316 \mathrm{~L}$ filler, 347 or 348 use 347 or $348 \mathrm{filler}, 321$ use 321 or 347 filler.

2) This procedure is qualified for welding metals requiring notch toughness testing in the base metal thickness range of 0.124 to 0.496 in.

* If charpy impact requirenents are imposed, the maximun joules/in. shall be: pass 135.6 $\mathrm{kJ} /$ in.; pass 2; $39.3 \mathrm{~kJ} /$ in.; pass 3 and greater $43.1 \mathrm{~kJ} / \mathrm{in}$.. Welding must be approved by an authorized Welding Enginear.

** Q225, Q877, Q4144, Q6233, Q6802

COMPANY: EGBG IDAHO, INC.

PREPARED BY: I) Juy tor D fandere DATE: $3 / 25 / 92$

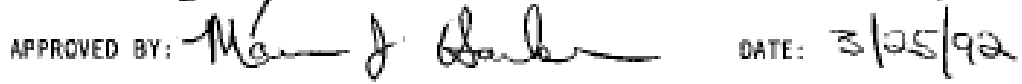




\section{Appendix D}

\section{Representative Test Specimen Data Sheet}




\section{Data Sheet - ITM Tensile Test Coupon - Page 1}

Coupon ID : $3 / 6 L=103$

Material Orientation: (L) $\mathrm{T}$ (circle one)

Drop Height: $2 \mathrm{ft} 6$ in

Heat Number: $\quad \frac{6}{67} \mathrm{ko}$

Weld Number: $\quad r / a$
Test Date: $7 / 12 / 06$

Pig Weight: 790 lbs

Pre-Test Temp : $\quad 79{ }^{\circ} \mathrm{F}$

Caliper Offset: $\quad 0.40$ in.

Specimen Geometry: $\Delta 4-4$

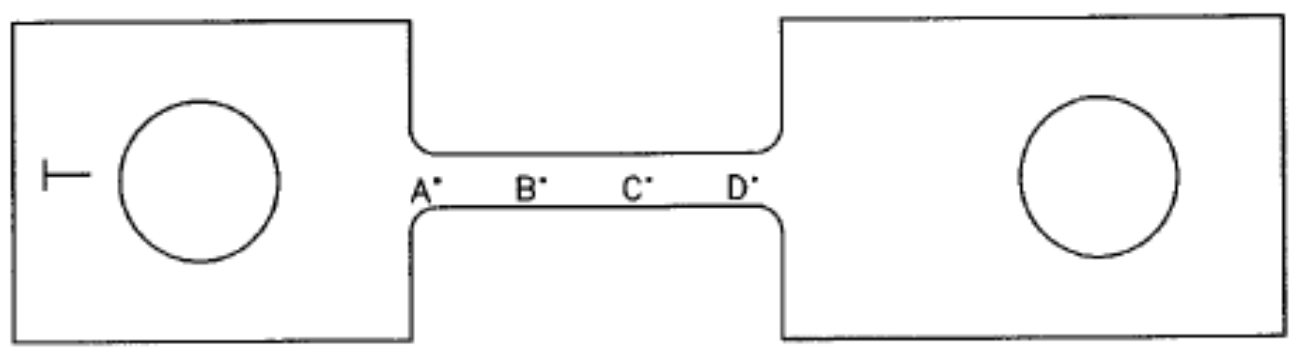

Front Side Shown

\begin{tabular}{|c|c|c|c|c|c|c|c|}
\hline Distance & $\begin{array}{l}\text { Target } \\
\text { Gage } \\
\text { Length } \\
\text { (inches) }\end{array}$ & $\begin{array}{c}\text { Pre-Test } \\
\text { Measured } \\
\text { Gage } \\
\text { Length } \\
\text { (inches) }\end{array}$ & $\begin{array}{c}\text { Pre-Test } \\
\text { Actual } \\
\text { Gage } \\
\text { Length, } \mathbf{L}^{\star} \\
\text { (inches) }\end{array}$ & $\begin{array}{l}\text { Post-Test } \\
\text { Measured } \\
\text { Gage } \\
\text { Length } \\
\text { (inches) }\end{array}$ & $\begin{array}{l}\text { Post-Test } \\
\text { Actual } \\
\text { Gage } \\
\text { Length } \\
\text { (inches) }\end{array}$ & $\begin{array}{c}\text { Change in } \\
\text { Gage } \\
\text { Length, } \\
\text { LL } \\
\text { (inches) }\end{array}$ & $\begin{array}{c}\text { Calipers } \\
\text { Calibration ID\# }\end{array}$ \\
\hline$A-B$ & 1.000 & .6070 & 1.0070 & .8635 & 1.2635 & .2565 & 721714 \\
\hline B-C & 1.000 & .6030 & 1.0030 & .8620 & 1.2620 & .2590 & $\lambda$ \\
\hline C-D & 1.000 & .6110 & 1.0110 & $.866^{\circ}$ & 1.2660 & .2550 & \\
\hline $\mathrm{A}-\mathrm{C}$ & 2.000 & 1.6035 & 2.0035 & 2.1200 & 2.5200 & .5165 & \\
\hline B-D & 2.000 & 1.6075 & 2.0075 & 2.1275 & 25275 & .5200 & \\
\hline A-D & 3.000 & 2.6090 & 3.0090 & 3.3835 & 3.7835 & .7745 & 721714 \\
\hline & & & & & & & \\
\hline & & & & & & & \\
\hline & & & & & & & \\
\hline & & & & & & & \\
\hline
\end{tabular}

*-includes caliper peints offset

\begin{tabular}{|c|c|c|c|c|c|c|c|c|c|}
\hline \multirow{3}{*}{ Pt } & \multicolumn{4}{|c|}{ Reduced Section Width } & \multicolumn{2}{c|}{$\begin{array}{c}\text { Reduced Section } \\
\text { Thickness }\end{array}$} & \multicolumn{2}{|c|}{$\begin{array}{c}\text { Reduced Section } \\
\text { Area (Wx T) }\end{array}$} & \multicolumn{2}{c|}{$\begin{array}{c}\text { Calipers } \\
\text { Calibration ID\# }\end{array}$} \\
\cline { 2 - 10 } & $\begin{array}{c}\text { Pre } \\
\text { Front }\end{array}$ & $\begin{array}{c}\text { Pre } \\
\text { Back }\end{array}$ & $\begin{array}{c}\text { Post } \\
\text { Front }\end{array}$ & $\begin{array}{c}\text { Post } \\
\text { Back }\end{array}$ & Pre & Post & Pre & Post & \\
\hline B & .4820 & .5005 & .4305 & .4485 & .5060 & .4495 & .2486 & .1976 & 721715 \\
\hline C & .4850 & .5000 & .4285 & .4475 & .5065 & .4500 & .2495 & .1971 & 721215 \\
\hline & & & & & & & & & \\
\hline
\end{tabular}

Pre-measurements performed by: TI Rall

Pre-measurements checked by: $\quad$ KL Blm 20 on

Post-measurements performed by: T2 Rabl

Post-measurements checked by:
Sosma>
Date: $\frac{7}{7}, \frac{10}{10} / \frac{06}{10}$

Date: $7,12 / 06$

Date: $\frac{7}{12}, 06$ 


\section{Data Sheet - ITM Tensile Test Coupon - Page 2}

Coupon ID : $316 \mathrm{~L}-103$

Accel FN : test307 071206

Cam FN: Test 307

See attached camera data for more details.

\begin{tabular}{|c|c|c|c|}
\hline Distance & $\begin{array}{c}\text { Target } \\
\text { Gage } \\
\text { Length } \\
\text { (inches) }\end{array}$ & $\begin{array}{c}\text { Engr. } \\
\text { Strain, } \\
\mathbf{\epsilon}_{\mathbf{L}} \\
(\mathbf{\Delta L} / \mathrm{L})\end{array}$ & $\begin{array}{c}\text { True } \\
\text { Strain, } \\
\mathbf{z}_{\mathbf{L}} \\
\text { ln }(\Delta \mathbf{L} / \mathbf{L}+\mathbf{1})\end{array}$ \\
\hline A-B & 1.000 & $\mathbf{n c}$ & $\mathbf{n c}$ \\
\hline B-C & 1.000 & $\mathbf{n c}$ & $\mathbf{n c}$ \\
\hline C-D & 1.000 & $\mathbf{n c}$ & $\mathbf{n c}$ \\
\hline A-C & 2.000 & $\mathbf{n c}$ & $\mathbf{n c}$ \\
\hline B-D & 2.000 & $\mathbf{n c}$ & $\mathbf{n c}$ \\
\hline A-D & 3.000 & .2574 & .2290 \\
\hline & & & \\
\hline & & & \\
\hline & & & \\
\hline & & & \\
\hline
\end{tabular}

\section{Comments:}

$\mathrm{nc}-$ not calculated for auxillary tests
Accel. Serial \# 38617

True strain rate from vamera $=27,5 \mathrm{sec}^{-1}$
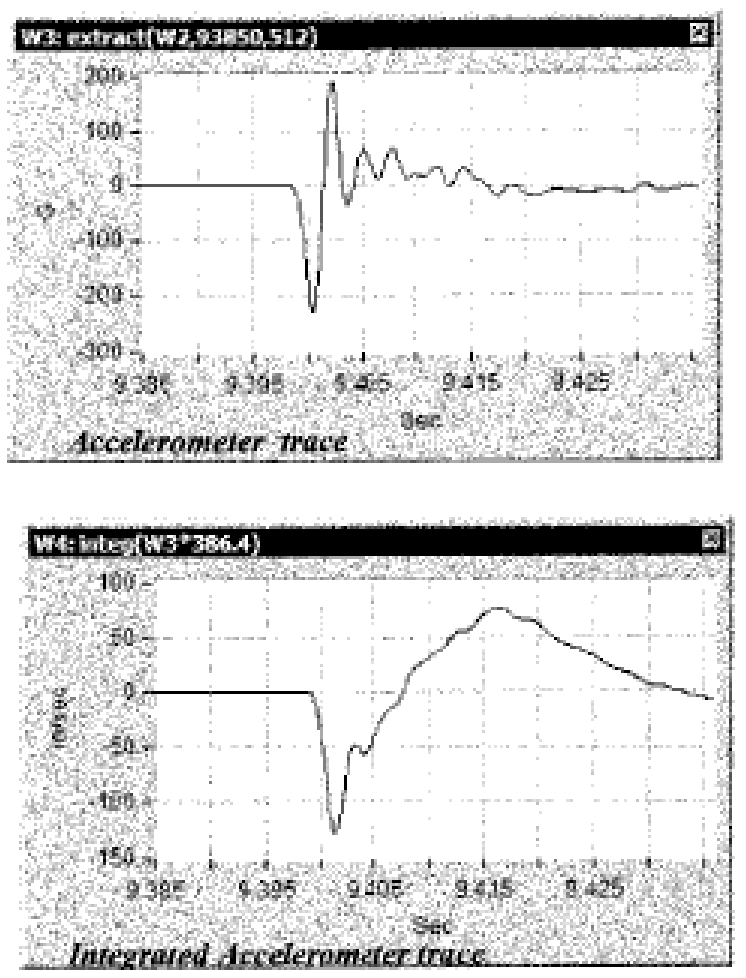

\begin{tabular}{|c|c|c|}
\hline $\mathbf{P t}$ & $\begin{array}{c}\text { Eegr.Strain, } \\
\epsilon_{s,} \\
\left(\frac{A_{p v}-A_{p w o}}{A_{x+1}}\right)\end{array}$ & $\begin{array}{c}\text { True Strain, } \\
\varepsilon_{\mathrm{s}} \\
\ln \left(\frac{A_{\text {pro }}}{A_{\text {pov }}}\right)\end{array}$ \\
\hline B & ne & ne \\
\hline C & ac & uc \\
\hline ave & .2620 & .2327 \\
\hline
\end{tabular}

Measurements performed by: Checked by: OK. A Woter
Date: $07 / 11 / 07$
Date: $07,16,07$ 


\section{Qualified Dimensional Inspector Data Sheet - ITM Tensile Test Coupon Page 3}

Coupon ID:316 - 103 Dimensional Inspector (print): Robert Mohwey

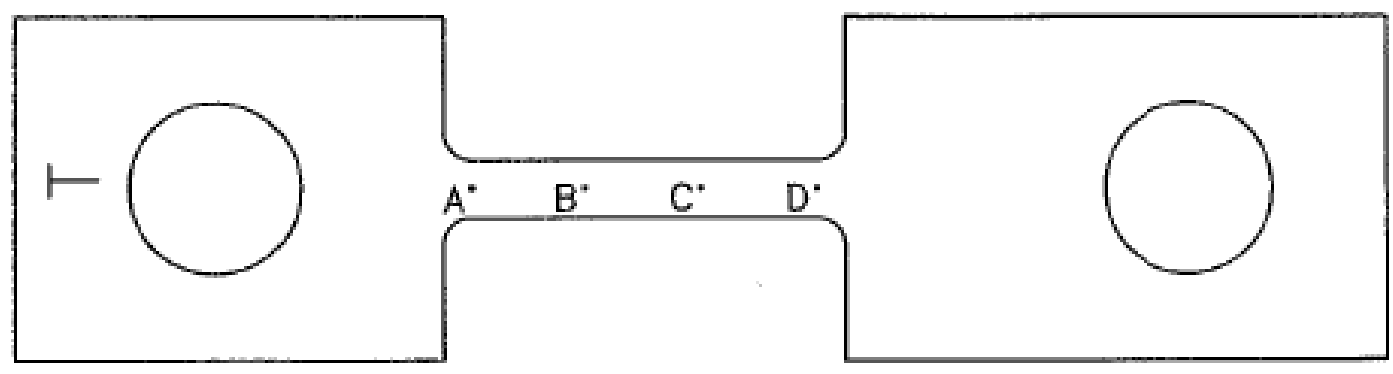

Front Side Shown

\begin{tabular}{|c|c|c|c|}
\hline Distance & $\begin{array}{l}\text { Gage Length } \\
\text { (inches) }\end{array}$ & $\begin{array}{l}\text { Post-Test } \\
\text { Length } \\
\text { (inches) }\end{array}$ & $\begin{array}{c}\text { Calipers } \\
\text { Calibration ID }\end{array}$ \\
\hline \multirow[t]{3}{*}{ A-D } & 3.000 & 3.779 .5 & 721714 2xp $9-26-07$ \\
\hline & . & & \\
\hline & & ' & \\
\hline
\end{tabular}

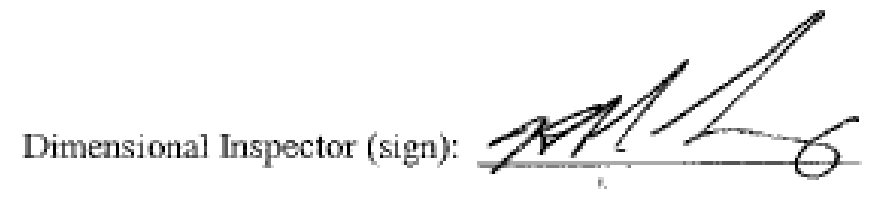

Date: $10,12,2006$ 


\section{Appendix E}

\section{Drop Weight Comparison}




\begin{tabular}{|c|c|c|c|c|c|c|c|c|}
\hline \multicolumn{9}{|c|}{ Results of ITM Weights Calibrations } \\
\hline \multirow[b]{2}{*}{$\begin{array}{l}\text { Cal Lab } \\
\text { ID }\end{array}$} & \multirow[b]{2}{*}{$\begin{array}{c}\text { Marked } \\
\text { Label }\end{array}$} & \multirow{2}{*}{$\begin{array}{l}\text { Marked } \\
\text { Weight }^{(1)} \\
\text { (lbs) }^{\text {(Ibs }}\end{array}$} & \multicolumn{2}{|c|}{$\begin{array}{c}\text { Calibration Laboratory } \\
\text { Measurement }\end{array}$} & \multirow{2}{*}{$\begin{array}{c}\text { Total } \\
\text { Weight }^{(5)} \\
\text { (lbs) }\end{array}$} & \multirow{2}{*}{$\begin{array}{c}\text { Nominal } \\
\text { Measured } \\
\text { Weight }^{(6)} \\
\text { (lbs) }\end{array}$} & \multirow{2}{*}{$\begin{array}{c}\text { Percent } \\
\text { Variation } \\
\text { From } \\
\text { Marked }\end{array}$} & \multirow[b]{2}{*}{ Comments } \\
\hline & & & $\begin{array}{l}\text { Item } \\
\text { Weight } \\
\text { (lbs) }\end{array}$ & $\begin{array}{c}\text { Shackle }^{(2)} \& \\
\text { Link Weight } \\
\text { (Ibs) }\end{array}$ & & & & \\
\hline 725131 & A & 1097 & 1080.88 & 5.73 & 1086.61 & 1087 & $<1 \%$ & $10 \mathrm{lb}$ variance \\
\hline 725132 & $B$ & 541 & 534.34 & 5.73 & 540.07 & 540 & $<0.2 \%$ & $1 \mathrm{lb}$ variance \\
\hline 725133 & C & 103 & 102.17 & 5.73 & 107.9 & 108 & $4.6 \%$ & (note 3) \\
\hline 725134 & $\# 1$ & $83^{(4)}$ & 83.44 & NA & 83.44 & 83 & 0 & - \\
\hline 725135 & $\# 2$ & $83^{(4)}$ & 83.4 & NA & 83.4 & 83 & 0 & - \\
\hline 725136 & \#3 & $83^{(4)}$ & 83.31 & NA & 83.31 & 83 & 0 & - \\
\hline 725137 & $\# 4$ & $83^{(4)}$ & 83.47 & NA & 83.47 & 83 & 0 & - \\
\hline 725138 & $\# 5$ & $84^{(4)}$ & 83.43 & NA & 83.43 & 83 & $1.2 \%$ & $1 \mathrm{lb}$ variance \\
\hline 725139 & $\# 6$ & $83^{(4)}$ & 83.39 & NA & 83.39 & 83 & 0 & - \\
\hline 725140 & CFA-S-05-1-12 & NA & 4.91 & NA & NA & NA & NA & - \\
\hline 725141 & CFA-S-05-1-7 & NA & 4.93 & NA & NA & NA & NA & - \\
\hline 725142 & CITRC-ML-02-2 & NA & 0.81 & NA & NA & NA & NA & - \\
\hline 725143 & CITRC-ML-07-1/2-2 & NA & 0.88 & NA & NA & NA & NA & Never Used \\
\hline \multicolumn{9}{|c|}{$\begin{array}{l}\text { 1. Weights measured and marked by NSNFP test personnel using calibrated load cells. } \\
\text { 2. Shackle weight used for total weight represents average weight of both shackles. } \\
\text { 3. Weight not used for qualified data testing. } \\
\text { 4. Weights } \# 1 \text { thru } \# 6 \text { include two bolts. } \\
\text { 5. Total weight is the sum of the calibration laboratory measurement 'Item Weight' and the 'Shackle \& Link Weight.' } \\
6 \text {. Nominal measured weight is the Total Weight rounded to the nearest whole number. }\end{array}$} \\
\hline
\end{tabular}




\section{Appendix F}

\section{INL Dimensional Inspector Qualifications}




\section{PERSONNEL CERTIFICATION DATA FORM}

SECTION I - Request (To be filled out by Applicant's Supervisor)

\begin{tabular}{|c|c|c|}
\hline $\begin{array}{l}\text { Applicant: Robert B. Mohney } \\
\text { Inspection activity candidate wi }\end{array}$ & $\begin{array}{l}\text { S\#: } 57562 \text { Current certification expires: 10/20/00 } \\
\text { forming: Precision Dimensional Inspections. }\end{array}$ & Date: $08 / 20 / 00$ \\
\hline
\end{tabular}

SECTION II - Processing Documentation and Evaluations: (To be filled out by Level II and others as requested)
1. Discipline: Mechanical
Method: Precision Dimensional
Level: II Inspector

Limits: None

2. Physical/Vision Examination Ref MCP-535 Appendix I

\begin{tabular}{|l|l|l|l|l|l|}
\hline Due Date 08/02/01 & A. Near Vision & B. Far Vision & C. Color Discrimination & $\square$ 4r. Degree & $\square 2$ Yr. Degree \\
\hline Requirement & $20 / 25$ Snellen & & & $\square$ H.S./Equal & $\square$ Other \\
\hline Corrected/Uncorrected & Corrected & Corrected & Verify contrast. & Note: See Inspectors Certification File \\
\hline
\end{tabular}

3. Training: * Sub Exp. $=$ additional experience permitted to substitute for formal training as specified in Appendix $F$ or $G$

\begin{tabular}{|c|c|c|c|c|c|}
\hline MCP-535 Appendix B. F, or G & \multicolumn{3}{|c|}{ Class Hr by Education Level } & \multicolumn{2}{|c|}{ Training Acquired (Ref MCP-535 Appendix D) } \\
\hline Subject/Topic/Description & H.S. & +2 Yr. & Sub Exp. ${ }^{*}$ & Hr. & Description \\
\hline \begin{tabular}{|ll} 
1. & Drawing interpretation \\
2. & Dimensional metrology \\
3. & Measuring hand tools \\
4. & Geometric tolerancing \\
5. & Coordinate measuring \\
6. & machine \\
7. & Contour Projector \\
7. & Optical Measuring \\
& Equipment.
\end{tabular} & $\begin{array}{l}4 \text { hours } \\
20 \text { hours } \\
20 \text { hours } \\
40 \text { hours } \\
40 \text { hours } \\
8 \text { hours } \\
8 \text { hours }\end{array}$ & $\begin{array}{l}-\overline{-} \\
\overline{-} \\
-\end{array}$ & $\begin{array}{l}3 \text { months } \\
6 \text { months } \\
6 \text { months } \\
1 \text { year } \\
1 \text { year } \\
4 \text { months } \\
4 \text { months }\end{array}$ & & $\begin{array}{l}\text { Experience continued since previous certification } \\
\text { obtained as a Precision Dimensional Inspector, } \\
\text { See Certification File. }\end{array}$ \\
\hline
\end{tabular}

3a.

OJT/Self Study:

\begin{tabular}{|ll|l|l|l|l|}
\hline Type \& Activity/Objective Required & Req. $\mathrm{Hr}$ & Date & $\mathrm{Hr}$. & Reference Documentation and comments: \\
\hline 1. & Drawing interpretation & 10 hours & & & \\
2. & Dimensional Metrology & 20 hours & & & See Certification File. \\
3. Measuring Hand Tools & 20 hours & & & \\
4. Geometric Tolerancing & 40 hours & & & \\
5. Coordinate Measuring Machine & 80 hours & & & \\
6. Contour Projector & 10 hours & & & \\
7. & Optical Measuring Equipment & 10 hours & & & \\
\hline
\end{tabular}

4. Experience: Ref MCP-535 Appendix A, B, F or G

\begin{tabular}{|c|c|c|c|c|c|}
\hline \multicolumn{2}{|c|}{ Hr. Required } & \multicolumn{2}{c|}{ Required Experience } & \multicolumn{2}{c|}{ Experience Obtained } \\
\hline H.S. & +2 Yr. & Other & Description & Hr. & Reference/Documentation \\
\hline 1 Year & 6 Month & & & $55 \mathrm{Hrs}$. & $\begin{array}{r}\text { Application \& Interpretation of Geometric } \\
\text { Dimensioning \& Tolerancing. } \\
\text { (Tech. Doc. Consultants INC.) }\end{array}$ \\
\hline
\end{tabular}

5. Examination Results:

\begin{tabular}{|c|c|c|c|c|c|c|c|}
\hline \multirow{3}{*}{$\begin{array}{l}\text { TEST } \\
\text { TYPE }\end{array}$} & \multicolumn{6}{|c|}{ INDIVIDUAL TEST SCORES } & \multirow{3}{*}{$\begin{array}{l}\text { COMPOSITE } \\
\text { SCORE }\end{array}$} \\
\hline & \multicolumn{3}{|c|}{ Written Examinations \& Min Number Questions } & \multicolumn{3}{|c|}{ Practical Examinations } & \\
\hline & Gen. $/(\quad)$ & Spec. $\quad /(\quad)$ & Other $97 /(117)$ & Demo & Oral & Other & \\
\hline Description & & & $\mathrm{G} / \mathrm{D} / \mathrm{\&} / \mathrm{T}-\mathrm{F}$ & Door Support & & $\mathrm{G} / \mathrm{D} / \mathrm{Q} / \mathrm{T}-\mathrm{Q} / \mathrm{H}$ & \multirow{3}{*}{$92 \%$} \\
\hline SCORES & & & $82 \%$ & $97 \%$ & & $96 \%$ & \\
\hline DATE & & & $01 / 18 / 2000$ & $10 / 10 / 20000$ & & $01 / 18 / 2000$ & \\
\hline
\end{tabular}

"The Mrimum number of examination questions is reduced when the scope of quallication Is LIMITED MCP.-535 Appendlx A \& D. Mn \# questions (achaal \# questions) 


\section{PERSONNEL CERTIFICATION DATA FORM}

6.

\begin{tabular}{|l|l|l|l|l|}
\hline Additional Training Required Prior to Re-examination: & \multicolumn{4}{|l|}{ Minimum up-date or re-certification training: } \\
\hline NONE & Hours & Subject Required & Hours & Ref. Documentation \\
\cline { 2 - 5 } & & & & \\
\hline
\end{tabular}

7. The "Applicant" is Certified in accordance with MCP- 535 to perform the above Discipline - Method.

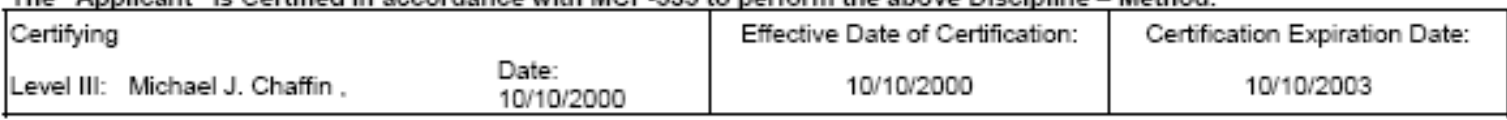

8. Certificate/Endorsement issued:

Entered into Database:

(Initlals \& Date)

(Intals \& Date) 
Rev. 04

Use with MCP-535

SECTION I - Request (To be filled out by Applicant's Supervisor)

Applicant: Robert B. Mohney $\quad$ SH: $57562 \quad$ Current certification expires: 10/10/2003

Date: $09 / 11 / 2003$

Inspection activity candidate will be performing: Precision Dimensional Inspections.

SECTION II - Processing Documentation and Evaluations: (To be filled out by Level II and others as requested.)

1. Discipline: Mechanical Method: Precision Dimensional Level: II Inspector Limits: NONE

2. Physical/Vision Examination Ref. MCP-535 Appendix |

\begin{tabular}{|l|l|l|l|l|l|}
\hline Due Date 08/18/2004 & A. Near Vision & B. Far Vision & C. Color Discrimination & $\square 4$ Yr. Degree & $\square 2$ Yr. Degree \\
\hline Requirement & $20 / 25$ Snellen & N/A & Verify Contrast & $\square$ H.S./Equal & $\square$ Other \\
\hline Corrected/Uncorrected & Corrected & & OK & Note: See Inspectors Certification File \\
\hline
\end{tabular}

3. Training: * Sub Exp. = additional experience permitted to substitute for formal training as specified in Appendix F or G

\begin{tabular}{|c|l|l|l|l|l|l|}
\hline MCP-535 Appendix B. F. or G & \multicolumn{3}{|l|}{ Class Hr. by Education Level } & \multicolumn{2}{|l|}{ Training Acquired (Ref. MCP-535 Appendix D) } \\
\hline Subject/Topic/Description & H.S. & +2 Yr. & Sub Exp. & Hr. & Description \\
\hline 1. Drawing Interpretation & 4 hours & & 1 year & & \\
2. Dimensional Metrology & 20 hours & & 1 year & & \\
3. Measuring Hand Tools & 20 hours & & 2 years & & Experience continued since previous certification \\
4. Geometric Tolerancing & 40 hours & & 1 year & & obtained as a Precision Dimensional Inspector. \\
5. Coordinate Measuring & 40 hours & & 1 year & & See Certification File. \\
6. Machine & Contour Projector & 8 hours & & 1 year & & \\
7. Optical Measuring & 8 hours & & 8 months & & \\
\hline
\end{tabular}

3a. OJT/Self Study:

\begin{tabular}{|c|l|l|l|l|l|}
\hline Type \& & Activity/Objective Required & Req. Hr. & Date & Hr. & Reference Documentation and Comments: \\
\hline 1. Drawing Interpretation & 10 hours & & & \\
2. Dimensional Metrology & 20 hours & & & See Certification File. \\
3. Measuring Hand Tools & 20 hours & & & \\
4. Geometric Tolerancing & 40 hours & & & \\
5. Coordinate Measuring & 80 hours & & & \\
$\quad$ Machine & 10 hours & & & \\
6. Contour Projector & & & \\
7. Optical Measuring Equipment & 10 hours & & \\
\hline
\end{tabular}

4. Experience: Ref. MCP-535 Appendix A, B, F or G

Experience: Ref. MCP-535 Appendix A, B. F or G
\begin{tabular}{|c|c|c|c|c|c|}
\hline \multicolumn{2}{|c|}{ Hr. Required } & Required Experience & \multicolumn{2}{c|}{ Experience Obtained } \\
\hline H.S. & +2 Yr. & Other & Description & Hr. & Reference/Documentation \\
\hline & & & & $55 \mathrm{Hrs}$. & $\begin{array}{r}\text { Application \& Interpretation of Geometric } \\
\text { Dimensioning \& Tolerancing. } \\
\text { (Tech. Doc. Consultants INC.) }\end{array}$ \\
\hline Year & B Month & & & 40 Hrs. & Gage Mentor (CBT Training) \\
\hline
\end{tabular}


414.73

02/20/2003

Rev. 04

Use with MCP-535

\section{BBWI PERSONNEL CERTIFICATION DATA FORM}

5. Examination Results:

\begin{tabular}{|c|c|c|c|c|c|c|c|}
\hline \multirow{3}{*}{$\begin{array}{l}\text { TEST } \\
\text { TYPE }\end{array}$} & \multicolumn{6}{|c|}{$\begin{array}{ll} & \text { INDIVIDUAL TEST SCORES } \\
\end{array}$} & \multirow{3}{*}{$\begin{array}{l}\text { COMPOSITE } \\
\text { SCORE }\end{array}$} \\
\hline & \multicolumn{3}{|c|}{ Written Examinations \& Min Number Questions ${ }^{x}$} & \multicolumn{3}{|c|}{ Practical Examinations } & \\
\hline & Gen.25/(30) & Spec. $\quad /(\quad)$ & Other $/(\quad)$ & Demo & Oral & Other & \\
\hline Description & Written & & & Plate/Holes & & Practical Demo & \multirow{3}{*}{$88 \%$} \\
\hline Scores & $83 \%$ & & & $90 \%$ & & $90 \%$ & \\
\hline Date & $9 / 02 / 03$ & & & $9 / 04 / 03$ & & 9/11/03 & \\
\hline
\end{tabular}

"The Mininum number of examination questions is reduced when the scope of quallication is LIMITED MCP-535 Appendlx A \& D. Mn \# questions|(actual \# questions)

6.

\begin{tabular}{|l|l|l|l|l|}
\hline Additional Training Required Prior to Re-examination: & \multicolumn{4}{l|}{ Minimum up-date or re-certification training: } \\
\hline \multirow{2}{*}{ None } & Hours & Subject Required & Hours & Ref. Documentation \\
\cline { 2 - 6 } & & & & \\
\hline
\end{tabular}

7. The "Applicant" is Certified in accordance with MCP-535 to perform the above Discipline - Method.

\begin{tabular}{|c|c|c|}
\hline $\begin{array}{l}\text { Effective Date of Certification: } \\
\qquad 09 / 11 / 03\end{array}$ & $\begin{array}{l}\text { Certification Expiration Date: } \\
\qquad 10 / 10 / 2008\end{array}$ & $\begin{array}{l}\text { TRAIN Qualification Code: } \\
\text { QLMECHO2 }\end{array}$ \\
\hline Michael J. Chaffin & & $09 / 11 / 03$ \\
\hline $\begin{array}{l}\text { Principle Level III Examiner } \\
\text { Print/Type Name }\end{array}$ & $\begin{array}{l}\text { Principle Level III Examiner } \\
\text { Signature }\end{array}$ & Date \\
\hline
\end{tabular}


Rev. 05

Use with MCP-535 \& MCP-1300

SECTION I - Request (To be filled out by Applicant's Supervisor)

\begin{tabular}{|lllll}
\hline Applicant: Robert B. Mohney & SH: 57582 & Current certification expires: $10 / 10 / 06$ & Date: $10 / 12 / 06$
\end{tabular}

SECTION II - Processing Documentation and Evaluations: (To be filled out by Level III)

1. Discipline: Precision Dimensional Inspector, 3 Year Re-Cerification Level: II Inspector

2. Physical/Vision Examination

\begin{tabular}{|l|l|l|l|l|l|}
\hline Due Date 08/07 & A. Near Vision & B. Far Vision & C. Color Discrimination & $\square 4$ Yr. Degree & $\square 2$ Yr. Degree \\
\hline Requirement & $20 / 25$ Snellen & & Verify Contrast & $\square$ H.S./Equal & $\square$ Other \\
\hline Corrected/Uncorrected & Corrected & Un-Corrected & OK & Note: & \\
\hline
\end{tabular}

3. Training: ${ }^{1}$ Sub Exp. $=$ additional experience permitted to substitute for formal training as specified in MCP-535 \& MCP 1309.

\begin{tabular}{|l|l|l|l|l|l|}
\hline & \multicolumn{3}{|l|}{ Class Hr. by Education Level } & \multicolumn{2}{l|}{ Training Acquired } \\
\hline Subject/Topic/Description & H.S. & $+2 \mathrm{Yr}$. & Sub Exp. ${ }^{1}$ & $\mathrm{Hr}$. & Description \\
\hline See Previous Certifications & & & & & See Certification File \\
\hline
\end{tabular}

3a. OJT/Self Study:

\begin{tabular}{|l|l|l|l|l|}
\hline Type \& Activity/Objective Required & Req. Hr. & Date & Hr. & Reference Documentation and Comments: \\
\hline N/A & & & & See Certification File \\
\hline
\end{tabular}

4. Experience:

\begin{tabular}{l} 
Experience: \\
\begin{tabular}{|c|c|c|c|c|c|}
\hline \multicolumn{2}{|c|}{ Hr. Required } & \multicolumn{2}{c|}{ Required Experience } & \multicolumn{2}{c|}{ Experience Obtained } \\
\hline H.S. & +2 Yr. & Other & Description & Hr. & Reference/Documentation \\
\hline & & & See Previous Certifications & & See Certification File \\
\hline
\end{tabular} \\
\hline
\end{tabular}

5. Examination Results: MCP1309. Min $\#$ questlons/(actual \# questlons)

\begin{tabular}{|c|c|c|c|c|c|c|c|}
\hline \multirow{3}{*}{$\begin{array}{l}\text { TEST } \\
\text { TYPE }\end{array}$} & \multicolumn{6}{|c|}{ INDIVIDUAL TEST SCORES } & \multirow{3}{*}{$\begin{array}{l}\text { COMPOSITE } \\
\text { SCORE }\end{array}$} \\
\hline & \multicolumn{3}{|c|}{ Written Examinations \& Min Number Questions ${ }^{2}$} & \multicolumn{3}{|c|}{ Practical Examinations } & \\
\hline & Gen. $/(\quad)$ & Spec. $/(\quad)$ & Other $l(\quad)$ & Demo & Oral & Other & \\
\hline Description & & & & & & & \multirow{3}{*}{ N/A } \\
\hline Scores & & & & & & & \\
\hline Date & & & & & & & \\
\hline
\end{tabular}

6. Additional Training Required Prior to Re-examination: None

\begin{tabular}{|l|l|l|l|}
\hline \multicolumn{4}{|c|}{ Minimum up-date or re-certification training: } \\
\hline Hours & Subject Required & Hours & Ref. Documentation \\
\hline & & & \\
\hline
\end{tabular}

7. The "Applicant" is Certified in accordance with MCP-535\& MCP1309 to perform the above Discipline - Method.

\begin{tabular}{|c|c|c|}
\hline $\begin{array}{l}\text { Effective Date of Certification: } \\
\qquad 10 / 10 / 06\end{array}$ & $\begin{array}{l}\text { Certification Expiration Date: } \\
\qquad 10 / 10 / 09\end{array}$ & $\begin{array}{l}\text { TRAIN Qualification Code: } \\
\text { QLMECH02 }\end{array}$ \\
\hline Michael J. Chaffin & \multirow{2}{*}{\multicolumn{2}{|c|}{$\begin{array}{l}\text { Principle Level III Examiner } \\
\text { Signature }\end{array}$}} \\
\hline $\begin{array}{c}\text { Principle Level III Examiner } \\
\text { Print Tyoe Name }\end{array}$ & & \\
\hline
\end{tabular}




\section{Appendix G}

\section{Electronic File Information}




\section{ELECTRONIC FILES}

The following electronic files associated with work performed in this report were generated and stored on 1 Digital Video Disk (DVD) using the +R DVD format. The DVD has the unique title "Electronic Files SR Test Comparisons". All ABAQUS/Explicit input (.inp) and output (.odb) files were transferred from PC (Govt. Property ID: 384252) to the DVD.

After the files were written to the DVD, the files were checked by accessing and visually checking the ABAQUS/Explicit input files and viewing the results in ABAQUS Viewer for the output files. This work was performed by the preparer (R. K. Blandford). The reviewer (S. D. Snow) performed random readability checks of the DVD.

The files were used for the work described in report Section 8 (USING RESULTS: ABAQUS/EXPLICIT ANALYSES USING STRAIN RATE ELEVATED TRUE STRESS-STRAIN CURVES) of this report and are listed below. The "Date Modified" indicates the date when the model file was last changed in any way and then saved to the identified PC hard drive and documents the final configuration as used in the analyses contained in this report.

The file names on the DVD are descriptive with the associated acronyms describing various model details that were used in the particular input file. The significant acronyms identifying the input files model configuration are:

Typical file title

$304 \mathrm{~L}$

70

T\#\#\#

D44

$72 \mathrm{~K} 9$

1097

175

FR

$$
\text { 304L_70_T290_D44_72K9_1097_175_FR.inp }
$$

$$
\text { material }(304 \mathrm{~L}, 316 \mathrm{~L})
$$$$
\text { temperature }\left(-20,70,300,600^{\circ} \mathrm{F}\right)
$$

strain rate test number

test specimen geometry (an included W implies a welded material otherwise base material is implied)

material heat number $(72 \mathrm{~K} 9,64 \mathrm{~A} 1,54 \mathrm{M} 7,485896,67 \mathrm{~K} 0,230468,48 \mathrm{R} 8,76 \mathrm{H} 3$

test drop weight magnitude

a number descriptor for the test drop height magnitude

$\begin{array}{llll}175 & 17.5 \text {-inches } & 14 & 14 \text {-inches } \\ 3 & 3 \text {-inches } & 2125 & 21.25 \text {-inches } \\ 21625 & 21.625 \text {-inches } & 250 & 2.50 \text {-inches } \\ 275 & 2.75 \text {-inches } & 18 & 18 \text {-inches } \\ 17375 & 17.375 \text {-inches } & 1150 & 11.50 \text {-inches } \\ 1450 & 14.50 \text {-inches } & 20 & 20 \text {-inches } \\ 2375 & 23.75 \text {-inches } & 1825 & 18.25 \text {-inches } \\ 18188 & 18.188 \text {-inches } & 1475 & 14.75 \text {-inches } \\ 16 & 16 \text {-inches } & 18688 & 18.688 \text {-inches } \\ 17875 & 17.875 \text {-inches } & 13 & 13 \text {-inches } \\ 11 & 11 \text {-inches } & 19 & 19 \text {-inches }\end{array}$

a descriptor for the true stress strain curve

FR or FRY implies a factored true stress-strain curve

$\mathrm{S}$ implies a quasi-static true stress-strain curve (no factors applied) 


\begin{tabular}{|c|c|c|c|}
\hline Name - & Size & Type & Date Modified \\
\hline [0] 304L_70_T290_D44_72K9_1097_175_FR.inp & $564 \mathrm{~KB}$ & INP File & $1 / 30 / 200812: 25 \mathrm{PM}$ \\
\hline 囷 304L_70_T290_D44_72K9_1097_175_FR.odb & $12,287 \mathrm{~KB}$ & ODB File & 1/30/2008 6:07 PM \\
\hline [1] 304L_70_T290_D44_72K9_1097_175_S.inp & $564 \mathrm{~KB}$ & INP File & 1/23/2008 8:38 AM \\
\hline 眯 304L_70_T290_D44_72K9_1097_175_S.odb & $12,275 \mathrm{~KB}$ & ODB File & 1/23/2008 9:27 AM \\
\hline [0] 304L_70_T312_D22_64A1_790_3_FR.inp & $256 \mathrm{~KB}$ & INP File & 1/30/2008 3:41 PM \\
\hline 國 304L_70_T312_D22_64A1_790_3_FR.odb & $6,623 \mathrm{~KB}$ & ODB File & 1/30/2008 5:15 PM \\
\hline [0] 304L_70_T312_D22_64A1_790_3_S.inp & $256 \mathrm{~KB}$ & INP File & 1/17/2008 3:35 PM \\
\hline 罍 304L_70_T312_D22_64A1_790_3_S.odb & $6,590 \mathrm{~KB}$ & ODB File & $1 / 21 / 200810: 34$ AM \\
\hline [8] 304L_70_T349_D44_54M7_790_21625_FR.inp & $564 \mathrm{~KB}$ & INP File & $1 / 30 / 20083: 43 \mathrm{PM}$ \\
\hline 箅 304L_70_T349_D44_54M7_790_21625_FR.odb & $12,289 \mathrm{~KB}$ & ODB File & 1/30/2008 5:13 PM \\
\hline [0] 304L_70_T349_D44_54M7_790_21625_S.inp & $564 \mathrm{~KB}$ & INP File & $1 / 23 / 2008$ 7:25 AM \\
\hline 眯 304L_70_T349_D44_54M7_790_21625_S.odb & $12,285 \mathrm{~KB}$ & ODB File & 1/23/2008 8:18 AM \\
\hline [1] 304L_70_T355_D22_4858_1097_275_FR.inp & $257 \mathrm{~KB}$ & INP File & 1/30/2008 8:35 AM \\
\hline 净 304L_70_T355_D22_4858_1097_275_FR.odb & $6,542 \mathrm{~KB}$ & ODB File & $1 / 30 / 200810: 23$ AM \\
\hline [1] 304L_70_T355_D22_4858_1097_275_S.inp & $257 \mathrm{~KB}$ & INP File & 1/17/2008 2:53 PM \\
\hline 固 304L_70_T355_D22_4858_1097_275_S.odb & $6,596 \mathrm{~KB}$ & ODB File & $1 / 21 / 20088: 43$ AM \\
\hline [1] 304L_70_T381_D44W_54M7_1097_17375_FR.inp & $565 \mathrm{~KB}$ & INP File & 1/30/2008 12:30 PM \\
\hline 暞 304L_70_T381_D44W_54M7_1097_17375_FR.odb & $12,311 \mathrm{~KB}$ & ODB File & $1 / 31 / 20088: 50 \mathrm{AM}$ \\
\hline [0] 304L_70_T381_D44W_54M7_1097_17375_S.inp & $565 \mathrm{~KB}$ & INP File & $1 / 23 / 200812: 35 \mathrm{PM}$ \\
\hline 葍 304L_70_T381_D44W_54M7_1097_17375_S.odb & $12,256 \mathrm{~KB}$ & ODB File & 1/23/2008 1:55 PM \\
\hline [0] 304L_300_T321_D22_64A1_790_3_FR.inp & $257 \mathrm{~KB}$ & INP File & 1/30/2008 2:10 PM \\
\hline 番 304L_300_T321_D22_64A1_790_3_FR.odb & $6,613 \mathrm{~KB}$ & ODB File & $1 / 31 / 200810: 54$ AM \\
\hline [0] 304L_300_T321_D22_64A1_790_3_S.inp & $256 \mathrm{~KB}$ & INP File & 1/22/2008 3:26 PM \\
\hline 国 304L_300_T321_D22_64A1_790_3_S.odb & $6,515 \mathrm{~KB}$ & ODB File & 1/23/2008 7:16 PM \\
\hline$[$ [] 304L_300_T376_D44_72K9_1097_1450_FR.inp & $564 \mathrm{~KB}$ & INP File & 1/30/2008 2:14 PM \\
\hline 囷 304L_300_T376_D44_72K9_1097_1450_FR.odb & $12,295 \mathrm{~KB}$ & ODB File & $1 / 31 / 200812: 53 \mathrm{PM}$ \\
\hline [1] 304L_300_T376_D44_72K9_1097_1450_S.inp & $564 \mathrm{~KB}$ & INP File & 1/22/2008 4:37 PM \\
\hline 畮 304L_300_T376_D44_72K9_1097_1450_S.odb & $12,278 \mathrm{~KB}$ & ODB File & 1/24/2008 8:22 AM \\
\hline [1] 304L_300_T388_D22_4858_1097_2375_FR.inp & $257 \mathrm{~KB}$ & INP File & 1/30/2008 2:05 PM \\
\hline 國 304L_300_T388_D22_4858_1097_2375_FR.odb & $6,602 \mathrm{~KB}$ & ODB File & $1 / 31 / 200810: 39 \mathrm{AM}$ \\
\hline [0] 304L_300_T388_D22_4858_1097_2375_S.inp & $256 \mathrm{~KB}$ & INP File & 1/17/2008 4:17 PM \\
\hline 㕑 304L_300_T388_D22_4858_1097_2375_S.odb & $6,595 \mathrm{~KB}$ & ODB File & 1/21/2008 11:40 AM \\
\hline [0] 304L_300_T405_D44_54M7_790_18188_FR.inp & $565 \mathrm{~KB}$ & INP File & $1 / 30 / 20082: 12 \mathrm{PM}$ \\
\hline 葍 304L_300_T405_D44_54M7_790_18188_FR.odb & $12,267 \mathrm{~KB}$ & ODB File & 1/31/2008 12:59 PM \\
\hline [0] 304L_300_T405_D44_54M7_790_18188_S.inp & $564 \mathrm{~KB}$ & INP File & $1 / 22 / 20084: 02 \mathrm{PM}$ \\
\hline 胻 304L_300_T405_D44_54M7_790_18188_S.odb & $12,259 \mathrm{~KB}$ & ODB File & 1/24/2008 8:31 AM \\
\hline [0] 304L_300_T516_D44W_54M7_1097_14_FR.inp & $564 \mathrm{~KB}$ & INP File & 1/30/2008 12:32 PM \\
\hline 䴗 304L_300_T516_D44W_54M7_1097_14_FR.odb & $12,267 \mathrm{~KB}$ & ODB File & 1/31/2008 8:51 AM \\
\hline [0] 304L_300_T516_D44W_54M7_1097_14_S.inp & $564 \mathrm{~KB}$ & INP File & 1/23/2008 3:47 PM \\
\hline 包 304L_300_T516_D44W_54M7_1097_14_S.odb & $12,284 \mathrm{~KB}$ & ODB File & 1/28/2008 6:17 PM \\
\hline []] 304L_600_T391_D22_4858_1097_2125_FRY.inp & $257 \mathrm{~KB}$ & INP File & 2/13/2008 12:30 PM \\
\hline 國 304L_600_T391_D22_4858_1097_2125_FRY.odb & $6,611 \mathrm{~KB}$ & ODB File & $2 / 14 / 20088: 09$ AM \\
\hline
\end{tabular}




\begin{tabular}{|c|c|c|c|}
\hline Name - & Size & Type & Date Modified \\
\hline [] 304L_600_T391_D22_4858_1097_2125_SY.inp & $257 \mathrm{~KB}$ & INP File & $2 / 13 / 200812: 31 \mathrm{PM}$ \\
\hline 眯 304L_600_T391_D22_4858_1097_2125_SY.odb & $6,597 \mathrm{~KB}$ & ODB File & 2/14/2008 8:39 AM \\
\hline [8] 304L_600_T410_D22_64A1_790_250_FR.inp & $257 \mathrm{~KB}$ & INP File & $1 / 30 / 20082: 18 \mathrm{PM}$ \\
\hline 圈 304L_600_T410_D22_64A1_790_250_FR.odb & $6,566 \mathrm{~KB}$ & ODB File & 1/31/2008 5:17 PM \\
\hline [త] 304L_600_T410_D22_64A1_790_250_S.inp & $257 \mathrm{~KB}$ & INP File & 1/23/2008 8:12 AM \\
\hline 囦 304L_600_T410_D22_64A1_790_250_S.odb & $6,596 \mathrm{~KB}$ & ODB File & 1/24/2008 12:13 PM \\
\hline [త] 304L_600_T415_D44_54M7_790_18_FR.inp & $564 \mathrm{~KB}$ & INP File & 1/30/2008 2:19 PM \\
\hline 圈 304L_600_T415_D44_54M7_790_18_FR.odb & $12,294 \mathrm{~KB}$ & ODB File & $1 / 31 / 20083: 35 \mathrm{PM}$ \\
\hline [d] 304L_600_T415_D44_54M7_790_18_S.inp & $564 \mathrm{~KB}$ & INP File & 1/23/2008 10:17 AM \\
\hline 國 304L_600_T415_D44_54M7_790_18_S.odb & $12,304 \mathrm{~KB}$ & ODB File & $1 / 24 / 20083: 59 \mathrm{PM}$ \\
\hline [d] 304L_600_T417_D44_72K9_1097_1450_FR.inp & $564 \mathrm{~KB}$ & INP File & $1 / 30 / 20082: 22 \mathrm{PM}$ \\
\hline 圈 304L_600_T417_D44_72K9_1097_1450_FR.odb & $12,269 \mathrm{~KB}$ & ODB File & $1 / 31 / 20085: 28 \mathrm{PM}$ \\
\hline [8] 304L_600_T417_D44_72K9_1097_1450_S.inp & $564 \mathrm{~KB}$ & INP File & 1/23/2008 10:39 AM \\
\hline 國 304L_600_T417_D44_72K9_1097_1450_S.odb & $12,289 \mathrm{~KB}$ & ODB File & 1/24/2008 5:52 PM \\
\hline [1] 304L_600_T507_D44W_54M7_1097_1150_FR.inp & $564 \mathrm{~KB}$ & INP File & $1 / 30 / 20082: 03 \mathrm{PM}$ \\
\hline 圄 304L_600_T507_D44W_54M7_1097_1150_FR.odb & $12,273 \mathrm{~KB}$ & ODB File & $1 / 31 / 20088: 44$ AM \\
\hline [1] 304L_600_T507_D44W_54M7_1097_1150_S.inp & $564 \mathrm{~KB}$ & INP File & $1 / 23 / 20083: 02 \mathrm{PM}$ \\
\hline 圄 304L_600_T507_D44W_54M7_1097_1150_S.odb & $12,252 \mathrm{~KB}$ & ODB File & $1 / 23 / 20086: 42 \mathrm{PM}$ \\
\hline [8] 304L_-20_T432_D22_64A1_790_3_FR.inp & $257 \mathrm{~KB}$ & INP File & 1/30/2008 11:16 AM \\
\hline 圈 304L_-20_T432_D22_64A1_790_3_FR.odb & $6,632 \mathrm{~KB}$ & ODB File & 1/30/2008 1:04 PM \\
\hline [1] 304L_-20_T432_D22_64A1_790_3_S.inp & $257 \mathrm{~KB}$ & INP File & 1/17/2008 2:09 PM \\
\hline 眯 304L_-20_T432_D22_64A1_790_3_S.odb & $6,551 \mathrm{~KB}$ & ODB File & 1/22/2008 8:06 AM \\
\hline [8] 304L_-20_T451_D22_4858_1097_250_FR.inp & $257 \mathrm{~KB}$ & INP File & 1/30/2008 11:13 AM \\
\hline 圈 304L_-20_T451_D22_4858_1097_250_FR.odb & $6,639 \mathrm{~KB}$ & ODB File & 1/30/2008 1:07 PM \\
\hline [త] 304L_-20_T451_D22_4858_1097_250_S.inp & $257 \mathrm{~KB}$ & INP File & 1/17/2008 12:43 PM \\
\hline 國 304L_-20_T451_D22_4858_1097_250_S.odb & $6,597 \mathrm{~KB}$ & ODB File & $1 / 22 / 20088: 32 \mathrm{AM}$ \\
\hline [8] 304L_-20_T457_D44_72K9_1097_175_FR.inp & $565 \mathrm{~KB}$ & INP File & 1/30/2008 11:58 AM \\
\hline 图 304L_-20_T457_D44_72K9_1097_175_FR.odb & $12,301 \mathrm{~KB}$ & ODB File & $1 / 30 / 20083: 28 \mathrm{PM}$ \\
\hline [1] 304L_-20_T457_D44_72K9_1097_175_S.inp & $565 \mathrm{~KB}$ & INP File & 1/21/2008 1:35 PM \\
\hline 圄 304L_-20_T457_D44_72K9_1097_175_S.odb & $12,263 \mathrm{~KB}$ & ODB File & $1 / 22 / 20082: 29 \mathrm{PM}$ \\
\hline [1] 304L_-20_T468_D44_54M7_790_20_FR.inp & $565 \mathrm{~KB}$ & INP File & 1/30/2008 11:57 AM \\
\hline 粆 304L_-20_T468_D44_54M7_790_20_FR.odb & $12,275 \mathrm{~KB}$ & ODB File & 1/30/2008 3:28 PM \\
\hline []] 304L_-20_T468_D44_54M7_790_20_S.inp & $565 \mathrm{~KB}$ & INP File & $1 / 21 / 200811: 32 \mathrm{AM}$ \\
\hline 圈 304L_-20_T468_D44_54M7_790_20_S.odb & $12,277 \mathrm{~KB}$ & ODB File & 1/22/2008 9:50 AM \\
\hline [1] 304L_-20_T491_D44W_54M7_1097_175_FR.inp & $564 \mathrm{~KB}$ & INP File & $1 / 30 / 200812: 28 \mathrm{PM}$ \\
\hline 圏 304L_-20_T491_D44W_54M7_1097_175_FR.odb & $12,274 \mathrm{~KB}$ & ODB File & 1/31/2008 8:28 AM \\
\hline [1] 304L_-20_T491_D44W_54M7_1097_175_S.inp & $564 \mathrm{~KB}$ & INP File & 1/21/2008 3:06 PM \\
\hline 圏 304L_-20_T491_D44W_54M7_1097_175_S.odb & $12,272 \mathrm{~KB}$ & ODB File & 1/23/2008 10:58 AM \\
\hline [0] 316L_70_T291_D44_67K0_1097_1475_FR.inp & $564 \mathrm{~KB}$ & INP File & $1 / 30 / 20083: 10 \mathrm{PM}$ \\
\hline 图 316L_70_T291_D44_67K0_1097_1475_FR.odb & $12,298 \mathrm{~KB}$ & ODB File & 2/4/2008 10:59 AM \\
\hline [] 316L_70_T291_D44_67K0_1097_1475_S.inp & $564 \mathrm{~KB}$ & INP File & 1/24/2008 11:21 AM \\
\hline 圈 316L_70_T291_D44_67K0_1097_1475_S.odb & $12,271 \mathrm{~KB}$ & ODB File & 1/25/2008 3:13 PM \\
\hline
\end{tabular}




\begin{tabular}{|c|c|c|c|}
\hline Name - & Size & Type & Date Modified \\
\hline [1]316L_70_T306_D22_76H3_790_3_FR.inp & $257 \mathrm{~KB}$ & INP File & 1/30/2008 3:07 PM \\
\hline 国 316L_70_T306_D22_76H3_790_3_FR.odb & $6,626 \mathrm{~KB}$ & ODB File & 2/4/2008 9:10 AM \\
\hline [త] 316L_70_T306_D22_76H3_790_3_S.inp & $257 \mathrm{~KB}$ & INP File & $1 / 21 / 20088: 18 \mathrm{AM}$ \\
\hline 圈 316L_70_T306_D22_76H3_790_3_S.odb & $6,601 \mathrm{~KB}$ & ODB File & $1 / 21 / 20082: 56 \mathrm{PM}$ \\
\hline [1] 316L_70_T352_D44_2304_790_1825_FR.inp & $564 \mathrm{~KB}$ & INP File & $1 / 30 / 20083: 09 \mathrm{PM}$ \\
\hline 氛 316L_70_T352_D44_2304_790_1825_FR.odb & $12,295 \mathrm{~KB}$ & ODB File & $2 / 4 / 2008$ 10:50 AM \\
\hline [] 316L_70_T352_D44_2304_790_1825_S.inp & $564 \mathrm{~KB}$ & INP File & 1/24/2008 10:10 AM \\
\hline 圈 316L_70_T352_D44_2304_790_1825_S.odb & $12,305 \mathrm{~KB}$ & ODB File & $1 / 29 / 20086: 24 \mathrm{PM}$ \\
\hline [8] 316L_70_T357_D22_48R8_1097_275_FR.inp & $257 \mathrm{~KB}$ & INP File & $1 / 30 / 20083: 05 \mathrm{PM}$ \\
\hline 圄 316L_70_T357_D22_48R8_1097_275_FR.odb & $6,580 \mathrm{~KB}$ & ODB File & 2/4/2008 8:44 AM \\
\hline [1] 316L_70_T357_D22_48R8_1097_275_S.inp & $257 \mathrm{~KB}$ & INP File & $1 / 25 / 200812: 00 \mathrm{PM}$ \\
\hline 尌 316L_70_T357_D22_48R8_1097_275_S.odb & $6,590 \mathrm{~KB}$ & ODB File & 1/25/2008 12:58 PM \\
\hline [8] 316L_70_T382_D44W_2304_1097_1475_FR.inp & $564 \mathrm{~KB}$ & INP File & $1 / 30 / 20083: 56 \mathrm{PM}$ \\
\hline 閫 316L_70_T382_D44W_2304_1097_1475_FR.odb & $12,269 \mathrm{~KB}$ & ODB File & $2 / 4 / 200812: 38 \mathrm{PM}$ \\
\hline [1] 316L_70_T382_D44W_2304_1097_1475_S.inp & $564 \mathrm{~KB}$ & INP File & $1 / 24 / 20084: 42 \mathrm{PM}$ \\
\hline 圈 316L_70_T382_D44W_2304_1097_1475_S.odb & $12,270 \mathrm{~KB}$ & ODB File & $1 / 25 / 20086: 09 \mathrm{PM}$ \\
\hline [0] 316L_300_T286_D44_67K0_1097_16_FR.inp & $565 \mathrm{~KB}$ & INP File & $1 / 31 / 20088: 20 \mathrm{AM}$ \\
\hline 國 316L_300_T286_D44_67K0_1097_16_FR.odb & $12,280 \mathrm{~KB}$ & ODB File & $2 / 5 / 20088: 52 \mathrm{AM}$ \\
\hline [] 316L_300_T286_D44_67K0_1097_16_S.inp & $565 \mathrm{~KB}$ & INP File & 1/25/2008 11:14 AM \\
\hline 圈 316L_300_T286_D44_67K0_1097_16_S.odb & $12,290 \mathrm{~KB}$ & ODB File & $1 / 28 / 20082: 55 \mathrm{PM}$ \\
\hline [8] 316L_300_T320_D22_76H3_790_250_FR.inp & $257 \mathrm{~KB}$ & INP File & 1/31/2008 8: $10 \mathrm{AM}$ \\
\hline 圈 316L_300_T320_D22_76H3_790_250_FR.odb & $6,496 \mathrm{~KB}$ & ODB File & 2/4/2008 5:44PM \\
\hline [8] 316L_300_T320_D22_76H3_790_250_S.inp & $256 \mathrm{~KB}$ & INP File & 1/21/2008 8:58 AM \\
\hline 圈 316L_300_T320_D22_76H3_790_250_S.odb & $6,586 \mathrm{~KB}$ & ODB File & 1/21/2008 4:17 PM \\
\hline [1] 316L_300_T400_D22_48R8_1097_250_FR.inp & $257 \mathrm{~KB}$ & INP File & 1/31/2008 8:03 AM \\
\hline 圈 316L_300_T400_D22_48R8_1097_250_FR.odb & $6,617 \mathrm{~KB}$ & ODB File & 2/4/2008 5:01 PM \\
\hline [8] 316L_300_T400_D22_48R8_1097_250_S.inp & $256 \mathrm{~KB}$ & INP File & 1/25/2008 9:10 AM \\
\hline 䴗 316L_300_T400_D22_48R8_1097_250_S.odb & $6,536 \mathrm{~KB}$ & ODB File & 1/28/2008 10:33 AM \\
\hline [1] 316L_300_T406_D44_2304_790_18688_FR.inp & $564 \mathrm{~KB}$ & INP File & $1 / 31 / 20088: 18 \mathrm{AM}$ \\
\hline 圄 316L_300_T406_D44_2304_790_18688_FR.odb & $12,279 \mathrm{~KB}$ & ODB File & 2/4/2008 5:29 PM \\
\hline [d] 316L_300_T406_D44_2304_790_18688_S.inp & $564 \mathrm{~KB}$ & INP File & $1 / 25 / 200810: 38 \mathrm{AM}$ \\
\hline 圈 316L_300_T406_D44_2304_790_18688_S.odb & $12,294 \mathrm{~KB}$ & ODB File & 1/28/2008 12:04 PM \\
\hline [d]316L_300_T514_D44W_2304_1097_14_FR.inp & $564 \mathrm{~KB}$ & INP File & $1 / 31 / 2008$ 7:52 AM \\
\hline 圏 316L_300_T514_D44W_2304_1097_14_FR.odb & $12,214 \mathrm{~KB}$ & ODB File & 2/4/2008 2:51 PM \\
\hline [0] 316L_300_T514_D44W_2304_1097_14_S.inp & $564 \mathrm{~KB}$ & INP File & $1 / 25 / 2008$ 7:53 AM \\
\hline
\end{tabular}




\begin{tabular}{|c|c|c|c|}
\hline Name - & Size & Type & Date Modified \\
\hline 眯 316L_300_T514_D44W_2304_1097_14_S.odb & $12,243 \mathrm{~KB}$ & ODB File & 1/28/2008 8:41 AM \\
\hline [0] 316L_600_T346_D22_76H3_790_250_FR.inp & $256 \mathrm{~KB}$ & INP File & $1 / 31 / 20088: 39 \mathrm{AM}$ \\
\hline 畐 316L_600_T346_D22_76H3_790_250_FR.odb & $6,584 \mathrm{~KB}$ & ODB File & 2/5/2008 8:20 AM \\
\hline []] 316L_600_T346_D22_76H3_790_250_S.inp & $256 \mathrm{~KB}$ & INP File & $1 / 21 / 200810: 55 \mathrm{AM}$ \\
\hline 固 316L_600_T346_D22_76H3_790_250_S.odb & $6,583 \mathrm{~KB}$ & ODB File & $1 / 21 / 20085: 26 \mathrm{PM}$ \\
\hline [] 316L_600_T390_D22_48R8_1097_2125_FR.inp & $257 \mathrm{~KB}$ & INP File & $1 / 31 / 20088: 25$ AM \\
\hline 國 316L_600_T390_D22_48R8_1097_2125_FR.odb & $6,499 \mathrm{~KB}$ & ODB File & 2/5/2008 8:16 AM \\
\hline [0] 316L_600_T390_D22_48R8_1097_2125_S.inp & $257 \mathrm{~KB}$ & INP File & 1/25/2008 1:56 PM \\
\hline 胻 316L_600_T390_D22_48R8_1097_2125_S.odb & $6,592 \mathrm{~KB}$ & ODB File & 1/28/2008 4:51 PM \\
\hline [1] 316L_600_T394_D44_2304_790_17875_FR.inp & $564 \mathrm{~KB}$ & INP File & $1 / 31 / 20088: 43 \mathrm{AM}$ \\
\hline 國 316L_600_T394_D44_2304_790_17875_FR.odb & $12,297 \mathrm{~KB}$ & ODB File & 2/5/2008 10:38 AM \\
\hline$[$ [] 316L_600_T394_D44_2304_790_17875_S.inp & $564 \mathrm{~KB}$ & INP File & 1/25/2008 2:03 PM \\
\hline 胻 316L_600_T394_D44_2304_790_17875_S.odb & $12,302 \mathrm{~KB}$ & ODB File & 1/28/2008 6:07 PM \\
\hline []] 316L_600_T418_D44_67K0_1097_13_FR.inp & $564 \mathrm{~KB}$ & INP File & $1 / 31 / 20088: 47 \mathrm{AM}$ \\
\hline 蜔 316L_600_T418_D44_67K0_1097_13_FR.odb & $12,277 \mathrm{~KB}$ & ODB File & 2/5/2008 9:48 AM \\
\hline [0] 316L_600_T418_D44_67K0_1097_13_S.inp & $564 \mathrm{~KB}$ & INP File & 1/25/2008 2:51 PM \\
\hline 臧 316L_600_T418_D44_67K0_1097_13_S.odb & $12,283 \mathrm{~KB}$ & ODB File & 1/29/2008 9:01 AM \\
\hline [0] 316L_600_T508_D44W_2304_1097_11_FR.inp & $564 \mathrm{~KB}$ & INP File & 1/31/2008 7:55 AM \\
\hline 罯 316L_600_T508_D44W_2304_1097_11_FR.odb & $12,267 \mathrm{~KB}$ & ODB File & 2/4/2008 3:12 PM \\
\hline [8] 316L_600_T508_D44W_2304_1097_11_S.inp & $564 \mathrm{~KB}$ & INP File & $1 / 25 / 20088: 42 \mathrm{AM}$ \\
\hline 畐 316L_600_T508_D44W_2304_1097_11_S.odb & $12,239 \mathrm{~KB}$ & ODB File & 1/28/2008 8:19 AM \\
\hline [] 316 L_-20_T431_D22_76H3_790_3_FR.inp & $257 \mathrm{~KB}$ & INP File & 1/30/2008 2:31 PM \\
\hline 畐 316L_-20_T431_D22_76H3_790_3_FR.odb & $6,532 \mathrm{~KB}$ & ODB File & 1/31/2008 6:09 PM \\
\hline [] 316 L_-20_T431_D22_76H3_790_3_S.inp & $256 \mathrm{~KB}$ & INP File & 1/23/2008 3:29 PM \\
\hline 番 316L_-20_T431_D22_76H3_790_3_S.odb & $6,608 \mathrm{~KB}$ & ODB File & 1/25/2008 9:02 AM \\
\hline [1] 316L_-20_T458_D44_67K0_1097_1475_FR.inp & $564 \mathrm{~KB}$ & INP File & 1/30/2008 2:34 PM \\
\hline 罍 316L_-20_T458_D44_67K0_1097_1475_FR.odb & $12,291 \mathrm{~KB}$ & ODB File & 2/4/2008 9:08 AM \\
\hline [1] 316L_-20_T458_D44_67 K0_1097_1475_S.inp & $564 \mathrm{~KB}$ & INP File & 1/24/2008 8:06 AM \\
\hline 胻 316L_-20_T458_D44_67K0_1097_1475_S.odb & $12,275 \mathrm{~KB}$ & ODB File & $1 / 25 / 200811: 25$ AM \\
\hline 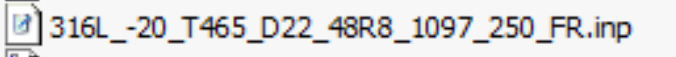 & $256 \mathrm{~KB}$ & INP File & 1/30/2008 2:26 PM \\
\hline 䀛 316L_-20_T465_D22_48R8_1097_250_FR.odb & $6,627 \mathrm{~KB}$ & ODB File & 1/31/2008 6:00 PM \\
\hline [8] 316L_-20_T465_D22_48R8_1097_250_S.inp & $256 \mathrm{~KB}$ & INP File & 1/23/2008 11:19 AM \\
\hline 國 316L_-20_T465_D22_48R8_1097_250_S.odb & $6,587 \mathrm{~KB}$ & ODB File & 1/24/2008 6:18 PM \\
\hline [0] 316L_-20_T471_D44_2304_790_18_FR.inp & $565 \mathrm{~KB}$ & INP File & 1/30/2008 2:33 PM \\
\hline 罍 316L_-20_T471_D44_2304_790_18_FR.odb & $12,298 \mathrm{~KB}$ & ODB File & 2/4/2008 8:57 AM \\
\hline [0] 316L_-20_T471_D44_2304_790_18_S.inp & $564 \mathrm{~KB}$ & INP File & $1 / 23 / 20084: 45 \mathrm{PM}$ \\
\hline 國 316L_-20_T471_D44_2304_790_18_S.odb & $12,280 \mathrm{~KB}$ & ODB File & 1/25/2008 8:52 AM \\
\hline [1] 316L_-20_T493_D44W_2304_1097_19_FR.inp & $564 \mathrm{~KB}$ & INP File & 1/30/2008 3:54 PM \\
\hline 眯 316L_-20_T493_D44W_2304_1097_19_FR.odb & $12,293 \mathrm{~KB}$ & ODB File & 2/4/2008 12:40 PM \\
\hline [1] 316L_-20_T493_D44W_2304_1097_19_S.inp & $564 \mathrm{~KB}$ & INP File & 1/24/2008 3:10 PM \\
\hline 夌 316L_-20_T493_D44W_2304_1097_19_S.odb & $12,262 \mathrm{~KB}$ & ODB File & 1/25/2008 4:41 PM \\
\hline
\end{tabular}

